\title{
POTENCIALIDADE DE LINHAGENS EXPERIMENTAIS DE SOJA EM SOLOS CONTRASTANTES NA SATURAÇÃO DE ALUMíNIO
}

\author{
JOAQUIM ADELINO DE AZEVEDO FILHO \\ Engenheiro Agrônomo
}

Orientador: Prof. Dr. NATAL ANTONIO VELLO

Tese apresentada à Escola Superior de Agricultura "Luiz de Queiroz", Universidade de São Paulo, para obtenção do título de Doutor em Agronomia, Área de Concentração: Genética e Melhoramento de Plantas .

PIRACICABA

Estado de São Paulo - Brasil

Julho - 1997 
Dados Internacionais de Catalogação na Publicação (CIP)

DIVISÃO DE BIBLIOTECA E DOCUMENTAĈ̣̃O - Campus "Luiz de Queiroz"/USP

Azevedo Filho, Joaquim Adelino de

Potencialidade de linhagens experimentais de soja em solos contrastantes na saturação de alumínio / Joaquim Adelino de Azevedo Filho. - - Piracicaba, 1997.

$139 \mathrm{p}$.

Tese (doutorado) - Escola Superior de Agricultura Luiz de Queiroz, 1997. Bibliografia.

1. Aluminio 2. Cruzamento dialélico $\$$. Melhoramento genético de plantas 4 . Soja 5. Solo de cerrado I. Título 


\section{POTENCIALIDADE DE LINHAGENS EXPERIMENTAIS DE SOJA EM SOLOS CONTRASTANTES NA SATURAÇÃO DE ALUMÍNIO}

\section{JOAQUIM ADELINO DE AZEVEDO FILHO}

Aprovada em: 24.10 .97

Comissão julgadora:

Prof. Dr. Natal Antonio Vello

ESALQ/USP

Prof. Dr. Gerhard Bandel

ES ALQ/USP

Dr. Luciano Lourenço Nass

CENARGEN/EMBRAPA

Dr. Carlos Roberto Spehar

CPAC/EMBRAPA

Dr. Sérgio Augusto Morais Carbonell

$$
\eta=1011.115 .
$$

Prof. Dr. NATAl ANTONio Vello Orientador 


\author{
À minha esposa Maria Aparecida \\ À minha filha Ana Carolina \\ pelo amor, carinho \\ compreensão e incentivo
}

\title{
OFEREÇO
}

\section{A Deus,}

Aos meus pais Joaquim e Mariana;

Aos meus irmãos;

Aos meus avós (in memorian);

Aos meus sogros Manoel e Maria;

Aos meus cunhados e concunhados;

Aos meus sobrinhos;

Aos demais familiares;

Aos meus amigos 


\section{AGRADECIMENTOS}

- A Deus, por ter tão pouco a pedir e tanto a agradecer;

- À Escola Superior de Agricultura “Luiz de Queiroz"/USP, pela oportunidade oferecida para a efetivação deste treinamento;

- À Coordenadoria de Aperfeiçoamento de Pessoal de Ensino Superior CAPES, pela concessão da bolsa de estudo;

- Ao Instituto Agronômico (IAC) pela oportunidade de concluir o concurso;

- Ao CNPq, à EMBRAPA e à FAPESP pelo apoio financeiro aos projetos de pesquisa relacionados às diferentes fases desta tese;

- Ao Professor Dr. Natal Antonio Vello, pela confiança, amizade, orientação, conselhos e ensinamentos constantes transmitidos;

- Aos Professores Dr. Gerhard Bandel, Dr. Luciano Lourenço Nass, Dr. Carlos Roberto Spehar, Dr. Sérgio Augusto Morais Carbonell, Dr. Roberto Tanaka, pela amizade e sugestões na redação desta tese;

- Aos Professores Dr. Roland Vencovsky, Dr. Gerhard Bandel e Dr. José Djair Vendramim, pelos ensinamentos e exemplo de vida profissional;

- A amiga Regina Lúcia Ferreira Gomes pela amizade, luta, companheirismo, incentivo, estudos para análise dos dados e colaboração valiosa na condução dos experimentos; 
- Aos amigos Claudio Takeda, Daniel Furtado Ferreira, Nelson Fonseca Júnior, Sérgio A. M. Carbonell pela amizade, disponibilidade e ajuda na realização das análises estatísticas;

- Aos amigos do Laborátorio de Soja, Ângela Celis, Dario Hiromoto, Francilene Campos, Gilberto Yokomizo, João Tomé, José Baldin, Lafayete, Luis Fernando, Milton Krieger, Mônica Martins, Sérgio Carbonell e Jorge Ramon pela boa amizade, convivência, companheirismo e ajuda nos experimentos;

- Aos funcionários do Laboratório de Soja, Roberto Cogo, Claudinei Didoné, José Guerreiro, Roberto Alonso, Marcos Nekatschalow, Osmair José da Silva e Fernando pela amizade e ajuda nos experimentos;

- Aos funcionários da Genética pela amizade, disponibilidade e serviços prestados, em especial Carmem, Léia e Adriana e aos funcionários de campo;

- Às funcionárias da Biblioteca da Genética, Silvana Marchizelli Gregório, pela revisão das referências bibliográficas e gentil atendimento no decorrer do curso juntamente com Aparecida Elizabeth;

- Aos funcionários da Biblioteca Central pela amizade e disponibilidade no atendimento em especial Silvana, Kátia, Adriana, Fátima e Nilce;

- Às funcionárias da Pós-graduação pela amizade e gentil atendimento;

- Aos colegas do IAC em especial Rui R. dos Santos, Orlando C. de Mello, Walkyria, Sérgio, Francisco, Arlete, Marcelo e Paulo Trani pela amizade e incentivo;

- A todos os amigos, aqueles que foram verdadeiros companheiros, pela convivência agrádavel, não vou citar nomes, porque graças a Deus são muitos;

- À minha esposa pelo companheirismo, incentivo e paciência compartilhando todos os momentos alegres e difíceis e também pela digitação e revisão deste trabalho. 


\section{SUMÁRIO}

Página

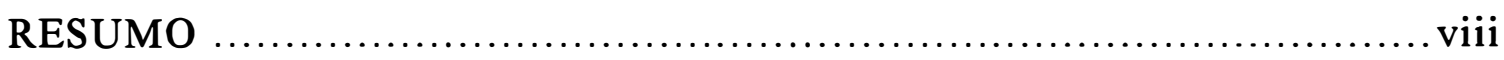

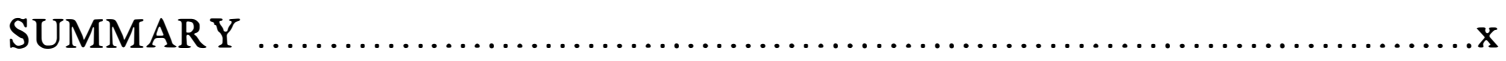

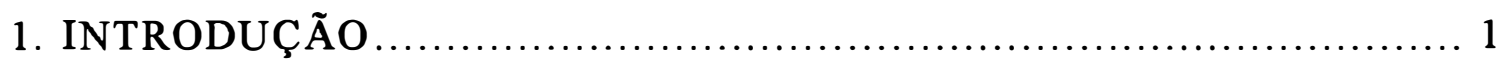

2. REVISÃO DE LITERATURA ........................................ 4

2.1. Solos sob vegetação de cerrado ............................... 5

2.2. Desenvolvimento das plantas nos solos ácidos.................. 7

2.3. Tolerância à acidez dos solos................................... 10

2.4. Controle genético da tolerância ao alumínio ...................... 15

2.5. Melhoramento para produtividade de grãos..................... 17

2.6. Genética de caracteres quantitativos ........................... 19

2.6.1. Herdabilidade ................................................. 20

2.6.2. Correlação entre caracteres ................................22

2.6.3. Interação genótipos $\mathrm{x}$ ambientes e o progresso genético ..25

2.7. Delineamento em blocos aumentados e o melh. de plantas .......27

3. MATERIAL E MÉTODOS ........................................... 30

3.1. Material genético .............................................. 30

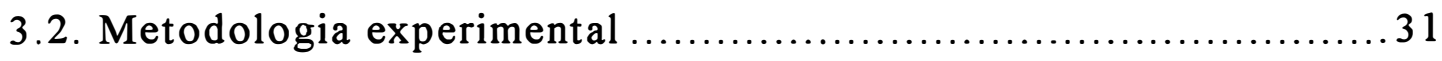

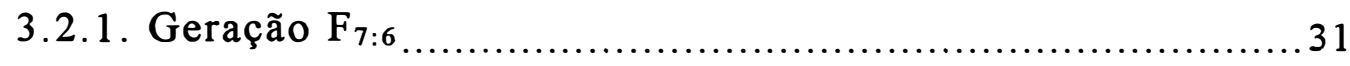

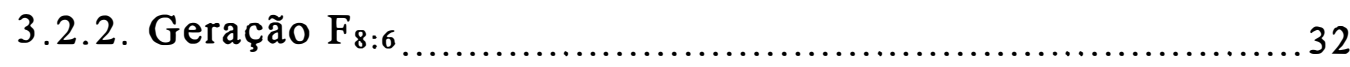

3.2.3. Caracteres avaliados ................................... 34

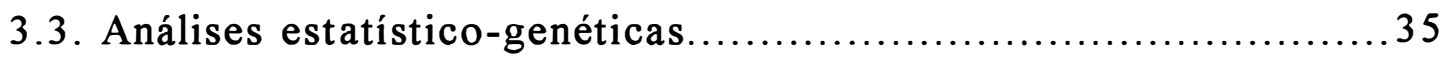

3.3.1. Análises de variância e covariância ............................. 35

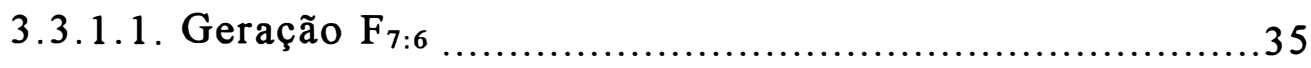

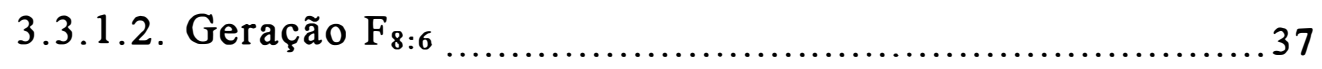

3.3.1.3. Análise conjunta .................................. 38

3.3.2. Herdabilidade .................................................. 39

3.3.3. Ganho com a seleção ........................................... 40 
3.3.4. Correlação entre caracteres na geração $F_{7: 6} \ldots \ldots \ldots \ldots \ldots \ldots . \ldots 1$

3.3.5. Capacidade média de combinação $\left(\mathrm{cmc}_{\mathbf{i}}\right) \ldots \ldots \ldots \ldots \ldots \ldots \ldots \ldots . \ldots \ldots$

3.3.6. Associação entre ambientes ................................... 46

4. RESULTADOS E DISCUSS ÃO .................................. 47

4.1. Análise de variância........................................... 47

4.2. Análise dos parentais e das linhagens .............................51

4.2.1. Número de dias para a maturidade (NDM) .................51

4.2.2. Altura da planta na maturidade (APM) .....................5 56

4.2.3. Valor agronômico (VA) ............................... 60

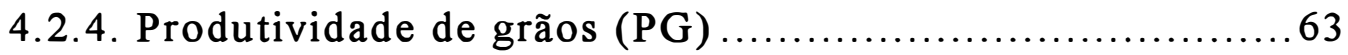

4.2.5. Considerações gerais..................................... 70

4.3. Herdabilidade .............................................. 71

4.3.1. Número de dias para a maturidade (NDM) .................72

4.3.2. Altura da planta na maturidade (APM) ................... 73

4.3.3. Valor agronômico (VA) ................................ 74

4.3.4. Produtividade de grãos (PG) ........................... 74

4.4. Correlação entre caracteres ......................................76

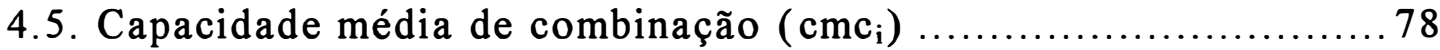

4.6. Ganho para produtividade de grãos............................. 81

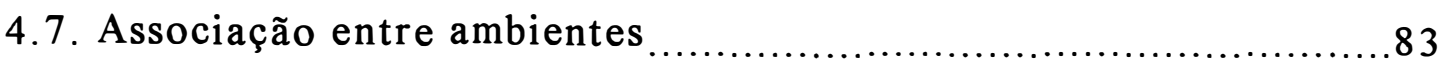

4.8. Considerações finais .............................................. 85

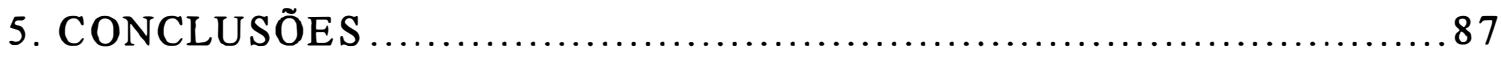

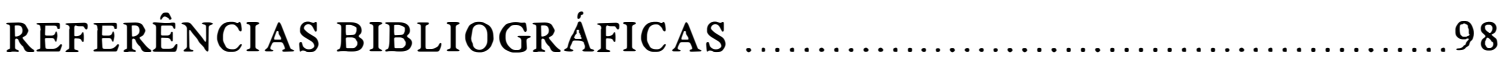

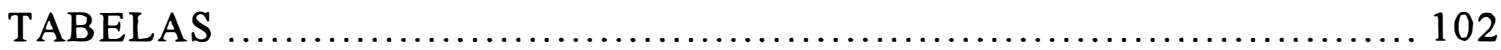

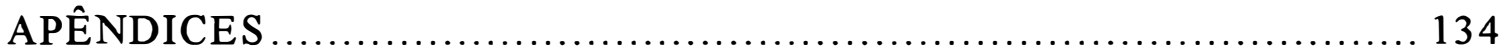




\section{POTENCIALIDADE DE LINHAGENS EXPERIMENTAIS DE SOJA EM SOLOS CONTRASTANTES NA SATURAÇÃO DE ALUMÍNIO}

Autor: Joaquim Adelino de Azevedo Filho Orientador: Prof. Dr. Natal Antonio Vello

\section{RESUMO}

A produção de soja [Glycine max (L.) Merrill] nos solos sob vegetação de cerrado (ácidos de baixa fertilidade) tem atingido $45 \%$ da produção brasileira nos últimos seis anos. Tais solos, sob condições naturais, apresentam teores de alumínio em níveis tóxicos para as plantas cultivadas. Foram estudadas 45 populações de soja obtidas por cruzamentos dialélicos entre dez parentais (FT-Cristalina, EMGOPA-301, IAC-4, IAC-5, IAC-6, IAC-8, IAC-9, IAC-11, Santa Rosa e SS-1) através da avaliação de suas linhagens $F_{7: 6}$ e $F_{8: 6}$ em dois locais (Anhembi e Areão), do município de Piracicaba-SP contrastantes na saturação de alumínio. O desempenho dos genótipos foi avaliado por quatro caracteres: produtividade de grãos (PG), número de dias para a maturidade (NDM), altura da planta na maturidade (APM) e valor agronômico (VA). O VA foi representado por uma escala de notas visuais (1: ruim a 5: ótima) que considerava: quantidade de vagens, altura da planta, vigor, acamamento, retenção foliar, debulha de vagens e sintomas de doenças. Em 1992-1993 foram avaliadas 900 linhagens $F_{7: 6}, 20$ de cada cruzamento, e os dez parentais em Anhembi e Areão, com saturações de alumínio na camada arável de $65 \%$ (Anhembi) e $11 \%$ (Areão), utilizando o delineamento experimental de blocos aumentados de Federer, sem repetição e parcela de uma fileira de 2,0 m x 0,5 m. 0 delineamento em blocos aumentados mostrou eficiência e facilidade de implementação, nessa etapa inicial com muitas linhagens para testes e baixa disponibilidade de sementes. Esses experimentos permitiram a prática da seleção 
truncada para PG e NDM, independentemente; nos dois casos, a seleção também considerou desempenhos agronômicos aceitáveis dos demais caracteres. Foram selecionadas quatro linhagens mais produtivas (QLPs) e quatro linhagens mais precoces (QLEs) em cada cruzamento, totalizando 360 linhagens. Em 19931994, as 360 linhagens $F_{8: 6}$ e os parentais foram avaliados em experimentos separados (QLPs e QLEs), delineados em blocos casualizados com duas repetições, parcela de uma fileira de $4,0 \mathrm{~m}$ x $0,5 \mathrm{~m}$; em cada repetição, os tratamentos foram subdivididos em quatro conjuntos experimentais, contendo cada um 45 linhagens e os dez parentais (testemunhas comuns). Antes desta última safra, os solos foram calcariados; no entanto, em Anhembi a camada subsuperficial ainda apresentava alta saturação de alumínio (48\%). 0 efeito da saturação de alumínio sobre as médias e parâmetros genéticos mostrou-se dependente do genótipo e do caráter considerado. Para capacidade média de combinação $\left(\mathrm{cmc}_{\mathbf{i}}\right)$ destacaram-se nos dois locais os parentais: FT-Cristalina para NDM e APM; EMGOPA-301 para NDM e APM; IAC-6 para APM; IAC-5 com cmc $_{i}$ negativa (precocidade) para NDM e EMGOPA-301 para PG em Anhembi (>Al). Com base nas médias de PG, destacaram-se os cruzamentos: FTCristalina x EMGOPA-301, FT-Cristalina x IAC-9, EMGOPA-301 x IAC-6, EMGOPA-301 x IAC-8, EMGOPA-301 x Santa Rosa em Anhembi; FTCristalina x IAC-9 e FT-Cristalina x IAC-11 em Areão (<Al). As estimativas de herdabilidade ao nível de linhagens nas gerações $F_{7: 6}$ e $F_{8: 6}$ variaram de: 0,58 a 0,98 para NDM; 0,62 a 0,84 para APM; 0,28 a 0,61 para VA; 0,38 a 0,63 para

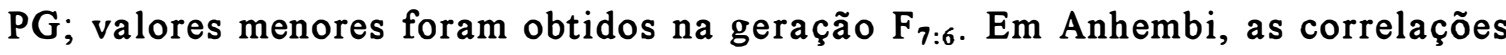
genotípicas entre os caracteres NDM, APM, VA e PG ao nível de linhagens F:6 variaram de 0,54 a 0,95 e foram superiores às fenotípicas. Destaca-se a correlação genotípica VA/PG ao nível de linhagens $(0,82)$, indicando que o valor agronômico (VA) pode ser usado na seleção para aumento de produtividade, com vantagem nas fases iniciais dos testes, quando se têm muitas linhagens para serem avaliadas. 


\section{POTENTIALITY OF SOYBEAN EXPERIMENTAL INBREED LINES ON CONTRASTING SOILS FOR ALUMINIUM SATURATION}

Author: Joaquim Adelino de Azevedo Filho Adviser: Prof. Dr. Natal Antonio Vello

\section{S U M M A RY}

The soybean [Glycine max (L.) Merrill] cultivation on soils under "cerrado" or Savannah conditions (acid with low fertility) has been responsible to $45 \%$ of Brazilian production in the last six years. Such soils have toxic levels of aluminium to the development of cultivated plants, under natural condition in the ploughed layer. Were studed 45 populations of soybean, obtained by diallel crosses among ten parental genotypes (FT-Cristalina, EMGOPA-301, IAC-4, IAC-5, IAC-6, IAC-8, IAC-9, IAC-11, Santa Rosa, SS-1), through evaluation from his $F_{7: 6}$ and $F_{8: 6}$ inbreed lines in two localities (Anhembi and Areão Experimental Stations, in Piracicaba county, State of São Paulo), contrasting for aluminium saturation. The genotype performance was evaluated an four characters: seed yield (PG), days to maturity (NDM), plant height at maturity (APM) and agronomic value (VA). The VA character was represented by a visual score considering: pod number, plant height, vigor, lodging, leaf retention, pod dehiscence, and diseases symptoms. In 1992-1993 were evaluated $900 \mathrm{~F}_{7: 6}$ lines, 20 of each cross, and the ten parents on soils with aluminium saturation in the ploughed layer by $65 \%$ (Anhembi) and $11 \%$ (Areão), in the Federer's augmented design with no replications and plots with $2.0 \mathrm{~m} \times 0.5 \mathrm{~m}$. The augmented design was effective and easy to conduct at this phase where many progenies need to be tested, of which a few seeds are available. This 
evaluation allowed the practice of truncated selection for PG and NDM. In both cases, acceptable performance levels for other characters was taken into account. Therefore, the four more productive inbreed lines (QLPs), and the four inbreed early maturity lines (QLEs), of each cross, were selected and resulted $360 \mathrm{~F}_{8: 6}$ lines. In 1993-1994, the $360 \mathrm{~F}_{8: 6}$ lines and the ten parents were evaluated in two experiments (QLPs and QLEs), through randomized blocks design with two replications, and plots with $4.0 \mathrm{~m} \times 0.5 \mathrm{~m}$; in each replication, the treatments were subdivides in four experiments sets, contained each one 45 lines (one from each cross) and the ten parents (common witness). Before last harvest, the soils received limestone; however, in Anhembi on undersuperficial layer even exhibited aluminium saturation high (48\%). The effect aluminium saturation over the mean performance and estimates of genetic parameters showed dependent tobe of genotype and evaluation character. For medium combining ability $\left(\mathrm{Cmc}_{\mathbf{i}}\right)$ the parents were thus distinguished: FT-Cristalina for NDM and APM, in the two localities; EMGOPA-301 for NDM e APM, in the two localities and PG for Anhembi (>Al); IAC-6 for APM and IAC-5 on $\mathrm{cmc}_{i}$ negative for NDM, two localities. Considering the medium values for $P G$, the best crosses were: FT-Cristalina x EMGOPA-301, FT-Cristalina x IAC-9, EMGOPA-301 x IAC-6, EMGOPA-301 x IAC-8, EMGOPA-301 x Santa Rosa in Anhembi; FT-Cristalina $x$ IAC-9 and FT-Cristalina $x$ IAC-11 in Areão. The heritability estimates on progeny at $F_{7: 6}$ and $F_{8: 6}$ varied from: 0.58 to 0.98 for NDM; 0.62 to 0.84 for APM; 0.28 to 0.61 to VA; 0.38 to 0.63 to PG; Lower values were obtained at $\mathrm{F}_{\text {7:6 }}$ generation. In Anhembi Experimental Station, the genotypic correlations between NDM, APM, VA and PG at $F_{7: 6}$ inbreed lines level varied from 0.54 to 0.95 and they were superior in relation to phenotypic ones. The VA/PG genotypic correlation at inbreed lines level was high (0.82), indicating that VA can be advantageously used to select indirectly for seed yield, in initial tests, with many entries in evaluation. 


\section{INTRODUÇÃO}

A soja [Glycine $\max$ (L.) Merrill] é a mais importante oleaginosa cultivada no mundo, participando com cerca de $50 \%$ da produção mundial de óleo e encontra-se entre os oito principais cultivos. O Brasil é o segundo produtor mundial desde 1976, com uma produção média de 25 milhões de toneladas/ano, que corresponde a $20 \%$ da produção mundial (AGRIANUAL, 1997).

A produção de soja até início de 1980 concentrava-se nos Estados de São Paulo, Paraná, Santa Catarina e Rio Grande do Sul. Com o aumento da demanda mundial e o apoio do governo, o seu cultivo expandiu-se para os cerrados da região do Brasil Central (Minas Gerais, Goiás, Mato Grosso do Sul, Mato Grosso, Distrito Federal, Bahia, Maranhão e recentemente sul do Piauí, Tocantins e Rondônia). Em 1980, foram cultivados 1.294 mil hectares nesta região, os quais quadruplicaramse em 1989. Esta rápida expansão foi devida a incentivos governamentais, produtores experientes imigrantes do sul do Brasil e aporte tecnológico (manejo químico do solo, cultivares adaptadas e tratos culturais) para a cultura; assim, desde 1989, a região do Brasil Central é responsável por aproximadamente $45 \%$ da produção brasileira (AGRIANUAL, 1997; Roessing \& Guedes, 1993).

A região do Brasil Central possui topografia plana que favorece a mecanização, mas, os solos apresentam sérios problemas tais 
como: acidez elevada; alta saturação de alumínio; baixos teores de cálcio, magnésio, fósforo e matéria orgânica; baixa capacidade de troca catiônica; alta capacidade de adsorção de fósforo; baixa capacidade de retenção de água, agravada com a ocorrência muito comum de veranico (déficit hídrico).

A prática de calagem é imprescindivel para que se tenha sucesso com a cultura da soja nesses solos. No entanto, a incorporação de calcário na camada subsuperficial (abaixo de $20 \mathrm{~cm}$ ) é praticamente impossível ao nível de lavoura; portanto, permanecem os problemas de toxidez de alumínio, manganês e acidez elevada. Assim, a penetração e o desenvolvimento radicular nesta camada são limitados, e acentuam-se os efeitos negativos da má distribuição de chuvas e do elevado índice de evapotranspiração sobre a produção de grãos. Nessas condições, a seleção de genótipos mais tolerantes aos fatores limitantes como a toxidez de alumínio e a efíciência na absorção e utilização de nutrientes, constitui-se numa maneira mais econômica de se contornar o problema a longo prazo. Espera-se que as raízes dos genótipos tolerantes explorem maior volume de solo, obtenham água e nutrientes de camadas mais profundas, tolerem o estresse imposto pelo veranico e contribuam para melhor colonização do solo pelas raízes.

Diante do descrito acima, é importante que a pesquisa sobre manejo químico do solo seja suplementada pelo melhoramento genético das plantas para tolerância ao alto alumínio e baixo teor de nutrientes na camada subsuperficial. A interação destas áreas de pesquisa é uma estratégia que pode tornar mais efíciente a utilização dos solos sob cerrado, pelo aumento da produtividade e previsibilidade das culturas e, com isto, dar sustentabilidade à utilização dos solos ácidos de baixa fertilidade. 
Este trabalho faz parte do programa de melhoramento de soja do Setor de Genética Aplicada às Espécies Autógamas, do Departamento de Genética da ESALQ/USP, no qual foram avaliados genótipos com ciclo semi-tardio a tardio, parentais e linhagens $F_{7: 6}$ e $F_{8: 6}$ obtidas em cruzamentos dialélicos; apresentou os seguintes objetivos:

a) Avaliação de 45 cruzamentos dialélicos de soja em condições contrastantes para saturação de alumínio, quanto à produtividade de grãos e outros caracteres agronômicos;

b) Estimativa de parâmetros genéticos de caracteres agronômicos. 


\section{REVISÃO DE LITERATURA}

A soja [Glycine $\max$ (L.) Merrill] é uma planta autógama, originária do leste da Ásia e a sua domesticação ocorreu por volta do século XI a.C., no nordeste da China. O centro primário de diversidade genética da espécie localiza-se na região centro-sul da China, com um centro secundário na região da Manchúria (Hymowitz, 1970). O centro de origem situa-se a uma latitude de $40^{\circ}$ Norte com clima continental, caracterizado por invernos frios e verões quentes com períodos secos (Mota, 1981). Neste ambiente, o florescimento ocorre sob dias curtos e a maturação no outono.

No Brasil, até 1960 a soja não tinha importância econômica; a partir desse período, houve expansão do seu cultivo, devido aos altos preços no mercado mundial e incentivos governamentais, com a abertura da fronteira agrícola. Em 1965, a produção foi de 500 mil toneladas, em 1970 de 1,5 milhões de toneladas, alcançando 15 milhões de toneladas em 1980. Neste período, houve um acréscimo de $40 \%$ na produtividade (IBGE, 1992), devido às técnicas de manejo do solo e da planta e ao melhoramento genético. Nos últimos cinco anos, a produção está estabilizada por volta de 25 milhões de toneladas (AGRIANUAL, 1997; Roessing \& Guedes, 1993).

No início, o cultivo da soja era restrito aos Estados do Sul e São Paulo. Hoje, graças aos programas de melhoramento genético, a soja é produzida do Rio Grande do Sul ao Maranhão e da Bahia ao Mato Grosso (Kiihl \& Almeida, 1992). O primeiro método de melhoramento utilizado na 
cultura da soja no Brasil foi a introdução de cultivares e linhagens do sul dos Estados Unidos, dos grupos de maturação $\mathrm{V}$ a $\mathrm{X}$ que, segundo Vello (1985), são os genótipos que apresentavam maior potencial de adaptação às condições tropicais e subtropicais. Em seguida, utilizou-se da prática da seleção massal e selecionaram-se novos cultivares com melhor adaptação e recuperaram-se mutantes naturais, com características de florescimento tardio e período juvenil longo. Numa nova etapa, foram realizados cruzamentos biparentais, os quais originaram cultivares superiores, que permitiram a exploração da cultura nas várias áreas de cerrado do Brasil (Kiihl \& Garcia, 1989; Spehar, 1994b). Hoje, utilizam-se cruzamentos múltiplos com o objetivo de ampliar a base genética do germoplasma cultivado no Brasil e, ao mesmo tempo, promover o desenvolvimento de novos cultivares (Vello, 1992).

\subsection{Solos sob vegetação de cerrado}

Os solos sob vegetação de cerrado representam $25 \%$ do território brasileiro, ou cerca de 150 milhões de ha aptos à agricultura; ocupam principalmente a região centro-oeste, parte da região norte, nordeste e sudeste (EMBRAPA, 1976). Estes apresentam topografia relativamente plana, boa estrutura e possibilitam o uso intensivo de máquinas. No entanto, no processo evolutivo em decorrência da intensidade das intempéries, principalmente precipitação e temperatura, estes solos perderam por lixiviação grande parte dos cátions, como cálcio (Ca), magnésio $(\mathrm{Mg})$, potássio $(\mathrm{K})$, sódio $(\mathrm{Na})$ e silício $(\mathrm{Si})$. Desta forma, na fração argila, predomina a caulinita e óxidos de ferro e alumínio; estes apresentam grande capacidade de adsorção de ânions. Como o pH destes 
solos é geralmente baixo, a capacidade de troca catiônica é baixa, devido ser altamente dependente do $\mathrm{pH}$.

Os solos sob cerrado são tipicamente ácidos, o que favorece a presença de alumínio ( $\mathrm{Al}$ ) na solução do solo e na forma trocável em concentrações tóxicas. Os ácidos presentes nestes solos reagem com as partículas de argila, e liberam sais de Al solúveis. Estes solos em sua maioria apresentam valor absoluto de $\mathrm{Al}$ considerado médio (menor que 10 $\mathrm{mmol}_{\mathrm{c}} / \mathrm{dm}^{3}$ ), porém seu valor relativo (saturação de alumínio) encontra-se acima de $40 \%$, valor este considerado prejudicial às plantas cultivadas (Kamprath, 1970). Desta forma, a elevada saturação de Al constituem-se numa das mais importantes limitações ao uso agrícola destes solos (Foy, 1976; Lopes, 1983; Malavolta et al., 1977).

Os teores de $\mathrm{Ca}, \mathrm{Mg}, \mathrm{K}$ e fósforo (P) nestes solos são extremamente baixos, levando a um crescimento subnormal das plantas, quando cultivadas sob às condições naturais. Além disso, a capacidade de troca catiônica (CTC) é baixa devido à predominância de argila de baixa atividade e a matéria orgânica (principal responsável pela formação de cargas negativas e troca de cátions nestes solos) nas condições naturais apresentar pouca atividade (Lopes, 1983). Assim, a capacidade produtiva destes solos em condições naturais é pequena, contudo, o potencial é grande, quando corrigidas as suas principais limitações. Haja visto que, a produtividade média da soja nestes solos tem sido superior a da região tradicional (Roessing \& Guedes, 1993).

Via de regra estes solos, sob condições naturais, são profundos, bem drenados, com textura variável entre arenosa até muito argilosa, bem estruturados e com alta estabilidade de agregados, especialmente micro agregados (Goedert, 1980). No entanto, a retenção de água é limitada mesmo quando possuem um elevado percentual de argila (até $83 \%$ ) e perdem cerca de $75 \%$ ou mais da "água disponível" entre 0,1 a 
1,0 bar (Lopes, 1983). Isto significa que a quantidade máxima de água que pode ser armazenada na camada arável é suficiente para manter uma cultura em pleno desenvolvimento por apenas 6 a 10 dias. Além do mais, nesta região, é elevada a probabilidade de que, durante a estação das chuvas, ocorra um período de seca prolongado (veranico), que causa sérios danos aos cultivos quando o sistema radicular é superficial.

Assim para um bom desenvolvimento das culturas nestes solos é necessário a prática da calagem, que tem como objetivos: reduzir a saturação de $\mathrm{Al}$; corrigir o $\mathrm{pH}$; fornecer $\mathrm{Ca}$ e $\mathrm{Mg}$; aumentar a atividade microbiana; aumentar a liberação de nutrientes como nitrogênio, fósforo e enxofre pela decomposição da matéria orgânica; diminuir a adsorção de fósforo; aumentar as cargas dependentes de $\mathrm{pH}$; entre outras. No entanto, como os efeitos benéficos da calagem ficam restritos à camada arável, o uso de cultivares que tolerem às condições impostas pela acidez é primordial, para se obter alta produtividade de grãos.

\subsection{Desenvolvimento das plantas nos solos ácidos}

O desenvolvimento das plantas nos solos ácidos de baixa fertilidade é limitado por uma "complexa infertilidade" que inclui: toxidez de alumínio; deficiência de certos nutrientes como $\mathrm{Ca}, \mathrm{Mg}, \mathrm{P}$ e Molibdênio (Mo). No entanto, o fator mais agravante é a toxidez causada pelo alumínio, especialmente nos solos com subsolos ácidos, porque restringe o desenvolvimento das raízes em profundidade, o que causa um decréscimo na tolerância à seca e no uso dos nutrientes do subsolo (Foy, 1976, 1988; Foy et al., 1978). O efeito do Al sobre as plantas, bem como a diferença de comportamento entre as espécies e a redução dos seus efeitos pela 
utilização de adubos fosfatados e calcário foram identificados no início do século (Hartwell \& Pember, 1918; Magistad, 1925; McLean \& Gilbert, 1927).

No entanto, estudos sobre o efeito do alumínio nas plantas datam de 1965, apesar de serem encontrados na literatura com certa abundância, porém 0 mecanismo pelo qual 0 Al prejudica 0 desenvolvimento das plantas tem sido objeto de muita discussão. Têm sido observados danos morfológicos e anatômicos nas raízes laterais e na extremidade da raiz principal; a presença de células binucleadas na região meristemática das raízes, indica que a divisão celular foi inibida (Clarkson, 1965, 1969; Fleming \& Foy, 1968). A divisão celular é afetada devido ao alumínio se associar com o fósforo dos ácidos nucléicos e com lipídios da membrana plasmática (Clarkson, 1969; Horst et al., 1992).

Além disso, a associação do alumínio com proteínas e lipídios da membrana plasmática, causa alterações na sua estrutura e permeabilidade (Bollard \& Butler, 1966; Foy \& Brown, 1964; Horst et al., 1992; Horton \& Edwards, 1976; Stab \& Horst, 1995). Mas seu efeito mais grave é a inibição da divisão celular nas raízes (Horst et al., 1983), como conseqüência, estas são curtas e grossas, de aparência espatulada, com as pontas amarronzadas (Foy, 1976; Foy \& Brown, 1964).

O efeito inibidor do alumínio na absorção de elementos nutrientes provavelmente é conseqüência de sua competição com outros íons por sítios de absorção, devido unir-se fortemente às cargas negativas do sistema radicular (Klimashevskii \& Dedov, 1975). Esta inibição pode estar associada também a alterações na estrutura e permeabilidade da membrana plasmática, causada pela ligação do alumínio com suas proteínas e lipídios (Horton \& Edwards, 1976).

$\mathrm{A}$ interferência do $\mathrm{Al}$ na absorção de $\mathrm{Ca}$ e $\mathrm{Mg}$ é um caso de inibição competitiva pois, pode ser anulada pela elevação da concentração 
dos dois nutrientes no meio (Alva et al., 1986, 1991; Foy et al., 1969, 1978; Malavolta et al., 1977). O alumínio combina com o fósforo presente na solução do solo, na superfície e dentro da raiz, forma complexos de baixa solubilidade e diminui a disponibilidade. A competição e a interferência na absorção e utilização é particularmente nociva em solos ácidos, com alto teor de Al e baixo de P (Alva et al., 1986; Foy, 1976; Foy et al., 1978; Vilela \& Anghinoni, 1984). Assim, os sintomas de toxidez de alumínio na parte aérea das plantas são freqüentemente caracterizados por sintomas semelhantes aos de deficiência de P e/ou de Ca (Alva et al., 1991; Foy et al., 1969, 1992, 1993).

O alumínio trocável provoca uma redução na sobrevivência da bactéria fixadora de nitrogênio $(\mathrm{N})$ em soja (Bradyrhizobium japonicum); reduz o número e o peso de nódulos e a capacidade de fixar o $\mathrm{N}$ (Alva et al., 1986; Cline \& Kaul, 1990; Mookherji \& Floyd, 1991; Munns, 1986; Sapra et al., 1982). No entanto, existem estirpes que são mais eficientes em estabelecer a simbiose (Taylor et al., 1991; Vargas et al., 1993), bem como hospedeiros com maior capacidade de nodulação (Alva et al., 1988) sob condições de solos ácidos. Entre os métodos utilizados para recomendação de calagem o método do alumínio trocável foi o que proporcionou melhores condições para o desenvolvimento do rizóbio em solos sob vegetação de cerrado (Mesones, 1991; Samrão et al., 1986).

A toxidez causada pelo alumínio evidencia-se não como um fator, mas sim, no produto da interação com elementos químicos essenciais que interfere no desenvolvimento de distintas espécies vegetais e afeta diferentes mecanismos físiológicos (Foy, 1976, 1988; Kerridge \& Kronstad, 1968). 


\subsection{Tolerância à acidez dos solos}

A tolerância das culturas à acidez dos solos está ligada à capacidade de absorção de nutrientes e à insensibilidade à toxidez de alumínio $\mathrm{Al}$ e/ou $\mathrm{Mn}$, características que dependem da variação genética das espécies e de cultivares dentro de uma mesma espécie (Foy, 1988; Foy \& Brown, 1964; Foy et al., 1978). Igualmente, os mecanismos pelos quais as plantas toleram os solos ácidos variam entre e dentro da espécie (Foy, 1988). As espécies/cultivares tolerantes podem evitar a adsorção ou absorção de alumínio em excesso por suas raízes (mecanismo de exclusão) ou desintoxicar-se após o Al ter sido absorvido (mecanismo de inativação).

Várias reações da planta em diferentes espécies têm sido descritas como responsáveis pela tolerância ao $\mathrm{Al}$ : modificação do $\mathrm{pH}$ do solo ou da solução nutritiva ao redor do sistema radicular (Clark \& Brown, 1974; Foy et al., 1965; Hanson, 1991); preferência pela absorção de amônio em relação ao nitrato (Klotz \& Horst, 1988); menor absorção de nitrato na presença do Al (Lazof et al., 1994); desintoxicação pela formação de quelatos de Al com ácidos orgânicos (Foy \& Brown, 1964; Lee \& Foy, 1986); maior absorção e utilização de P na presença de Al (Foy \& Brown, 1964; Foy et al., 1974; Vilela \& Anghinoni, 1984); alta capacidade de absorção e transporte de Ca, Mg e K (Foy, 1976; Foy et al., 1969, 1978; Hanson, 1991; Wagatsuma, 1983); menor CTC radicular (Foy, 1988; Foy et al., 1978; Wagatsuma, 1983).

O ambiente tem papel importante sobre o modelo de vida sob sua influência, assim plantas originadas em áreas que contêm nutrientes em níveis que causam toxidez ou deficiência desenvolvem mecanismos para tolerar os respectivos fatores que limitam o seu desenvolvimento. Desta forma, a resposta à tolerância ao $\mathrm{Al}$ tem sido associada com a origem do 
germoplasma (Camargo, 1981; Camargo \& Oliveira, 1981; Foy et al., 1974, 1978; Silva, 1976; Spehar, 1994a). Silva (1976) mostra a adaptação de cultivares de trigo aos solos ácidos do Brasil, nos quais a pressão da seleção natural levou os melhoristas a selecionar indiretamente variedades de trigo tolerantes. Estudos sobre a diversidade do germoplasma de soja adaptada ao cultivo nos cerrados indicam que a tolerância ao Al foi preservada durante o processo de seleção. Isto ocorreu devido à seleção ter sido realizada em solos corrigidos, mas cuja camada subsuperficial ainda apresentava acidez elevada e altos teores de alumínio, embora o material genético seja homogêneo quanto às características agronômicas, conforme resultados obtidos em solo corrigido (Spehar, 1994a).

Uma séria limitação para seleção de plantas tolerantes ao $\mathrm{Al}$ é a metodologia de "screening". Os métodos utilizados variam muito entre os diversos trabalhos com respeito ao: estresse de Al (tempo e intensidade); pH do meio; meio de desenvolvimento (solução nutritiva, solo em vaso ou diretamente no campo); características analisadas. Em consequência, muitas vezes, os resultados são contraditórios, uma vez que o índice de tolerância é uma medida relativa. Assim, um mesmo cultivar pode ser considerado tolerante em um trabalho e sensível em outro. Estudos realizados em soluções nutritivas permitem estudar isoladamente a tolerância ao $\mathrm{Al}, \mathrm{Mn}$ e a interação destes com outros nutrientes ou fatores. Mas, quando se utiliza solo (vaso ou campo) é praticamente impossível isolar as causas e efeitos, de maneira que a tolerância detectada nesta condição é generalizada.

Estudos em solução nutritiva têm normalmente como objetivo principal determinar os efeitos do alumínio sobre o alongamento e divisão das células. Enquanto que, estudos em solo tem avaliado o efeito continuado do Al sobre a parte aérea, raízes e absorção de nutrientes. Em 
adição, os efeitos da acidez como um todo, influenciam também o desenvolvimento da planta e a atividade microbiana.

Nos estudos conduzidos em casas-de-vegetação/câmaras de crescimento, com soluções nutritivas e/ou solos ácidos, foram identificadas diferenças no comportamento dos genótipos (Armiger et al., 1968; Campbell \& Carter Júnior, 1990; Foy et al., 1969, 1992, 1993; Goldman et al., 1989; Hanson, 1991; Hanson \& Kamprath, 1979; Melo, 1980; Miranda et al., 1982; Sapra et al., 1982; Sartain \& Kamprath, 1978; Silva et al., 1984; Spehar \& Makita, 1994). Nessas condições, os caracteres normalmente avaliados são: peso e comprimento da parte aérea e do sistema radicular; sintomas de toxicidade nas raízes e/ou parte aérea; concentração de ácidos orgânicos e nutrientes nas diferentes partes da planta; sendo o sistema radicular o principal caráter de estudo.

A tolerância a solos ácidos em soja também tem sido avaliada em condições de campo, observando-se diferenças nas reações dos genótipos (Bataglia et al., 1981; Miranda et al., 1988; Muzilli et al., 1978; Spehar, 1989, 1994a,c). O sistema radicular é o sítio primário a sofrer os efeitos da toxidez de $\mathrm{Al}$, mas, ao nível de campo, tal observação é praticamente impossível de ser mensurada, assim os caracteres observados são: desenvolvimento da parte aérea; teor de nutrientes e sintomas típicos da parte aérea; produtividade de grãos, sendo este último o que tem merecido atenção especial.

Para contornar esse problema tem-se buscado correlações com outros caracteres de mais fácil mensuração. Em soja Foy et al. (1993) observou elevada correlação $(r=0,89$ e 0,86$)$ entre o desenvolvimento do sistema radicular e da parte aérea, aos 37 dias em condição de casa-devegetação em solo com 7 e $70 \%$ de saturação de alumínio, respectivamente. Entretanto, não houve correlação, quando a exposição ao 
Al foi por 18 dias; o peso seco do sistema radicular reduziu-se em mais de $50 \%$, comparado com o controle, enquanto o peso seco da parte aérea não foi afetado (Hanson, 1991). Isto pode ter ocorrido devido à utilização de uma camada de $5 \mathrm{~cm}$ de solo corrigido, suprimindo os efeitos do $\mathrm{Al}$ presente na camada inferior, e o tempo de exposição ao $\mathrm{Al}$ não ter sido suficiente para que os efeitos prejudicassem a parte aérea. Realmente, Armiger et al. (1968), Sartain \& Kamprath (1978) e Goldman et al. (1989) observaram que o desenvolvimento da parte aérea foi drasticamente afetado quando a exposição ao Al tóxico foi mantida por mais de 30 dias.

Em soja Hanson \& Kamprath (1979) observaram correlação significativa $(r=0,79)$ entre os resultados obtidos em solução nutritiva e os de solo em vasos, em casa-de-vegetação, com herdabilidade de 0,67 para tolerância ao Al. Campbell \& Carter Júnior (1990) também encontraram correlação alta $(0,81)$ entre o comprimento das raízes de plântulas em solução nutritiva e o peso seco da parte aérea obtida em solo, em casa-de-vegetação. Entretanto, Sartain \& Kamprath (1978) e Sapra et al. (1982) verificaram baixa correlação entre os danos causados pelo Al às raízes em solução nutritiva e os danos causados às raízes e parte aérea das plantas quando cultivadas no solo com alta saturação de Al em casa-devegetação.

Hanson \& Kamprath (1979), em estudo sobre comportamento de diferentes genótipos de soja, selecionados para a tolerância ao alumínio, em solo contendo $0,24,48$ e $79 \%$ de saturação de Al, observaram que nas saturações de 24 e $79 \%$ não foram detectadas diferenças entre os genótipos, concluindo que a saturação de $48 \%$ foi a melhor para discriminar o material. Silva et al. (1984) não detectaram diferenças para tolerância ao Al através da análise do peso seco do sistema radicular e da parte aérea, entre 10 genótipos de soja, quando cultivados em vasos por 33 dias. Melo (1980) testando 50 cultivares de soja em solo com alta 
saturação de Al em condições de casa-de-vegetação, classificou apenas quatro como sensíveis, com base no comportamento do sistema radicular. Isto mostra que em condições de alta saturação de alumínio os genótipos podem apresentar comportamento semelhante quanto ao desenvolvimento do sistema radicular.

Spehar (1994c) encontrou diferença entre genótipos, com base na produtividade de grãos, número de dias para a maturidade e altura da planta na maturidade, ao nível de campo utilizando solo ácido com $29 \%$ de saturação de alumínio na camada arável e $83 \%$ na camada subsuperficial. Nesta condição, houve uma maior discriminação entre os genótipos do que no mesmo solo com $3 \%$ de saturação de Al na camada arável.

Kamprath (1970) mostrou que a soja não tolera níveis de saturação de alumínio superior a $20 \%$. No entanto, Muzilli et al. (1978) obtiveram produtividades de grãos relativamente altas em solos com $28 \%$ de saturação de alumínio com $9 \mathrm{mmol}_{\mathrm{c}} / \mathrm{dm}^{3}$ de alumínio trocável. Já Bataglia et al. (1981) em solo com $14 \mathrm{mmol}_{\mathrm{c}} / \mathrm{dm}^{3}$ de $\mathrm{Al}$ e saturação de $\mathrm{Al}$ de $24 \%$ não obtiveram o mesmo sucesso. Isto indica que a quantidade de alumínio trocável também é importante.

Bataglia et al. (1981) encontraram fortes evidências de que a toxicidade por alumínio era a principal causa da "queima das folhas" em soja. Miranda et al. (1988) encontraram correlação alta e significativa (0,92) entre o peso da matéria seca e a nota de "queima das folhas", e sugeriram a utilização como critério para seleção de genótipos com resistência à acidez do solo.

A produtividade de soja em solos ácidos apresenta outros fatores limitantes tais como: redução nos teores de magnésio das folhas; a soma dos teores de magnésio e cálcio trocáveis do solo estão 
correlacionados positivamente com a produtividade de grãos (Raij et al., 1977); em latossolo vermelho-escuro, de São Paulo, tanto o alumínio quanto o manganês limitaram sensivelmente a produtividade (Mascarenhas et al., 1982); o estresse hídrico agrava os efeitos da toxidez de alumínio (Goldman et al., 1989).

\subsection{Controle genético da tolerância ao alumínio}

A literatura é abundante quanto à resposta diferencial de cultivares para tolerância ao $\mathrm{Al}$, mas pouco se conhece sobre o controle genético, o qual é importante na definição de estratégias para explorar plenamente a variabilidade. Estudos sobre o controle genético da tolerância ao Al em diferentes espécies iniciaram-se por volta de 1970.

Em trigo, Kerridge \& Kronstad (1968) concluíram que a tolerância foi condicionada por um gene, o alelo dominante é que condiciona a tolerância. Camargo (1981) testando progênies de cruzamentos entre variedades tolerantes e sensíveis, concluiu que a tolerância é condicionada por dois genes dominantes.

Em milho, Garcia Júnior \& Silva (1979) concluíram que a tolerância foi controlada por um alelo dominante, com possibilidade de ocorrência de genes modificadores. Miranda et al. (1984) relataram que a tolerância é condicionada por dois alelos dominantes complementares.

Em soja, o controle genético da tolerância ao alumínio foi estudado por Hanson \& Kamprath (1979), Spehar (1989) e Spehar \& Galwey (1995) através da análise do sistema radicular e da produtividade 
de grãos; concluíram que o controle da tolerância ao alumínio é de natureza quantitativa.

Hanson \& Kamprath (1979) testaram 152 linhagens de uma população de soja com base genética ampla para tolerância ao $\mathrm{Al}$ e selecionaram 12 linhagens tolerantes e 12 linhagens sensíveis, obtendo-se duas populações divergentes. Realizaram três ciclos de seleção recorrente com base no comprimento do sistema radicular de plântulas, com três dias de idade, submetidas por dois dias em solução nutritiva contendo 0 e 0,4 ppm de Al. A seleção foi baseada em dois índices criados a partir de um modelo linear: $I_{1}=($ comprimento final - inicial $) /$ tempo para $0 \mathrm{ppm} \mathrm{de} \mathrm{Al}$; $\mathrm{I}_{2}=$ (comprimento final - inicial) $/$ tempo para $0,4 \mathrm{ppm}$ de Al. No primeiro ciclo, a seleção foi baseada na razão $\mathrm{I}_{2} / \mathrm{I}_{1}$. Já nos segundo e terceiro ciclos, a seleção foi baseada no índice $I_{2}$. A herdabilidade foi de 0,67 e 0,60 para os índices $I_{2}$ e $I_{2} / I_{1}$, respectivamente; já a herdabilidade realizada no primeiro ciclo para o índice $I_{2} / I_{1}$ foi de 0,50 . A variabilidade não diminuiu com os ciclos de seleção em nenhuma das duas populações, fícando evidente que a característica é de natureza quantitativa.

Spehar (1989) avaliou as 36 populações $F_{2}$ obtidas de um cruzamento dialélico completo e os nove parentais (IAC-2, IAC-5, UFV-1, V x 5-282.5, IAC-8, IAC-7, IAC-9, Biloxi e FT-Cristalina) em solo sob "vegetação de cerrado" em dois níveis de saturação de alumínio $(3,4 \%$ e $28,8 \%$ ). A análise genética para produtividade de grãos em cada ambiente e a razão entre os dois ambientes, pelo método de Griffing (1956) mostrou efeito significativo para capacidade geral de combinação (CGC) e capacidade específica de combinação (CEC), mas a CGC foi superior, principalmente para o ambiente com alta saturação de Al e para a razão alto Al/baixo Al. Esses resultados, indicam que a herança para produtividade de grãos em soja é controlada predominantemente por efeitos aditivos nos dois ambientes. A razão entre os dois ambientes, 
elimina possíveis interferências de diferença de potencial genético entre os cultivares, confirmando que a tolerância ao Al para produtividade de grãos é basicamente aditiva.

Spehar \& Galwey (1995) estudaram o controle genético da tolerância ao $\mathrm{Al}$ através do comprimento da raiz em meio hidropônico, com base no desempenho das plantas das gerações $P_{1}, P_{2}, F_{2}, R_{1}$ e $R_{2}$ dos cruzamentos IAC-7 $x$ Biloxi, IAC-7 $x$ IAC-2 e IAC-7 $x$ IAC-9, pelo método de Cavalli (1952). Um segundo experimento composto pelas famílias $\mathrm{P}_{1}, \mathrm{P}_{2}, \mathrm{~F}_{2}, \mathrm{~F}_{3}, \mathrm{RC}_{1}$ e $\mathrm{RC}_{2}$ foi analisado pelo método modificado sugerido por Mather \& Jinks (1982). O controle genético para o cruzamento IAC-7 x Biloxi é melhor explicado quando inclui as interações aditiva $x$ aditiva e aditiva $x$ dominante; já para o 'IAC-7 x IAC-9' melhor explicação é obtida quando se incluem as interações aditiva $x$ aditiva $e$ dominante $\mathrm{x}$ dominante. Com base nesses resultados, concluíram que 0 modelo aditivo-dominante simples não é suficiente para explicar a herança para tolerância ao $\mathrm{Al}$, mostrando ser uma característica poligênica com efeitos predominantemente aditivos.

\subsection{Melhoramento para produtividade de grãos}

O aumento da produtividade de grãos tem sido o principal objetivo dos programas de melhoramento genético de soja. Os cultivares apresentam grande potencial genético para adaptação às condições específicas de ambientes, resistência à doenças e pragas e ao cultivo moderno (Kiihl \& Almeida, 1992; Kiihl \& Garcia, 1989; Spehar, 1994b, 1995; Toledo et al., 1990). Contudo, a hibridação para obtenção de novos cultivares tem sido às custas de uma redução do progresso genético (Fehr, 
1987). Assim, existe uma dificuldade em superar o progresso genético obtido com os cultivares que estão bem adaptados.

Como a maioria dos solos cultivados com soja nos trópicos apresenta subsolo ácido, com restrição ao desenvolvimento do sistema radicular e da simbiose, a conseqüência é um aproveitamento inadequado da água e dos nutrientes. Esforços têm sido empregados para produzir cultivares que tolerem às condições impostas pelo "complexo acidez do solo" (Miranda et al., 1993; Arantes \& Miranda, 1993; Spehar, 1994b, 1995).

O aumento da produtividade de soja tem sido alcançado às custas de uma redução na variabilidade genética. Vello et al. (1988), ao analisarem 69 cultivares, observaram que o tamanho efetivo da população era relativamente pequeno $\left(N_{\mathrm{e}}=11\right.$ a 15); Hiromoto \& Vello (1986), em estudo da genealogia de 74 cultivares constataram que 11 ancestrais asiáticos contribuíram com $89 \%$ do seu conjunto gênico. Essa redução de variabilidade tem dificultado suplantar os patamares de produtividade, devido a dificuldade de identificar parentais com alta produção e que não tenham ancestrais comuns.

Com o objetivo de ampliar a base genética do germoplasma de soja, genótipos introduzidos estão sendo usados como parentais. Vello et al. (1984) encontraram aproximadamente o dobro da variabilidade genética para produção de grãos, em populações sintetizadas com $25,50,75$ e $100 \%$ de genótipos introduzidos quando comparado com populações sintetizadas com $100 \%$ de material adaptado para alta produtividade. No entanto, a média de produção e a frequência de segregantes de alta produtividade foram maiores nas populações desenvolvidas com parentais adaptados. Assim a curto prazo é provável que o uso destes genótipos introduzidos não proporcione aumentos na produtividade. 
Outra estratégia que tem sido usada para suplantar a baixa diversidade genética do germoplasma de soja é o uso da prática da seleção recorrente, para obter genótipos superiores via recombinação, com possível quebra de blocos gênicos e obtenção de variabilidade para os ciclos posteriores (Kenworthy \& Brim, 1977; Rose et al., 1992; Sumarno \& Fehr, 1982; Vello, 1992; Wilcox, 1994).

\subsection{Genética de caracteres quantitativos}

Uma das principais contribuições da genética quantitativa ao melhoramento de plantas têm sido a interpretação das estimativas dos componentes da variância. Estes são necessários para definir métodos de melhoramento, os quais são eficazes se consideram a variabilidade genética e o tipo de ação gênica predominante no controle do caráter sob seleção (Ramalho \& Vencovsky, 1978). O ideal é que a variância genética predominante seja devida aos efeitos aditivos dos genes. Uma vez que, em culturas como a soja, a exploração comercial da heterose se satisfatória, não é viável, até o presente momento.

Alguns trabalhos têm mostrado que o efeito aditivo é o principal componente da variância genética em soja (Brim \& Cockerham, 1961; Bonato, 1989; Freire Filho, 1988; Gomes, 1995; Leffel \& Weiss, 1958; Nass, 1989; Pinheiro, 1993). Esta evidência é relevante, uma vez que as médias das gerações permanecem constantes, e a variância genética é realmente transmitida de uma geração para outra. Isto permite realização de testes precoces e a seleção em vários níveis de endogamia (Brim \& Cockerham, 1961). No entanto, estimativas de variância de dominância 
superiores as aditivas também tem sido observadas (Brim \& Cockerham, 1961; Leffel \& Hanson, 1961; Leffel \& Weiss, 1958; Pacova, 1992).

Por outro lado, aproximadamente $70 \%$ da variância genética para produção de grãos tem sido atribuída a epistasia aditiva $\mathrm{x}$ aditiva (Hanson \& Weber, 1962; Hanson et al., 1967; St. Martin, 1981). Isto implica que a seleção para produção de grãos em soja seja mais eficiente em gerações mais avançadas onde, esta epistasia é capitalizada. Apesar deste componente ser explorado pela seleção, ele não pode ser transmitido via cruzamento (St. Martin, 1981, 1985) uma vez que seus efeitos estão associados às combinações de alelos pertencentes a locos gênicos diferentes, sendo portanto, sujeito a modificações durante as recombinações e autofecundações.

\subsubsection{Herdabilidade}

A herdabilidade é a fração da variância fenotípica que é devida às causas genéticas numa população. Expressa a proporção da variância total decorrente do efeito médio dos genes, e isso é que determina o grau de semelhança entre parentes (Falconer, 1987).

A herdabilidade não é um valor constante referente a um caráter, mas sim uma propriedade de um caráter em uma determinada população, avaliada em um determinado ambiente (Dudley \& Moll, 1969; Falconer, 1987; Fehr, 1987). Portanto, não se pode extrapolar valores de herdabilidade para outras populações ou ambientes, diferentes daqueles em que foram estudados. Neste sentido, é preciso conhecer a magnitude da herdabilidade em ambientes específicos. 
A função mais importante da herdabilidade é o seu papel preditivo, pois expressa a confiança do valor fenotípico como um indicativo do valor genético (Falconer, 1987). Em programas de melhoramento a sua magnitude auxilia na definição de estratégias de seleção e na predição de ganhos com seleção (Brim, 1973; Fehr, 1987).

O coeficiente de herdabilidade pode ser estimado nos sentidos amplo e restrito e a diferença situa-se no numerador da fração que o define. No sentido amplo, é a razão entre a variância genética total e a variância fenotípica e no sentido restrito, é a razão entre a variância genética aditiva e a variância fenotípica. O coeficiente de herdabilidade $\left(h^{2}\right)$ pode variar de zero a um, no entanto, estimativas negativas de herdabilidade podem ocorrer em função de componentes de variância muito pequenos ou de erros de amostragem (Comstock \& Robinson, 1948). O termo coeficiente de herdabilidade é utilizado quando os indivíduos em estudo compreendem uma amostra aleatória de uma população genética. Quando se trata de população fixa de genótipos, utiliza-se o termo coeficiente de determinação genotípico (Falconer, 1987).

Cockerham (1963) apresenta uma metodologia para a estimação dos componentes da variância genética em plantas autofecundadas por gerações sucessivas. Ramalho \& Vencovsky (1978) e Vello (1985) discutem a aplicação dessa metodologia e mostram o tipo de variabilidade à disposição dos melhoristas pelos vários métodos de melhoramento de plantas autógamas.

A seleção para caracteres de baixa herdabilidade deve ser praticada em gerações mais avançadas, devido haver um aumento na herdabilidade com o decorrer das gerações de endogamia em função do aumento da variância genética aditiva e diminuição da variância de dominância (Ramalho \& Vencovsky, 1978). Para caracteres de alta herdabilidade, a seleção nas gerações iniciais é eficaz. Entretanto, alta 
pressão de seleção para estes caracteres, em gerações precoces, pode resultar em diminuição da variabilidade para caracteres de baixa herdabilidade, como produção de grãos, na população remanescente (Brim, 1973). Entre linhagens homozigóticas, a variância genética total inclui somente a variância genética aditiva e epistática aditiva $\mathrm{x}$ aditiva (Dudley $\&$ Moll, 1969). Assim, espera-se que as herdabilidades nos sentidos amplo e restrito sejam semelhantes nestas gerações.

Estimativas de herdabilidade de caracteres de soja têm sido relatadas em inúmeros trabalhos, algumas dessas foram obtidas através dos componentes de variância, a partir da avaliação de genótipos em diferentes gerações de autofecundação, em um ou mais ambientes (Hanson \& Weber, 1962; Johnson et al., 1955a; Kwon \& Torrie, 1964; Prado, 1994; Santos, 1994; Shimoya, 1990).

Brim (1973), em trabalho de revisão, mostra que os coeficientes de herdabilidade para produção de grãos foram os mais baixos (3 a 58\%); para os outros caracteres quantitativos comumente avaliados em programas de melhoramento foram maiores que 50\%. Nem sempre é aceita a comparação entre estimativas de herdabilidade obtidas em populações de genótipos e/ou em condições experimentais diferentes (Dudley \& Moll, 1969).

\subsubsection{Correlação entre caracteres}

A importância do conhecimento das estimativas das correlações entre caracteres reside no fato de auxiliar no planejamento e na avaliação de programas de melhoramento. Além disso facilita a interpretação dos resultados e fornece subsídios para elaboração de 
programas mais eficientes no futuro (Johnson et al., 1955b). Tais estimativas são importantes na formação de índices de seleção, principalmente se um dos caracteres desejáveis apresenta baixa herdabilidade ou problemas na medição e identificação (Cruz \& Regazzi, 1994), como é o caso, da mensuração do sistema radicular em experimentos de campo.

A correlação fenotípica é aquela mensurada diretamente a partir da avaliação de dois caracteres, em certo número de indivíduos da população. Essa correlação é devida às causas genéticas e ambientais, no entanto, só as genéticas envolvem uma associação de natureza herdável. A principal causa da correlação genética é a pleiotropia, visto que a ligação gênica é transitória, especialmente em populações derivadas de cruzamento entre linhagens divergentes. Assim a correlação genética devida à ligação gênica é desfeita quando a população atinge o equilíbrio de ligação (Falconer, 1987).

Quando dois caracteres apresentam correlação genética positiva é possível obter ganhos para um deles por meio da seleção indireta no outro associado. A seleção indireta, através de um caráter de alta herdabilidade e fácil mensuração, com base na resposta correlacionada, pode conduzir a progressos mais rápidos no melhoramento (Cruz \& Regazzi, 1994). Entretanto, Byth et al. (1969) verificaram que a seleção indireta para produção por caracteres agronômicos correlacionados não foi tão eficiente quanto a direta.

A correlação ambiental aparece quando dois caracteres são influenciados do mesmo modo pelas condições ambientais. Contudo, o coeficiente de correlação ambiental não representa somente a correlação devida aos fatores ambientais, uma vez que os componentes da variância e covariância referentes ao resíduo podem incluir, além desses fatores, aqueles devidos aos efeitos de dominância, da epistasia e da interação 
genótipos x ambientes (Silva et al., 1982). Valores negativos da correlação ambiental indicam que o ambiente favorece um caráter em detrimento do outro, e valores positivos indicam que os dois caracteres são beneficiados ou prejudicados pelas mesmas causas de variações ambientais (Cruz \& Regazzi, 1994).

Os coeficientes de correlação genética e ambiental geralmente apresentam o mesmo sinal. Contudo, quando isso não ocorre, existe indicativo de que as causas da variação genética e ambiental influenciam os caracteres por meio de diferentes mecanismos fisiológicos (Falconer, 1987). Valor negativo entre caracteres selecionados no mesmo sentido indica que a seleção conjunta terá problemas, pois a seleção para aumento em um caráter implicará numa tendência em diminuição no outro (Silva, 1982).

A correlação entre caracteres tem sido objeto de estudos em trabalhos com a cultura da soja, nos quais observa-se superioridade das estimativas de correlações genotípicas sobre as fenotípicas (Anand \& Torrie, 1963; Bays, 1975; Farias Neto, 1995; Freire Filho, 1988; Gomes, 1995; Johnson et al., 1955b; Kwon \& Torrie, 1964; Montenegro, 1994; Pacova, 1992; Santos, 1994).

Estimativas de correlação genotípica positivas têm sido observadas entre o caráter produtividade de grãos e altura da planta na maturidade (Farias Neto, 1995; Gomes, 1995; Johnson et al., 1955b; Montenegro, 1994; Prado, 1994; Santos, 1994; Shimoya, 1990) e número de dias para a maturidade (Farias Neto, 1995; Freire Filho, 1988; Gomes, 1995; Johnson et al., 1955b; Montenegro, 1994; Pacova, 1992; Prado, 1994; Santos, 1994). Correlações negativas da produtividade de grãos com altura da planta e número de dias, avaliados na maturidade, também foram encontradas (Montenegro, 1994; Prado, 1994).

Os coeficientes de correlação entre os pares de caracteres de soja dos trabalhos revisados, mostraram variação em direção e 
principalmente em magnitude para cruzamentos ou populações diferentes. Estas estimativas mostram uma tendência na correlação entre os caracteres, o que representa um subsídio importante para o melhorista. Entretanto, para maior eficiência na seleção, os coeficientes de correlação devem ser estimados em cada população a ser melhorada (Cruz \& Regazzi, 1994; Falconer, 1987; Johnson et al., 1955b).

\subsubsection{Interação genótipos $x$ ambientes e o progresso genético}

O melhorista de plantas, normalmente, determina o potencial da população segregante e a melhor época para fazer seleção, através das variâncias genéticas e fenotípicas. A variância fenotípica é constituída de uma porção atribuída a um componente genético e uma outra ao ambiente. $O$ conhecimento da proporção devida às diferenças genéticas é de fundamental importância na condução eficiente da população segregante e na previsão do sucesso a ser obtido com a seleção (Ramalho \& Vencovsky, 1978).

Quando os genótipos são avaliados em mais de um ambiente, identifica-se uma terceira fonte de variação, que é a interação de genótipos por ambientes ( $G \times A)$. Um problema que ocorre quando os genótipos são avaliados em um local ou ambientes pouco representativos para onde se quer fazer a seleção, é que as estimativas da variância genética podem não representar o seu verdadeiro valor; pode estar confundida com a interação $G \times$ A. Portanto, constitui-se em uma das causas dos erros associados a ela, com superestimação dos seus valores (Allard, 1971; Moll \& Stuber, 1974). Conseqüentemente, a herdabilidade pode ser afetada pela interação, já que é definida como o quociente entre a variância genética e variância fenotípica. E também, ocorrerá discrepância entre o ganho esperado e o realizado com a 
seleção, pois o progresso esperado é diretamente proporcional à herdabilidade.

A magnitude da interação $G \times$ A dependerá do material genético avaliado e das condições ambientais. Vencovsky (1987) destaca que esta interação é devida a variabilidade genética do material dentro dos ambientes e a falta de correlação entre o material genético de um ambiente para outro. Sendo que, pode ocorrer interação mesmo na presença de alta correlação.

Em soja, Johnson et al. (1955a) enfatiza a importância da interação $\mathrm{G} \times \mathrm{A}$ no desenvolvimento de cultivares e seu efeito na seleção de genótipos superiores. Estes autores observaram que o comportamento da altura da planta e do teor de óleo são mais consistentes do que a produtividade de grãos em diversos ambientes. Kwon \& Torrie (1964) observaram que a estimativa da interação genótipos $x$ anos foi maior que a interação genótipos $\mathrm{x}$ locais para a maioria dos caracteres, especialmente para a produtividade de grãos.

A avaliação de genótipos em vários locais e épocas, permite identificar e remover quantidades crescentes de variâncias devido às interações. Portanto, as avaliações de progênies devem ser realizadas em um número representativo de ambientes da região, para que as estimativas da variância genética sejam $o$ mais livre possível da interação e, consequentemente, o ganho previsto seja o mais próximo daquele obtido com a seleção (Allard, 1971), permitindo assim antever os potenciais de genótipos selecionados.

O sucesso de um programa de melhoramento está na dependência da variabilidade genética e da capacidade de se identificar os genótipos superiores na população sob seleção. A estimativa dessa variabilidade por parâmetros genéticos permite fundamentar os trabalhos de melhoramento em bases científicas. O efeito da seleção sobre a estrutura genética de uma população depende das frequências gênicas dos caracteres selecionados, da 
intensidade de seleção e da precisão das estimativas, assim, quanto maior a intensidade de seleção maior será o progresso genético; no entanto, a variabilidade genética é exaurida rapidamente.

Com base no exposto acima muitos melhoristas utilizam intensidades de seleção mais brandas para melhor exploração da variabilidade disponivel, de modo a aumentar as chances do progresso obtido com a seleção em um ambiente possa ser extrapolado para outras regiões e para os anos subsequentes.

\subsection{Delineamento em blocos aumentados e o melhoramento de plantas}

O sucesso de um programa de melhoramento depende diretamente da eficiência da experimentação, principalmente para os caracteres de baixa herdabilidade, como a produtividade de grãos. Para identificar genótipos produtivos e possuidores de caracteres agronômicos desejáveis, extensivos testes ao nível de campo precisam ser realizados. Dessa forma, é preciso compatibilizar boa avaliação de genótipos com uso de recursos material e humano.

Nas fases iniciais de programas de melhoramento normalmente têm-se um grande número de genótipos para serem testados. Assim, o uso de delineamentos tradicionais (inteiramente casualizado, blocos completos, látice, etc.) torna-se difícil, em razão de exigência de grandes áreas relativamente homogêneas, baixa disponibilidade de sementes dos genótipos, dificuldade de implantação e condução, limitação de recurso material e humano. 
Para suplantar estas dificuldades, Federer (1956) desenvolveu os chamados 'modelos aumentados' para o programa de seleção de novos híbridos de cana-de-açúcar da "HAWAIIAN SUGAR PLANTER'S ASSOCIATION", em substituição a modelos anteriores.

A expressão delineamentos aumentados foi definida por Federer (1961) como um delineamento tradicional qualquer (inteiramente casualizado, blocos completos, quadrado latino, etc), onde novos tratamentos são adicionados sem repetição. Assim esses esquemas apresentam um conjunto de tratamentos repetidos chamados comuns, e um segundo grupo de tratamentos adicionais, não repetidos, chamados regulares. Os tratamentos comuns, genótipos conhecidos, estão presentes em todos os blocos e atuarão como medidores da variação ambiental e como testemunhas para os tratamentos regulares.

A análise do delineamento padrão utilizado é efetuada para os tratamentos comuns, enquanto que a análise do delineamento aumentado é realizada para os tratamentos comuns e regulares conjuntamente. $E$ as estimativas dos efeitos dos tratamentos são ajustadas para blocos, e viceversa, de modo semelhante ao que é feito em blocos incompletos. As expressões dos estimadores e a análise de variância estão baseadas na análise intrablocos.

Este delineamento tem sido utilizado em programas de melhoramento com as culturas da soja (Farias Neto, 1995; Gomes, 1995; Spehar, 1989, 1994b) e batata (Bearzoti, 1994; Momenté, 1994). Nestes trabalhos este delineamento apresentou desempenho considerado satisfatório uma vez que a magnitude dos coeficientes de variação encontrados, foram semelhantes aos observados na literatura com o uso dos delineamentos tradicionais.

Os delineamentos em blocos aumentados apresentam as seguintes vantagens: flexibilidade quanto ao número de tratamentos a 
serem testados; facilidade de planejamento e implantação; a perda de tratamentos regulares não prejudica a análise de variância; menor gasto com recurso material e humano. Estas vantagens são conseguidas as custas de uma menor precisão das estimativas dos componentes de variância, uma vez que parte das diferenças entre tratamentos está na soma de quadrados de blocos, por se tratar de uma análise intrablocos (Bearzoti, 1994). Mas isto não chega a comprometer sua utilidade nas fases para as quais é recomendado, uma vez que nestas utiliza-se de pressões de seleções brandas. 


\section{MATERIAL E MÉtOdOS}

\subsection{Material genético}

O presente estudo envolveu 45 populações de soja [Glycine max (L.) Merrill] obtidas por cruzamentos dialélicos e os dez parentais (FT-Cristalina, EMGOPA-301, IAC-4, IAC-5, IAC-6, IAC-8, IAC-9, IAC11, Santa Rosa e SS-1), com ciclo de maturação de semi-tardio a tardio (Apêndices 1 e 2). Os parentais foram selecionados por apresentarem tolerância às variações do fotoperíodo, alta produtividade e divergência genética estimada pelos coeficientes de parentesco baseados nas genealogias (Vello et al., 1988). A seleção destes parentais foi realizada após testes de campo conduzidos em três locais (ESALQ, Sertãozinho e Anhembi) durante os anos agrícolas 1983-1984 e 1984-1985 (Vello, 1992).

As gerações $F_{1}$ e $F_{2}$ foram conduzidas por Nass (1989), a geração $F_{3}$ por Moreira (1992), as gerações $F_{4}$ e $F_{5}$ pelo Setor de Genética Aplicada às Espécies Autógamas do Departamento de Genética da Escola Superior de Agricultura "Luiz de Queiroz", da Universidade de São Paulo, e a geração $\mathrm{F}_{6}$ por Gomes (1995). 


\subsection{Metodologia experimental}

Os experimentos foram conduzidos nas Estações Experimentais de Anhembi e Areão, ambas pertencentes à ESALQ/USP e localizadas no município de Piracicaba-SP, situada a $22^{\square} 45^{\prime}$ de latitude sul, $47^{\square} 38^{\prime}$ de longitude oeste e cerca de $540 \mathrm{~m}$ de altitude.

A E.E. Anhembi fica a $60 \mathrm{~km}$ da cidade de Piracicaba e a E.E. Areão localiza-se a $3 \mathrm{~km}$ da sede da ESALQ/USP. Em Anhembi, o solo pertence à classe aluvial distrófico, textura média-arenosa e relevo plano. Em Areão, o solo pertence à classe podzólico vermelho amarelo distrófico, textura argilosa e relevo ondulado. O Apêndice 3 mostra as composições química e física médias nas camadas de $0-20 \mathrm{~cm}$ e de $20-40 \mathrm{~cm}$ dos solos onde foram instalados os experimentos. De acordo com o Apêndice 3, os locais se apresentavam contrastantes para saturação de alumínio: Anhembi apresentava alta saturação (>Al), enquanto que Areão mostrava baixa saturação $(<\mathbf{A l})$.

\subsubsection{Geração $\mathbf{F}_{7: 6}$}

Os 45 cruzamentos dialélicos foram avaliados através de 20 linhagens experimentais por cruzamento; uma linhagem $\mathrm{F}_{7: 6}$ originou-se de uma planta individual $F_{6}$, totalizando 910 tratamentos (900 linhagens e os dez parentais). O delineamento utilizado foi o de blocos aumentados de Federer (1956) com 20 conjuntos, sem repetição, em dois locais (Anhembi e Areão). Cada conjunto foi composto de 55 tratamentos (uma linhagem $\mathrm{F}_{7: 6}$ de cada cruzamento e os dez parentais). A parcela experimental foi representada por uma fileira de $2,0 \mathrm{~m} \times 0,5 \mathrm{~m}$. 
Além dos contrastes para saturação de alumínio e, conseqüentemente, saturação de bases, os dois locais apresentavam ainda valores distintos de: $\mathrm{pH}$; teores de fósforo $(\mathrm{P})$, cálcio $(\mathrm{Ca})$, magnésio $(\mathrm{Mg})$ e manganês (Mn) (Apêndice 3).

Nos dois locais, a semeadura foi realizada em 17/12/1992 e a adubação de plantio foi de $25 \mathrm{~g} / \mathrm{m}$ linear de sulco $(500 \mathrm{~kg} / \mathrm{ha}) \mathrm{da}$ formulação 4-20-20 de N-P $\mathrm{O}_{5}-\mathrm{K}_{2} \mathrm{O}$, respectivamente. A inoculação das sementes foi feita com Bradyrhizobium japonicum, sendo o inoculante diluído em água (800 g/20 1) e aplicado com pulverizador costal no sulco, minutos antes da semeadura. No início foram realizadas irrigações suplementares para o bom estabelecimento da cultura. O controle de plantas invasoras foi feito com duas aplicações de herbicidas pósemergente e capina manual para retirada dos escapes. Foram realizadas três e cinco aplicações de inseticidas, respectivamente em Anhembi e Areão, para o controle de pragas, principalmente percevejos. Não houve ocorrência de doença que necessitasse de controle.

Os experimentos foram conduzidos do mesmo modo nos dois locais. Em Anhembi, as plantas apresentaram fortes sintomas de deficiência de nitrogênio aos 45 dias após a emergência, devido à simbiose não ter ocorrido normalmente; assim, foi realizada uma adubação de cobertura com uréia na base de $20 \mathrm{~kg}$ de N/ha. Em Areão, ocorreu veranico na fase de florescimento e granação (enchimento de grãos), ocasião em que foi realizada irrigação para evitar a perda do experimento.

\subsubsection{Geração $F_{8: 6}$}

Com base nos resultados dos experimentos com a geração $F_{7: 6}$ (safra 1992-1993) nos dois locais, foi realizada seleção truncada para produtividade de grãos (PG) e número de dias para a maturidade (NDM), 
independentemente; nos dois casos, a seleção também considerou desempenhos agronômicos aceitáveis dos demais caracteres. Assim, foram selecionadas as quatro linhagens $F_{7: 6}$ mais precoces (QLEs) e as quatro mais produtivas (QLPs) em cada cruzamento. Estas foram avaliadas na geração $F_{8: 6}$ (safra 1993-1994) em dois experimentos (QLEs e QLPs), com a finalidade de reduzir a competição entre linhagens que poderiam apresentar diferentes números de dias para a maturidade.

Para a safra 1993-1994 foi realizada calagem em Anhembi e Areão, de modo que na camada arável os locais deixaram de ser contrastantes para as saturações de alumínio e bases. No entanto, na camada subsuperficial os ambientes ainda permaneceram contrastantes para saturação de alumínio, 47,6\% em Anhembi e 1,4\% em Areão (Apêndice 3). Assim, as linhagens $F_{8: 6}$ e os parentais foram avaliados em condições próximas as normais de lavoura: em Anhembi, as condições representam o que ocorre comumente em lavouras do Brasil Central, ou seja, a correção fica restrita à camada arável e a subsuperficial sofre pouca alteração, permanecendo com baixo $\mathrm{pH}$, alta saturação de $\mathrm{Al}$ e baixa saturação de bases; o solo corrigido em Areão representa uma situação comum em lavouras das regiões tradicionais de cultivo da soja.

Foi utilizado o delineamento de blocos ao acaso, com as repetições subdivididas em quatro conjuntos experimentais, cada conjunto com 55 tratamentos, uma linhagem $F_{8: 6}$ de cada cruzamento e os dez parentais (como testemunhas comuns). Dessa forma, foram testadas 180 linhagens $\mathrm{F}_{8: 6}$ e os dez parentais em cada experimento (QLEs e QLPs), em dois locais (Anhembi e Areão), com duas repetições por local e a parcela experimental representada por uma fileira de $4,0 \mathrm{~m} \times 0,5 \mathrm{~m}$.

Em 1993-1994, a semeadura foi realizada em 08-11 e 18-11 em Anhembi e Areão, respectivamente. A adubação de plantio foi de $20 \mathrm{~g} / \mathrm{m}$ linear de sulco $(400 \mathrm{~kg} / \mathrm{ha})$ da formulação 0-20-20 de $\mathrm{N}-\mathrm{P}_{2} \mathrm{O}_{5}-\mathrm{K}_{2} \mathrm{O}$, respectivamente. Os experimentos foram conduzidos do mesmo modo nos 
dois locais e receberam os mesmos tratos culturais anteriormente descritos para a geração $F_{7: 6}$.

\subsubsection{Caracteres avaliados}

Os seguintes caracteres foram avaliados, com base no conjunto de plantas da fileira correspondente à parcela experimental, nos dois anos agrícolas:

NDM: número de dias para a maturidade; compreende o período entre a data da semeadura até a data em que $95 \%$ das vagens apresentaramse maduras (estádio $\mathbf{R}_{8}$ da escala de Fehr \& Caviness, 1977);

APM: altura da planta na maturidade; corresponde à medida em centímetros da base da planta até o ápice da haste principal, avaliada em plantas com altura representativa da parcela;

VA: valor agronômico; refere-se à avaliação feita na maturidade, com base em uma escala de notas visuais de 1 a 5 , sendo a nota 1 correspondente a uma fileira sem valor agronômico e a nota 5 a uma fileira com excelentes características agronômicas (plantas vigorosas, com grande número de vagens bem granadas, altura superior a $60 \mathrm{~cm}$, sem acamamento, ausência de hastes verdes e retenção foliar, sem debulha de vagens e sem sintomas de doenças);

PG: produtividade de grãos em $\mathrm{g} / \mathrm{m}^{2}$; nos experimentos de 1992-1993 (F $7: 6$ ) as análises basearam-se na produção total da parcela, constituída por uma fileira de 2,0 m x 0,5 m; nos experimentos de 1993-1994 (F:6 a 
produção total da parcela, constituída por uma fileira de $4,0 \mathrm{~m} \times 0,5$ $\mathrm{m}$, foi dividida por dois.

\subsection{Análises estatístico-genéticas}

\subsubsection{Análises de variância e covariância}

\subsubsection{Geração $F_{7: 6}$}

Os dados obtidos em $\mathrm{F}_{7: 6}$ foram submetidos às análises de variância e covariância, em blocos aumentados de Federer (1956), para cada local, com auxílio do "software" MAPGEN" de acordo com o seguinte modelo matemático:

$$
Y_{i j}=\mu+t_{i}+t_{i^{\prime} j}+b_{j}+e_{i j}
$$

sendo:

$\mathrm{Y}_{\mathrm{ij}}$ : valor observado na parcela do bloco $\mathrm{j}$ que recebeu o tratamento comum i ou o tratamento regular i';

$\mu$ : efeito fixo da média geral;

$t_{i}$ : efeito fixo do tratamento comum $i ; i=1,2, \ldots, T$;

$\mathrm{t}_{\mathrm{i}}$ 'j: efeito do tratamento regular $\mathrm{i}$ 'do bloco $\mathrm{j}$, tido como aleatório;

$\mathrm{i}^{\prime}=1,2, \ldots, \mathrm{N}_{\mathrm{j}} ; \mathrm{N}_{\mathrm{j}}+\mathrm{T}=$ número de parcelas do bloco $\mathrm{j}$;

$\mathrm{b}_{\mathrm{j}}$ : efeito aleatório do bloco $\mathrm{j} ; \mathrm{j}=1,2, \ldots, \mathrm{B}$;

"MAPGEN-"software" desenvolvido pelo Prof. Dr. Daniel Furtado Ferreira do Departamento de Ciências Exatas da Universidade Federal de Lavras (UFLA), Lavras-MG (não publicado). 
$\mathrm{e}_{\mathrm{ij}}$ : efeito aleatório do erro experimental associado à parcela do bloco $\mathrm{j}$ que recebeu o tratamento comum i ou o tratamento regular i'; NID $\cap\left(0, \sigma^{2}\right)$.

Como tratamentos comuns foram considerados os dez parentais e como tratamentos regulares as 900 linhagens (20 linhagens x 45 cruzamentos).

A partir deste modelo foram desenvolvidas as análises de variância e covariância, cujas fontes de variação encontram-se nas Tabelas 1 e 2 . O erro intrablocos $\left(\sigma_{e}^{2}\right)$ obtido na referida análise só permite comparações entre tratamentos regulares avaliados nos mesmos blocos. Como as linhagens de um mesmo cruzamento situam-se em blocos diferentes, a comparação entre elas deve ser realizada com o erro interblocos $\left(\sigma^{2}{ }^{\prime}\right)$, utilizando-se médias ajustadas ${ }^{*}$ dos tratamentos regulares. $O$ erro interblocos $\left(\sigma^{2}{ }^{\prime}\right)$ foi calculado conforme a expressão (Vizioni, 1984):

$$
\sigma_{e^{\prime}}^{2}=[1+(1 / \mathrm{c})] \sigma_{e}^{2}
$$

onde:

$\sigma_{\mathrm{e}}^{2}$ : Quadrado médio do erro intrablocos;

c: número de tratamentos comuns.

O erro assim calculado foi usado para compor novas análises de variância e covariância, realizadas com as médias ajustadas dos tratamentos regulares, cujos esquemas se encontram nas Tabelas 3 e 4 , de acordo com o modelo matemático dado a seguir:

$$
Y_{i^{\prime} z}=\mu+c_{z}+t^{\prime}{ }^{\prime}(z)+e^{\prime}{ }^{\prime} z
$$

onde: 
$Y_{i}{ }^{\prime}$ : valor observado da linhagem i' do cruzamento $z$;

$\mu$ : efeito fixo da média geral;

$\mathbf{c}_{\mathbf{z}}$ : efeito fixo do cruzamento $\mathrm{z} ; \mathrm{z}=1,2, \ldots, \mathrm{C}$;

$t_{i}{ }^{\prime}(z)$ : efeito aleatório da progênie i'dentro do cruzamento $z$; $i^{\prime}=1,2, \ldots, P$;

$\mathrm{e}_{\mathrm{i}}{ }^{\prime} \mathrm{z}$ : efeito aleatório do erro experimental associado à observação $\mathrm{Y}_{\mathrm{i}}{ }^{\prime} \mathrm{z}$.

\subsubsection{Geração $F_{8: 6}$}

Inicialmente, foi realizada uma análise de variância considerando-se somente os dez parentais (testemunhas comuns) e mantendo-se o delineamento de conjuntos experimentais. As significâncias dos efeitos de conjuntos e da interação testemunhas $x$ conjuntos indicará a necessidade de se realizar ajuste dos valores das linhagens para neutralizar o efeito de conjuntos experimentais. A não-significância dos efeitos mencionados anteriormente permitirá ignorar-se a estratificação em conjuntos e, conseqüentemente, tornará possível a realização das análises de variância das linhagens, ao nível de parcela para cada caráter, de acordo com o modelo comum de blocos ao acaso:

$$
Y_{\left(i i^{\prime}\right) j}=\mu+t_{\left(i^{\prime}\right)}+b_{j}+e_{\left(i i^{\prime}\right) j}
$$

sendo:

$Y_{\left(i{ }^{\prime}\right) j}$ : valor observado na unidade experimental do bloco $\mathrm{j}$ que recebeu o tratamento i $x$ i';

$\mu$ : efeito da média geral;

$t_{(i i)}$ : efeito fixo do tratamento $i x i^{\prime}$, sendo: $i=i^{\prime}$, efeito de parental; e i = i': $1,2, \ldots, T$; 
$i \neq i^{\prime}$, efeito do cruzamento obtido entre os parentais $i$ e i'; $\mathrm{b}_{\mathrm{j}}$ : efeito aleatório do bloco $\mathrm{j} ; \mathrm{e} \mathrm{j}=1,2$;

$\mathrm{e}_{(\mathrm{ii}) \mathrm{j}} \mathrm{j}$ : efeito aleatório do erro experimental, associado a $\mathrm{Y}_{(\mathrm{ii}) \mathrm{j}}$ $\operatorname{NID} \cap\left(0, \sigma^{2}\right)$.

A partir deste modelo foram desenvolvidas as análises de variância, cujas fontes de variação e esperanças matemáticas dos quadrados médios se encontram na Tabela 4.

\subsubsection{Análise conjunta}

Posteriormente, foi realizada a análise de variância conjunta para os dois locais, utilizando-se as médias ajustadas das linhagens, com posterior multiplicação dos quadrados médios pelo número de repetições, de acordo com Cochran \& Cox (1966).

A análise de variância conjunta considerou como aleatórios os efeitos de linhagens e como fixos os efeitos de locais, parentais e cruzamentos, de acordo com o seguinte modelo matemático (Cochran \& Cox, 1966):

$$
Y_{S\left(i i^{\prime}\right) j}=\mu_{S}+t_{S\left(i i^{\prime}\right)}+b_{S_{j}}+e_{S\left(i i^{\prime}\right) j}
$$

sendo:

$Y_{S(i i) j}$ : valor observado na unidade experimental do bloco $j$ que recebeu o tratamento $\mathrm{i} x \mathrm{i}^{\prime}$, no local s;

$\mu_{\mathrm{s}}$ : efeito da média geral, no local s; $\mathrm{s}=$ Anhembi e Areão;

$t_{s\left(i i^{\prime}\right)}$ : efeito fixo do tratamento $i x i^{\prime}$, no local $s$; sendo:

$i=i^{\prime}$, efeito de parental; e i = i': $1,2, \ldots, T$; 
$i \neq i^{\prime}$, efeito do cruzamento obtido entre os parentais $i$ e i';

$\mathrm{b}_{\mathrm{sj}}$ : efeito aleatório do bloco $\mathrm{j}$, no local $\mathrm{s}$; e $\mathrm{j}=1,2$;

$\mathrm{e}_{\mathrm{S}\left(\mathrm{ii}^{\prime}\right) \mathrm{j}}$ : efeito aleatório do erro experimental, associado a $\mathrm{Y}_{(\mathrm{ii}) \mathrm{j}}$, no local s NID $\cap\left(0, \sigma^{2}\right)$.

A partir deste modelo foram desenvolvidas as análises de variância, cujas fontes de variação e esperanças matemáticas dos quadrados médios se encontram na Tabela 5 .

\subsubsection{Herdabilidade}

As estimativas do coeficiente de herdabilidade $\left(h^{2}\right)$ foram obtidas da seguinte forma:

$$
\begin{gathered}
\hat{\mathrm{h}}^{2}=\hat{\sigma}^{2} \mathrm{G} / \hat{\sigma}^{2} \mathrm{~F} \\
\hat{\sigma}_{\mathrm{G}}^{2}=\hat{\sigma}^{2} \mathrm{~F}-\hat{\sigma}^{2} \mathrm{e}^{\prime}
\end{gathered}
$$

logo:

$$
\hat{\mathrm{h}}^{2}=\left(\hat{\sigma}^{2} \mathrm{~F}-\hat{\sigma}^{2} \mathrm{e}^{\prime}\right) / \hat{\sigma}^{2} \mathrm{~F}
$$

sendo:

$\hat{\sigma}^{2} \mathrm{G}$ : estimativa da variância genotípica entre linhagens $\mathrm{F}_{7: 6}$ de um cruzamento;

$\hat{\sigma}^{2} \mathrm{~F}$ : estimativa da variância fenotípica entre linhagens $F_{7: 6}$ de um cruzamento; 
$\hat{\sigma}^{2} \mathrm{e}^{\prime}$ : estimativa da variância experimental ou quadrado médio do erro interblocos.

\subsubsection{Ganho com a seleção}

O ganho com a seleção para o caráter produtividade de grãos para cada cruzamento por local, nos experimentos com as QLEs e QLPs foi calculado através da seguinte expressão:

$$
\left.\mathrm{G}_{\mathrm{S}} \%=\left(\mathrm{M}_{8}-\mathrm{E}_{\mathrm{A}}\right)-\mathrm{M}_{7}\right) / \mathrm{M}_{7}
$$

Logo:

$$
\mathrm{E}_{\mathrm{A}}=\mathrm{LS}_{8}-\mathrm{LS}_{7}
$$

onde:

Gs \%: ganho com a seleção em porcentagem no experimento $p$, no local a; $\mathrm{M}_{8}$ : média das quatro linhagens selecionadas em 1992-1993 e avaliadas em 1993-1994, para cada cruzamento;

$\mathrm{E}_{\mathrm{A}}$ : efeito do ano no local $\mathrm{A}$;

M7: média das 20 linhagens avaliadas em 1992-1993, para cada cruzamento;

LS : desempenho médio das linhagens avaliadas em 1993-1994, em cada local;

LS $_{7}$ : desempenho médio em 1992-1993 em cada local, das linhagens selecionadas.

$O$ efeito de ano em cada local foi calculado com base no desempenho das linhagens comuns nos dois anos agrícolas. Para que o 
ganho calculado se apresentasse o mais real possível, o efeito de ano foi subtraído.

\subsubsection{Correlação entre caracteres na geração $F_{7: 6}$}

Os coefícientes de correlação fenotípica, genotípica e residual entre os pares de caracteres foram obtidos através das respectivas estimativas da variância e covariância (Tabelas 1,2 e 3), com base na expressão relatada por Vencovsky \& Barriga, 1992:

$$
r_{X Y}=\operatorname{cov}(X, Y) / \sqrt{V(X) V(Y)}
$$

sendo:

$\operatorname{COV}(\mathrm{X}, \mathrm{Y})$ : covariância entre os caracteres $\mathrm{X}$ e $\mathrm{Y}$; $\mathrm{V}(\mathrm{X})$ e $\mathrm{V}(\mathrm{Y})$ : variância dos caracteres $\mathrm{X}$ e $\mathrm{Y}$, respectivamente.

Segundo Kempthorne (1973), tomando-se duas observacões X e $\mathrm{Y}$, de um mesmo indivíduo ou parcela, pode-se considerar a observação composta $(X+Y)$ e fazer a análise de variância, do mesmo modo como é feita para cada observação X e $Y$, isoladamente. Assim, é possível calcular as covariâncias entre os pares de caracteres por meio da relação:

$$
\mathrm{V}(\mathrm{X}+\mathrm{Y})=\mathrm{V}(\mathrm{X})+\mathrm{V}(\mathrm{Y})+2 \operatorname{COV}(\mathrm{X}, \mathrm{Y})
$$

logo:

$$
\operatorname{COV}(X, Y)=[\mathrm{V}(\mathrm{X}+\mathrm{Y})-\mathrm{V}(\mathrm{X})-\mathrm{V}(\mathrm{Y})] / 2
$$


sendo:

$\mathrm{V}(\mathrm{X}+\mathrm{Y})$ : variância da soma dos caracteres $\mathrm{X}$ e $\mathrm{Y}$.

a) Coeficiente de correlação fenotípica $\left(r_{F}\right)$

$a_{1}$ ) Com base nos parentais (Tabela 3):

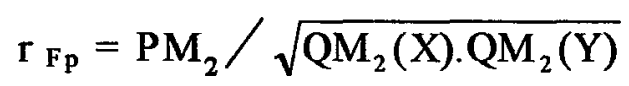

$a_{2}$ ) Com base nos cruzamentos (Tabela 3 ):

$$
\mathrm{r}_{\mathrm{Fc}}=\mathrm{PM}_{49} / \sqrt{\mathrm{QM}_{49}(\mathrm{X}) \cdot \mathrm{QM}_{49}(\mathrm{Y})}
$$

$a_{3}$ ) Com base nas linhagens (Tabela 3 ):

$$
\mathrm{r}_{\mathrm{F}}=\mathrm{PM}_{50} / \sqrt{\mathrm{QM}_{50}(\mathrm{X}) \cdot \mathrm{QM}_{50}(\mathrm{Y})}
$$

em que:

$\mathrm{PM}_{2}, \mathrm{PM}_{49}$ e $\mathrm{PM}_{50}$ : estimativas dos produtos médios de parentais, cruzamentos e linhagens $F_{7: 6}$ e, respectivamente, para o par de caracteres $\mathrm{X}$ e $\mathrm{Y}$;

$\mathrm{QM}_{2}(\mathrm{X}), \quad \mathrm{QM}_{49}(\mathrm{X})$ e $\mathrm{QM}_{50}(\mathrm{X})$ : estimativas dos quadrados médios de parentais, cruzamentos e linhagens $F_{7: 6}$ respectivamente, do caráter $\mathrm{X}$; 
$\mathrm{QM}_{2}(\mathrm{Y}), \quad \mathrm{QM}_{49}(\mathrm{Y})$ e $\mathrm{QM}_{50}(\mathrm{Y})$ : estimativas dos quadrados médios de parentais, cruzamentos e linhagens $F_{7: 6}$ respectivamente, do caráter $Y$.

b) Coeficiente de correlação genotípica $\left(\mathbf{r}_{G}\right)$

$b_{1}$ ) Com base nos parentais (Tabela 3 ):

$$
r_{G p}=\hat{\phi}_{t}(X, Y) / \sqrt{\hat{\phi}_{t}^{2}(X) \cdot \hat{\phi}_{t}^{2}(Y)}
$$

sendo:

$\hat{\phi}_{\mathrm{t}}(\mathrm{X}, \mathrm{Y})=\left(\mathrm{PM}_{2}-\mathrm{PM}_{1}\right) / \mathrm{B}$

$\hat{\phi}^{2}{ }_{t}(X)=\left[Q M_{2}(X)-Q M_{1}(X)\right] / B$

$\hat{\phi}_{t}^{2}(\mathrm{Y})=\left[\mathrm{QM}_{2}(\mathrm{Y})-\mathrm{QM}(\mathrm{Y})\right] / \mathrm{B}$

$\hat{\phi}_{\mathrm{t}}(\mathrm{X}, \mathrm{Y})$ : estimativa da covariância genotípica, com base nos parentais, para o par de caracteres $\mathrm{X}$ e $\mathrm{Y}$;

$\hat{\phi}^{2}(X)$ e $\hat{\phi}_{t}^{2}(Y)$ : estimativas da variância genotípica, com base nos parentais, dos caracteres $\mathrm{X}$ e $\mathrm{Y}$, respectivamente;

$\mathrm{PM}_{1}$ : estimativa do produto médio do erro intrablocos para o par de caracteres $\mathrm{X}$ e $\mathrm{Y}$;

$\mathrm{QM}_{1}(\mathrm{X})$ : estimativa do quadrado médio do erro intrablocos do caráter $\mathrm{X}$; $\mathrm{QM}_{1}(\mathrm{Y})$ : estimativa do quadrado médio do erro intrablocos do caráter $\mathrm{Y}$;

B: número de blocos. 
$\mathrm{b}_{2}$ ) Com base nos cruzamentos (Tabela 3 ):

$$
\mathrm{r}_{\mathrm{Gc}}=\hat{\phi}_{\mathrm{C}}(\mathrm{X}, \mathrm{Y}) / \sqrt{\hat{\phi}_{\mathrm{C}}^{2}(\mathrm{X}) \hat{\phi}_{\mathrm{C}}^{2}(\mathrm{Y})}
$$

sendo:

$\hat{\phi}_{\mathrm{C}}(\mathrm{X}, \mathrm{Y})=\left(\mathrm{PM}_{49}-\mathrm{PM}_{3}\right) / \mathrm{V}$

$\hat{\phi}^{2} \mathrm{C}(\mathrm{X})=\mathrm{QM}_{49}(\mathrm{X})-\mathrm{QM}_{3}(\mathrm{X}) / \mathrm{V}$

$\hat{\phi}^{2} \mathrm{C}(\mathrm{Y})=\mathrm{QM}_{49}(\mathrm{Y})-\mathrm{QM}_{3}(\mathrm{Y}) / \mathrm{V}$

em que:

$\hat{\phi}_{C}(X, Y)$ : estimativa da covariância genotípica, com base nos cruzamentos, para o par de caracteres $\mathrm{X}$ e $\mathrm{Y}$;

$\hat{\phi}^{2} \mathrm{C}(\mathrm{X})$ e $\hat{\phi}^{2} \mathrm{C}(\mathrm{Y})$ : estimativas da variância genotípica, com base nos cruzamentos, dos caracteres $\mathrm{X}$ e $\mathrm{Y}$, respectivamente;

$\mathrm{PM}_{3}$ : estimativa do produto médio do erro interblocos para o par de caracteres $\mathrm{X}$ e $\mathrm{Y}$;

$\mathrm{V}$ : número de linhagens por cruzamento.

$b_{3}$ ) Com base nas linhagens (Tabela 3):

$$
r_{G}=\operatorname{CÔV}_{g}(X, Y) / \sqrt{\hat{\sigma}_{g}^{2}(X) \cdot \hat{\sigma}_{g}^{2}(Y)}
$$

sendo:

$\operatorname{CÔV}_{\mathrm{g}}(\mathrm{X}, \mathrm{Y})=\mathrm{PM}_{50}-\mathrm{PM}_{3}$ 
$\hat{\sigma}_{\mathrm{g}}^{2}(\mathrm{X})=\mathrm{QM}_{50}(\mathrm{X})-\mathrm{QM}_{3}(\mathrm{X})$

$\hat{\sigma}_{\mathrm{g}}^{2}(\mathrm{Y})=\mathrm{QM}_{50}(\mathrm{Y})-\mathrm{QM}_{3}(\mathrm{Y})$

em que:

$\operatorname{CÔV}_{\mathrm{g}}(\mathrm{X}, \mathrm{Y})$ : estimativa da covariância genotípica, com base nas linhagens, para o par de caracteres $\mathrm{X}$ e $\mathrm{Y}$;

$\hat{\sigma}_{\mathrm{g}}^{2}(\mathrm{X})$ e $\hat{\sigma}_{\mathrm{g}}^{2}(\mathrm{Y})$ : estimativas de variância genotípica, com base nas linhagens, dos caracteres $\mathrm{X}$ e $\mathrm{Y}$, respectivamente.

c) Coeficiente de correlação ambiental $\left(\mathbf{r}_{E}\right)$

$$
\mathrm{r}_{\mathrm{E}}=\mathrm{PM}_{1} / \sqrt{\mathrm{QM}_{1}(\mathrm{X}) \cdot \mathrm{QM}_{1}(\mathrm{Y})}
$$

$\mathrm{PM}_{1}$ : estimativa do produto médio do erro intrablocos para o par de caracteres $\mathrm{X}$ e $\mathrm{Y}$;

$\mathrm{QM}_{1}(\mathrm{X})$ : estimativa do quadrado médio do erro intrablocos do caráter $\mathrm{X}$;

$\mathrm{QM}_{1}(\mathrm{Y})$ : estimativa do quadrado médio do erro intrablocos do caráter $\mathrm{Y}$.

\subsubsection{Capacidade média de combinação $\left(\mathrm{cmc}_{\mathfrak{i}}\right)$}

A capacidade média de combinação $\left(\mathrm{cmc}_{\mathbf{i}}\right)$ dos parentais em combinações híbridas em cada experimento foi estimada pelo desempenho de suas linhagens $F_{7: 6}$ e $F_{8: 6}$ (QLEs e QLPs).

$$
\mathrm{cmc}_{\mathrm{i}}=\mathrm{C}_{\mathrm{i} .}-\mathrm{C}_{\text {.. }}
$$


sendo:

$\sum \mathrm{cmc}_{\mathbf{i}}=0$

onde:

cmc $_{\mathbf{i}}$ : capacidade média de combinação do parental $i$;

$C_{i}$ : : média dos cruzamentos em que o parental i participa;

C.. : média geral dos cruzamentos.

\subsubsection{Associação entre ambientes}

Os coeficientes de correlação de Spearman $\left(r_{s}\right)$ foram estimados entre os ambientes, com base no desempenho das linhagens $F_{7: 6} e$ $\mathrm{F}_{\text {8:6 }}$ para o grupo das QLEs e QLPs de acordo com a expressão abaixo (Steel \& Torrie, 1980), para os caracteres estudados, com base nos 180 pares de valores individuais de parcelas. Através destas estimativas procurou-se observar o efeito de escala ambiental na ordem classificatória "rank" dos valores individuais $F_{7: 6}$ e $F_{8: 6}$, já que as semeaduras foram realizadas em diferentes anos agrícolas, diferentes condições de fertilidade do solo e diferentes épocas de semeadura.

$$
\mathrm{r}_{\mathrm{s}}=\left[1-\left(6 \sum_{i} d i^{2}\right)\right] /[(\mathrm{n}-1) \mathrm{n}(\mathrm{n}+1)]
$$

sendo:

di: diferença entre o i-ézimo par;

$\mathrm{n}$ : número de pares. 


\section{RESULTADOS E DISCUSSÃO}

\subsection{Análise de variância}

As estimativas dos quadrados médios em blocos aumentados, nas quais se utiliza o erro intrablocos, correspondentes aos experimentos com as linhagens $\mathrm{F}_{7: 6}$ em Anhembi e Areão são apresentadas na Tabela 6 . Na Tabela 7 é apresentado o desdobramento em efeitos de cruzamentos e linhagens $\mathrm{F}_{7: 6}$ dentro de cruzamento, a partir das médias ajustadas pela análise anterior, com o erro interblocos para o teste F. Foram detectadas diferenças significativas $(P<0,01)$ entre parentais, cruzamentos $\mathrm{e}$ linhagens dentro de cruzamento em todos os caracteres analisados. Essas diferenças mostram variabilidade entre parentais, cruzamentos e linhagens resultantes, que possibilita a seleção de linhagens com diferentes combinações de caracteres. Resultados semelhantes para parentais e cruzamentos foram observados nas gerações anteriores $F_{2}$ (Nass, 1989), $F_{3}$ (Moreira, 1992), $F_{6}$ e F 7:6 (Gomes, 1995).

Observa-se que o número de cruzamentos com diferenças significativas entre suas respectivas linhagens em Anhembi e Areão foram: 29 e 36 para NDM; 26 e 27 para APM; 18 e oito para VA; nove e 13 para PG (Tabela 7). Estes resultados indicam que, ao nível de linhagem, dentro de cruzamento foi detectada maior variabilidade para NDM e APM do que 
para VA e PG. Observa-se, também, que para NDM todos os cruzamentos que apresentaram diferenças significativas entre suas linhagens em Anhembi apresentaram também em Areão, exceto o cruzamento 'IAC-5 x IAC-9'. Para APM, VA e PG o número de cruzamentos que apresentaram diferenças significativas entre suas linhagens nos dois locais foram: 18, cinco e três, respectivamente. Esses resultados mostram que o caráter NDM e APM são menos influenciados pelo ambiente e mostraram maior variabilidade do que os caracteres VA e PG. Isto pode ser notado, pelo pequeno número de cruzamentos que apresentaram resultado semelhante nos dois ambientes e pelo pequeno número de cruzamentos com diferenças significativas, assim, o êxito no melhoramento destes caracteres deve ser menor.

Nos experimentos com a geração $\mathrm{F}_{8: 6}$ (QLEs- quatro linhagens mais precoces e QLPs- quatro linhagens mais produtivas) instalados em Anhembi e Areão, procedeu-se primeiramente a análise dos parentais (testemunhas comuns) segundo modelo de conjuntos experimentais. Observa-se a não-significância do efeito de conjuntos e da interação conjunto $\mathrm{x}$ parentais para a maioria dos caracteres (Apêndice 4). Com base nestes resultados ignorou-se a estratificação em conjuntos, e as análises foram realizadas considerando o modelo de blocos casualizados, sendo as estimativas dos quadrados médios obtidas pelas ANAVAs apresentadas nas Tabelas 8 e 9 . O efeito de tratamentos foi decomposto em efeitos de parentais, linhagens e no contraste parentais vs linhagens; o efeito de linhagens foi decomposto em cruzamentos e linhagens dentro de cruzamento. Foram detectadas diferenças significativas $(\mathrm{P}<0,01$ e $\mathrm{P}<$ $0,05)$ para parentais, linhagens e linhagens dentro de cruzamento em todos os caracteres nos dois ambientes, exceto entre parentais no experimento com as QLEs e entre cruzamentos com as QLPs para o caráter VA, ambas em Areão. O contraste "parentais vs cruzamentos" não foi significativo 
para: NDM em Areão e APM nos dois locais, nos experimentos com as QLEs; e para VA nos dois locais, nos experimentos com as QLPs.

O número de cruzamentos com diferenças significativas entre suas linhagens em Anhembi e Areão respectivamente, nos experimentos com as QLEs $\left(\mathrm{F}_{8: 6}\right)$ foi: 26 e 18 para NDM; 26 e 19 para APM; 12 e 9 para VA; 14 e 17 para PG (Tabela 8). Já com as $Q L P s ~\left(F_{8: 6}\right)$ foi: 20 e três para NDM; 20 e 13 para APM; oito e seis para VA; 13 e 13 para PG (Tabela 9). Observa-se um maior número de cruzamentos com diferenças significativas entre suas linhagens para todos os caracteres nos experimentos com as QLEs. Isto mostra, que a seleção para precocidade manteve maior variabilidade do que a seleção para produtividade. Observa-se também, que o número de cruzamentos que apresentaram diferenças significativas nos dois ambientes para os caracteres NDM, APM, VA e PG foram respectivamente: 12,14 , dois e cinco nos experimentos com as QLEs; três, sete, um e quatro nos experimentos com as QLPs.

$\mathrm{Na}$ geração $\mathrm{F}_{7: 6}$, o cruzamento 'IAC-5 x Santa Rosa' foi o único que não mostrou diferenças significativas entre suas linhagens para todos os caracteres e ambientes. Na geração $F_{8: 6}$, este comportamento foi observado nos seguintes cruzamentos: 'FT-Cristalina x IAC-6', 'EMGOPA301 x IAC-6', 'EMGOPA-301 x Santa Rosa' e 'IAC-5 x Santa Rosa', nos experimentos com as QLEs; 'FT-Cristalina $x$ IAC-8', 'EMGOPA-301 $x$ IAC-4', 'EMGOPA-301 x IAC-5', 'IAC-4 x Santa Rosa' e 'IAC-6 x IAC9', nos experimentos com as QLPs.

Quando se comparam as duas gerações quanto ao número de cruzamentos com diferenças significativas, observa-se na geração $F_{8: 6}$ uma redução para NDM, APM e VA e um aumento para PG. A redução para NDM, APM e VA pode ser explicado pela seleção praticada em $F_{7: 6}$ e pelo menor número de linhagens avaliadas por cruzamento. $O$ aumento para PG pode ser explicado pelas melhores condições de fertilidade do solo nos 
dois ambientes, pela ausência de estresse climático e pela semeadura mais cedo, as quais possibilitaram maior expressão do potencial genético para produtividade de grãos e, conseqüentemente, maior discriminação entre as linhagens.

Os coeficientes de variação (CV\%) dos experimentos de ambas as gerações mostram maior precisão experimental para NDM $(1,4$ a $4,7 \%)$ e VA (3,8 a 5,8\%); APM apresentou valores intermediários $(9,2$ a 10,5\%); PG apresentou menor precisão com valores entre 26,0 a 30,9\% (Tabelas 6, 8 e 9). Entretanto, as magnitudes dos CVs das duas gerações podem ser consideradas como aceitáveis, sendo concordantes com as relatadas na literatura com experimentos desta natureza (Farias Neto, 1995; Gomes, 1995; Mauro et al., 1995; Pinheiro, 1993; Prado, 1994).

Os resumos das análises de variância conjuntas dos dois locais dos experimentos com as linhagens $F_{7: 6}$, QLEs e QLPs para todos os caracteres são apresentados, respectivamente nas Tabelas 10,11 e 12 . O efeito de local só não foi significativo para APM e VA nos experimentos com as QLEs; o efeito de tratamentos e tratamentos $x$ local e seus respectivos desdobramentos em efeito de parental, linhagem, cruzamento e linhagens dentro de cruzamento foram significativos para todos os caracteres, em sua maioria com $P<0,01$, teste $F$.

Nas Tabelas $(10,11$ e 12) é apresentado o número de cruzamentos com diferenças significativas $(P<0,05)$ para os efeitos de linhagens dentro de cada cruzamento (L/C) e da interação locais $x$ linhagens dentro de cada cruzamento (E $\times$ L/C) para todos os caracteres. NDM e APM apresentaram maior número de cruzamentos com diferenças significativas para o efeito L/C do que VA e PG, como detectado nas análises individuais. Nota-se, também, menor número de cruzamentos com efeitos significativos para a interação $(E x \quad L / C)$ na geração $F_{8: 6}$, provavelmente em razão do menor número de linhagens por cruzamento e 
pelo fato da seleção ter sido realizada com base no desempenho médio nos dois locais.

Como a interação tratamentos $\mathrm{x}$ locais e seus desdobramentos, principalmente linhagens dentro de cruzamento $x$ locais, foram significativas para todos os caracteres com as linhagens $F_{7: 6}$, QLEs e QLPs, a apresentação dos resultados será baseada nas análises individuais.

\subsection{Análise dos parentais e das linhagens}

Os valores médios para os caracteres NDM, APM, VA e PG referentes ao comportamento dos parentais e dos cruzamentos com base em suas linhagens $F_{7: 6}$ e $F_{8: 6}$ (QLEs e QLPs) em Anhembi (>Al) e Areão (<Al), encontram-se nas Tabelas $13,14,15$ e 16. Os valores mínimos e máximos para estes caracteres, com base nas linhagens $F_{7: 6}$ são apresentados nas Tabelas 17 e 18 .

\subsubsection{Número de dias para a maturidade (NDM)}

As médias relativas ao caráter NDM dos parentais e dos 45 cruzamentos dialélicos, nos experimentos com as gerações $F_{7: 6}$ e $F_{8: 6}$ avaliados em Anhembi (>Al) e Areão (<Al), constam da Tabela 13.

As médias gerais dos parentais nos experimentos com as linhagens $F_{7: 6}$, QLEs e QLPs foram respectivamente: 136, 159 e 161 dias em Anhembi; 136, 149 e 150 dias em Areão. 'FT-Cristalina', 'EMGOPA- 
301' e 'IAC-9' apresentaram médias superiores às médias gerais em todos os experimentos; em Areão destaca-se também 'IAC-6'. Os demais parentais apresentaram médias inferiores às médias gerais na maioria dos experimentos, com destaque para 'SS-1', 'IAC-4' e 'IAC-5'. Os parentais FT-Cristalina, EMGOPA-301, IAC-6 e IAC-9 também foram os mais tardios nos experimentos com as gerações $F_{6}$ e $F_{7: 6}$ em cultivos de verão (Gomes, 1995). Em cultivos de inverno, 'FT-Cristalina' e 'IAC-6' foram os mais tardios e 'IAC-4' e 'Santa Rosa' os mais precoces (Nass, 1989; Moreira, 1992). Observando as médias dos parentais nos experimentos com a geração $F_{8: 6}$, nota-se que foram dez dias mais tardios em Anhembi e, quando comparado com os valores da geração $F_{7: 6}$, foram mais tardios em 24 e 12 dias, respectivamente em Anhembi e Areão.

As linhagens $F_{7: 6}$ apresentaram médias gerais de NDM de 138 e 139 dias respectivamente em Anhembi e Areão; 23 e 22 cruzamentos respectivamente em Anhembi e Areão apresentaram médias superiores as estas; destes cruzamentos 19 foram mais tardios nos dois locais.

As QLEs apresentaram médias gerais respectivamente: $160 \mathrm{e}$ 150 dias em Anhembi e Areão; 23 e 20 cruzamentos apresentaram médias superiores as estas, respectivamente em Anhembi e Areão; destes cruzamentos 19 foram mais tardios nos dois locais.

As QLPs apresentaram médias gerais de 164 e 153 dias, respectivamente em Anhembi e Areão, 18 e 23 cruzamentos foram superiores a estas médias, destes 15 foram mais tardios nos dois locais.

A diferença entre as médias das linhagens $F_{8: 6}$ e $F_{7: 6}$ foi a mesma observada para os parentais incluídos nestes experimentos. Essas diferenças no ciclo dos parentais e linhagens entre gerações e locais podem ser explicadas pelos efeitos de épocas de semeadura: 17/12/1992 ( $\mathrm{F}_{7: 6} \mathrm{em}$ Anhembi e Areão); 8/11/1993 ( $\mathrm{F}_{8: 6}$ em Anhembi); 18/11/1993 ( $\mathrm{F}_{8: 6} \mathrm{em}$ 
Areão); efeitos semelhantes a estes relatados foram observados por Gomes (1995).

O cruzamento EMGOPA-301 $\times$ IAC-5 foi o mais precoce em todos os experimentos; este cruzamento envolve um dos parentais mais tardios (EMGOPA-301) e um dos mais precoces (IAC-5), evidenciando complementação gênica para precocidade. Este cruzamento também foi o mais precoce nos experimentos da geração $F_{7: 6}$ conduzidos por Gomes (1995). O cruzamento IAC-5 x Santa Rosa apresentou-se como precoce em todos os experimentos e a sua média de NDM foi sempre inferior ao comportamento médio dos parentais, mostrando comportamento transgressivo para precocidade.

O cruzamento FT-Cristalina x EMGOPA-301 apresentou-se como um dos mais tardios em todos os experimentos; o mesmo desempenho foi observado em gerações anteriores: $F_{2}$ (Nass, 1989), $F_{3}$ (Moreira, 1992), $\mathrm{F}_{6}$ e $\mathrm{F}_{7: 6}$ (Gomes, 1995). Este cruzamento reúne os parentais mais tardios e, em todos os casos, a sua média foi superior à média dos parentais, evidenciando complementação gênica para ciclo tardio. Como o controle genético para ciclo, apesar de ser considerado como quantitativo, envolve genes maiores; o florescimento tardio é determinado pelo efeito de seus alelos recessivos (Tisselli Junior, 1981; Toledo \& Kiihl, 1982a,b). Assim, o ciclo tardio pode ser fixado nas gerações iniciais.

Nove cruzamentos foram mais tardios às médias gerais das linhagens em todos os experimentos:

FT-Cristalina x EMGOPA-301

FT-Cristalina $x$ IAC-9

EMGOPA-301 x IAC-9

EMGOPA-301 x Santa Rosa

IAC-6 x Santa Rosa.
FT-Cristalina x IAC-4

EMGOPA-301 x IAC-6

EMGOPA-301 x IAC-11

IAC- 4 x IAC-9 
Por outro lado 12 cruzamentos foram precoces em relação às médias gerais das linhagens:

EMGOPA-301 x IAC-5

IAC $-4 \times$ IAC -11

IAC $-5 \times$ IAC -8

IAC $-5 \times$ Santa Rosa

IAC- $6 \times$ IAC- 11

IAC-9 x Santa Rosa
IAC- $4 \times$ IAC- 8

IAC $-4 \times$ SS -1

IAC $-5 \times$ IAC -11

IAC $-5 \times$ SS -1

IAC $-8 \times$ Santa Rosa

IAC $-9 \times$ SS- 1 .

As médias dos cruzamentos FT-Cristalina $x$ IAC-8, FTCristalina $x$ SS-1, IAC-5 x IAC-9, IAC-6 6 IAC-8, IAC-8 8 IAC-9 e IAC-9 $x$ SS-1 foram superiores à média geral das linhagens na geração $F_{7: 6}$ e inferiores na $\mathrm{F}_{8: 6}$.

Os valores mínimos e máximos entre as linhagens $\mathrm{F}_{7: 6}$ foram de 123,5 dias (IAC-4 x IAC-5 e IAC-9 x SS-1) e 162,7 dias ( FT-Cristalina $x$ IAC-9) em Anhembi e de 126,2 dias (IAC-4 x IAC-5) e 168,2 dias (FTCristalina $\times$ SS-1) em Areão. As menores amplitudes foram apresentadas pelos cruzamentos IAC- 6 x SS-1 e EMGOPA-301 $\times$ IAC-5 com valores de 10,6 e 6,4 dias em Anhembi e Areão, respectivamente. O cruzamento FTCristalina x SS-1 foi o que apresentou maior amplitude nos dois ambientes, 37,5 e 39,4 dias em Anhembi e Areão, respectivamente (Tabela 17). Através destes limites, verifica-se que existem segregantes transgressivos com NDM abaixo e acima das médias dos parentais, evidenciando a possibilidade de selecionar linhagens mais precoces e mais tardias do que os parentais em estudo. Os valores mínimos e máximos para os parentais foram de 130 e 162 dias em Anhembi e 130 e 157 dias em Areão (Tabela 17).

A variância ambiental média dos parentais entre blocos nos experimentos de 1992-1993 foi de 34,06 dias² em Anhembi e 9,71 dias em Areão (Tabela 19). 'SS-1' apresentou menor variância ambiental e 'FTCristalina' e 'EMGOPA-301' apresentaram variâncias ambientais acima da 
média dos parentais nos dois locais. Gomes (1995) observou menor variância ambiental para os parentais 'SS-1' e 'IAC-4' e maior para 'FTCristalina', 'IAC-6' e 'EMGOPA-301'. Nass (1989) e Moreira (1992) também observaram variância ambiental alta para os parentais, sugerindo que os mesmos podem ter sido influenciados pelo ambiente ou, ainda, que nem todos os parentais correspondem a linhagens homozigotas.

A variância fenotípica para $\mathrm{NDM}$ entre linhagens $\mathrm{F}_{7: 6}$ dentro dos cruzamentos oscilou de 6,77 (IAC-6 x SS-1) a 134,17 dias ${ }^{2}$ (IAC-9 x SS-1) com média de 68,80 dias ${ }^{2}$ em Anhembi; em Areão, a variação foi de 2,55 (EMGOPA-301 x IAC-5) a 127,21 dias² (Santa Rosa x SS-1), com média de 62,53 dias ${ }^{2}$ (Tabela 7). As maiores variâncias fenotípicas nos dois locais, foram apresentadas pelos cruzamentos FT-Cristalina x IAC-4, FTCristalina x SS-1, EMGOPA-301 x IAC-6, EMGOPA-301 x Santa Rosa, IAC-6 x Santa Rosa, IAC-9 x SS-1 e Santa Rosa x SS-1; as menores variâncias fenotípicas ocorreram nos cruzamentos EMGOPA-301 x IAC-5, IAC-5 x Santa Rosa, IAC-6 x IAC-11 e IAC-8 x SS-1. Gomes (1995) encontrou resultados semelhantes nas gerações $F_{6}$ e $F_{7: 6}$, exceto para 0 cruzamento EMGOPA-301 1 SS-1 que se apresentou entre os de maior variância e para IAC-9 x SS-1 que apresentou variância abaixo da média na geração $F_{7: 6}$. Nas gerações $F_{2}$ e $F_{3}$, os cruzamentos FT-Cristalina $x$ SS-1, EMGOPA-301 x SS-1, IAC-5 x SS-1, IAC-8 x SS-1, IAC-9 x SS-1 e IAC$9 \times$ SS-1 foram os que apresentaram maiores variâncias fenotípicas (Nass, 1989; Moreira, 1992). Esses resultados indicam a existência de variabilidade genética passível de seleção entre as linhagens de um mesmo cruzamento e que a expressão do NDM em alguns cruzamentos foi influenciada pela época de semeadura. 


\subsubsection{Altura da planta na maturidade (APM)}

As médias relativas ao caráter APM dos parentais e dos 45 cruzamentos dialélicos, nos experimentos com as gerações $F_{7: 6}$ e $F_{8: 6}$ avaliados em Anhembi e Areão, constam da Tabela 14.

As médias gerais de APM para os parentais nos experimentos com as linhagens $F_{7: 6}$, QLEs e QLPs foram respectivamente: 80,1, 112,7 e $114,6 \mathrm{~cm}$, em Anhembi; 91,3, 117,6 e $111,1 \mathrm{~cm}$ em Areão. Foram observados valores superiores às médias gerais de APM, para os seguintes parentais: 'EMGOPA-301' e 'IAC-6', em todos os experimentos; 'IAC-11' e 'IAC-8', nos experimentos com a geração $\mathrm{F}_{7: 6}$; 'IAC-5' nos experimentos com a geração $F_{8: 6}$. Os outros parentais apresentaram médias de APM inferiores às médias gerais da maioria dos experimentos, com destaque para IAC-4 e Santa Rosa. Comportamento semelhante foi observado por Gomes (1995) em cultivos de verão, nos quais 'IAC-5' se apresentou entre os de maior porte. Em cultivos de outono/inverno, 'EMGOPA-301', 'IAC6' e 'IAC-8' destacaram-se entre os de maior porte e 'IAC-4' e 'Santa Rosa' entre os de menor (Nass, 1989; Moreira, 1992). Quando se observam as médias dos parentais nos experimentos de 1993-1994, nota-se que apresentaram porte mais alto, em torno de $33 \mathrm{~cm}$ em Anhembi e $23 \mathrm{~cm}$ em Areão, quando comparados com os valores de 1992-1993.

As linhagens $F_{7: 6}$ apresentaram médias gerais de $82 \mathrm{~cm}$ em Anhembi e $93 \mathrm{~cm}$ em Areão; valores de APM superiores a estas médias ocorreram em 22 e 24 cruzamentos, respectivamente em Anhembi e Areão; 21 apresentaram porte superior nos dois locais.

As QLEs $\left(\mathrm{F}_{8: 6}\right)$ apresentaram médias gerais de $115 \mathrm{~cm}$ tanto em Anhembi quanto em Areão; 28 e 23 cruzamentos ficaram acima destas 
médias, respectivamente em Anhembi e Areão; 22 apresentaram porte superior nos dois locais.

As QLPs $\left(\mathrm{F}_{8: 6}\right)$ apresentaram médias gerais de $127 \mathrm{~cm}$ em Anhembi e $117 \mathrm{~cm}$ em Areão; 23 e 25 cruzamentos foram superiores a estas médias, respectivamente em Anhembi e Areão; 19 apresentaram porte superior nos dois locais.

A diferença entre as médias das linhagens $F_{8: 6}$ e $F_{7: 6}$ foi a mesma observada para os parentais incluídos nestes experimentos. Diferenças no porte dos parentais e linhagens entre os dois anos agrícolas podem ser explicadas pelos efeitos da melhoria da fertilidade do solo e da época de semeadura: 17/12/1992 (Anhembi e Areão) para geração $F_{7: 6}$; 8/11/1993 (Anhembi) e 18/11/1993 (Areão) para geração $F_{8: 6}$. O porte maior dos parentais e linhagens em Areão, na safra 1992-1993, pode ser explicado pelas melhores condições do solo, tanto em fertilidade quanto pela ausência de alumínio em nível tóxico, proporcionadas pela calagem. Uma vez que, o desenvolvimento da parte aérea é afetado pelo $\mathrm{Al}$, em conseqüência a planta apresenta porte menor (Armiger et al., 1968; Foy et al., 1993; Goldman et al., 1989; Sartain \& Kamprath, 1978).

Os cruzamentos EMGOPA-301 x IAC-5, IAC-8 x Santa Rosa e IAC-4 $x$ IAC-8 apresentaram menor porte em ambos os locais, nos experimentos com as linhagens $F_{7: 6}$, QLEs e QLPs respectivamente. $O$ cruzamento EMGOPA-301 x IAC-5 envolveu parentais de porte elevado e apresentou comportamento muito inferior à média dos parentais nas gerações $F_{7: 6}$ e $F_{8: 6}$; neste caso, a complementação gênica ocorreu para menor APM. Este cruzamento também foi o de menor porte nos experimentos com a geração $F_{7: 6}$ conduzidos por Gomes (1995). O cruzamento IAC-5 x SS-1 apresentou-se como de porte mais elevado nos experimentos com as linhagens $F_{7: 6}$ e QLPs, mesmo desempenho foi observado por Gomes (1995) na geração $F_{7: 6}$. IAC-6 encontra-se entre os 
parentais de porte mais elevado em todos os experimentos e IAC-5 nos experimentos com a geração $\mathrm{F}_{8: 6}$.

Os cruzamentos FT-Cristalina x EMGOPA-301, EMGOPA-301 x IAC-6, EMGOPA-301 x IAC-8, EMGOPA-301 x IAC-9, EMGOPA-301 x Santa Rosa, IAC-5 x IAC-6, IAC-5 x IAC-11, IAC-5 x SS-1, IAC-6 x IAC8, IAC-6 x IAC-11, IAC-6 x Santa Rosa e IAC-6 x SS-1 apresentaram porte superior às médias gerais das linhagens. Por outro lado, os cruzamentos FT-Cristalina x SS-1, EMGOPA-301 x IAC-5, IAC-4 x IAC-6, IAC-4 x IAC-8, IAC-4 x IAC-11, IAC-4 x Santa Rosa, IAC-8 x Santa Rosa e IAC-9 9 SS-1 apresentaram portes inferiores em todos os experimentos. Estes cruzamentos apresentaram comportamento semelhante nas gerações $F_{6}$ e $F_{7: 6}$ (Gomes, 1995).

Os cruzamentos FT-Cristalina $x$ IAC-8, IAC-5 $x$ IAC-8, IAC-8 x SS-1 e Santa Rosa x SS-1 foram superiores a média geral das linhagens na geração $F_{7: 6}$ e inferiores na $F_{8: 6}$. Nas gerações $F_{2}$ e $F_{3}$ os cruzamentos FT-Cristalina $x$ EMGOPA-301, FT-Cristalina $x$ IAC-8, EMGOPA-301 $x$ IAC-6, EMGOPA-301 x IAC-8, EMGOPA-301 x SS-1, IAC-5 x IAC-6, IAC-5 $x$ IAC-8, IAC-5 $x$ IAC-11, IAC-5 $x$ SS-1, IAC-8 $x$ SS-1 apresentaram porte superior (Nass, 1989; Moreira, 1992). Observa-se que entre estes, seis cruzamentos apresentaram o mesmo comportamento em $F_{7: 6}$, apesar das avaliações das gerações $F_{2}$ e $F_{3}$ terem sido realizadas no inverno. Este fato mostra que a expressão do caráter APM pode ser avaliada nas gerações iniciais e a sua manifestação é pouco influenciada pela época de semeadura, neste grupo de genótipos. Isto pode ser explicado pela presença de genes para período juvenil longo nos parentais envolvidos nestes cruzamentos, uma vez que o comportamento destas populacões foi o mesmo em diferentes épocas de cultivos (Farias Neto, 1987; Kiihl \& Garcia, 1989). 
Os valores mínimos e máximos para APM entre as linhagens $F_{7: 6}$ foram: $35 \mathrm{~cm}$ (FT-Cristalina $x$ IAC-4) e $128 \mathrm{~cm}$ (IAC-5 x IAC-6) em Anhembi; 29,5 cm (EMGOPA-301 x IAC-5) e 135,3 cm (IAC-5 x IAC-6) em Areão. Os cruzamentos IAC-8 x Santa Rosa e EMGOPA-301 x IAC-9 foram os que apresentaram menores amplitudes, 25,4 e $29,3 \mathrm{~cm}$ respectivamente em Anhembi e Areão; Santa Rosa x SS-1 e IAC-5 x IAC-6 foram os que apresentaram maiores amplitudes, ambas de 78,6 cm (Tabela 17). Estes limites mostram que há segregantes transgressivos, com APM abaixo e acima das médias dos parentais, com possibilidade para se selecionar linhagens de porte superior e inferior aos parentais em estudo. Os valores mínimos e máximos para os parentais foram, respectivamente de 45 e $105 \mathrm{~cm}$ em Anhembi, e 45 e $120 \mathrm{~cm}$ em Areão.

A variância ambiental média dos parentais entre blocos nos experimentos de 1992-1993 foi de $80,12 \mathrm{~cm}^{2}$ em Anhembi e $91,32 \mathrm{~cm}^{2} \mathrm{em}$ Areão (Tabela 19). Os parentais que apresentaram variâncias ambientais elevadas foram: 'IAC-4' e 'IAC- 6', nos dois locais; 'EMGOPA-301', 'IAC-11', 'Santa Rosa' e 'SS-1', nos experimentos conduzidos em Areão; 'IAC-9', nos experimentos conduzidos em Anhembi. Gomes (1995) também observou maior variância ambiental para os parentais citados acima. Nass (1989) e Moreira (1992) observaram variâncias ambientais elevadas para 'EMGOPA-301', 'IAC-6' e 'IAC-8'.

A variância fenotípica para $A P M$ entre linhagens $F_{7: 6}$ dentro dos cruzamentos oscilou de $46,81 \mathrm{~cm}^{2}$ (IAC-5 x Santa Rosa) a $276,52 \mathrm{~cm}^{2}$ (IAC-9 x Santa Rosa) com média de $180,56 \mathrm{~cm}^{2}$ em Anhembi; em Areão oscilou de $58,83 \mathrm{~cm}^{2}$ (IAC-9 $\times$ IAC-11) a $325,38 \mathrm{~cm}^{2}$ (IAC-4 x SS-1) com média de $212,87 \mathrm{~cm}^{2}$ (Tabela 7). Os cruzamentos IAC-4 x SS-1, IAC-5 $x$ IAC-6, IAC-9 x Santa Rosa e Santa Rosa $x$ SS-1 foram os que apresentaram maiores variâncias fenotípicas nos dois locais; entretanto, FT-Cristalina x IAC-8, FT-Cristalina x Santa Rosa e IAC-5 x Santa Rosa 
apresentaram as menores variâncias. Estes cruzamentos apresentaram comportamentos semelhantes em outros experimentos com a geração $F_{7: 6}$ (Gomes, 1995). Nas gerações $F_{2}$ e $F_{3}$ apenas o cruzamento IAC-9 x Santa Rosa não esteve entre os de maiores variâncias fenotípicas (Nass, 1989; Moreira, 1992). Esses resultados indicam a existência de variabilidade genética passível de seleção entre as linhagens de um mesmo cruzamento.

\subsubsection{Valor agronômico (VA)}

As análises dos dados de VA foram realizadas com a transformação dos mesmos para $(\sqrt{\mathrm{x}+0,5}) \times 10)$ com objetivo de aproximar da distribuição normal e melhor representar a magnitude dos quadrados médios. O caráter VA reflete o valor global de um genótipo, visto que é constituído por uma série de caracteres agronômicos, no entanto é subjetivo, devido depender do avaliador e do desenvolvimento geral do experimento.

As médias relativas ao caráter VA dos parentais e dos 45 cruzamentos dialélicos, nos experimentos com as geraçõs $F_{7: 6}$ e $F_{8: 6}$ avaliados em Anhembi e Areão, constam da Tabela 15.

As médias gerais dos parentais nos experimentos com as linhagens $F_{7: 6}$ e $F_{8: 6}$ (QLEs e QLPs) foram respectivamente: 3,53, 3,13 e 3,04 em Anhembi; 3,86, 3,20 e 3,05 em Areão. SS-1 apresentou VA inferior à média dos parentais em todos os experimentos e 'IAC-4' apresentou o menor $V A$ nos experimentos com a geração $F_{7: 6}$. Os parentais FT-Cristalina, EMGOPA-301, IAC-6, IAC-8 e IAC-11 apresentaram VA superior às médias gerais dos experimentos com a geração $F_{7: 6}$; na geração 
$\mathrm{F}_{8: 6}$ somente os dois primeiros foram superiores às médias gerais nos dois locais. $\mathrm{Na}$ geração $\mathrm{F}_{8: 6}$ 'IAC-4' e 'Santa Rosa' apresentaram notas superiores à média dos parentais em Areão. Comportamento semelhante para os parentais FT-Cristalina, EMGOPA-301 e SS-1 foi observado por Gomes (1995) em cultivos de verão. 'IAC-4' foi o de menor VA em cultivo de outono/inverno (Nass, 1989), e em cultivos de verão (Gomes, 1995).

As linhagens $\mathrm{F}_{7: 6}$ mostraram médias gerais de 3,58 para VA em Anhembi e 3,87 em Areão; 23 e 18 cruzamentos apresentaram médias superiores a estas, respectivamente em Anhembi e Areão; destes 15 foram superiores nos dois locais. Assim como os parentais, a média das linhagens foi superior $(0,30)$ em Areão.

As QLEs apresentaram médias gerais de 3,02 e 3,04 em Anhembi e Areão, respectivamente; 18 e 26 cruzamentos ficaram acima destas médias, respectivamente em Anhembi e Areão; destes 15 apresentaram maior VA nos dois locais.

As QLPs apresentaram médias gerais de 3,09 e 2,96 respectivamente em Anhembi e Areão; 21 e 22 cruzamentos foram superiores a estas médias, respectivamente em Anhembi e Areão; destes 10 apresentaram maior VA nos dois locais.

Quando se comparam os valores de VA entre gerações, notase, menores valores para os parentais e linhagens nos experimentos com a geração $\mathrm{F}_{8: 6}$. Isto pode ser explicado pelo maior rigor no critério de notas, uma vez que, no segundo ano o avaliador (o autor) foi mais crítico devido uma maior convivência com a cultura. O maior VA dos parentais e linhagens em 1992-1993 em Areão, pode ser explicado pela maior fertilidade e ausência de alumínio em nível tóxico no solo.

Os cruzamentos EMGOPA-301 x IAC-5 e IAC-9 x SS-1 apresentaram VA inferiores às médias gerais das linhagens em todos os 
experimentos. EMGOPA-301 x IAC-5 foi o de menor VA nos experimentos com a geração $F_{7: 6}$ (Gomes, 1995); IAC-9 x SS-1 também apresentou desempenho inferior nas gerações $F_{2}, F_{6}$ e $F_{7: 6}$ (Gomes, 1995; Nass, 1989).

Os cruzamentos FT-Cristalina x EMGOPA-301, FT-Cristalina x IAC-11, EMGOPA-301 x IAC-6, EMGOPA-301 x IAC-8 e IAC-6 x SS-1 apresentaram notas de VA superiores à média em cinco dos seis experimentos com as gerações $F_{7: 6}$ e $F_{8: 6}$ (QLEs e QLPs); estes cruzamentos também apresentaram desempenho superior nas gerações $F_{2}$, $F_{6}$ e $F_{7: 6}$ (Gomes, 1995; Nass, 1989).

Os valores mínimos e máximos para VA entre as linhagens $F_{7: 6}$ foram de 1,9 (EMGOPA-301 x IAC-5) e 5,1 (IAC-5 x SS-1) em Anhembi e de 1,5 (EMGOPA-301 x IAC-5) e 4,9 (IAC-5 x SS-1 e IAC-6 x Santa Rosa) em Areão. Valores maiores que cinco devem-se ao ajuste de tratamentos baseado no desempenho dos parentais nos diferentes blocos. Os cruzamentos IAC-6 x SS-1 e FT-Cristalina $x$ IAC-8 foram os que apresentaram menores amplitudes, 1,0 e 0,7 em Anhembi e Areão, respectivamente; IAC-9 $x$ Santa Rosa e EMGOPA-301 x IAC-5 apresentaram as maiores amplitudes, ambas de 2,5, em Anhembi e Areão (Tabela 18). Segregantes transgressivos com VA superior aos parentais ocorreram em todos os cruzamentos.

A variância ambiental média dos parentais nos experimentos com a geração $F_{7: 6}$ foi de 1,01 em Anhembi e de 0,91 em Areão. EMGOPA301, IAC-4, Santa Rosa e SS-1 apresentaram variâncias ambientais superiores.

A variância fenotípica de VA dentro de cruzamento para as linhagens $\mathrm{F}_{7: 6}$ oscilou de 0,47 (IAC-6 x SS-1) a 3,00 (IAC-4 x SS-1), com média de 1,79 em Anhembi e de 0,25 (FT-Cristalina x IAC-8) a 3,58 (EMGOPA-301 x IAC-5), com média de 1,04 em Areão (Tabela 7). Em Anhembi $(>\mathbf{A l})$ as variâncias fenotípicas mostram que as condições neste 
local foram melhores para discriminar as linhagens. 'FT-Cristalina x IAC6', 'IAC-4 x Santa Rosa', 'IAC-4 x SS-1', 'IAC-6 x IAC-9' e 'IAC-9 x Santa Rosa', apresentaram variâncias fenotípicas superiores nos dois locais. Estes resultados indicam a presença de variabilidade genética para VA, indicando ser possível obter sucesso com a seleção.

\subsubsection{Produtividade de grãos (PG)}

As médias relativas ao caráter PG dos parentais e dos 45 cruzamentos dialélicos, nos experimentos com as gerações $F_{7: 6}$ e $F_{8: 6}$ avaliados em Anhembi e Areão, constam da Tabela 16.

As médias gerais dos parentais nos experimentos com as linhagens $F_{7: 6}$, QLEs e QLPs foram respectivamente: 239,488 e $367 \mathrm{~g} / \mathrm{m}^{2}$, em Anhembi; 154, 304 e $292 \mathrm{~g} / \mathrm{m}^{2}$, em Areão que corresponde a uma produtividade variando de 1540 a $4880 \mathrm{~kg} / \mathrm{ha}$. Quando se comparam as médias entre os dois anos agrícolas, nota-se que apresentaram maior produtividade em 1993-1994, ou seja, em torno de $190 \mathrm{~g} / \mathrm{m}^{2}$ em Anhembi e $140 \mathrm{~g} / \mathrm{m}^{2}$ em Areão. Neste sentido, a aplicação de calcário mostrou-se eficiente em corrigir a acidez e eliminar o alumínio da camada superficial do solo, de maneira que as plantas tiveram melhores condições para o pleno desenvolvimento em 1993-1994, detectado pela maior PG e APM. Maior APM pode ter aumentado a competição entre as plantas principalmente de parcelas vizinhas, fato este que pode ter resultado em menor produtividade dos parentais de menor porte nos experimentos com as QLPs em Anhembi. Além disso, variações climáticas nos dois anos agrícolas, também podem ter contribuído para as diferenças de produtividade dos parentais. 
Os parentais que apresentaram médias superiores às médias gerais foram: 'FT-Cristalina', 'EMGOPA-301' e 'IAC-9' em todos os experimentos; 'IAC-6' nos experimentos de 1992-1993; IAC-4 e Santa Rosa nos experimentos de 1993-1994 em Areão. Observa-se ainda que em todos os experimentos, 'EMGOPA-301' é o mais produtivo em Anhembi e 'FT-Cristalina' em Areão. 'IAC-5' e 'SS-1' apresentaram comportamento inferior à média geral em todos os experimentos. Resultados concordantes foram obtidos por Gomes (1995) em cultivos de verão das gerações $F_{6} e$ $F_{7: 6}$ : 'FT-Cristalina', 'EMGOPA-301' e 'IAC-9' foram os mais produtivos e 'IAC-5' e 'SS-1' os de menor produtividade nas duas gerações, no caso da geração $F_{7: 6}$ destacaram-se ainda 'IAC-6' e 'IAC-11' entre os mais produtivos. Também em cultivos de outono/inverno (Moreira, 1992; Nass, 1989), 'FT-Cristalina', 'IAC-9', 'IAC-11' e 'SS-1' foram os de maior produtividade, enquanto que 'IAC-4' e Santa Rosa mostraram menor produtividade.

Em 1992-1993, as linhagens $F_{7: 6}$ apresentaram médias gerais de $238 \mathrm{~g} / \mathrm{m}^{2}$ em Anhembi e $154 \mathrm{~g} / \mathrm{m}^{2}$ em Areão; 20 e 26 cruzamentos apresentaram médias superiores as estas, respectivamente em Anhembi e Areão; destes 19 foram superiores nos dois locais.

Em Areão, solo corrigido ( $<A l)$, houve melhor desempenho evidenciado pelos maiores valores de APM e VA. No entanto, não correspondeu à maior $\mathrm{PG}$, provavelmente devido à ocorrência de veranico, no início do florescimento (65 a 85 dias) e durante a granação (115 a 130 dias) Apêndice 5. Outro fator que pode ter contribuído para reduzir PG é a presença de $\mathrm{Mn}\left(>22,7 \mathrm{mg} / \mathrm{dm}^{3}\right.$ ) no solo, ainda que não causasse sintomas visuais de toxidez na parte aérea. Experimentos com solo em vaso mostram que $6 \mathrm{mg} / \mathrm{dm}^{3}$ de Mn prejudicaram o desenvolvimento do cultivar resistente (Miranda et al., 1982). Além disso, o solo em Areão apresenta maior 
compactação, devido a sua estrutura física, o que pode ter contribuido para reduzir PG.

Por outro lado, a maior produtividade de grãos em Anhembi pode ser devida ao maior nível de fósforo $\left(>30 \mathrm{mg} / \mathrm{dm}^{3}\right.$ ) no solo e à ausência de veranico (observação de campo). O fósforo, além de contribuir diretamente para um melhor desenvolvimento, pode ter reduzido os efeitos do alumínio (Foy, 1976; Foy et al., 1978; Vilela \& Anghinoni, 1984). Além disso, a abundância de água pode ter contribuído para a diluição do Al na solução do solo a uma concentração menos prejudicial às plantas (Adams \& Lund, 1966) e na ausência de estresse hídrico, a planta não necessita de um sistema radicular bem desenvolvido para suprir suas necessidades em água e nutrientes (Freire, 1984, 1985).

Em 1993-1994, as QLEs apresentaram médias gerais de 416 $\mathrm{g} / \mathrm{m}^{2}$ em Anhembi e $247 \mathrm{~g} / \mathrm{m}^{2}$ em Areão; 20 e 23 cruzamentos ficaram acima destas médias, respectivamente em Anhembi e Areão; destes 15 foram superiores nos dois locais. Já as QLPs apresentaram médias gerais de 403 $\mathrm{g} / \mathrm{m}^{2}$ em Anhembi e $241 \mathrm{~g} / \mathrm{m}^{2}$ em Areão; 21 e 23 cruzamentos foram superiores a estas médias, respectivamente em Anhembi e Areão; destes 15 foram superiores nos dois locais. As QLEs apresentaram médias de PG semelhantes as QLPs nos dois locais, isto deve-se provavelmente a antecipação da semeadura em 1993-1994, a qual proporcionou: bom desenvolvimento das QLEs; crescimento excessivo (APM) e queda na produtividade das QLPs, devido maior competição e sombreamento. A produtividade superior em Anhembi tem sido constatada em outros experimentos e suas causas ainda necessitam de maiores estudos (Vello, N.A., comunicação pessoal 1997).

Observa-se que em 1992-1993 as linhagens apresentaram desempenho semelhante aos parentais; em 1993-1994 os parentais foram superiores, exceto no experimento com as QLPs em Anhembi. As 
diferenças entre as médias das linhagens $F_{8: 6}$ e $F_{7: 6}$ foram 170 e $90 \mathrm{~g} / \mathrm{m}^{2}$ em Anhembi e Areão, respectivamente; estas diferenças são menores que as observadas entre as médias dos parentais, nos dois anos agrícolas, concordam com relatos de maior estabilidade em populações segregantes ou mistas (Bisognin et al., 1995; Guazzelli, 1975; Schweitzer et al., 1986; Takeda et al., 1991).

Os cruzamentos EMGOPA-301 x IAC-5, IAC-9 x SS-1 e IAC$5 \times$ Santa Rosa, destacam-se entre os de menor produtividade, nos dois locais, nos experimentos com as linhagens $F_{7: 6}$, QLEs $e$ QLPs, respectivamente.

O cruzamento IAC-5 x EMGOPA-301, com parentais de menor e maior produtividade em todos experimentos, apresentou comportamento muito inferior à média dos parentais nos dois anos; neste caso, a complementação gênica foi desfavorável. Este cruzamento também se apresentou entre os de menor produtividade no estudo realizado por Gomes (1995) com a geração $F_{7: 6}$.

O cruzamento FT-Cristalina $\mathrm{x}$ EMGOPA-301 apresentou a maior produtividade em todos os experimentos conduzidos em Anhembi (>Al). Nass (1989) observou que este cruzamento foi o segundo mais produtivo na geração $F_{2}$ e apresentou maior heterose $(94,8 \%)$, destacandose dos demais para seleção de linhagens visando ao cultivo de outono/inverno.

Destacaram-se ainda em Anhembi os cruzamentos FTCristalina $x$ IAC-9, EMGOPA-301 x IAC-6, EMGOPA-301 x IAC-8 e EMGOPA-301 x Santa Rosa. Em Areão (<Al) destacaram-se FT-Cristalina $x$ IAC-9 e FT-Cristalina $x$ IAC-11; observa-se ainda que, FT-Cristalina $x$ IAC-9 apresentou bom desempenho nas duas condições. 
Destacam-se, ainda, como mais produtivos na maioria dos experimentos, os cruzamentos:

FT-Cristalina x IAC-6

FT-Cristalina $x$ Santa Rosa

EMGOPA-301 x IAC-11

EMGOPA-301 $\times$ SS-1

IAC $-6 \times$ IAC -9

IAC $-6 \times$ SS -1

IAC $-8 \times$ IAC -9
FT-Cristalina $x$ IAC-5

FT-Cristalina $x$ IAC-8

EMGOPA-301 $\times$ IAC- 4

EMGOPA-301 $\times$ IAC-9

EMGOPA-301 x Santa Rosa

IAC-6 x Santa Rosa

Os cruzamentos FT-Cristalina x EMGOPA-301, FT-Cristalina x IAC-9, FT-Cristalina x IAC-11, EMGOPA-301 x IAC-6, EMGOPA-301 x IAC-9 e IAC-6 x IAC-9 destacaram-se como os mais produtivos nas

gerações $F_{6}$ e $F_{7: 6}$ (Gomes, 1995). Os cruzamentos FT-Cristalina $x$ Santa Rosa, EMGOPA-301 x IAC-4, EMGOPA-301 x Santa Rosa, IAC-6 x Santa Rosa, e IAC- 6 x SS-1 destacaram-se entre os mais produtivos neste estudo e nas gerações $F_{6}$ e $F_{7: 6}$ (Gomes, 1995); na geração $F_{2}$ eles situaram-se entre os de pior desempenho (Nass, 1989).

Destaques de baixa produtividade envolveram os seguintes cruzamentos:

EMGOPA-301 $\times$ IAC -5

IAC $-5 \times$ IAC -11

IAC $-5 \times$ SS -1

IAC $-9 \times$ SS -1

FT-Cristalina $x$ SS-1

Santa Rosa x SS-1
IAC- $5 \times$ IAC -9

IAC-5 x Santa Rosa

IAC $-9 \times$ SS -1

IAC $-4 \times$ IAC -8

IAC $-4 \times$ IAC -5

IAC -4 x Santa Rosa

Os cruzamentos FT-Cristalina $\mathrm{x}$ SS-1, IAC-5 x IAC-9, IAC-5 x IAC-11, IAC-5 x SS-1, IAC-9 x SS-1 e IAC-9 9 SS-1 foram os de pior desempenho neste estudo e nas gerações $F_{6}$ e $F_{7: 6}$ (Gomes, 1995); na geração $F_{2}$ se destacaram entre os mais produtivos (Nass, 1989); FTCristalina x SS-1, IAC-9 x SS-1, Santa Rosa x SS-1 foram os de pior desempenho, no entanto, na geração $F_{3}$ (Moreira, 1992) apresentaram-se entre os mais produtivos; IAC-4 x IAC-5, IAC-4 x Santa Rosa e IAC-5 x 
Santa Rosa também apresentaram pior desempenho nas gerações $F_{2}$ e $F_{3}$ (Moreira, 1992; Nass, 1989).

A divergência entre o desempenho dos cruzamentos para PG das gerações iniciais $F_{2}$ e $F_{3}$ e os das gerações avançadas $F_{6}, F_{7: 6}$ e $F_{8: 6}$ pode ser explicada pelos seguintes fatos: presença da heterose nas gerações iniciais (Brim \& Cockerham, 1961; Leffel \& Hanson, 1961; Nass, 1989; Pacova, 1992); presença de epistasia do tipo aditiva $\mathrm{x}$ aditiva, à qual pode ter grande participação na variância genética para produtividade de grãos em soja (Hanson \& Weber, 1962; Hanson et al., 1967; St. Martin, 1981); diferentes épocas de avaliação, cultivos de outono/inverno nas gerações iniciais e verão nas avançadas (Farias Neto, 1987); diferentes anos de avaliações. Como PG é muito influenciado pelas condições ambientais, isto contribuiu para a divergência entre as gerações iniciais e avançadas (Allard, 1971; Sediyama et al., 1981).

A heterose estimada em $F_{2}$ para a população em estudo oscilou de $-38,3 \%$ (IAC-4 x IAC-6) a 94,8\% (FT-Cristalina x EMGOPA-301) com média de $28,1 \%$ (Nass, 1989), como a cada geração de autofecundação esta é reduzida a metade, então quanto maior o valor da heterose maior a diferença de desempenho entre as gerações.

Os valores mínimos e máximos para $P G$ entre as linhagens $F_{7: 6}$ foram de $-10,7$ (IAC-5 x IAC-6) e $561,2 \mathrm{~g} / \mathrm{m}^{2}$ (FT-Cristalina x EMGOPA301) em Anhembi e de $-4,5$ (FT-Cristalina x IAC-6) e $349,4 \mathrm{~g} / \mathrm{m}^{2}$ (FTCristalina x IAC-9) em Areão. Valores negativos devem-se ao ajuste de tratamentos baseado no desempenho dos parentais nos diferentes blocos. Os cruzamentos IAC-5 x Santa Rosa e IAC-5 x IAC-9 foram os que apresentaram menores amplitudes: 168,1 e $115,1 \mathrm{~g} / \mathrm{m}^{2}$ em Anhembi e Areão, respectivamente; por outro lado, os cruzamentos IAC-5 x IAC-6 e FT-Cristalina $\times$ SS-1 foram os que apresentaram maiores amplitudes: 518,4 e $291,5 \mathrm{~g} / \mathrm{m}^{2}$ em Anhembi e Areão, respectivamente (Tabela 18). Esses 
limites mostram que há segregantes transgressivos com PG acima das médias dos parentais, com a possibilidade de sucesso na seleção de linhagens superiores.

A variância ambiental média dos parentais nos experimentos com a geração $\mathrm{F}_{7: 6}$ em Anhembi apresentou magnitude três vezes superior a obtida em Areão (Tabela 19). 'FT-Cristalina', 'EMGOPA-301', 'IAC-6' e 'IAC-9' apresentaram variâncias ambientais superiores. Estes parentais e 'IAC-11' também foram os que apresentaram maiores variâncias ambientais nos experimentos com as gerações $F_{6}$ e $F_{7: 6}$ (Gomes 1995). Variâncias ambientais altas para FT-Cristalina, 'IAC-6', 'IAC-9' e 'SS-1' também foram observadas por Nass (1989) e Moreira (1992). Os valores máximos e mínimos para os parentais foram: 530 e $30 \mathrm{~g} / \mathrm{m}^{2}$ em Anhembi; 288 e 20 $\mathrm{g} / \mathrm{m}^{2}$ em Areão.

A variância fenotípica da $P G$ entre linhagens $F_{7: 6}$ dentro dos

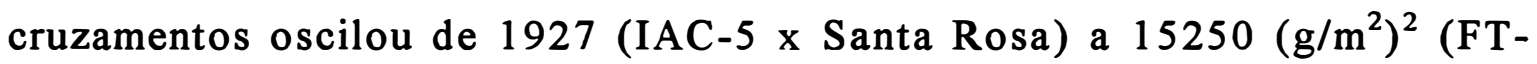
Cristalina x EMGOPA-301) com média de $9351,45\left(\mathrm{~g} / \mathrm{m}^{2}\right)^{2}$ em Anhembi; em Areão as variâncias fenotípicas oscilaram de 865 ( FT-Cristalina x IAC4) a $4748\left(\mathrm{~g} / \mathrm{m}^{2}\right)^{2}$ (IAC-4 x IAC-9), com variância média de $2838\left(\mathrm{~g} / \mathrm{m}^{2}\right)^{2}$ (Tabela 7). Em Anhembi (>Al) as variâncias fenotípicas mostram que este ambiente foi melhor para discriminar as linhagens. Nos experimentos com as linhagens $\mathrm{F}_{7: 6}$ os cruzamentos FT-Cristalina $x$ EMGOPA-301, EMGOPA$301 \times$ IAC-4 e EMGOPA-301 x Santa Rosa foram os que apresentaram maiores variâncias nos dois locais. Esses resultados indicam a presença de variabilidade para PG e confirmam a vantagem do seu uso em um programa de melhoramento. 


\subsubsection{Considerações gerais}

A análise dos parentais e linhagens para os caracteres NDM, APM, VA e PG (Tabelas 13, 14, 15 e 16) mostra que estes foram influenciados diferentemente pelas condições contrastantes de saturação de Al: NDM apresentou mesma média na geração $F_{7: 6}$, enquanto na geração $\mathrm{F}_{8: 6}$ apresentou média dez dias superior em Anhembi; APM e VA apresentaram médias superiores em Areão na geração $F_{7: 6}$, enquanto na geração $F_{8: 6}$ apresentaram praticamente os mesmos valores; PG apresentou médias superiores em Anhembi, nas duas gerações.

Observa-se melhor desempenho dos parentais e linhagens para os caracteres NDM, APM e PG nos experimentos com a geração $F_{8: 6}$ do que com a geração $F_{7: 6}$. Esses resultados podem ser explicados pelos efeitos direto da melhoria do ambiente pela calagem, pela antecipação da época de semeadura, pela seleção e pelas melhores condições climáticas em 1993-1994.

Os cruzamentos que apresentaram médias superiores às médias gerais das linhagens em todos os experimentos foram: a) FT-Cristalina $x$ EMGOPA-301, EMGOPA-301 x IAC-6 e EMGOPA-301 x IAC-8 para todos os caracteres; b) EMGOPA-301 x IAC-9, EMGOPA-301 x Santa Rosa, EMGOPA-301 x IAC-11 e IAC-6 x Santa Rosa para NDM, APM e PG; c) EMGOPA-301 x IAC-8 e IAC-6 x SS-1 para APM, VA e PG; d) FTCristalina x Santa Rosa, EMGOPA-301 x SS-1 e IAC-6 x IAC-9 para APM e PG; e) FT-Cristalina x IAC-9 para NDM e PG.

Os mesmos cruzamentos apresentaram bom desempenho para PG e para NDM e/ou APM; portanto, é difícil encontrar genótipos com alta PG e menor NDM e APM. No entanto, os cruzamentos FT-Cristalina $x$ IAC-11, FT-Cristalina x IAC-6, FT-Cristalina x IAC-8, EMGOPA-301 x 
IAC-4 e IAC-8 x IAC-9 constituem exceção e apresentam maior possibilidade de sucesso na seleção de linhagens produtivas, com altura ideal (80-100 cm) e ciclo entre 130 a 145 dias.

\subsection{Herdabilidade}

As estimativas do coeficiente de herdabilidade $\left(h^{2}\right)$ para os caracteres NDM, APM, VA e PG em cada cruzamento, com base no desempenho das linhagens $F_{7: 6}$, em Anhembi ( $>A$ I) e Areão (<Al) são apresentadas na Tabela 20. Os coeficientes de determinação genotípica (b) e herdabilidade respectivamente para os parentais e linhagens nos experimentos com as linhagens $\mathrm{F}_{\text {7:6 }}$ e $\mathrm{F}_{8: 6}$ (QLEs e QLPs) são apresentados na Tabela 21.

A ampla variação entre as estimativas de herdabilidade para todos os caracteres em diferentes cruzamentos é esperada, em função do tipo de população e das condições ambientais em que esta é avaliada. Basicamente, a magnitude da herdabilidade é dependente da diversidade genética entre os parentais e da maior ou menor sensibilidade destes às flutuações ambientais (Brim, 1973; Dudley \& Moll, 1969; Johnson \& Bernard, 1963). Em trabalhos de revisão, Brim (1973) e Johnson \& Bernard (1963) mostra que os coeficientes de $h^{2}$ apresentaram magnitude entre 0,03 a 0,58 para PG; 0,45 a 0,90 para APM; 0,55 a 0,94 para NDM.

Ocorreram algumas estimativas negativas de herdabilidade para os caracteres e essas resultaram de componentes de variância muito pequenos, que podem ser devido a pequena divergência genética dos parentais ou ao desvio de amostragem. 


\subsubsection{Número de dias para a maturidade (NDM)}

As estimativas de herdabilidade $\left(\mathrm{h}^{2}\right)$ de NDM oscilaram entre 3,30 (IAC-6 x SS-1) e 0,78 (IAC-9 x SS-1) em Anhembi, com oito cruzamentos com $\mathrm{h}^{2}>0,70$; em Areão, as estimativas de $\mathrm{h}^{2}$ oscilaram de 3,03 (EMGOPA-301 x IAC-5) a 0,92 (Santa Rosa x SS-1), com 25 cruzamentos apresentando $h^{2}>0,70$; observa-se também, que 41 cruzamentos apresentaram maior valor de $h^{2}$ em Areão (Tabela 20). Gomes (1995) obteve maiores estimativas de $h^{2}$ nas gerações $F_{6}$ e $F_{7: 6}$, para os mesmos cruzamentos.

Menores valores de $\mathrm{h}^{2}$ em Anhembi podem ser explicados pela limitação da expressão genética máxima das linhagens, devido, principalmente, às diferenças de saturação de $\mathrm{Al}$ e ao maior erro experimental, três vezes superior ao observado em Areão (Tabela 6). Os valores de $h^{2}$ obtidos ao nível de linhagens $F_{7: 6}$ dentro de cada cruzamento em Areão estão muito próximos dos encontrados por Gomes (1995) nesta mesma geração, com o dobro do número de linhagens desta pesquisa.

Ao nível de linhagem observa-se que os valores de herdabilidade obtidos em Areão foram superiores aos de Anhembi na geração $F_{7: 6}$ e inferiores na geração $F_{8: 6}$ (Tabela 21). As estimativas de $h^{2}$ foram de intermediárias a altas $\left(0,58<\mathrm{h}^{2}<0,98\right)$ e evidenciam a maior importância dos fatores genéticos na variação fenotípica do caráter NDM.

As magnitudes dos coeficientes de herdabilidade estão dentro das estimativas observadas em outros estudos: 0,55 a 0,78 (Johnson \& Bernard, 1963); 0,75 a 0,94 (Brim, 1973); 0,92 a 0,98 para linhagens $F_{9}$ (Shimoya, 1990); 0,47 a 0,84 para linhagens $F_{8}$ (Prado, 1994); 0,37 a 0,99 para linhagens $F_{6}$ e 0,41 a 0,93 para $F_{7: 6}$ (Gomes, 1995). 
Portanto, pode-se considerar que NDM é um caráter relativamente fácil de ser alterado por seleção.

\subsubsection{Altura da planta na maturidade (APM)}

As estimativas de herdabilidade $\left(\mathrm{h}^{2}\right)$ para APM oscilaram entre -0,38 (FT-Cristalina x IAC-9) e 0,77 (IAC-9 x Santa Rosa) em Anhembi, com 12 cruzamentos com $\mathrm{h}^{2}>0,60$; em Areão, oscilaram entre -0,25 (FTCristalina x IAC-8) a 0,75 (IAC-4 x Santa Rosa), com 13 cruzamentos $\mathrm{h}^{2}>$ 0,$60 ; 22$ cruzamentos apresentaram maiores valores de $h^{2}$ em Areão (Tabela 20).

A herdabilidade para APM ao nível de linhagens foi de mesma magnitude $(0,60)$ nos dois locais na geração $F_{7: 6}$; na geração $F_{8: 6}$ os valores obtidos em Anhembi foram superiores aos encontrados em Areão (Tabela 21). As estimativas de $\mathrm{h}^{2}$ oscilaram de 0,62 a 0,84 e mostram a importância dos fatores genéticos na variação fenotípica do caráter APM.

As magnitudes dos coeficientes de herdabilidade deste estudo se aproximam das observadas por outros autores, cujas estimativas oscilaram de: 0,45 a 0,75 (Johnson \& Bernard, 1963); 0,66 a 0,90 (Brim, 1973); 0,60 a 0,97 para linhagens $F_{9}$ (Shimoya, 1990); 0,58 a 0,95 para linhagens $\mathrm{F}_{8}$ (Prado, 1994); 0,37 a 0,85 para linhagens $\mathrm{F}_{6}$, com média de 0,65 e de 0,02 a 0,77 para linhagens $F_{7: 6}$, com média de 0,50 (Gomes, 1995). Portanto, APM é um caráter facilmente alterado por seleção. 


\subsubsection{Valor agronômico (VA)}

As estimativas de herdabilidade $\left(\mathrm{h}^{2}\right)$ para VA oscilaram entre 0,90 (IAC-6 x SS-1) e 0,70 (IAC-4 x SS-1) em Anhembi; 15 cruzamentos apresentaram $h^{2}>0,40$. Em Areão, oscilaram entre -1,68 (FT-Cristalina $x$ IAC-8) a 0,81 (EMGOPA-301 x IAC-5); seis cruzamentos apresentaram $\mathrm{h}^{2}$ $>0,40 ; 35$ cruzamentos apresentaram maiores valores de $h^{2}$ em Anhembi (Tabela 20). Estimativas de $h^{2}$ dentro de cada cruzamento não foram consistentes nos dois locais e evidenciam a influência das condições ambientais sobre o caráter, principalmente as diferenças de fertilidade do solo. Os valores de $\mathrm{h}^{2}$ ao nível de linhagens para VA oscilaram de 0,28 a 0,61 ; em Anhembi foram superiores a 0,50 e em Areão inferiores a 0,36 (Tabela 21). Isto mostra que sob $>$ Al (Anhembi) é melhor para discriminar as linhagens.

As magnitudes dos coeficientes de herdabilidade estão dentro do intervalo observado por Gomes (1995), cujas estimativas variaram de 0,47 a 0,84 para linhagens $F_{6}$, com média de 0,69 e de $-0,33$ a 0,77 para $F_{7: 6}$, com média de 0,37 . Portanto, VA indica ser mais difícil de se alterar por seleção do que NDM e APM.

\subsubsection{Produtividade de grãos (PG)}

As estimativas de herdabilidade $\left(h^{2}\right)$ para $P G$ oscilaram entre 1,99 (IAC-5 x Santa Rosa) a 0,62 (FT-Cristalina x EMGOPA-301) em Anhembi, onde sete cruzamentos apresentaram $\mathrm{h}^{2}>0,40$; em Areão, oscilaram entre -1,04 (FT-Cristalina x IAC-4) a 0,63 (IAC-4 x IAC-9), 
onde 11 cruzamentos apresentaram $h^{2}>0,40$; observa-se também, que 23 cruzamentos apresentaram maiores valores de $h^{2}$ em Areão (Tabela 20). Estimativas de $\mathrm{h}^{2}$ dentro de cada cruzamento não foram consistentes nos dois locais, indicando que o caráter é muito influenciado pelas condições ambientais, entre elas os diferentes níveis de saturação de $\mathrm{Al}$.

Ao nível de linhagem os valores foram de 0,38 na geração $F_{7: 6}$ e próximos de 0,60 na geração $F_{8: 6}$ (Tabela 21). As estimativas foram praticamente as mesmas nos dois locais e os níveis contrastantes de saturação de Al não influenciaram as estimativas de $h^{2}$ para o caráter PG.

Estes valores se comparam com os obtidos em outros trabalhos: 0,05 a 0,38 (Johnson \& Bernard, 1963); 0,03 a 0,58 (Brim, 1973); 0,22 a 0,86 para linhagens $F_{9}$ (Shimoya, 1990); 0,01 e 0,13 nas gerações $\mathrm{F}_{4}$ e $\mathrm{F}_{5}$ (Montenegro, 1994); 0,48 a 0,61 para linhagens $\mathrm{F}_{8}$ (Prado, 1994); 0,38 a 0,85 para linhagens $F_{6}$, com média de 0,62 e $-0,29$ a 0,58 para linhagens $F_{7: 6}$, com média de 0,29 (Gomes, 1995). Portanto, espera-se mais dificuldades na seleção para alterar PG e, conseqüentemente, VA do que para melhorar NDM e APM.

Os parentais apresentaram coeficientes de determinação genotípica (b) superiores aos valores de $\mathrm{h}^{2}$ ao nível de linhagem, para os caracteres em estudo. Isto pode ser explicado pela ampla variação entre os parentais para todos os caracteres.

As estimativas de $\mathrm{h}^{2}$ dos caracteres NDM, APM e PG, ao nível de linhagem, foram superiores nos experimentos com a geração $F_{8: 6}$. Nesta geração, a semeadura foi mais cedo (08 e 18-11-1993) e possibilitou que as linhagens expressassem o potencial genético de desenvolvimento, o qual resultou em maior variância genética. A maior estimativa de $h^{2}$ para todos os caracteres nos experimentos com as QLEs, pode ser explicada pela maior variação genética entre linhagens precoces do que entre as produtivas e/ou pelo menor erro experimental. 
As estimativas dos componentes de variância estão sujeitas a erros, principalmente quando existem interações. Estes afetam os parâmetros obtidos a partir destas estimativas, como a herdabilidade. Além disto, as condições dos solos variaram muito entre os locais. A estimativa de $h^{2}$, razão entre variância genotípica e fenotípica, pode variar grandemente, em função da unidade de seleção e das interações genótipos $x$ ambientes (Johnson et al, 1955a). Logo, qualquer comparação significativa das estimativas obtidas em situações experimentais diferentes deve incluir uma avaliação cuidadosa dos métodos e material empregados.

\subsection{Correlação entre caracteres}

As estimativas dos coeficientes de correlação fenotípica, genotípica e ambiental entre os caracteres NDM, APM, VA e PG, dos parentais, cruzamentos e linhagens dentro de cruzamento, nas gerações $F_{7: 6}$ em Anhembi (>Al) e Areão (<Al) encontram-se na Tabela 22.

As correlações fenotípicas e genotípicas foram positivas e maiores em Anhembi. Observa-se uma semelhança entre as correlações obtidas para os parentais (homozigóticos) e cruzamentos(heterogêneos). Os coeficientes das correlações fenotípicas estimados com base nas linhagens $F_{7: 6}$ foram inferiores aos calculados para os outros dois grupos nos dois locais, provavelmente devido à ausência de repetições na avaliação. No entanto, as estimativas das correlações genotípicas para as linhagens foram semelhantes às obtidas com os parentais e cruzamentos para todos os pares, em Anhembi; NDM/APM, NDM/VA e APM/VA em Areão. 
As diferenças observadas entre as estimativas de correlação nos dois locais é provável que sejam mais devidas às conseqüências do veranico ocorrido na fase reprodutiva em Areão (Apêndice 5), do que à diferença de saturação de Al entre os locais. O veranico afetou mais a produtividade de grãos dos genótipos tardios e interferiu nas estimativas das correlações que envolvem PG.

Em geral, as correlações genotípicas foram superiores às fenotípicas, exceto para os pares APM/PG e VA/PG em Areão. Superioridade da correlação genotípica também foi observada em outros trabalhos (Anand \& Torrie, 1963; Bays, 1975; Farias Neto, 1995; Gomes, 1995; Johnson et al., 1955b; Kwon \& Torrie, 1964; Montenegro, 1994; Santos, 1994). Isso indica que a expressão fenotípica da associação entre os caracteres é diminuída frente às variações ambientais, o que atrapalha o processo seletivo. Portanto, sempre que possível, deve-se estimar a correlação genotípica durante os trabalhos de seleção em soja.

As correlações genotípicas entre NDM/APM, NDM/PG e APM/PG para as linhagens foram respectivamente: $0,54,0,54$ e 0,62 , em Anhembi; 0,43, 0,11 e 0,07 em Areão, esses pequenos valores para os dois últimos pares devem-se provavelmente aos efeitos do veranico. Os resultados obtidos em Anhembi estão de acordo com aqueles obtidos por outros autores (Anand \& Torrie, 1963; Byth et al., 1969; Farias Neto, 1995; Gomes, 1995; Johnson et al., 1955b; Kwon \& Torrie, 1964; Santos, 1994; Shimoya, 1990). A associação positiva e moderada entre PG, NDM e APM dificulta a obtenção de linhagens produtivas, precoces e de porte médio (ideótipo), visto que, para isto, a seleção é efetuada em direção contrária para PG em relação aos outros dois. Essas associações devem ter surgido porque os caracteres são afetados pelos mesmos processos fisiológicos fundamentais na planta (Johnson \& Bernard, 1963). 
As estimativas entre APM/VA e VA/PG foram respectivamente: 0,95 e 0,83 , em Anhembi e 0,67 e 0,09 em Areão. Desconsiderando o último valor, as demais correlações concordam com as observadas em outros estudos (Farias Neto, 1995; Gomes, 1995; Pacova, 1992). Estes pares foram os que apresentaram maiores valores de correlações fenotípicas, nos dois locais, com base nas linhagens. Essas associações mostraram que o VA, mesmo sendo um caráter complexo, avaliado através de uma escala subjetiva de notas visuais, pode ser útil no processo de avaliação do desempenho agronômico (principalmente da produtividade de grãos).

As correlações entre NDM/VA foram 0,54 em Anhembi e 0,24 em Areão. O resultado obtido em Anhembi está de acordo com outros autores (Farias Neto, 1995; Gomes, 1995; Pacova, 1992).

As estimativas de correlação ambiental, em geral, foram de menor magnitude, no entanto, os valores para APM/VA nos dois locais e para APM/PG e VA/PG em Areão foram positivos e de média magnitude. Resultados semelhantes foram verificados na geração $F_{6}$ e sugerem que a ação do ambiente atuou no mesmo sentido na expressão desses caracteres (Gomes, 1995).

\subsection{Capacidade média de combinação $\left(\mathrm{cmc}_{\mathbf{i}}\right)$}

As estimativas de capacidade média de combinação $\left(\mathrm{cmc}_{\mathrm{i}}\right)$ dos parentais para NDM, APM, VA e PG, com base no desempenho de suas linhagens $F_{7: 6}$ e $F_{8: 6}$, são apresentadas na Tabela 23. Constam também nesta Tabela, os valores de $g_{i}$ obtidos na geração $F_{2}$ por Nass (1989), em cultivo de outono/inverno. 
Observa-se que para NDM, os parentais FT-Cristalina, EMGOPA-301, IAC-6 e IAC-9 apresentaram valores positivos de cmci (aumentar o ciclo); os dois primeiros apresentaram valores superiores e IAC-6 e IAC-9 apresentaram cmc $_{\mathbf{i}}$ maior em Areão $(<\mathbf{A l})$; os demais parentais apresentaram valores de pequena magnitude, com valores negativos de cmci $_{i}$ (reduzir o ciclo) para IAC-5 e IAC-11 na geração $F_{7: 6} e$ IAC-5, IAC-8 e SS-1 na geração $F_{8: 6}$. Nass (1989) estudando a Capacidade Geral de Combinação $\left(\mathrm{g}_{\mathrm{i}}\right)$, geração $\mathrm{F}_{2}$, encontrou estimativas positivas para NDM para os parentais FT-Cristalina, EMGOPA-301, IAC-6 e IAC-9. Esta concordância de resultados indica que a avaliação do NDM em gerações precoces é segura.

Para APM, os parentais que apresentaram $\mathrm{cmc}_{\mathbf{i}}$ positiva (aumentar a altura) foram: IAC-6 nos dois anos agrícolas e EMGOPA-301 em 1993-1994 ( $\left.\mathrm{F}_{8: 6}\right)$. Apresentaram $\mathrm{cmc}_{i}$ negativa (reduzir a altura): IAC-4 nos dois anos agrícolas; IAC-8 e SS-1 em 1993-1994, no qual SS-1 apresentou valores inferiores em Anhembi (>Al). Nass (1989) em cultivo de outono/inverno, geração $F_{2}$, encontrou maiores estimativas de $g_{i}$ para EMGOPA-301 e IAC-5; já os parentais IAC-4 e Santa Rosa apresentaram os menores valores.

Para VA, a maioria dos parentais apresentou pequenos valores de $\mathrm{cmc}_{\mathrm{i}}$, provavelmente devido à subjetividade do caráter, cujas notas dependem de uma série de atributos. Entretanto, destacaram-se com cmc $_{i}$ positiva (aumentar VA) os parentais IAC-6 e IAC-8 em 1992-1993 (F F:6 ); FT-Cristalina e EMGOPA-301 em 1993-1994 (F:6) em Anhembi. Com cmci negativa (reduzir VA) destacaram-se IAC-4 e IAC-5, no entanto, IAC-4 apresentou $\mathrm{cmc}_{\mathrm{i}}$ positiva em Areão em 1993-1994. Na geração $\mathrm{F}_{2}$ (Nass, 1989), somente IAC-4 e Santa Rosa apresentaram estimativas de $\mathrm{g}_{\mathrm{i}}$ negativas para VA, enquanto que FT-Cristalina, EMGOPA-301, IAC-5, IAC-6 e IAC-8, destacaram-se entre os que apresentaram $g_{i}$ positivo. 
$\mathrm{Na}$ cmc $_{i}$ para PG, destacaram-se os parentais FT-Cristalina com valores positivos de $\mathrm{cmc}_{\mathbf{i}}$ (aumentar PG) e de mesma magnitude nos dois ambientes; EMGOPA-301 com $\mathrm{cmc}_{i}$ positiva e superior em Anhembi; IAC-5 com valores de cmc $_{i}$ negativos; os demais apresentaram valores de cmc $_{i}$ de pequena magnitude. Na geração $F_{2}$, em cultivo de outono/inverno (Nass, 1989) os parentais FT-Cristalina, IAC-11 e SS-1 destacaram-se com maiores estimativas de $g_{i}$, enquanto que IAC-4 e Santa Rosa apresentaram estimativas negativas; EMGOPA-301, IAC-8 e IAC-9 apresentaram pequenos valores de $g_{i}$.

FT-Cristalina contribuiu para aumentar NDM e PG, enquanto que EMGOPA-301 e IAC-6 para aumentar NDM, APM e PG na maioria dos experimentos, confirmando a tendência de associação entre os três caracteres. IAC-5 contribuiu para aumentar APM e para reduzir NDM em todos os experimentos, comportamento este também observado por Nass (1989) na geração $F_{2}$ em cultivo de outono/inverno; desta forma, o parental IAC-5 contribui simultaneamente para precocidade e para maior porte; este fato está relacionado provavelmente com $o$ hábito de crescimento indeterminado.

As estimativas de correlação de Spearman entre os valores de $\mathrm{g}_{\mathrm{i}}\left(\mathrm{F}_{2}\right)$ e $\mathrm{cmc}_{\mathrm{i}}\left(\mathrm{F}_{7: 6}\right.$ e $\left.\mathrm{F}_{8: 6}\right)$ dos parentais para os caracteres NDM, APM, VA e PG constam da Tabela 24.

As estimativas de correlação obtidas entre $g_{i}$ e $\mathrm{cmc}_{i}$ foram em sua maioria de pequena magnitude, mostrando que o potencial dos parentais medidos em $F_{2}$ não correspondeu ao medido em gerações avançadas. Isto pode ter ocorrido devido à diferença de época de avaliação destas gerações, outono/inverno para $F_{2}$ e verão para $F_{7: 6}$ e $F_{8: 6}$. No entanto, para os parentais que se destacaram para os valores de $\mathrm{g}_{\mathrm{i}}$ e $\mathrm{cmc}_{i}$, de uma maneira geral, apresentaram concordância quanto a magnitude dos valores. 
As correlações entre os valores de $\mathrm{cmc}_{\mathrm{i}}$ obtidos em Anhembi e Areão no mesmo ano agrícola, ou seja, correlações $2 / 3,4 / 5$ e $6 / 7$, para NDM, APM e PG foram em sua maioria significativas, mostrando que houve uma boa concordância dos valores de $\mathrm{cmc}_{i}$ obtidos em locais diferentes num mesmo ano agrícola.

As estimativas de correlação, entre os valores de $\mathrm{cmc}_{\mathrm{i}}$ obtidos nas gerações $F_{7: 6}$ e $F_{8: 6}$, foram em sua maioria não significativas, mostrando que a seleção e as condições ambientais diferentes mudaram o comportamento de alguns parentais quanto a $\mathrm{cmc}_{\mathrm{i}}$, principalmente para APM e VA. Para NDM e PG as correlações entre $F_{7: 6}$ e as QLEs foram em sua maioria significativas.

\subsection{Ganho para produtividade de grãos}

O ganho (\%) realizado para produtividade de grãos por cruzamento e para cada parental, baseado no desempenho das suas linhagens $F_{8: 6}$, selecionadas na geração $F_{7: 6}$, é apresentado na Tabela 25 . Como houve diferenças de produtividade entre os anos, houve necessidade, de neutralizar este efeito para o cálculo do ganho com a seleção.

Os ganhos nos experimentos com as QLEs oscilaram de: 29,84\% (IAC-5 x IAC-6) a 97,84\% (Santa Rosa x SS-1) em Anhembi, com média de 27,73\%; $-43,07 \%$ (FT-Cristalina $x$ SS-1) a 102,68\% (FTCristalina x EMGOPA-301) em Areão, com média de 20,54\%. Nos experimentos com as QLPs oscilaram de: $-22,78 \%$ (IAC-5 x Santa Rosa) a 221,47\% (EMGOPA-301 x IAC-5) em Anhembi, com média de 22,60\%; $31,96 \%$ (EMGOPA-301 x IAC-6) a 77,94\% (IAC-5 x IAC-8) em Areão, com média de $17,03 \%$. Na média dos locais os ganhos variaram de: - 
25,75\% (FT-Cristalina x SS-1) a 81,47\% (FT-Cristalina x EMGOPA-301), no experimento com as QLEs, com média de $24,14 \%$; $-15,80 \%$ (IAC-6 $x$ IAC-11) a 148,40\% (EMGOPA-301 x IAC-5) para as QLPs, com média de $19,81 \%$.

Observa-se que os parentais que proporcionaram maiores ganhos médios para produtividade de grãos foram: FT-Cristalina, EMGOPA-301, IAC-4 e Santa Rosa no experimento com as QLEs; IAC-5, IAC-8 e Santa Rosa no experimento com as QLPs.

Os ganhos foram bem diferentes entre os dois locais, em $60 \%$ dos cruzamentos Anhembi apresentou mais cruzamentos com ganhos superiores que Areão. No grupo das QLEs e QLPs 20\% e 10\% dos cruzamentos superaram $50 \%$ de ganho. Os cruzamentos que tem como um dos parentais FT-Cristalina, EMGOPA-301 e SS-1 apresentaram em sua maioria, ganhos superiores em Anhembi (>Al). De uma maneira geral, os ganhos foram superiores em Anhembi e para o grupo das QLEs. Isto pode ser explicado pelo melhor desempenho das linhagens para produção de grãos em Anhembi, principalmente após a melhoria do ambiente com a calagem. As QLEs também se mostraram responsivas à semeadura mais cedo, a qual possibilitou um bom desenvolvimento e conseqüentemente produtividade de grãos semelhante as QLPs na safra 1993-1994.

Os ganhos obtidos com a seleção podem ser considerados relativamente altos para a maioria dos cruzamentos. No entanto, observase que alguns cruzamentos não apresentaram ganhos com a seleção em um ou mais experimentos, estes em sua maioria apresentaram coeficientes de herdabilidade pequenos ou negativos na geração $F_{7: 6}$, devido à pequena variabilidade, a qual resultou em ganhos negativos com a seleção. 


\subsection{Associações entre ambientes}

As estimativas das correlações fenotípicas de Spearman $\left(r_{s}\right)$ entre os ambientes (anos e locais), baseado no comportamento de 180 linhagens de 45 cruzamentos dialélicos, para os caracteres NDM, APM, VA e PG em cada experimento (QLEs e QLPs) as quais representam a correlação entre anos (A e B), locais (C e D) e anos x locais (E e F) constam da Tabela 26.

Para estudo da correlação entre anos (A e B) fixou-se o local; ressaltando que além do efeito do ano em si houve efeito do estresse de alumínio em Anhembi (1992-1993) e efeito de veranico em Areão (19921993). Comparando-se os valores de correlação obtidos em Anhembi (A) e Areão (B) observa-se uma superioridade dos valores obtidos em Anhembi. Isto sugere que o efeito do estresse de alumínio sobre o comportamento das linhagens foi menos pronunciado do que o efeito do veranico.

Para estudo da associação entre locais (C e D) fixou-se o ano; além do efeito de locais em si ressalta-se que em 1992-1993 os locais apresentaram condições contrastantes para saturação de Al nas camadas arável e subsuperficial e ocorreu veranico em Areão; em 1993-1994 os locais apresentaram solos com condição química semelhante e houve maior representatividade, devido ao uso de repetição e parcela maior. Comparando-se os valores de correlação obtidos em 1992-1993 (C) e 1993-1994 (D), observa-se uma superioridade dos obtidos em 1993-1994. Isto indica que quando os solos são corrigidos e a distribuição de chuva é normal o comportamento dos genótipos é mais estável.

As correlações $\mathrm{E}$ e $\mathrm{F}$ envolvem o efeito de ano e locais, razão pela qual apresentaram valores inferiores às demais. Os valores de $r_{s}$ obtidos entre os ambientes podem ser classificados como médios para 
NDM e APM (próximos de 0,50); baixos para VA e PG (entre 0,20 e 0,30) em Anhembi (>Al); muito baixos para VA e PG $(<0,12)$ em Areão (<Al). Provavelmente, estes baixos valores foram, devidos à ocorrência do veranico em Areão na safra 1992-1993, o qual prejudicou o desempenho principalmente das linhagens mais tardias.

Valores maiores de correlação foram obtidos para NDM e APM, mostrando que estes caracteres são menos influenciados pelo ambiente, principalmente quando as diferenças entre ambientes são minimizadas (correlação D).

O caráter PG é mais influenciado pelo ambiente, como pode ser observado pelos menores valores de correlação, inclusive apresentando valores não significativos quando os ambientes se apresentam contrastantes como no caso das correlações B (ano + veranico) e C (local + alumínio + veranico). Ainda para PG, as QLPs mostraram-se mais instáveis (menores valores de $r_{s}$ ) frente às variações ambientais do que as QLEs.

O comportamento dos genótipos em diferentes locais é mais previsível (maiores valores de $r_{s}$ ) quando, diferenças entre locais são minimizadas (correlação D) e condições climatológicas entre os anos são semelhantes (correlação A).

Os valores de correlações obtidos estão próximos dos valores encontrados por outros autores: Gomes (1995) estimou a correlação entre linhagens $\mathrm{F}_{6}$ (plantas individuais) e $\mathrm{F}_{7: 6}$ (em fileiras) para 44 cruzamentos dialélicos, obtendo valores médios de: 0,50 para NDM; 0,27 para APM e VA; -0,07 para PG. Bartley \& Weber (1952) obteve valores de: 0,76 para $\mathrm{NDM} ; 0,73$ para $\mathrm{APM} ; 0,34$ para $\mathrm{PG}$, entre $\mathrm{F}_{3}$ (plantas individuais) e suas progênies $\mathrm{F}_{4}$ (em fileira). Weiss et al. (1947) estimaram a correlação entre progênies $F_{3}$ e $F_{4}$, encontrando valores de: 0,50 para NDM; 0,41 para APM; -0,18 para PG. Valores negativos para PG segundo os autores foram devido à extrema diferença entre as condições climáticas nos dois anos de 
cultivo. Estes resultados mostram que a predição do desempenho de genótipos para caracteres de baixa herdabilidade, como por exemplo PG, não é confiável quando as condições climáticas entre as gerações são muito diferentes.

Assim, para maior eficiência de programas de melhoramento, a seleção deve ser realizada com base na média dos ambientes nãocontroláveis (anos agrícolas); já para os ambientes controláveis (épocas de cultivo e locais), maior progresso será alcançado com a seleção praticada no ambiente em que os novos cultivares serão utilizados.

\subsection{Considerações finais}

As condições contrastantes para a saturação de alumínio influenciaram diferentemente os caracteres como pode ser notado pelas médias dos parentais e linhagens na geração $F_{7: 6}$ : NDM apresentou mesmo valor nas duas condições; APM e VA apresentaram maiores médias em Areão (<Al); PG apresentou maiores médias em Anhembi (>Al).

De uma maneira geral, o efeito da saturação de alumínio sobre as estimativas de herdabilidade mostrou-se dependente do caráter considerado: para APM e PG as estimativas ao nível de linhagem $F_{7: 6}$ foram semelhantes nas duas condições e ao nível de cruzamento metade apresentou herdabilidade superior em Anhembi; para NDM ao nível de linhagem maiores valores foram obtidos em Areão e ao nível de cruzamento $75 \%$ apresenta maior $\mathrm{h}^{2}$ em Areão, enquanto o inverso ocorreu para VA. As estimativas obtidas com base nas linhagens $F_{8: 6}$ mostraram maiores valores em Anhembi, para todos os caracteres, sendo que PG e APM apresentaram valores mais próximos entre os dois locais. 
Evidenciou-se, pela magnitude dos coeficientes de correlações entre caracteres, a sua dependência das condições ambientais, principalmente as climáticas. A associação positiva e moderada entre PG, NDM e APM, em soja, dificulta a obtenção de linhagens produtivas, precoces e de porte médio (ideótipo).

Os parentais que se destacaram para $P G$ apresentaram $\mathbf{c m c}_{\mathbf{i}}$ dependente da saturação de alumínio: FT-Cristalina apresentou $\mathrm{cmc}_{i}$ de mesma magnitude nos dois ambientes; já EMGOPA-301 apresentou $\mathrm{cmc}_{\mathbf{i}}$ superior em Anhembi (>Al).

Os ganhos obtidos com a seleção podem ser considerados relativamente altos para a maioria dos cruzamentos, no entanto, observa-se ganhos diferentes entre os locais em $60 \%$ dos cruzamentos; maiores ganhos em Anhembi e no grupo das QLEs. 


\section{CONCLUSÕES}

a) Para capacidade média de combinação $\left(\mathrm{cmc}_{\mathrm{i}}\right)$ aumentando a expressão dos caracteres nos quatro ambientes, destacaram-se os parentais: FT-Cristalina para NDM e PG; EMGOPA-301 para NDM e APM; IAC-6 para APM. O parental EMGOPA-301 também foi superior para $\mathbf{c m c}_{\mathbf{i}}$ aumentando PG em Anhembi (>Al) nos dois anos agrícolas. Para maior precocidade $\left(\mathrm{cmc}_{i}\right.$ diminuíndo NDM) houve destaque para os parentais IAC-5, IAC-8, IAC-11 e SS-1 nos dois anos agrícolas.

b) Com base nas médias de PG destacaram-se os cruzamentos: FT-Cristalina $x$ EMGOPA-301, FT-Cristalina x IAC-9, EMGOPA-301 x IAC-6, EMGOPA-301 x IAC-8, EMGOPA-301 x Santa Rosa em Anhembi; FT-Cristalina $x$ IAC-9 e FT-Cristalina $x$ IAC-1 1 em Areão $(<A l)$.

c) Alguns cruzamentos ainda apresentaram elevada variabilidade mesmo após a seleção, o que viabiliza a obtenção de ganhos futuros, na seleção de linhagens dentro de cruzamento.

d) O efeito da saturação de alumínio sobre a herdabilidade mostrou-se dependente do caráter; NDM e APM apresentaram $\mathrm{h}^{2}$ superior a VA e PG.

e) As correlações genotípicas entre os caracteres NDM, APM, VA e PG foram positivas e superiores às fenotípicas; destaca-se a correlação genotípica VA/PG indicando que VA pode ser usado para seleção visando o aumento de $\mathrm{PG}$, principalmente nas fases iniciais. 


\section{REFERÊNCIAS BIBLIOGRÁFICAS}

ADAMS, F.; LUND, Z.F. Effect of chemical activity of soil solution aluminum of cotton root penetration of acid subsoils. Soil Science, v.101, n.3, p.193-198, mar. 1966.

AGRIANUAL. FNP Consultoria \& Comércio. p.387-388, 1997.

ALlARD, R.W. Princípios do melhoramento genético das plantas. São Paulo: Edgard Blucher, 1971. $381 \mathrm{p}$.

ALVA, A.K.; EDWARDS, D.G.; ASHER, C.J. Effects of acid soil infertility factors on mineral composition of soybean and cowpea tops. Journal of Plant Nutrition, v. 14, n.2, p.187-203, 1991.

ALVA, A.K.; EDWARDS, D.G.; ASHER, C.J.; BLAMEY, F.P.C. Effects of phosphorus/aluminum molar ratio and calcium concentration on plant response to aluminum toxicity. Soil Science Society of America Proceedings, v.50, p.133-137, 1986.

ALVA, A.K.; EDWARDS, D.G.; CARROLL, B.J; ASHER, C.J; GRESSHOFF, P.M. Nodulation and early growth of soybean mutants with increased nodulation capacity under acid soil infertility factors. Agronomy Journal, v.80, p.836-841, Sep./Oct. 1988.

ANAND, S.C.; TORRIE, J.H. Heritability of yield and other traits and interrelationships among traits in $F_{3}$ and $F_{4}$ generation of three soybean crosses. Crop Science, v.3, n.6, p.508-511, Nov./Dec. 1963.

ARANTES, N.E.; MIRANDA, M.A.C. Melhoramento genético e cultivares de soja para os cerrados da Região Sudeste do Brasil. In: ARANTES, N.E.; SOUZA, P.I.M. Cultura da soja nos cerrados. Piracicaba: Potafos, 1993. p.209-227.

ARMIGER, W.H.; FOY, C.D.; FLEMING, A.L.; CALDWELL, B.E. Differential tolerance of soybean varieties to an acid soil high in exchangeable aluminum. Agronomy Journal, v.60, p.67-70, Jan./Feb. 1968. 
BATAGLIA, O.C.; MIRANDA, M.A.C.; MASCARENHAS, H.A.A. Caracterização da toxicidade por alumínio em dois cultivares de soja com diferentes graus de tolerância à queima de folhas. Revista Brasileira Ciência do Solo, v.5, p.161-166, 1981.

BAYS, I.A. Heritability and association of several quantitative characters in segregating populations of soybeans (Glycine $\max$ (L.) Merril). Mississipi, 1975. 91p. Thesis (Ph.D. - Facult of Mississippi State University).

BEARZOTI, E. Comparação entre métodos estatísticos na avaliação de clones de batata em um programa de melhoramento. Lavras, 1994. 128p. Dissertação (Mestrado) - Escola Superior de Agricultura de Lavras.

BISOGNIN, D.A.; VERNETTI, F.J.; GASTAL, M.F.C.; ZONTZ, E.P. Competição intergenotípica em soja. Pesquisa Agropecuária Brasileira, v.30, n.7, p.939-946, jul. 1995.

BOLlard, E.G.; BUtLer, G.W. Mineral nutrient of plants. Annual Review of Plant Physiology, v.17, p.77-112, 1966.

BONATO, E.R. Herança do tempo para o florescimento e para a maturidade em variantes naturais de soja (Glycine max (L.) Merrill). Piracicaba, 1989. 166p. Tese (Doutorado) - Escola Superior de Agricultura "Luiz de Queiroz"/USP.

BRIM, C.A. Quantitative genetics and breeding. In: BERNARD, R.L.; WEISS, M.G. (Ed.) Soybeans: improvement production and uses. Madison: American Society of Agronomy, 1973. cap.5, p.155-185.

BRIM, C.A.; COCKERHAM, C.C. Inheritance of quantitative character in soybean. Crop Science, v.1, n.3, p.187-190, May/June, 1961.

BYTH, D.E.; WEBER, C.R.; CALDWELL, B.E. Correlated truncation selection for yield in soybean. Crop Science, v.9, n.6, p.699-702, Nov./Dec. 1969.

CAMARGO, C.E.O. Wheat breeding $\mathrm{I}$ : inheritance of tolerance to aluminium toxicity in wheat cultivars. Bragantia, v.40, p.35-45, 1981.

CAMARGO, C.E.O.; OLIVEIRA, O.F. Tolerance of wheat cultivars to different levels of aluminum toxicity. Bragantia, v.40, p.21-31, 1981 .

CAMBRAIA, J.; LEMOS FILHO, J.P.; ESTEVÃO, M.M.; OLIVA, M.A. Efeito do alumínio sobre os teores de $\mathrm{Mg}, \mathrm{Fe}, \mathrm{Mn}$ e $\mathrm{Cu}$ em sorgo. Revista Ceres, v.30, n.167, p. 45-54, jan./fev. 1983. 
CAMPBELL, K.A.G.; CARTER JÚNIOR, T.E. Aluminum tolerance in soybean. I. Genotypic correlation and repeatability of solution culture and greenhouse screening methods. Crop Science, v.30, p.1049-1054, 1990 .

CAVALLI, L.L. An analysis of linkage in quantitative inheritance. In: REEVE, E.C.R.; WADDINGTON, C.H. (Ed.) Quantitative inheritance. London: IIMSO, 1952. p. 135-144.

CLARK, R.B.; BROWN, J.C. Differential phosphorus uptake by phosphorus - stressed corn inbreds. Crop Science, v. 14, n.4, p.505, July/Aug. 1974.

CLARKSON, D.T. The effect of aluminum and some other trivalent metal cations on cell division in the root apices of Allium cepa. Annals of Botany, v.29, n.3, p. 309-315, Sept. 1965.

CLARKSON, D.T. Metabolic aspects of aluminum toxicity and some possible mechanisms for resistence. In: RORISON, I.H. Ecological aspects for the mineral nutrition of plants. Oxford: Blackwell Scientific Publications, 1969. p.381-397.

CLINE, G.R.; KAUL, K. Inhibitory effects of acidified soil on the soybean/Bradyrhizobium symbiosis. Plant and Soil, v.127, p.243-249, 1990.

COCHRAN, W.G.; COX, G. M. Experimental designs. 2.ed. New York: John Wiley \& Sons, 1966. 617p.

COCKERHAM, C.C. Estimation of genetic variances. In: HANSON, W.D.; ROBINSON, H.F., (Ed.) Statistical genetics an plant breeding. Washington: National Academy of Sciences National Research Council, 1963. p.53-94.

COMSTOCK, R.E.; ROBINSON, H.F. The components of genetic variance in populations of biparental progenies and their use in estimating the average degree of dominance. Biometrics, v.4, n.4, p.254-266, Dec. 1948 .

CRUZ, C.D.; REGAZZI, A.J. Modelos biométricos aplicados ao melhoramento genético. Viçosa: Impressa Universitária da UFV, 1994. 390p.

DUDLEY, J.W.; MOLL, R.H. Interpretation and use of estimates of heritability and genetic variances in plant breeding. Crop Science, v.9, n.3, p.257-262, May/June 1969.

EMPRESA BRASILEIRA DE PESQUISA AGROPECUÁRIA, Relatório técnico anual 1975-1976, Planaltina: EMBRAPA/CPAC, 1976. 150p. 
FALCONER, D.S. Introdução à genética quantitativa. Viçosa: Impressa Universitária da UFV, 1987. 279p.

FARIAS NETO, J.T. Comportamento e variabilidade de genótipos de soja [Glycine max (L.) Merrill] em cultivos de verão e inverno. Piracicaba, 1987. 87p. Dissertação (M.S.) - Escola Superior de Agricultura "Luiz de Queiroz"/USP.

FARIAS NETO, J.T. Potencialidade de progênies $F_{4: 3}$ e $F_{5: 3}$ derivadas de cruzamentos em cadeia para produtividade de óleo em soja .Piracicaba, 1995. 153p. Tese (Doutorado) - Escola Superior de Agricultura "Luiz de Queiroz"/USP.

FEDERER, W.T. Augmented (or hoonuiaku) designs. Hawaiian Planters' Record, Aica, v.55, p.191-208, 1956.

FEDERER, W.T. Augmented designs with one way elimination of heterogeneity. Biometrics, v.17, n.3, p.447-473, Sep. 1961.

FEHR, W. R. Breeding methods for cultivar development. In: WILCOX, J. R., (Ed.) Soybeans: improvement, productions and uses. 2.ed. Madison, ASA/CSSA/ SSSA, 1987. p.249-293.

FEHR, N.R.; CAVINESS, C.E. Stages of soybean development. Ames: Iowa State University, 1977. 12p. (Special Report, 80).

FLEMING, A.L.; FOY, C.D. Root structure reflects differential aluminum tolerance in wheat varieties. Agronomy Journal, v.60, n.2, p. 171176, Mar./Apr. 1968.

FOY, C.D. Differential aluminum and manganese tolerances of plant species and varieties in acid soils. Ciência e Cultura, v.28, n.2, p.150-155, Feb. 1976.

FOY, C.D. Plant adaptation to acid, aluminum-toxic soils. Communications in Soil Science Plant Analysis, v.19, n.7/12, p.959$987,1988$.

FOY, C.D.; BROWN, J.C. Toxic factors in acid soils: II. differential aluminum tolerance of plant species. Soil Science Society of America Proceedings, v. 28 n.1, p.27-32, 1964.

FOY, C.D.; BURNS, G.R.; BROWN, J.L.; FLEMING, A.L. Differential aluminum tolerance of two wheat varieties associated with plant induced $\mathrm{pH}$ changes around their roots. Soil Science Society of America Proceedings, v.29, p.64-67, 1965.

FOY, C.D.; CARTER JUNIOR., T.E.; DUKE, J.A.; DEVINE, T.E. Correlation of shoot and root growth and its role in selecting for aluminum tolerance in soybean. Journal of Plant Nutrition, v.16, n.2, p.305-325, 1993. 
FOY, C.D.; CHANEY, R.L.; WHITE, M.C. The physiology of metal toxicity in plants. Annual Review of Plant Physiology, v.29, p.511$566,1978$.

FOY, C.D.; DUKE, J.A.; DEVINE, T.E. Tolerance of soybean germplasm to an acid tatum subsoil. Journal of Plant Nutrition, v.15, n.5, p.527-547, 1992 .

FOY, C.D.; FLEMING, A.L.; ARMIGER, W.H. Aluminum tolerance of soybean varieties in relation to calcium nutrition. Agronomy Journal, v.61, p.505-511, 1969.

FOY, C.D.; LAFEVER, H.N.; SCHWARTZ, J.W.; FLEMING, A.L. Aluminum tolerance of wheat cultivars related to region of origin. Agronomy Journal, v.66, p.751-758, 1974.

FREIRE FILHO, F.R. Análise genética de um dialelo entre genótipos precoces de soja (Glycine max (L.) Merril). Piracicaba, 1988. 224p. Tese (Doutorado) - Escola Superior de Agricultura "Luiz de Queiroz"/USP.

FREIRE, J.C. Resposta do milho a níveis de água e formas de aplicação em dois solos originalmente sob cerrado em casa-de-vegetação. Revista Brasileira de Ciência do Solo, v.8, n.3, p.305-308, set./dez. 1984 .

FREIRE, J.C. Efeitos de níveis de água e formas de aplicação de calcário na produção de matéria seca do feijoeiro (Phaseolus vulgaris L.) cultivado em dois solos de cerrado em casa-de-vegetação. Ciência e Prática, v.9, n.1, p.59-70, jun./jul. 1985.

GARCIA JÚNIOR, O.; SILVA, W.J. Análise genética da tolerância ao alumínio em milho. In: REUNIÃO ANUAL DA SOCIEDADE BRASILEIRA PARA O PROGRESSO DA CIÊNCIA, 31, São Paulo, 1979. Resumos. São Paulo, SBPC, 1979. p.585.

GOEDERT, W.J. Uso e manejo dos recursos naturais do cerrado: solo e clima. In: SIMPÓSIO SOBRE O CERRADO, USO E MANEJO, 5., Brasília, 1979. Brasília, Editerra, 1980. p.475-498.

GOLDMAN, I.L.; CARTER, T.E.; PATTERSON, R.P. A. detrimental interaction of subsoil aluminum and drought stress on the lef water status of soybeam. Agronomy Journal, v.81, p.461-463, May/June, 1989.

GOMES, R.L.F. Análise genética de progênies $F_{6}$ e $F_{7: 6}$ de soja obtidas de cruzamentos dialélicos. Piracicaba, 1995. 140p. Tese (Doutorado) Escola Superior de Agricultura "Luiz de Queiroz"/USP. 
GRIFFING, B. Concept of general and specific combining ability in relation do diallel crossing systems. Australian Journal Biological Science, v.9, p.463-493, 1956.

GUAZZELLI, R.I. Competição intergenotípica em feijão (Phaseolus vulgaris L.) estimação da capacidade competitiva. Piracicaba, 1975. 115 p. Dissertação (M.S.) - Escola Superior de Agricultura "Luiz de Queiroz"/USP.

HANSON, W.D. Root characteristics associated with divergent selection for seedling aluminum tolerance in soybean. Crop Science, v.31, p.125-129, Jan./Feb. 1991.

HANSON, W.D.; KAMPRATH, E.J. Selection for aluminum tolerance in soybeans based on seedling-root growth. Agronomy Journal, v.71, p.581-586, July/Aug. 1979.

HANSON, W.D.; WEBER, C.R. Analysis of genetic variability from generations of plant-progeny lines in soybeans. Crop Science, v.2, n.1, p.63-67, Jan./Feb. 1962.

HANSON, W.D.; PROBST, A.H.; CALDWELL, B.E. Evaluation of a population of soybean genotypes with implications for improving selfpollinated crops. Crop Science, v.7, n.2, p.99-103, Mar./Apr. 1967.

HARTWELL, B.L.; PEMBER, F.R. The presence of aluminum as a reason for the difference in the effect of so-called acid soil on barley and rye. Soil Science, v.6, n.4, p.259-280, 1918.

HIROMOTO, D.M.; VELLO, N.A. The genetic base of Brazilian soybean (Glycine max (L.) Merrill) cultivars. Revista Brasileira de Genética, v.9, n.2, p.295-306, 1986.

HORST, W.J.; ASHER, C.J.; CAKMAK, I.; SZULKIEWICZ, P.; WISSEMEIER, A.H. Short-term responses of soybean roots to aluminium. Journal Plant Physiology, v.140, p.174-178, 1992.

HORST, W.J,; WAGNER, A.; MARSCHNER. Effect of aluminium on root growth, cell-division rate and mineral element contents in roots of Vigna unguiculata genotypes. Zeitsdriftfür Pflanzernärung und Bodenkunde, v.109, p.95-103, 1983.

HORTON, B.D.; EDWARDS, J.H. Diffusive resistance rates and stomatal aperatures of peach seedlings as affected by Al concentrations. Horticultural Science, v.11, p.591-593, 1976.

HYMOWITZ, T. On the domestication of soybean. Economic Botany, v.24, n.4, p.408-421, Oct./Dec. 1970. 
INSTITUTO BRASILEIRO DE GEOGRAFIA E ESTATÍSTICA. Levantamento Sistemático da Produção Agrícola. Rio de Janeiro: IBGE, 1992. p. 54-55.

JOHNSON, H.W.; BERNARD, R.L. Soybean genetics and breeding. In: NORMAM, A.G. (Ed.) The soybean: genetics, breeding, physiology, nutrition, management. New York: Academic Press, 1963. p.1-73.

JOHNSON, H.W.; ROBINSON, H.F.; COMSTOCK, R.E. Estimates of genetic and environmental variability in soybeans. Agronomy Journal, v.47, n.7, p.314-318, July, 1955a.

JOHNSON, H.W.; ROBINSON, H.F.; COMSTOCK, R.E. Genotypic and phenotypic correlations in soybeans and their implications in seletion. Agronomy Journal, v.47, n.10, p.477-483, Oct. 1955b.

KAMPRATH, E.J. Exchangeable aluminum as a criterion for liming leached mineral soils. Soil Science Society of America Proceedings, v.34, p.252-254, 1970.

KEMPTHORNE, $O$. An introduction to genetics statistics. 3.ed. Ames: Iowa State University Press, 1973. 545p.

KENWORTHY, W.J.; BRIM, C.A. Recurrent selection for yield in soybeans. Soybean Gennetics Newsletter, v.4, p.44-46, 1977.

KERRIDGE, P.C.; KRONSTAD, W.E. Evidence of genetic resistance to aluminum toxicity in wheat (Triticum aestivum vill., host). Agronomy Journal, v.60, n.6, p.710-711, Nov./Dec. 1968.

KIIHL, R.A.S.; ALMEIDA, L.A. Situação atual e perspectivas do melhoramento genético da soja no Brasil. In: SIMPOSIO SOBRE A CULTURA E PRODUTIVIDADE DA SOJA, 1., Piracicaba, 1991. Anais; editado por G. M. S. Câmara; J. Marcos Filho; E. A. M. Oliveira. Piracicaba, FEALQ, 1992. p.38-40.

KIIHL, R.A.S.; GARCIA, A. The use of the long-juvenile trait in breeding soybean cultivars. In: WORLD SOYBEAN RESEARCH CONFERENCE, 4., Buenos Aires, 1989, Proceedings. Buenos Aires, SRL, 1989. v.2, p.994-1000.

KLIMASHEVSKII, E.L.; DEDOV, V.M. Localization of the mechanisms of growth inhibiting action of $\mathrm{Al}^{+3}$ in elongation cell walls. Soviet Plant Physiology, v.22, n.6, p.1040-1047, May 1975.

KLOTZ, F.; HORST, W.J. Effect of ammonium-and nitrate-nitrogen nutrition on aluminium tolerance of soybean (Glycine max L.). Plant and Soil, v. 111, p.59-65, 1988. 
KWON, S.H.; TORRIE, J.H. Heritability of and interrelatioships among traits of two soybean populations. Crop Science, v.4, p.196-198, 1964.

LAZOF, D.B.; RINCÓN, M.; RUFTY, T.W.; MACKOWN, C.T.; CARTER, T.E. Aluminum accumulation and associated effects on $\mathrm{NO}_{3}^{-}$influx in roots of two soybean genotypes differing in Al tolerance. Plant and Soil, v.164, p.291-297, 1994.

LEE, E.H.; FOY, C.D. Aluminum tolerance of two snapbean by highperformance liquid chromatography. Journal of Plant Nutrition, v.9, n.12, p.1481-1498, 1986.

LEFFEL, R.C.; HANSON, W.D. Early generation testing of diallel crosses of soybeans. Crop Science, v.1, p.169-174, May/June 1961.

LEFFEL, R.C.; WEISS, M.G. Analysis of diallel crosses among ten varieties of soybeans. Agronomy Journal, v.50, n.9, p.528-534, Sep. 1958.

LOPES, A.S. Solos sob cerrado: características, propriedades e manejo. Piracicaba, Potafos, 1983. 162p.

MAGISTAD, O.C. The aluminum content of the soil solution and its relation to soil reaction and plant growth. Soil Science, v.20, n.3, p.181-226, 1925 .

MALAVOLTA, E.; SARRUGE, J.R.; BITTENCOURT, V.C. Toxidez de alumínio e de manganês. In: SIMPÓSIO SOBRE O CERRADO; bases para utilização agropecuária, 4., Brasília, 1976. Belo Horizonte: Itatiaia, 1977, p.275-301.

MASCARENHAS, H.A.A.; BRAGA, N.R.; BULISANI, E.A; FEITOSA, C.T.; HIROCE, R.; BATAGLIA, O.C. Efeito do corretivo sobre soja cultivada em solo de cerrado contendo $\mathrm{Al}$ e $\mathrm{Mn}$. IN: SEMINÁRIO NACIONAL DE PESQUISA DE SOJA, 2., Brasília, 1981. Anais. Londrina, EMBRAPA-CNPSo, 1982. v.2, p.567-573.

MATHER, K.; JINKS, J.L. Biometrical genetics. 3.ed. London: Chapman and Hall, 1982. 396p.

MAURO, A.O; SEDIYAMA, T.; SEDIYAMA, C.S. Estimativas de parâmetros genéticos em diferentes tipos de parcelas experimentais em soja. Pesquisa Agropecuária Brasileira, v.30, n.5, p.667-672, maio, 1995.

McLEAN, F.T.; GILBERT, B.E. The relative aluminum tolerance of crop plants. Soil Science, v.24, n.3, p.163-176, 1927. 
MELO, B. de. Tolerância da soja [Glycine $\max$ (L.) Merrill] à saturação de alumínio, em condições de casa-de-vegetação, par solo sob cerrado. Lavras, ESAL, 1980. 56p. Dissertação (M.S.) ESAL - Escola Superior de Agricultura de Lavras.

MESONES, W.G. de la P. Comportamento de cultivares de soja [Glycine max (L.) Merrill] sob três métodos de recomendação de calcário. Lavras, 1991. 88p. (Mestrado - Escola Superior de Agricultura de Lavras)

MIRANDA, L.T. de; FURLANI, P.R.; MIRANDA, L.E.C. de; SAWAZAKI, E. Genetics of environmental resistence and super genes latent aluminum tolerance. Maize Genetics Cooperation Newsletter, v. 58, p. $46-48,1984$.

MIRANDA, M.A.C.; MASCARENHAS, H.A.A.; BULISANI, E.A.; VALADARES, J.M.A.S.; HIROCE, R.; Comportamento de dois cultivares de soja em função do manganês do solo. Bragantia, v.41, n. 14, p.135-143, jul. 1982 .

MIRANDA, M.A.C.; MASCARENHAS, H.A.A.; BATAGLIA, O.C.; BULISANI, E.A. Soja: queima das folhas como critério de seleção para resistência à acidez do solo. Bragantia, v.47, n.1, p.43-54, 1988.

MIRANDA, L.C.; MENOSSSO, O.G.; LANTMAN, A.F.; PALHANO, J.B.; KIIHL, R.A.S.; SILVA FILHO, P.M. da. Desenvolvimento de cultivares tolerantes ao complexo acidez e com alta capacidade de extração de fósforo do solo. In: EMBRAPA/Centro Nacional de Pesquisa de Soja. Resultados de pesquisa de soja 1989-1990. Londrina, 1993. p.244-252 (Documentos, 58).

MOLL, R.H.; STUBER, C.W. Quantitative genetics-empirical results releyant to plant breeding. Advances in Agronomy, v.26, p.277-313,

MOMENTÉ, V.G. Comparação entre diferentes tipos de famílias clonais para o melhoramento genético da batata (Solanum tuberosum L.). Lavras, 1994. 83p. Dissertação (Mestrado) - Escola Superior de Agricultura de Lavras.

MONTENEGRO, E.E. Estimativas de parâmetros genéticos, no verão e no inverno, em cruzamentos entre cultivares de soja (Glycine max (L.) Merril), divergentes quanto à juvenilidade. Viçosa, 1994. 97p. (Mestrado) - Universidade Federal de Viçosa.

MOOKHERJI, S.; FLOYD, M. The effect of aluminium on grouth of and nitrogen fixation in vegetable soybean germplasm. Plant and Soil, v.136, p.25-29, 1991. 
MOREIRA, R.M.P. Predição do comportamento de cruzamentos dialélicos de soja avaliados na geração $\mathrm{F}_{3}$ em cultivo de inverno. Piracicaba, 1992. 96p. (Mestrado) - Escola Superior de Agricultura "Luiz de Queiroz"/USP.

MOTA, F.S. da. Condições climáticas dos principais centros produtores mundiais. In: MIYASAKA, S.; MEDINA, J.C. A soja no Brasil. Campinas: ITAL, 1981. p.7-16.

MUNNS, R.P. Acid soil tolerance in legumes and rhizobia. Advances in Plant Nutrition, v.2, p.63-91, 1986.

MUZILLI, O.; SANTOS, D.; PALHANO, J.B.; MANETTI FILHO, J.; LANTMANN, A.F.; GARCIA, A.; CATANEO, A. Tolerância de cultivares de soja e de trigo a acidez do solo. Revista Brasileira Ciência Solo, v.2, p.34-40, 1978.

NASS, L.L. Potencialidade de genótipos de soja (Glycine max (L.) Merrill) para cultivo de inverno avaliada por cruzamentos dialélicos. Piracicaba, 1989. 112p. Dissertação (Mestrado) - Escola Superior de Agricultura "Luiz de Queiroz"/USP.

PACOVA, B.E.V. Análise genética de progênies segregantes de soja apropriada para o consumo humano. Piracicaba, 1992. 217p. Tese (Doutorado) - Escola Superior de Agricultura "Luiz de Queiroz"/USP.

PINHEIRO, J.B. Dialelo parcial entre parentais de soja resistentes e suscetíveis a insetos. Piracicaba, 1993. 143p. Tese (Mestrado) Escola Superior de Agricultura "Luiz de Queiroz"/USP.

PRADO, L.C. Perspectivas para o melhoramento de linhagens homozigóticas de soja, com ênfase em produção de grãos e teor de proteína. Piracicaba, 1994. 128p. Tese (Mestrado) - Escola Superior de Agricultura "Luiz de Queiroz"/USP.

RAIJ, B.van; CAMARGO, A.P.; MASCARENHAS, H.A.A.; HIROCE, R.; FEITOSA, C.T.; NERY, C.; LAUN, C.R.P. Efeito de níveis de calagem na produção de soja em solo de cerrado. Revista Brasileira Ciência Solo, v.1, p.28-31, 1977.

RAMALHO, M.A.P.; VENCOVSKY, R. Estimação dos componentes de variância genética em plantas autógamas. Ciência e Prática, v.2, n.2, p.117-140, jul./dez. 1978.

ROESSING, A.C.; GUEDES, L.C.A. Aspectos econômicos do complexo soja: sua participação na economia brasileira e evolução na Região do Brasil Central In: ARANTES, N.E.; SOUZA, P.I.M. Cultura da soja nos cerrados. Piracicaba: Potafos, 1993. p.1-69. 
ROSE, J.L.; BUTLER, D.G.; RYLEY, M.J. Yield improvement in soybeans using recurrent selection. Australian Journal Agricultural Research, v.43, n.1, p.135-144, Jan. 1992.

SAMRÃO, S.S.; DIDONET, A.D.; NEIVA, L.S.; GOI, S.R.; JACOB NETO, J.; MONTEIRO, P.M.F.O.; ROLIM, R.B. Influência da calagem e micronutrientes na nodulação da soja por Rhizobium japonicum em solos ácidos. Pesquisa Agropecuária Brasileira, v.21, n.3, p.237-244, mar. 1986.

SANTOS, C.A.F. Análise de trilha e estimativas de parâmetros genéticos em progênies $\mathrm{F}_{6}$ de um cruzamento de soja (Glycine max (L.) Merril). Viçosa, 1994. 71p. Tese (Mestrado) - Universidade Federal de Viçosa.

SAPRA, V.T.; MEBRAHTU, T.; MUGWIRA, L.M. Soybean germplasm and cultivar aluminum tolerance in nutrient solution and Bladen clay loam soil. Agronomy Journal, v.74, p.687-690, July/Aug. 1982.

SARTAIN, J.B.; KAMPRATH, E.J. Aluminum tolerance of soybean cultivars based on root elongation in solution culture compared with growth in acid soil. Agronomy Journal, v.70, p.17-20, Jan./Feb. 1978.

SCHWEITZER, L.E.; NYQUIST, W.E.; SANTINI, J.B.; KIMES, T.M. Soybean cultivar mixtures in a narrow-row non cultivable production system. Crop Science, v.26, p.1043-1046, 1986.

SEDIYAMA, T.; ALMEIDA, L.A. de; MIYASAKA, S.; KIIHL, R.A. de S. Genética e métodos de melhoramento. In: MIYASAKA, S.; MEDINA, J.C. A soja no Brasil. Campinas: ITAL, 1981. p.209-226.

SHIMOYA, A. Comportamento de genótipos de soja (Glycine max (L.) Merrill) nas gerações $F_{9}$ e $F_{10}$ selecionados pelo método do teste de geração precoce. Viçosa, 1990. 132p. Tese (Mestrado) Universidade Federal de Viçosa.

SILVA, A.R. Aplication of the plant genetic approach to wheat culture in Brazil. In: WRIGHT, M.J.; FERRARI, S.A. (Ed.). Plant adaptation to mineral stress in problem soils. Ithaca: Cornel University Press, 1976. p.223-231.

SILVA, R.G. da. Métodos de genética quantitativa aplicados ao melhoramento animal. Ribeirão Preto: SBG, 1982. $162 \mathrm{p}$.

SILVA, J.B.C.; NOVAIS, R.F.; SEDIYAMA, C.S. Comportamento de genótipos de soja em solo com alta saturação de alumínio. Pesquisa Agropecuária Brasileira, v.19, n.3, p.287-298, mar. 1984. 
SPEHAR, C.R. The genetics of aluminium tolerance in soya beans [Glycine $\max$ (L.) Merrill]. D.Phil. Cambridge, $1989.123 \mathrm{p}$., Thesis (Ph.D.) University of Cambridge, 1989.

SPEHAR, C.R. Screening soybean germplasm for aluminium tolerance using cluster analysis. Pesquisa Agropecuária Brasileira, v.29, n.1, p.113-122, jan. 1994a.

SPEHAR, C.R. Breeding soybeans to the low latitudes of Brazilian cerrados (savannahs). Pesquisa Agropecuária Brasileira, v.29, n.8, p.1167-1180, ago. 1994b.

SPEHAR, C.R. Field screening of soya bean [Glycine max (L.) Merrill] germplasm for aluminium tolerance by the use of augmented design. Euphytica, v.76, p. 203-213, 1994c.

SPEHAR, C.R. Impact of strategic genes in soybean on agricultural development in the Brazilian tropical savannahs. Field Crops Research, v.41, p.141-146, 1995.

SPEHAR, C.R.; GALWEY, N.W. Generation mean analysis of root growth under aluminium-stress hydroponics in the soybeans (Glycine max (L.) Merrill). Pesquisa Agropecuária Brasileira, v.30, n.7, p.963-970, jul. 1995.

SPEHAR, C.R.; MAKITA, M. Tolerância ao alumínio em plântulas de soja e sua utilização. Pesquisa Agropecuária Brasileira, v.29, n.12, p.1927-1932, dez. 1994.

St. MARTIN, S.K. Epistasis and soybean breeding. Soybean Genetics Newsletter, v.8, p.104-107, Apr. 1981.

St. MARTIN, S.K. The application of quantitative genetics theory to plant breeding problems. In: WORLD SOYBEAN RESEARCH CONFERENCE, 3., Ames, 1984. Proceeding. Boulder: Westview Press, 1985. p.311-317.

STAB, A.; HORST, W.J. Effect of aluminium on membrane properties of soybean (Glycine max) cells in suspension culture. Plant and Soil, v.171, p.113-118, 1995.

STEEL, R.G.D.; TORRIE, J.H. Principles and procedures of statistics. 2.ed. New York: McGraw-Hill Book Company, 1980. 633p.

SUMARNO; FEHR, W.R. Response to recurrent selection for yield in soybeans. Crop Science, Madison, v.22, n.2, p.295-299, Mar./Apr. 1982. 
TAKEDA, C.; SANTOS, J.B. dos; RAMALHO, M.A.P. Choice of parental lines for common bean (Phaseolus vulgaris L.) breeding. II. Reaction of cultivars of their segregant populations to variations in different environments. Revista Brasileira de Genética, v.14, n.2, p.455-465, 1991.

TAYLOR, R.W.; WILLIAMS, M.L.; SISTANI, K.R. $\mathrm{N}_{2}$ fixation by soybean-Bradyrhizobium combinations under acidity, low $\mathrm{P}$ and high Al stresses. Plant and Soil, v.131, p.293-300, 1991.

TISSELI JÚNIOR, $O$. Inheritance study of the long-juvenile characteristic in soybeans under long-and short-day conditions. Mississipi, 1981. 77p. Thesis (Ph.D.) - Mississipi State University.

TOLEDO, J.F.F.; KIIHL, R.A.S. Análise do modelo genético envolvido no controle de dias para florescimento em soja. Pesquisa Agropecuária Brasileira, v.17, n.4, p.623-631, abr. 1982a.

TOLEDO, J.F.F.; KIIHL, R.A.S. Métodos de análise dialélica do modelo genético em controle das características dias para floração e número de folhas trifoliadas em soja. Pesquisa Agropecuária Brasileira, v. 17, n.5, p.745-755, maio 1982 b.

TOLEDO, J.F.F.; ALMEIDA, L.A.; KIIHL, R.A.S.; MENOSSO, O.G. Ganho genético em soja no Estado do Paraná, via melhoramento. Pesquisa Agropecuária Brasileira, v. 25, n.1, p.89-94, jan. 1990.

VARGAS, M.A.T.; MENDES, I.C.; SUHET, A.R.; PERES, J.R.R. Fixação biológica do nitrogênio. In: ARANTES, N.E.; SOUZA, P.I.M. Cultura da soja nos cerrados. Piracicaba: Potafos, 1993. p.159-180.

VELLO, N.A. Efeitos da introdução de germoplasma exótico sobre a produtividade e relações com a base genética dos cultivares de soja (Glycine max (L.) Merrill). Piracicaba, 1985. 91 p. Tese (LivreDocência) - Escola Superior de Agricultura "Luiz de Queiroz"/USP.

VELLO, N.A. Ampliação da base genética do germoplasma e melhoramento da soja na ESALQ/USP. In: SIMPÓSIO SOBRE A CULTURA E PRODUTIVIDADE DA SOJA, 1., Piracicaba, 1991. Anais; editado por G. M. S. Câmara; J. Marcos Filho; E. A. M. Oliveira. Piracicaba, FEALQ, 1992. p.60-81.

VELLO, N.A.; FEHR, W.R.; BAHRENFUS, J.B. Genetic variability and agronomic performance of soybean populations developed from plant introductions. Crop Science, v.24, p.511-514, 1984.

VELlO, N.A.; HIROMOTO, D.M.; AZEVEDO FILHO, A.J.B.V. Coefficient of parentage and breeding of Brazilian soybean germplasm. Revista Brasileira de Genética, v. 11, n.3, p.679-697, Sep. 1988. 
VENCOVSKY, R. Herança quantitativa. In: PATERNIANI, E.; VIEGAS, G.P., (Ed.) Melhoramento e produtividade do milho. Campinas: Fundação Cargill, 1987. cap.5, p.137-214.

VENCOVSKY, R.; BARRIGA, P. Genética biométrica no fitomelhoramento. Ribeirão Preto: Revista Brasileira de Genética, 1992. 486p.

VILELA, L.; ANGHINONI, I. Morfologia do sistema radicular e cinética da absorção de fósforo em cultivares de soja afetados pela interação alumínio-fósforo. Revista Brasileira de Ciência do Solo, v.8, p.9196, 1984.

VIZONI, E. Análise de experimentos em blocos casualizados completos aumentados (Blocos de Federer) com parcelas subdivididas no tempo. Piracicaba, 1984. 125p. Tese (Mestrado) - Escola Superior de Agricultura "Luiz de Queiroz"/USP.

WAGATSUMA, T. Characterization of absorption sites for aluminum in the roots. Soil Science and Plant Nutrition, v.29, n.4, p.499-515, 1983.

WEISS, M. G; WEBER, C. R.; KALTON, R. R. Early generation testing in soybeans. Journal of the American Society of Agronomy, v.39, n. 9, p.791-811, Sep. 1947.

WILCOX, J.R. An efficient recurrent selection breeding method for soybean. In: WORLD SOYBEAN RESEARCH CONFERENCE, 5., Chiang Mai, 1994. Abstracts of papers, 1994. p.1. 
TABELAS 
Tabela 1. Esquema da análise de variância em blocos aumentados, referente aos experimentos da geração $F_{7: 6}$.

\begin{tabular}{lccc}
\hline Fontes de Variação & GL & QM & Teste F \\
\hline Blocos & $\mathrm{B}-1$ & -- & --- \\
Tratamentos (ajustados) & $(\mathrm{P}+\mathrm{T}-1)$ & $\mathrm{QM}_{4}$ & $\mathrm{QM}_{4} / \mathrm{QM}_{1}$ \\
$\quad$ Parentais (T) & $\mathrm{T}-1$ & $\mathrm{QM}_{3}$ & $\mathrm{QM}_{3} / \mathrm{QM}_{1}$ \\
$\quad$ Linhagens $\mathrm{F}_{7: 6}+(\mathrm{P}$ vs T) & $\mathrm{P}$ & $\mathrm{QM}_{2}$ & $\mathrm{QM}_{2} / \mathrm{QM}_{1}$ \\
Erro intrablocos & $\mathrm{N}_{1}$ & $\mathrm{QM}_{1}$ & \\
\hline Total & $\mathrm{N}-1$ & \\
$\mathrm{~N}_{1}=(\mathrm{T}-1)(\mathrm{B}-1)$ & \\
$\mathrm{T}:$ número de parentais (tratamentos comuns); \\
$\mathrm{P}:$ número de linhagens $\mathrm{F}_{7: 6}$ (tratamentos regulares); \\
$\mathrm{N}:$ número total de parcelas; \\
B : número de blocos.
\end{tabular}

Tabela 2. Esquema da análise de variância com as médias de linhagens ajustadas, desdobramento da soma de quadrados de linhagens $F_{7: 6} \mathrm{em}$ efeito de cruzamentos e linhagens $F_{7: 6}$ dentro de cruzamentos, em cada experimento, com a utilização do erro interblocos $\left(\sigma^{2}{ }^{\prime}\right)$.

\begin{tabular}{|c|c|c|c|c|}
\hline Fontes de Variação & GL & $\mathbf{Q M}$ & Teste $\mathbf{F}$ & $E(Q M)$ \\
\hline Linhagens $F_{7: 6}$ & $\bar{P}-1$ & $\overline{\mathrm{QM}_{48}}$ & $\mathrm{QM}_{48} / \mathbf{Q M}_{1}$ & $\sigma_{e}^{2}+\sigma_{F}^{2}$ \\
\hline Cruzamentos (C) & $\mathrm{C}-1$ & $\mathbf{Q M}_{47}$ & $\mathrm{QM}_{47} / \mathrm{QM}_{1}$ & $\sigma_{e}^{2}+v_{\phi_{c}}^{2}$ \\
\hline Linh. $F_{7: 6} / C(1 \times 2)$ & $P_{1 \times 2}-1$ & $\mathbf{Q M}_{46}$ & $\mathrm{QM}_{46} / \mathrm{QM}_{1}$ & $\sigma_{e}^{2},+\sigma_{g}^{2}$ \\
\hline Linh. $F_{7: 6} / C(1 \times 3)$ & $P_{1 \times 3}-1$ & $\mathbf{Q M}_{45}$ & $\mathbf{Q M}_{45} / \mathbf{Q M}_{1}$ & $\sigma_{e}^{2}+\sigma_{g 1 \times 3}^{2}$ \\
\hline . & . & . & & \\
\hline$\cdot$ & . & . & & $\cdot$ \\
\hline Linh. $F_{7: 6} / C(9 \times 10)$ & $P_{9 \times 10}-1$ & $\mathrm{QM}_{2}$ & $\mathrm{QM}_{2} / \mathrm{QM}_{1}$ & $\sigma_{e}^{2},+\sigma_{g 9 \times 10}^{2}$ \\
\hline Erro interblocos & $\mathrm{N}_{1}$ & $\mathbf{Q M}_{1}$ & & $\sigma_{\mathrm{e}}^{2}$ \\
\hline
\end{tabular}

$\sigma_{g^{1 \times 2},}^{2}, \sigma_{g 1 \times 3, \ldots,}^{2} \sigma_{g^{9 \times 10}}^{2}$ : variância genética entre linhagens dentro dos cruzamentos $1 \times 2$, $\sigma^{2}{ }_{\mathrm{e}}$ : variância do erro interblocos; $1 \times 3, \ldots, 9 \times 10$, respectivamente;

$\phi^{2} \mathrm{c}:(1 / \mathrm{C}-1) \sum_{z} \mathrm{c}^{2} \mathrm{z}, \mathrm{z}=1,2 \ldots, \mathrm{C}$;

$\mathrm{V}$ : número médio de linhagens por cruzamento;

$\mathrm{P}_{1 \times 2}, \mathrm{P}_{1 \times 3}, \ldots, \mathrm{P}_{9 \times 10}$ : número de linhagens dentro dos cruzamentos $1 \times 2,1 \times 3$, $\ldots, 9 \times 10$, respectivamente. 
Tabela 3. Esquema da análise de covariância, com as respectivas esperanças matemáticas dos produtos médios, referente aos experimentos da geração $F_{7: 6}$.

\begin{tabular}{|c|c|c|c|c|c|}
\hline \multirow[t]{2}{*}{ Fontes de Cov. } & \multirow[t]{2}{*}{ GL } & \multicolumn{2}{|c|}{ QM } & $\mathrm{PM}$ & \multirow[t]{2}{*}{$E(P M)$} \\
\hline & & $\mathrm{X}$ & $\mathbf{Y}$ & $(X, Y)$ & \\
\hline Parentais & $\mathrm{T}-1$ & $\overline{\mathrm{QM}_{2}(\mathrm{x})}$ & $\overline{\mathrm{QM}_{2}(\mathrm{y})}$ & $\mathrm{PM}_{2}$ & $\operatorname{cov}_{\mathbf{i}}(\mathrm{x}, \mathrm{y})+\mathrm{B} \phi_{\mathrm{t}}(\mathrm{x}, \mathrm{y})$ \\
\hline Erro intrablocos & $\mathrm{N}_{1}$ & $\mathrm{QM}_{1}(\mathrm{x})$ & $\mathrm{QM}_{1}(\mathrm{y})$ & $\mathbf{P M}_{1}$ & $\operatorname{Cov}_{\mathrm{i}}(\mathrm{x}, \mathrm{y})$ \\
\hline $\begin{array}{l}\text { Linh. } F_{7: 6} \\
\text { Cruzamentos (C) }\end{array}$ & $\begin{array}{c}\text { P1 } \\
(\mathrm{C}-1)\end{array}$ & $\begin{array}{l}\mathrm{QM}_{50}(\mathrm{x}) \\
\mathrm{QM}_{49}(\mathrm{x})\end{array}$ & $\begin{array}{l}\mathrm{QM}_{50}(\mathrm{y}) \\
\mathrm{QM}_{49}(\mathrm{y})\end{array}$ & $\begin{array}{l}\mathrm{PM}_{50} \\
\mathrm{PM}_{49}\end{array}$ & 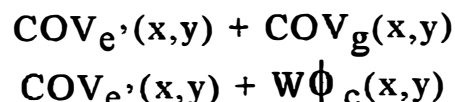 \\
\hline $\begin{array}{l}\text { Linh. } F_{7: 6} / C_{1 \times 2} \\
\text { Linh. } F_{7: 6} / C_{1 \times 3}\end{array}$ & & $\begin{array}{l}\mathrm{QM}_{48}(\mathrm{x}) \\
\mathrm{QM}_{47}(\mathrm{x})\end{array}$ & $\begin{array}{l}\mathrm{QM}_{48}(\mathrm{y}) \\
\mathrm{QM}_{47}(\mathrm{y})\end{array}$ & $\begin{array}{l}\mathrm{PM}_{48} \\
\mathrm{PM}_{47}\end{array}$ & --- \\
\hline$\cdot$ & & & $\cdot$ & & \\
\hline $\begin{array}{l}\text { Linh. } F_{7: 6} / C_{9 \times 10} \\
\text { Erro interblocos }\end{array}$ & $\mathrm{N}_{1}$ & $\begin{array}{l}\mathrm{QM}_{4}(\mathrm{x}) \\
\mathrm{QM}_{3}(\mathrm{x})\end{array}$ & $\begin{array}{l}\mathrm{QM}_{4}(\mathrm{y}) \\
\mathrm{QM}_{3}(\mathrm{y})\end{array}$ & $\begin{array}{l}\mathrm{PM}_{4} \\
\mathrm{PM}_{3}\end{array}$ & 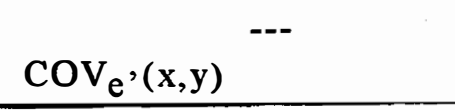 \\
\hline
\end{tabular}

$\phi_{t}(x, y)$ : covariância genotípica para o par de caracteres $x$ e $y$, com base nos parentais;

$\operatorname{coV}_{\mathrm{i}}(\mathrm{x}, \mathrm{y})$ : covariância ambiental para o par de caracteres $\mathrm{x}$ e $\mathrm{y}$, com base nos parentais;

$\operatorname{cov}_{\mathrm{g}}(\mathrm{x}, \mathrm{y})$ : covariância genotípica para o par de caracteres $\mathrm{x}$ e $\mathrm{y}$, com base nas linhagens;

$\phi_{\mathrm{c}}(\mathrm{x}, \mathrm{y})$ : covariância genotípica para o par de caracteres $\mathrm{x}$ e $\mathrm{y}$, com base nos cruzamentos;

$\operatorname{cov}_{\mathrm{e}}(\mathrm{x}, \mathrm{y})$ : covariância ambiental para o par de caracteres $\mathrm{x}$ e y, com base nas linhagens e cruzamentos;

W : número de progênies por cruzamento. 
Tabela 4. Esquema da análise de variância em blocos ao acaso, ao nível de parcelas, com as esperanças matemáticas dos quadrados médios das fontes de variação, referente aos experimentos das geração $\mathrm{F}_{\text {8:6 }}$ (QLEs e QLPs).

\begin{tabular}{|c|c|c|c|c|}
\hline Fontes de variação & GL & $\mathbf{Q M}$ & Teste F & $\overline{E(Q M)}$ \\
\hline Repetição (R) & $\overline{R-1}$ & $\cdots$ & -- & \\
\hline Tratamentos & $N-1$ & $\mathrm{QM}_{\mathrm{\theta}}$ & $Q M_{g} / Q M_{1}$ & $\sigma_{e}^{2}+\nabla \phi^{2} g$ \\
\hline Parentais ( $\mathrm{T}$ ) & $T-1$ & $\mathrm{QM}_{4}$ & $\mathrm{QM}_{4} / \mathrm{QM}_{1}$ & $\sigma_{e}^{2}+B \phi_{t}^{2}$ \\
\hline Linhagens $F_{8: 6}$ & CP-1 & $\mathrm{QM}_{50}$ & $\mathrm{QM}_{50} / \mathrm{QM}_{1}$ & $\sigma_{e}^{2}+R \sigma_{F_{0.6}}^{2}$ \\
\hline Cruzamentos (C) & $C-1$ & $\mathrm{QM}_{49}$ & $\mathrm{QM}_{49} / \mathrm{QM}_{1}$ & $\sigma^{2}+R V \phi_{c}^{2}$ \\
\hline Linh./c & $C(P-1)$ & $\mathrm{QM}_{48}$ & $\mathrm{QM}_{48} / \mathrm{QM}_{1}$ & $\dot{\sigma}_{\mathrm{e}}^{2}+R \mathrm{~V}_{\mathrm{F}_{8: 6} / \mathrm{c}}$ \\
\hline Linh. $F_{8: 6} / C(1 \times 2)$ & $P_{1 \times 2-1}$ & $\mathrm{QM}_{47}$ & $\mathrm{QM}_{47} / \mathrm{QM}_{1}$ & $\sigma_{e}^{2}+R \sigma_{g_{1 \times 2}}^{2}$ \\
\hline Linh. $F_{8: 6} / C(1 \times 3)$ & $P_{1 \times 3}-1$ & $\mathrm{QM}_{46}$ & $\mathrm{QM}_{46} / \mathrm{QM}_{1}$ & $\sigma_{e}^{2}+R \sigma_{g_{1 \times 3}}^{2}$ \\
\hline - & - & - & - & • \\
\hline - & - & - & - & $\cdot$ \\
\hline Linh. $F_{8: 6} / \mathrm{C}(\dot{9 \times 10})$ & $\mathrm{P}_{9 \times 10^{-1}}^{\cdot}$ & $\dot{\mathrm{QM}}_{3}$ & $\mathrm{QM}_{3} / \mathrm{QM}_{1}$ & $\sigma^{2}+R \sigma_{g_{9 \times 10}}^{2}$ \\
\hline $\begin{array}{l}\text { T vs C } \\
\text { Erro }\end{array}$ & $\begin{array}{c}1 \\
(\mathrm{~B}-1)(\mathrm{N}-1)+ \\
\mathrm{RT}(\mathrm{B}-1)\end{array}$ & $\begin{array}{l}\mathrm{QM}_{2} \\
\mathrm{QM}_{1}\end{array}$ & $\mathrm{QM}_{2} / \mathrm{QM}_{1}$ & $\sigma_{e}^{2}$ \\
\hline
\end{tabular}

$\phi^{2} \mathrm{~g}=[1 /(\mathrm{N}-1)] \sum_{\mathrm{w}} \mathrm{g}_{\mathrm{w}}{ }^{2}:$ componente quadrático da variação genética entre tratamentos;

$\phi^{2} \mathrm{t}=[1 /(\mathrm{T}-1)] \sum_{\mathrm{i}} \mathrm{t}_{\mathrm{i}}{ }^{2}$ : componente quadrático da variação genética entre parentais;

$\phi^{2} \mathrm{c}=[1 /(\mathrm{C}-1)] \sum_{\mathrm{z}} \mathrm{c}_{\mathrm{z}}{ }^{2}:$ componente quadrático da variação genética entre cruzamentos;

B : número de blocos

$\mathrm{V}$ : número médio de linhagens por cruzamento;

$\sigma^{2}$ e : variância ambiental entre parcelas. 
Tabela 5. Esquema da análise de variância conjunta, ao nível de parcelas, com as esperanças matemáticas dos quadrados médios das fontes de variação, referente aos experimentos das geração $F_{7: 6}$ e $F_{8: 6}$ (QLEs e QLPs).

\begin{tabular}{|c|c|c|c|c|}
\hline Fontes de variação & GL & $\mathrm{QM}$ & Teste F & $\mathrm{E}(\mathrm{QM})$ \\
\hline Repetição & $\mathrm{R}-1$ & & & \\
\hline Local (E) & L-1 & --- & --- & -- \\
\hline Tratamentos & $\mathrm{N}-1$ & $\mathrm{QM}_{5}$ & $\mathrm{QM}_{5} / \mathrm{QM}_{1}$ & $\sigma_{e}^{2}+B \phi^{2} g$ \\
\hline Parentais $(T)$ & $\mathrm{T}-1$ & $\mathrm{QM}_{4}$ & $\mathrm{QM}_{4} / \mathrm{QM}_{1}$ & $\sigma_{e}^{2}+B \phi_{t}^{2}$ \\
\hline Linhagens $F_{8: 6}$ & $\mathrm{CP}-1$ & $\mathrm{QM}_{108}$ & $\mathrm{QM}_{108} / \mathrm{QM}_{1}$ & $\sigma_{e}^{2}+R L \sigma_{F_{8: 6}}^{2}$ \\
\hline Cruzamentos (C) & $C-1$ & $\mathrm{QM}_{107}$ & $\mathrm{QM}_{107} / \mathrm{QM}_{1}$ & $\sigma_{\mathrm{e}}^{2}+\operatorname{RLV} \phi^{2}{ }_{\mathrm{c}}$ \\
\hline Linh./c & $C(P-1)$ & $\mathrm{QM}_{106}$ & $\mathrm{QM}_{106} / \mathrm{QM}_{1}$ & $\sigma_{\mathrm{e}}^{2}+\operatorname{RLV}_{\mathrm{F}_{8: 6} / \mathrm{c}}$ \\
\hline $\begin{array}{l}\text { E x Tratamentos } \\
\text { E x Parentais } \\
\text { E x Linhagens } F_{8: 6}\end{array}$ & $\begin{array}{l}(\mathrm{N}-1)(\mathrm{L}-1) \\
(\mathrm{T}-1)(\mathrm{L}-1) \\
(\mathrm{CP}-1)(\mathrm{L}-1)\end{array}$ & $\begin{array}{l}\mathrm{QM}_{7} \\
\mathrm{QM}_{6} \\
\mathrm{QM}_{105}\end{array}$ & $\begin{array}{l}\mathrm{QM}_{7} / \mathrm{QM}_{1} \\
\mathrm{QM}_{6} / \mathrm{QM}_{1} \\
\mathrm{QM}_{105} / \mathrm{QM}_{1}\end{array}$ & $\sigma_{\mathrm{e}}^{2}+\mathrm{RL} / \mathrm{L}-1 \sigma^{2} \mathrm{~F}_{8: 6 \mathrm{~L}}$ \\
\hline $\mathrm{E} \times \mathrm{C}$ & $(C-1)(L-1)$ & $\mathrm{QM}_{104}$ & $\mathrm{QM}_{104} / \mathrm{QM}_{1}$ & $\sigma_{e}^{2}+R L / L-1 V \phi_{C L}^{2}$ \\
\hline E $x$ Linh./C & $\mathrm{C}(\mathrm{P}-1)(\mathrm{L}-1)$ & $\mathrm{QM}_{103}$ & $\mathrm{QM}_{103} / \mathrm{QM}_{1}$ & $\sigma_{e}^{2}+R L / L-1 V_{F_{8: 6 / C L}}$ \\
\hline Linh. / C (1x2) & $P_{1 \times 2-1}$ & $\mathrm{QM}_{102}$ & $\mathrm{QM}_{102} / \mathrm{QM}_{1}$ & $\sigma_{e}^{2}+R L \sigma^{2} g_{1 \times 2}$ \\
\hline $\mathrm{E} \times \mathrm{Linh} . / \mathrm{C}(1 \times 2)$ & $P_{1 \times 3}-1(L-1)$ & $\mathrm{QM}_{101}$ & $\mathrm{QM}_{101} / \mathrm{QM}_{1}$ & $\sigma_{\mathrm{e}}^{2}+\mathrm{RL} / \mathrm{L}-1 \sigma^{2} \mathrm{gL}_{1 \times 3}$ \\
\hline Linh. / C (1x3) & $P_{1 \times 2}-1$ & $\mathrm{QM}_{100}$ & $\mathrm{QM}_{100} / \mathrm{QM}_{1}$ & $\sigma_{\mathrm{e}}^{2}+\mathrm{RL} \sigma_{\mathrm{g}_{1 \times 2}}$ \\
\hline E $x$ Linh. / $C(1 \times 3)$ & $P_{1 \times 3}-1(L-1)$ & $\mathrm{QM}_{99}$ & $\mathrm{QM}_{99} / \mathrm{QM}_{1}$ & $\sigma^{2}{ }_{\mathrm{e}}+\mathrm{RL} / \mathrm{L}-1 \sigma^{2} \mathrm{gL}_{1 \times 3}$ \\
\hline - & - & - & - & - \\
\hline - & - & - & - & - \\
\hline - & - & - & - & - \\
\hline Linh. / C (9x10) & $P_{9 \times 10^{-1}}$ & $\mathrm{QM}_{9}$ & $\mathrm{QM}_{9} / \mathrm{QM}_{1}$ & $\sigma_{e}^{2}+R L \sigma^{2} g_{9 \times 10}$ \\
\hline E $x$ Linh./ $C(9 \times 10)$ & $P_{9 \times 10^{-1}}(\mathrm{~L}-1)$ & $\mathrm{QM}_{8}$ & $\mathrm{QM}_{8} / \mathrm{QM}_{1}$ & $\sigma_{e}^{2}+R L / L-1 \sigma^{2} \mathrm{gL}_{9 \times 10}$ \\
\hline $\begin{array}{l}\text { T vs C } \\
\text { ExT vs C }\end{array}$ & $\begin{array}{c}1 \\
1(\mathrm{~L}-1)\end{array}$ & $\begin{array}{l}\mathrm{QM}_{3} \\
\mathrm{QM}_{2}\end{array}$ & $\begin{array}{l}\mathrm{QM}_{3} / \mathrm{QM}_{1} \\
\mathrm{QM}_{2} / \mathrm{QM}_{1}\end{array}$ & $\begin{array}{lll}-- & - \\
---\end{array}$ \\
\hline Erro & $\begin{array}{c}(\mathrm{B}-1)(\mathrm{N}-1)+ \\
\mathrm{RT}(\mathrm{B}-1)\end{array}$ & $\mathrm{QM}_{1}^{2}$ & & $\sigma_{\mathrm{e}}^{2}$ \\
\hline Total & $\mathrm{RB}(\mathrm{T}+\mathrm{C})-1$ & & & \\
\hline
\end{tabular}

$\sigma^{2} \mathrm{e}$ : variância ambiental média . 

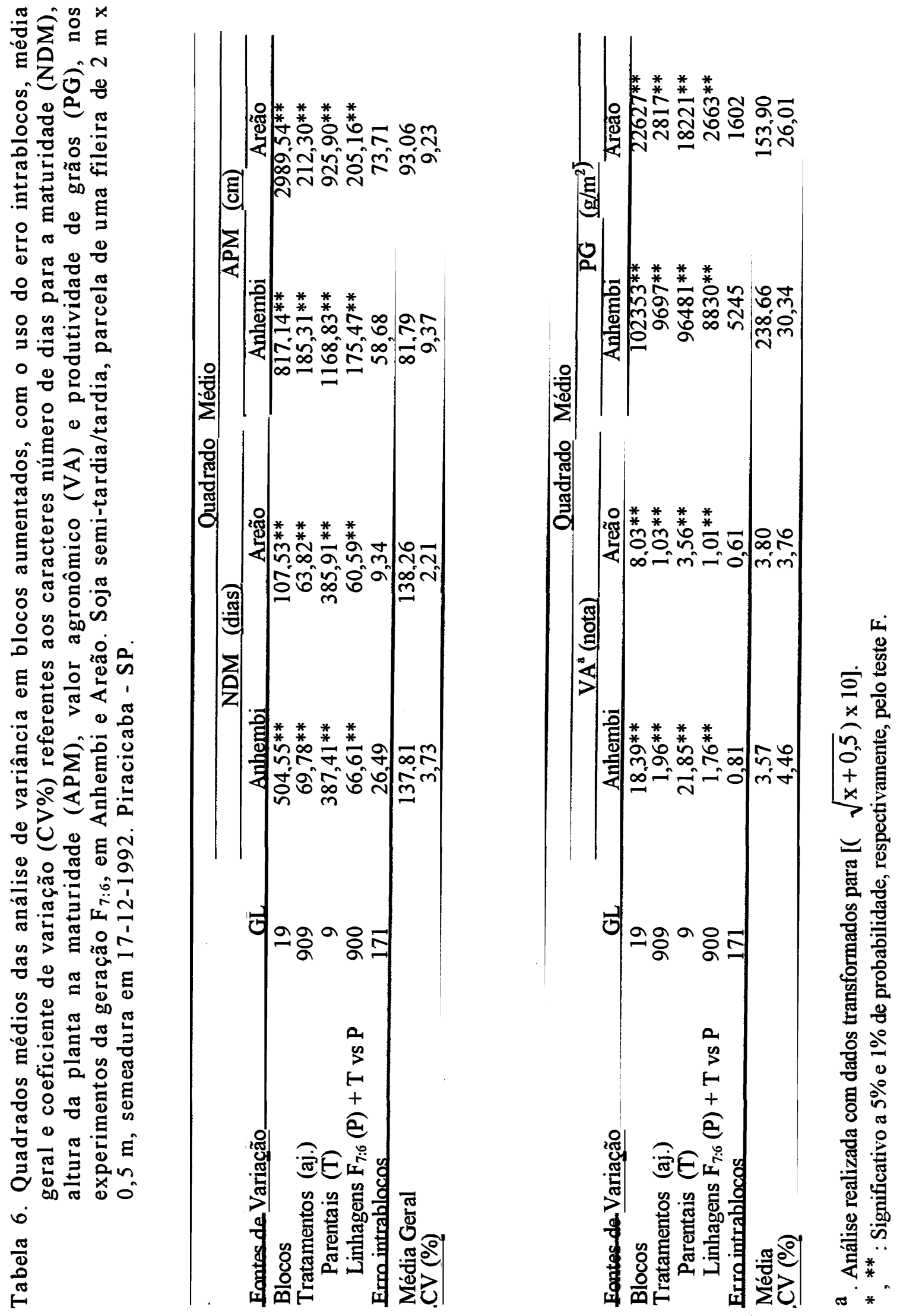


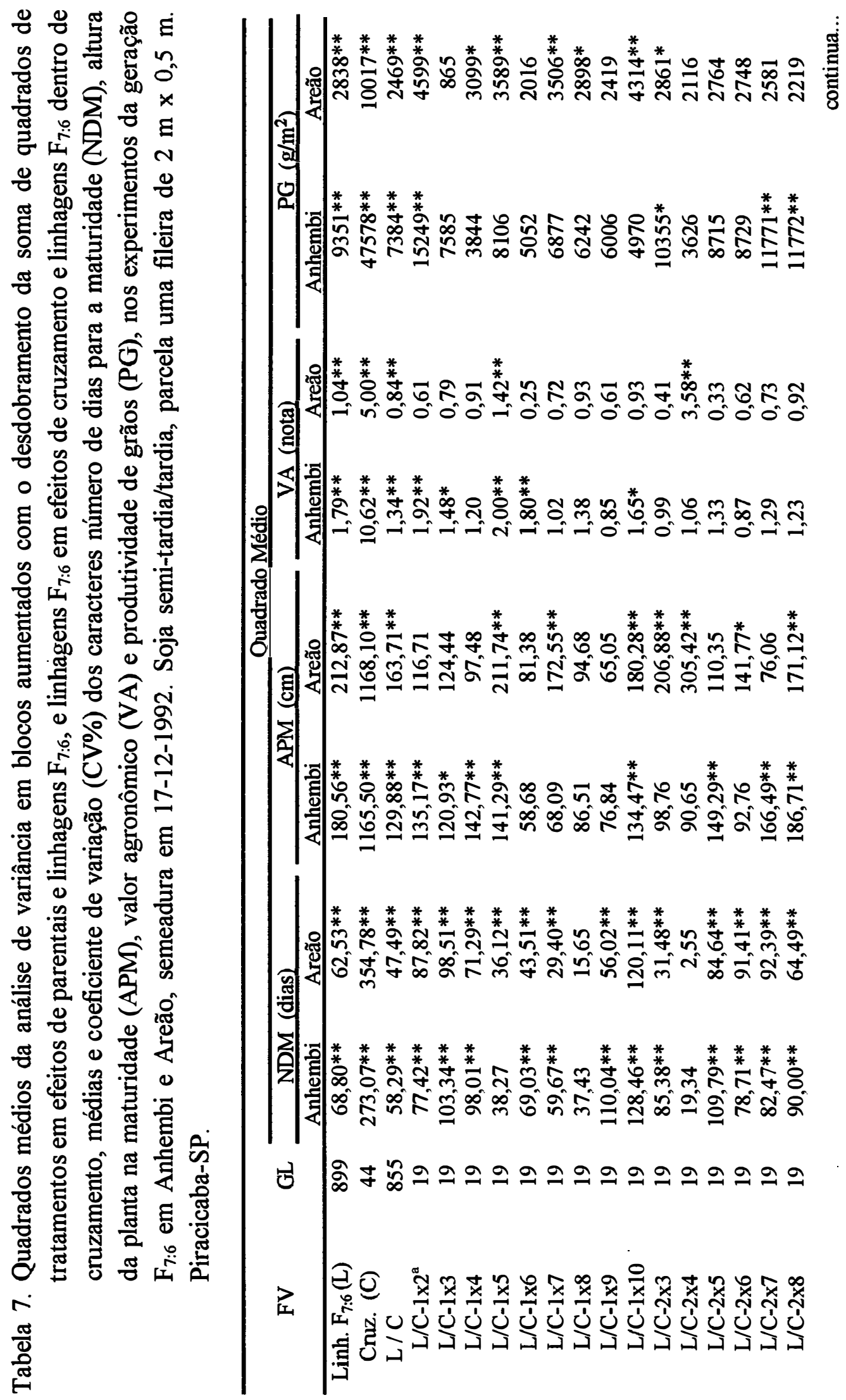




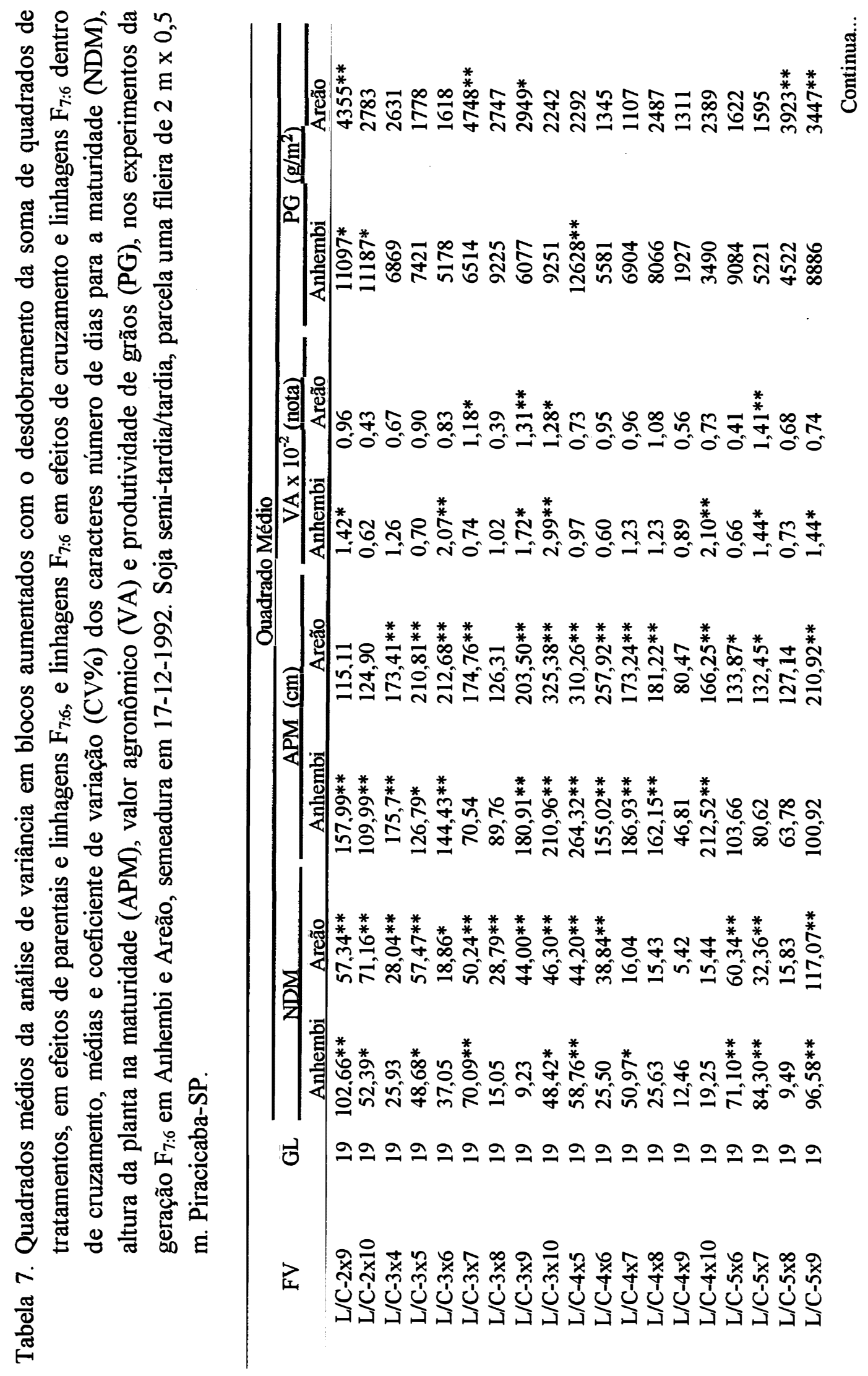




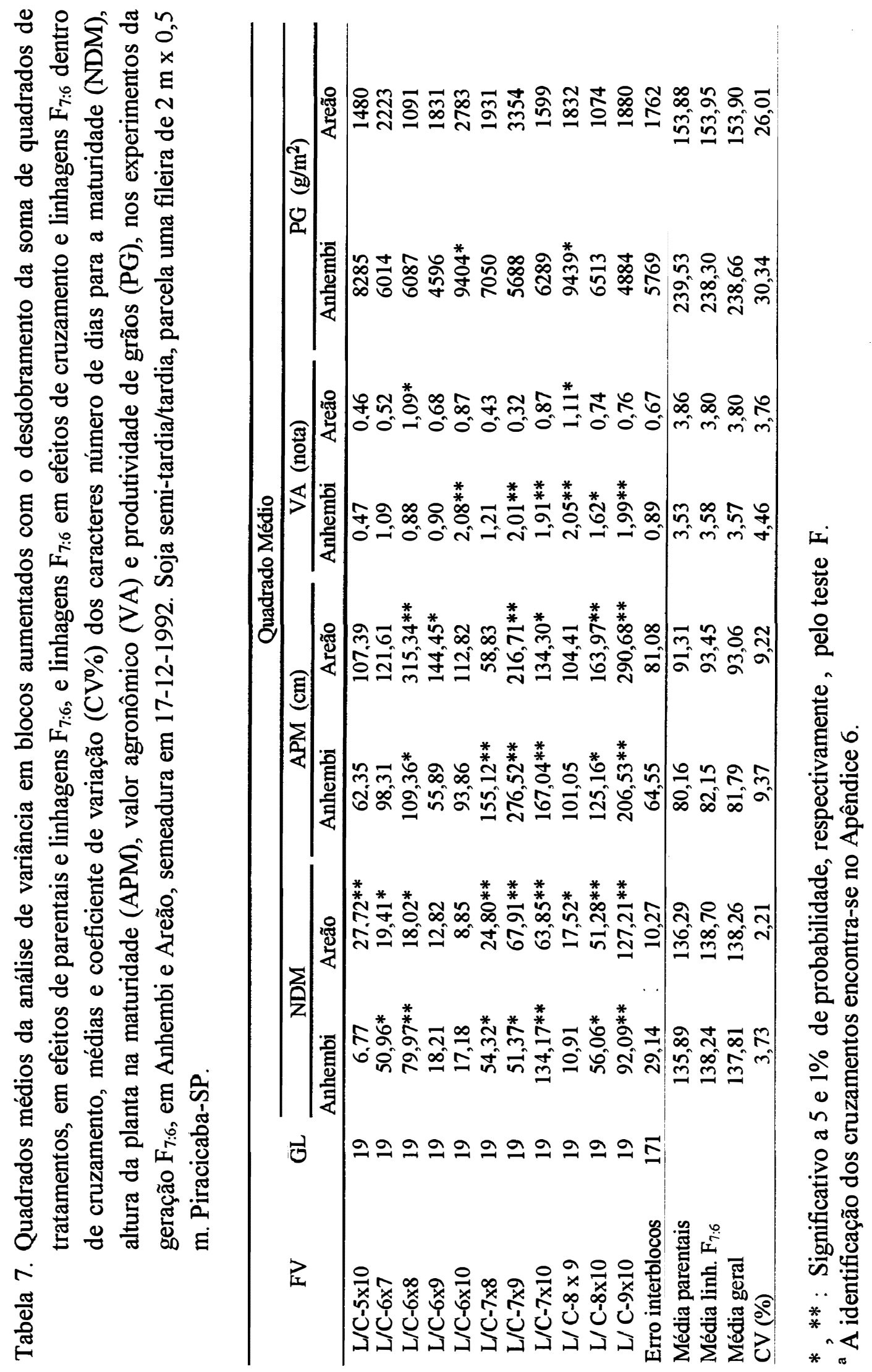



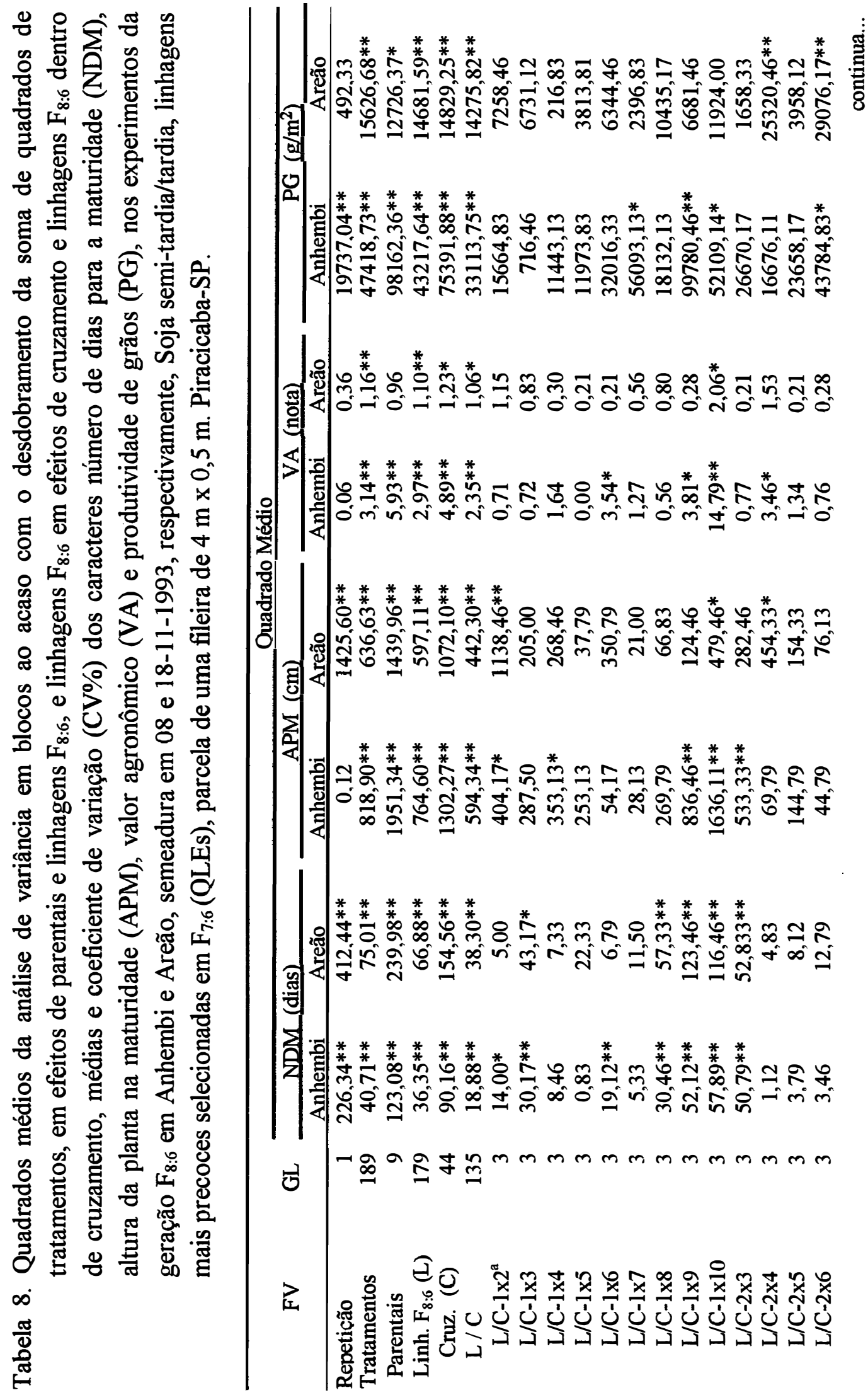

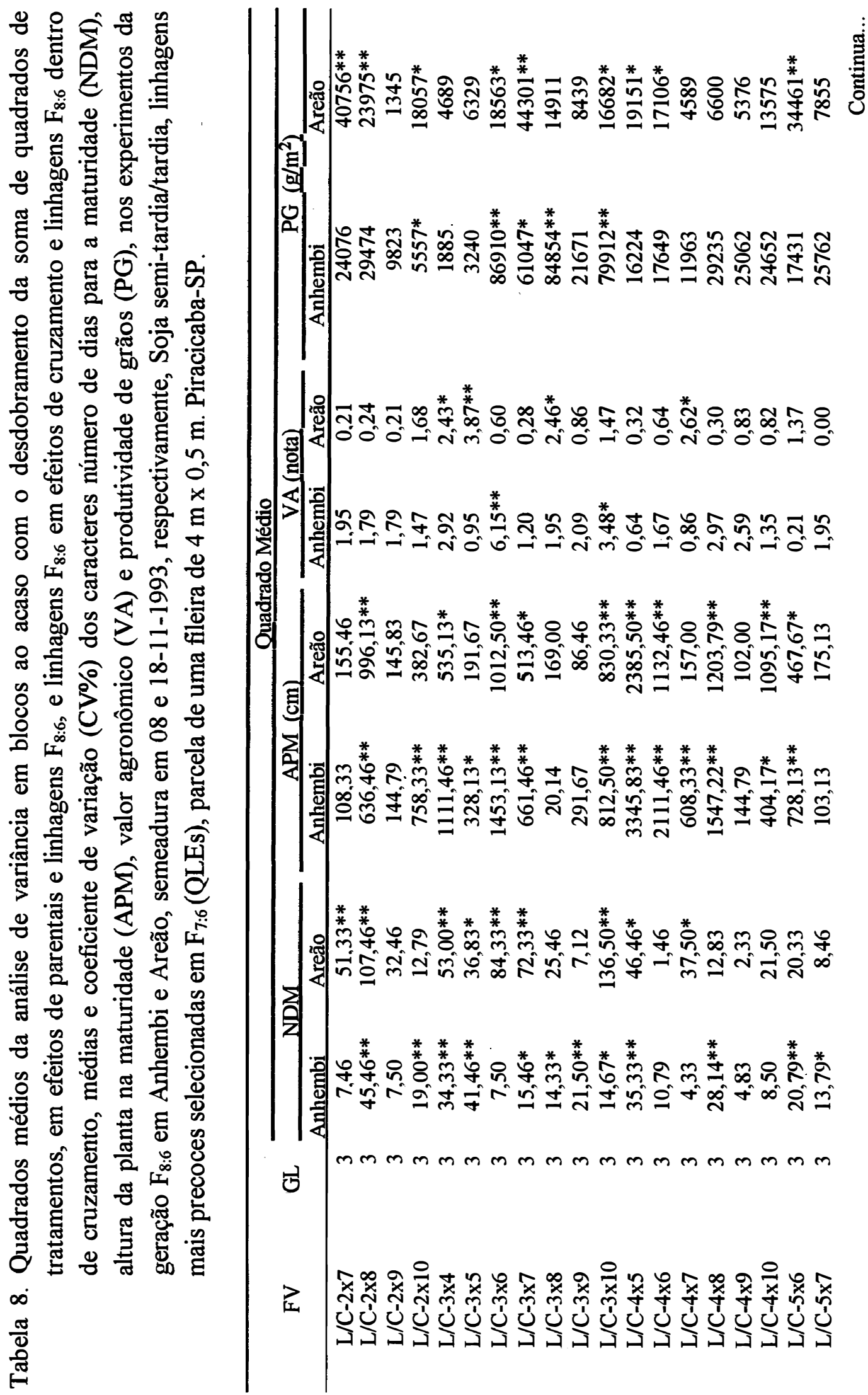


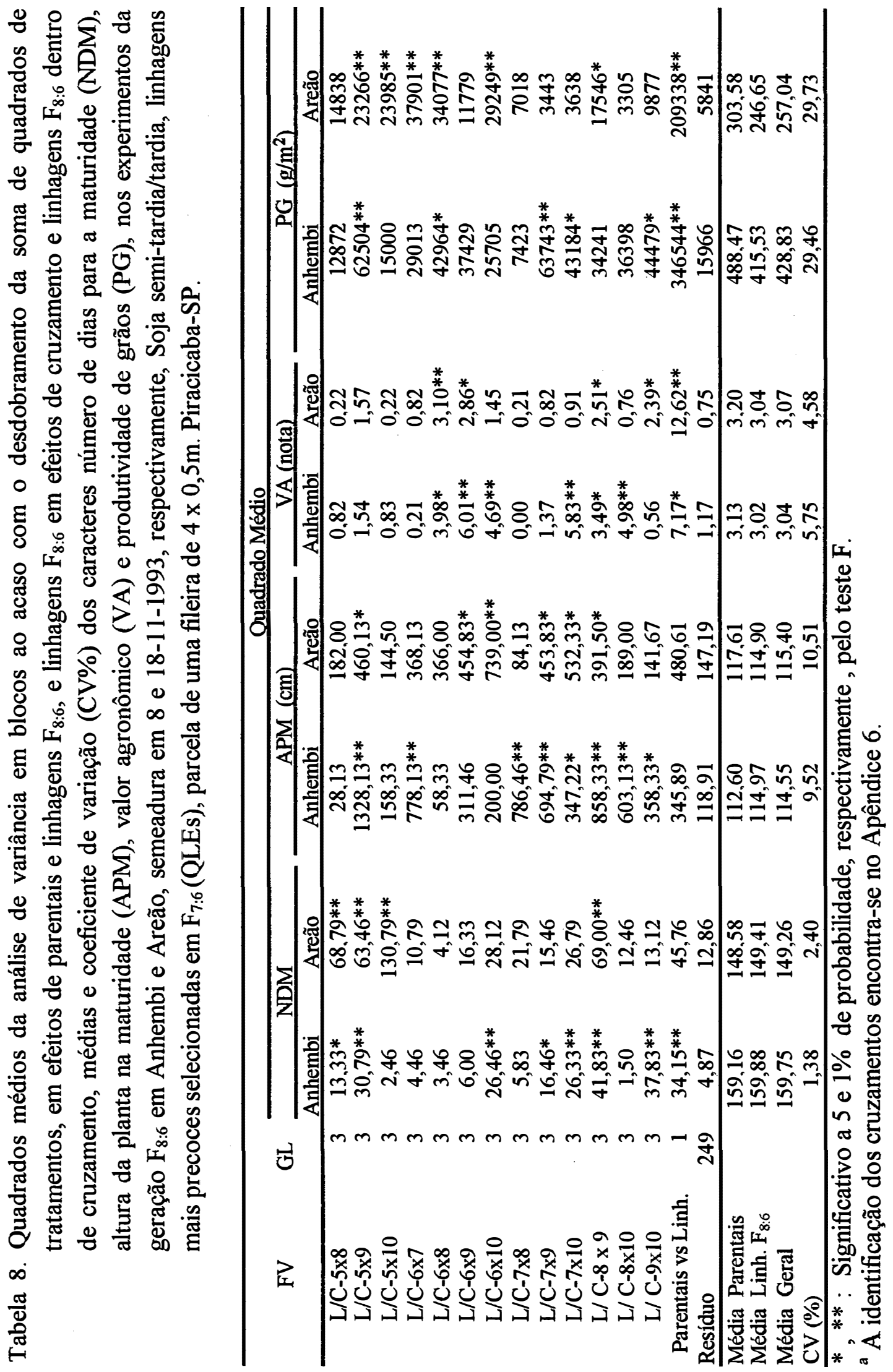




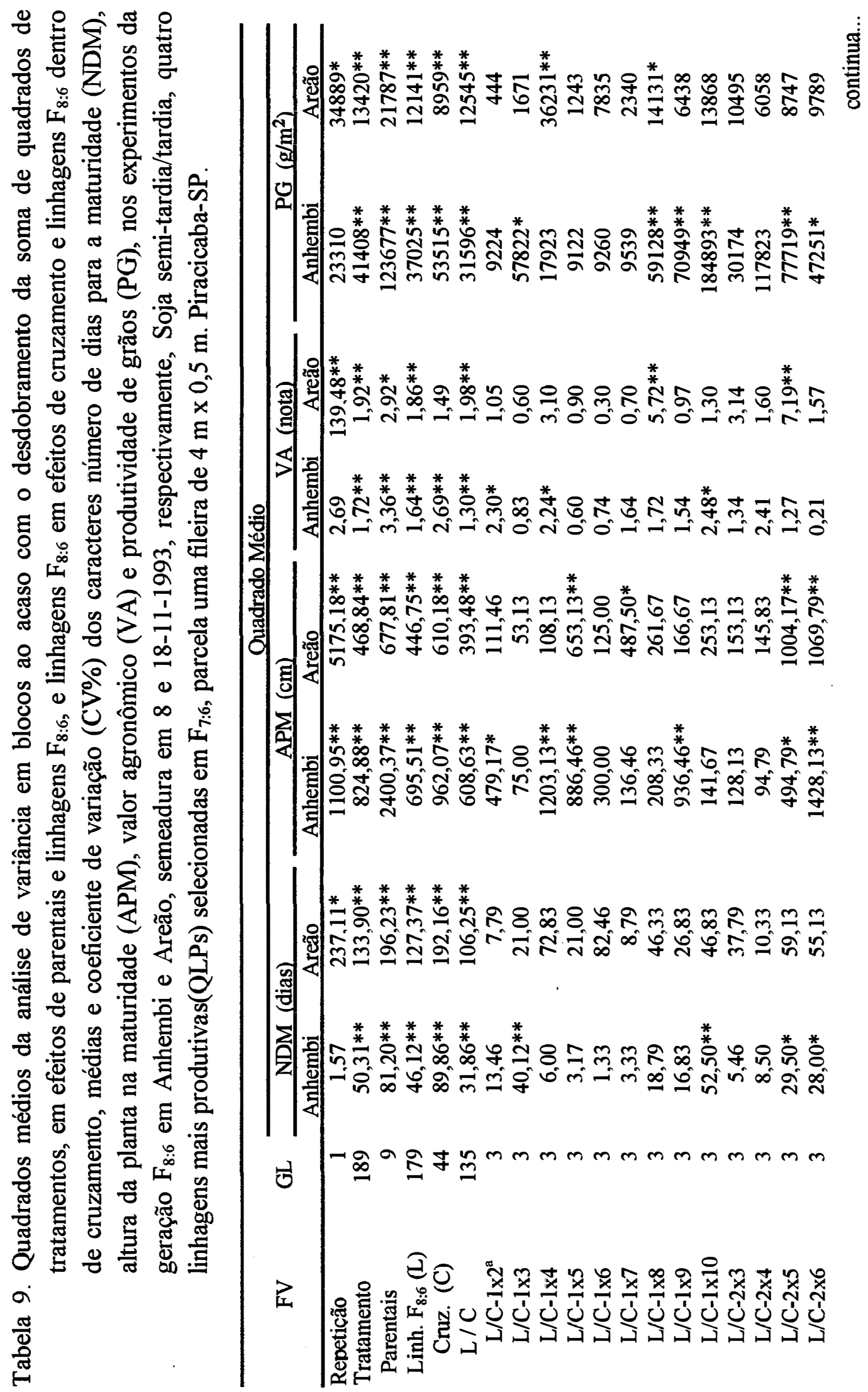



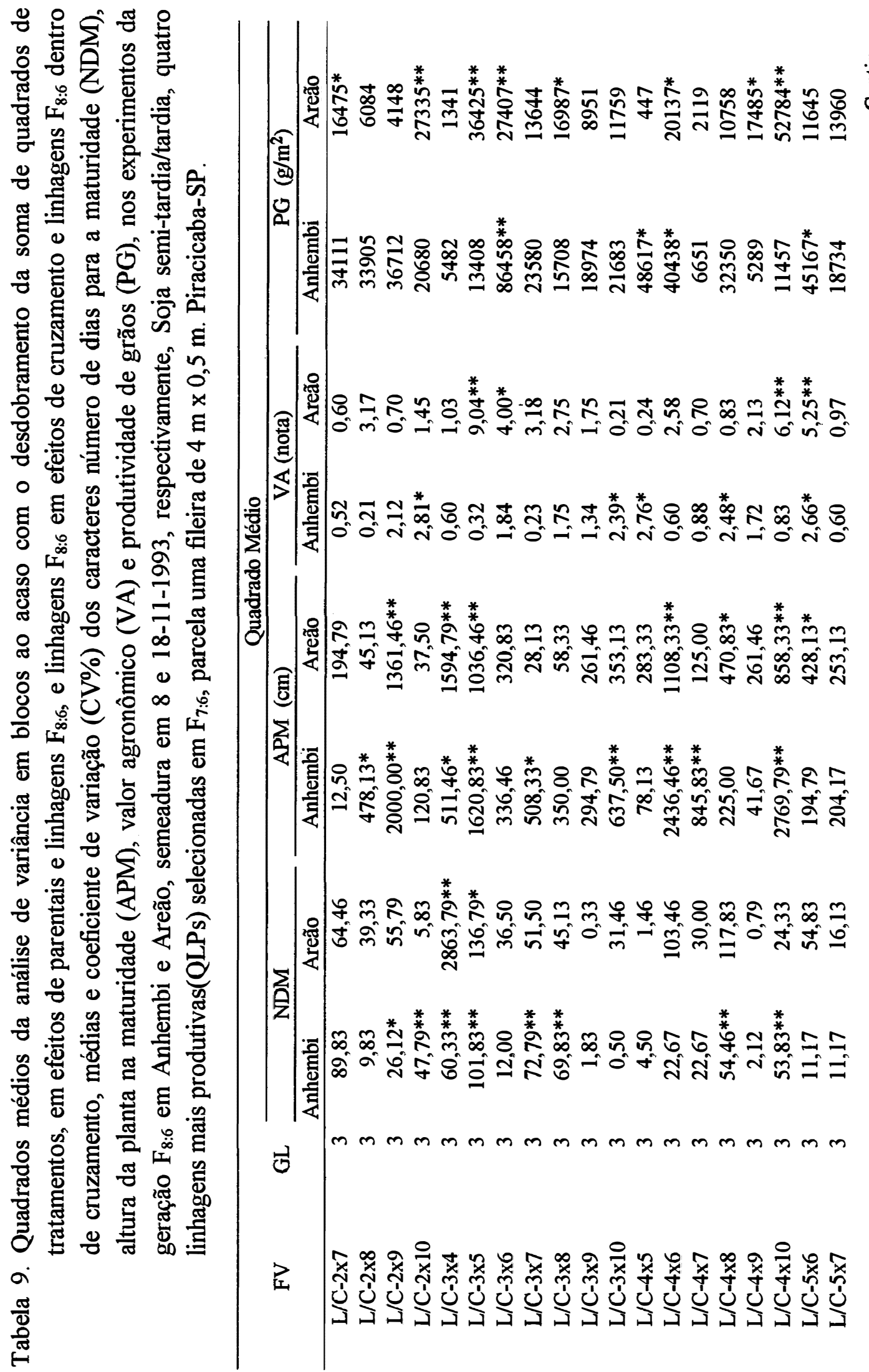


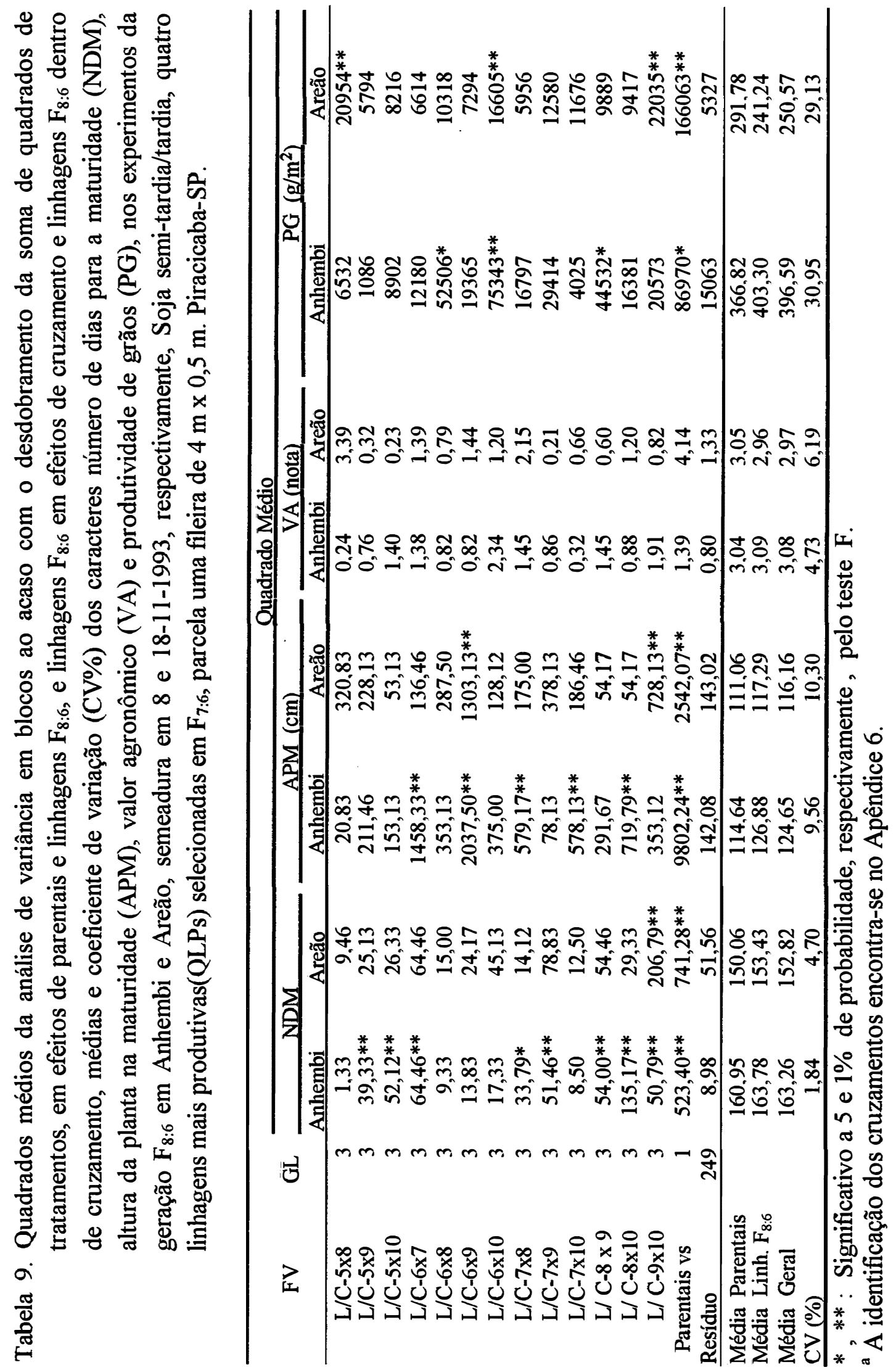


Tabela 10. Quadrados médios da análise de variância conjunta com o desdobramento da soma de quadrados de tratamentos $\mathrm{x}$ locais, em efeitos de parentais $\mathrm{x}$ locais $\mathrm{e}$ linhagens $F_{7: 6} \times$ locais, e linhagens $F_{7: 6} \times$ locais em efeitos de cruzamento $x$ locais e linhagens $\mathrm{F}_{7: 6}$ dentro de cruzamento $\mathrm{x}$ locais, dos caracteres número de dias para a maturidade (NDM), altura da planta na maturidade (APM), valor agronômico (VA) e produtividade de grãos (PG), nos experimentos da geração $F_{7: 6}$ em Anhembi e Areão, semeadura em 17-12-1992. Soja semi-tardia/tardia, parcela uma fileira de $2 \mathrm{~m} \times 0,5 \mathrm{~m}$. Piracicaba-SP.

\begin{tabular}{|c|c|c|c|c|c|}
\hline \multirow[b]{2}{*}{ FV } & \multirow[b]{2}{*}{ GL } & \multicolumn{4}{|c|}{ Quadrado Médio } \\
\hline & & NDM (dias) & $\overline{\mathrm{APM}}(\mathrm{cm})$ & VA (nota) & $\mathrm{PG}\left(\mathrm{g} / \mathrm{m}^{2}\right)$ \\
\hline Local (E) & 1 & $96,46^{*}$ & $58059,97 * *$ & $139,37 * *$ & $3238895^{* * *}$ \\
\hline Tratamentos (N) & 909 & $104,64 * *$ & $303,74 * *$ & $1,97 * *$ & $7311^{* *}$ \\
\hline Parentais & 9 & $726,20 * *$ & $1946,20 * *$ & $21,20 * *$ & $95905 * *$ \\
\hline Linh. $F_{7: 6}(L)$ & 899 & $105,32 * *$ & $306,05 * *$ & $1,99 * *$ & $7374 * *$ \\
\hline Cruz. (C) & 44 & $587,09 * *$ & $2236,47 * *$ & $13,82 * *$ & $44136 * *$ \\
\hline P/Cruz. & 855 & $80,52 * *$ & $206,70 * *$ & $1,37 * *$ & $5451 * *$ \\
\hline$E \times N$ & 909 & $25,75^{* *}$ & $86,50 * *$ & $0,84 * *$ & $4802 * *$ \\
\hline E x Parentais & 9 & $47,20 * *$ & $148,40 *$ & $5,60 * *$ & $20939 * *$ \\
\hline E x Local & 899 & $26,01 * *$ & $87,38 * *$ & 0,85 & $4845^{* *}$ \\
\hline $\mathrm{E} \times \mathrm{C}$ & 44 & $40,76 * *$ & $97,16^{*}$ & $1,80 * *$ & $13460 * *$ \\
\hline $\mathrm{E} \times \mathrm{L} / \mathrm{C}$ & 855 & $25,25 * *$ & $86,88 * *$ & $0,80 * *$ & $4402 * *$ \\
\hline Parentais Vs L & 1 & $112,31 *$ & 84,05 & 0,00 & 6,59 \\
\hline E x Parentais Vs L & 1 & 65,17 & 195,18 & 1,41 & 6060 \\
\hline Erro Médio & 342 & 17,91 & 66,20 & 0,70 & 3423 \\
\hline Média Parentais & & 136,09 & 85,74 & 2,05 & 196,7 \\
\hline Média Linh. $\mathrm{F}_{7: 6}$ & & 138,47 & 87,80 & 2,05 & 196,1 \\
\hline CV\% & & 2,97 & 9,30 & 4,11 & 28,2 \\
\hline $\mathrm{L} / \mathrm{Ci} \times \mathrm{j}^{1}$ & 19 & 34 & 41 & 27 & 22 \\
\hline $\mathrm{E} \times \mathrm{L} / \mathrm{Ci} \times \mathrm{j}^{1}$ & 19 & 14 & 11 & 8 & 11 \\
\hline
\end{tabular}


Tabela 11. Quadrados médios da análise de variância conjunta com o desdobramento da soma de quadrados de tratamentos $\mathrm{x}$ locais, em efeitos de parentais $\mathrm{x}$ locais $\mathrm{e}$ linhagens $F_{8: 6} x$ locais, e linhagens $F_{8: 6} x$ locais em efeitos de cruzamento $x$ locais e linhagens $\mathrm{F}_{8: 6}$ dentro de cruzamento $\mathrm{x}$ locais, dos caracteres número de dias para a maturidade (NDM), altura da planta na maturidade (APM), valor agronômico (VA) e produtividade de grãos (PG), nos experimentos da geração $\mathrm{F}_{8: 6}$ em Anhembi e Areão, semeadura em 08 e 18-11-1993, respectivamente. Soja semi-tardia/tardia, linhagens mais precoces (QLEs), parcela uma fileira de $4 \mathrm{~m} \times 0,5 \mathrm{~m}$. Piracicaba-SP.

\begin{tabular}{|c|c|c|c|c|c|}
\hline & & \multicolumn{4}{|c|}{ Quadrado Médio } \\
\hline FV & GL & NDM(dias) & $\mathrm{APM}(\mathrm{cm})$ & VA (nota) & PG $\left(\mathrm{g} / \mathrm{m}^{2}\right)$ \\
\hline$\overline{\text { Local (E) }}$ & 1 & $20729,26^{* *}$ & 19,04 & 2,80 & $5200572 * *$ \\
\hline Tratamentos (N) & 189 & $87,72 * *$ & $1183,42 * *$ & $2,94 * *$ & $42495 * *$ \\
\hline Parentais & 9 & $332,56 * *$ & $3076,32 * *$ & $4,00 * *$ & $76203 * *$ \\
\hline Linh. F8:6 (L) & 179 & $88,34 * *$ & $1210,84 * *$ & $3,02 * *$ & $42999 * *$ \\
\hline Cruz. (C) & 44 & $222,46 * *$ & $2172,56^{* *}$ & $4,98 * *$ & $69072 * *$ \\
\hline $\mathrm{L} / \mathrm{C}$ & 135 & $44,62 * *$ & $897,40 * *$ & $2,40 * *$ & $34502 * *$ \\
\hline$E \times N$ & 189 & $15,34^{* *}$ & $152,22 *$ & $1,38 * *$ & $17217 * *$ \\
\hline E x Parentais & 9 & $30,80 * *$ & $317,76^{* *}$ & $2,80 * *$ & $35133^{* *}$ \\
\hline $\mathrm{ExL}$ & 179 & $15,80^{* *}$ & $155,42^{*}$ & $1,42 * *$ & $17713^{* *}$ \\
\hline$E \times C$ & 44 & $22,92 * *$ & $205,24 *$ & $1,80 * *$ & $26299 * *$ \\
\hline $\mathrm{E} \times \mathrm{L} / \mathrm{C}$ & 135 & $13,48 * *$ & $139,18^{*}$ & $1,30 * *$ & $14915 * *$ \\
\hline Parentais vs $\mathrm{L}$ & 1 & 21,16 & 2,06 & $6,24 *$ & $163288 * *$ \\
\hline $\begin{array}{l}\text { E x Parentais vs } \\
\text { L }\end{array}$ & 1 & 0,28 & 232,3 & 0,08 & 4296 \\
\hline Resíduo médio & 498 & 8,86 & 133,05 & 0,96 & 10903 \\
\hline $\begin{array}{l}\text { Media dos } \\
\text { parentais }\end{array}$ & & 153,88 & 115,11 & 3,15 & 395,67 \\
\hline Média linhagens & & 154,63 & 114,88 & 3,03 & 330,02 \\
\hline CV \% & & 1,89 & 10,01 & 5,16 & 29,60 \\
\hline $\mathrm{L} / \mathrm{Ci} \times \mathrm{j}^{1}$ & 3 & 26 & 29 & 13 & 23 \\
\hline $\mathrm{E} \times \mathrm{L} / \mathrm{CL}_{\mathrm{C}} \times \mathrm{j}^{1}$ & 3 & 7 & 4 & 5 & 6 \\
\hline
\end{tabular}

${ }^{1}$ Número de cruzamentos com efeitoss significativos $(P<0,05)$ para as fontes de variação.

$*, * *$ : Significativo a 5 e $1 \%$ de probabilidade, respectivamente, pelo teste $\mathrm{F}$. 
Tabela 12. Quadrados médios da análise de variância conjunta com o desdobramento da soma de quadrados de tratamentos $\mathrm{x}$ locais, em efeitos de parentais $\mathrm{x}$ locais $\mathrm{e}$ linhagens $\mathrm{F}_{8: 6} \mathrm{x}$ locais, e linhagens $\mathrm{F}_{8: 6} \mathrm{x}$ locais em efeitos de cruzamento $\mathrm{x}$ locais e linhagens $\mathrm{F}_{8: 6}$ dentro de cruzamento $\mathrm{x}$ locais, dos caracteres número de dias para a maturidade (NDM), altura da planta na maturidade (APM), valor agronômico (VA) e produtividade de grãos (PG), nos experimentos da geração F $_{8: 6}$, em Anhembi e Areão, semeadura em 08 e 18-11-1993, respectivamente. Soja semi-tardia/tardia, linhagens mais produtivas (QLPs), parcela uma fileira de $4 \mathrm{~m} \times 0,5 \mathrm{~m}$. Piracicaba-SP.

\begin{tabular}{|c|c|c|c|c|c|}
\hline \multirow[b]{2}{*}{ FV } & \multirow[b]{2}{*}{ GL } & \multicolumn{4}{|c|}{ Quadrado Médio } \\
\hline & & NDM(dias) & $\overline{\mathrm{APM}}(\mathrm{cm})$ & VA (nota) & PG $\left(\mathrm{g} / \mathrm{m}^{2}\right)$ \\
\hline Local (E) & 1 & $20463,96^{* *}$ & $16308,34^{* *}$ & $25,06^{* *}$ & $4707828^{* *}$ \\
\hline Tratamentos (N) & 189 & $121,46^{* *}$ & $922,04 * *$ & $1,92 * *$ & $31904 * *$ \\
\hline Parentais & 9 & $247,84^{* *}$ & $2737,04 * *$ & $2,32 *$ & $89723 * *$ \\
\hline Linh. F8:6 (L) & 179 & $123,10 * *$ & $921,10 * *$ & $1,98 * *$ & $32545^{* *}$ \\
\hline Cruz. (C) & 44 & $221,50 * *$ & $1375,02 * *$ & $2,36 * *$ & $40321 * *$ \\
\hline $\mathrm{L} / \mathrm{C}$ & 135 & $91,04 * *$ & $773,16 * *$ & $1,88 * *$ & $30010^{* *}$ \\
\hline $\mathrm{E} \times \mathrm{N}$ & 189 & $48,08 * *$ & $215,32 * *$ & $1,54^{*}$ & $18109 * *$ \\
\hline E x Parentais & 9 & $29,52 * *$ & $341,36 * *$ & $4,00 * *$ & $55789 * *$ \\
\hline $\mathrm{E} \times \mathrm{L}$ & 179 & $50,38 * *$ & $221,16 * *$ & $1,56 * *$ & $18020 * *$ \\
\hline $\mathrm{E} \times \mathrm{C}$ & 44 & $60,52 * *$ & $197,24 *$ & $1,90 * *$ & $25776^{* *}$ \\
\hline $\mathrm{E} \times \mathrm{L} / \mathrm{C}$ & 135 & $47,08 * *$ & $228,94 * *$ & $1,44 * *$ & $15493 * *$ \\
\hline Parentais vs L & 1 & $362,94 * *$ & $3230,26 * *$ & 0,08 & 2534 \\
\hline E x Parentais vs & & 2,68 & 341,34 & 1,38 & $71388 * *$ \\
\hline Resíduo & 498 & 30,27 & 142,55 & 1,07 & 10195 \\
\hline Média Parentais & & 155,50 & 112,85 & 3,04 & 330,82 \\
\hline Média Linh. $\mathrm{F}_{8: 6}$ & & 158,61 & 120,40 & 3,03 & 323,58 \\
\hline CV (\%) & & 3,27 & 9,93 & 5,46 & 30,04 \\
\hline $\mathrm{L} / \mathrm{Ci} \times \mathrm{j}^{1}$ & 3 & 13 & 25 & 12 & 25 \\
\hline$E \times L / C i \times j^{1}$ & 3 & 1 & 6 & 6 & 6 \\
\hline
\end{tabular}

${ }^{1}$ Número de cruzamentos com efeitoss significativos $(P<0,05)$ para as fontes de variação.

*, **: Significativo a 5 e $1 \%$ de probabilidade, respectivamente, pelo teste $\mathrm{F}$. 
Tabela 13. NDM: número de dias para a maturidade (dias), médias dos parentais e das linhagens $\mathrm{F}_{7: 6}$ e $\mathrm{F}_{8: 6}$ dos 45 cnuzamentos dialélicos, em Anhembi e Areão. Soja semi-tardia/tardia, parcela de uma fileira de $2 \mathrm{~m}$ x 0,5 m com semeadura em 17-12-1992 nos dois locais para $F_{7: 6}$ e parcela de uma fileira de $4 \mathrm{~m} \times$ 0,5 $\mathrm{m}$ com semeadura em 08 e 18-11-1993 em Anhembi e Areão, respectivamente para $\mathrm{F}_{8: 6}$ (QLEs e QLPs). Piracicaba-SP.

\begin{tabular}{|c|c|c|c|c|c|c|}
\hline \multirow[b]{2}{*}{ Tratamentos } & \multicolumn{2}{|c|}{$F_{7: 6}$} & \multicolumn{2}{|c|}{$F_{8: 6}(\mathrm{QLEs})$} & \multicolumn{2}{|c|}{$F_{8: 6}(\mathrm{QLPs})$} \\
\hline & Anhembi & Areão & Anhembi & Areão & Anhembi & Areāo \\
\hline 1 -FT-Cristalina & 143,5 & 143,7 & 166,0 & 154,9 & 166,3 & 159,0 \\
\hline 2 - EMGOPA-301 & 142,3 & 138,7 & 165,4 & 158,3 & 166,5 & 157,1 \\
\hline 3 - LAC-4 & 132,2 & 131,5 & 157,1 & 146,0 & 158,5 & 147,1 \\
\hline $4-I A C-5$ & 133,6 & 132,1 & 157,9 & 143,1 & 159,8 & 146,9 \\
\hline 5 - IAC-6 & 135,6 & 138,9 & 158,3 & 151,8 & 161,0 & 151,0 \\
\hline $6-$ IAC-8 & 135,8 & 137,9 & 156,1 & 144,6 & 157,5 & 147,3 \\
\hline 7- IAC-9 & 138,8 & 141,3 & 160,7 & 153,3 & 161,0 & 153,9 \\
\hline $8-$ IAC-11 & 132,1 & 133,8 & 157,4 & 145,6 & 157,5 & 145,6 \\
\hline 9-Santa Rosa & 134,6 & 133,2 & 159,5 & 145,6 & 160,0 & 147,4 \\
\hline 10 - SS-1 & 130,3 & 131,6 & 153,5 & 142,6 & 161,5 & 145,4 \\
\hline FT-Cristalina x EMGOPA-301 & 147,1 & 154,9 & 166,5 & 156,5 & 170,6 & 164,4 \\
\hline FT-Cristalina x LAC-4 & 140,1 & 140,5 & 162,3 & 150,3 & 167,1 & 163,5 \\
\hline FT-Cristalina $\times$ IAC-5 & 139,4 & 138,6 & 165,4 & 154,5 & 166,5 & 155,8 \\
\hline FT-Cristalina x IAC-6 & 137,5 & 138,2 & 163,3 & 155,5 & 165,8 & 155,5 \\
\hline FT-Cristalina x IAC-8 & 140,5 & 141,1 & 157,4 & 148,6 & 162,0 & 152,4 \\
\hline FT-Cristalina x IAC-9 & 142,7 & 143,2 & 166,0 & 156,3 & 165,5 & 155,9 \\
\hline FT-Cristalina x LAC-1 1 & 136,2 & 137,0 & 160,4 & 151,0 & 163,9 & 155,0 \\
\hline FT-Cristalina $x$ Santa Rosa & 142,9 & 139,5 & 161,4 & 150,6 & 171,8 & 162,3 \\
\hline FT-Cristalina x SS-1 & 139,9 & 142,1 & 160,9 & 148,4 & 162,8 & 150,8 \\
\hline EMGOPA-301 x IAC-4 & 139,2 & 136,1 & 164,9 & 153,8 & 169,1 & 153,6 \\
\hline EMGOPA-301 x IAC-5 & 131,8 & 130,3 & 153,4 & 142,8 & 156,3 & 146,0 \\
\hline EMGOPA-301 x IAC-6 & 146,4 & 144,8 & 162,4 & 157,9 & 169,3 & 158,6 \\
\hline EMGOPA-301 x IAC-8 & 142,0 & 143,6 & 162,9 & 154,1 & 163,0 & 151,6 \\
\hline EMGOPA-301 x IAC-9 & 143,1 & 143,5 & 162,1 & 150,5 & 165,3 & 157,9 \\
\hline EMGOPA-301 x IAC-11 & 141,4 & 139,3 & 161,6 & 153,9 & 164,8 & 155,5 \\
\hline EMGOPA-301 x Santa Rosa & 143,8 & 140,3 & 166,3 & 156,4 & 171,9 & 158,6 \\
\hline EMGOPA-301 x SS-1 & 139,4 & 138,7 & 157,5 & 147,1 & 165,6 & 151,8 \\
\hline IAC-4 x IAC-5 & 134,4 & 134,0 & 162,0 & 151,0 & 167,5 & 137,6 \\
\hline IAC- $4 \times$ IAC- 6 & 136,9 & 137,0 & 161,1 & 148,8 & 164,8 & 154,3 \\
\hline IAC-4 x IAC- 8 & 135,8 & 135,1 & 159,3 & 148,0 & 162,0 & 148,8 \\
\hline IAC-4 x IAC-9 & 141,4 & 143,5 & 163,1 & 151,0 & 163,9 & 153,8 \\
\hline IAC-4 x IAC-11 & 135,2 & 137,5 & 158,9 & 146,4 & 161,8 & 150,6 \\
\hline IAC-4 x Santa Rosa & 134,4 & 136,3 & 160,8 & 146,9 & 159,8 & 148,0 \\
\hline IAC-4 x SS-1 & 134,8 & 136,2 & 157,0 & 145,8 & 163,3 & 152,4 \\
\hline IAC-5 x IAC-6 & 139,4 & 138,8 & 158,5 & 148,4 & 164,8 & 160,9 \\
\hline IAC-5 x IAC-8 & 135,4 & 136,2 & 155,1 & 141,9 & 162,0 & 151,9 \\
\hline IAC-5 x IAC-9 & 138,4 & 139,7 & 162,5 & 146,8 & 163,0 & 153,5 \\
\hline IAC-5 x IAC-11 & 134,7 & 134,8 & 157,6 & 145,3 & 162,4 & 152,8 \\
\hline IAC-5 x Santa Rosa & 133,0 & 131,7 & 157,8 & 142,5 & 159,1 & 146,1 \\
\hline IAC-5 x SS-1 & 133,6 & 134,5 & 157,8 & 145,3 & 159,8 & 148,5 \\
\hline IAC-6 x IAC-8 & 138,6 & 139,5 & 157,1 & 144,5 & 162,3 & 154,8 \\
\hline IAC-6 x IAC-9 & 142,3 & 142,7 & 160,4 & 155,4 & 163,3 & 157,9 \\
\hline IAC-6 x IAC-11 & 135,0 & 137,0 & 159,0 & 147,9 & 160,0 & 149,1 \\
\hline IAC- 6 x Santa Rosa & 142,1 & 145,2 & 160,9 & 152,9 & 165,5 & 156,4 \\
\hline IAC-6 x SS-1 & 135,1 & 138,0 & 159,4 & 153,4 & 161,9 & 152,5 \\
\hline IAC-8 x IAC-9 & 139,6 & 138,9 & 157,1 & 149,6 & 163,6 & 153,6 \\
\hline IAC-8 x IAC-11 & 139,2 & 136,4 & 155,4 & 143,4 & 161,0 & 152,5 \\
\hline IAC-8 x Santa Rosa & 134,7 & 134,0 & 156,5 & 144,0 & 159,8 & 149,3 \\
\hline IAC-8 x SS-1 & 134,8 & 136,5 & 155,6 & 144,9 & 159,0 & 148,1 \\
\hline IAC-9 x IAC-11 & 137,6 & 139,4 & 160,8 & 153,4 & 162,4 & 152,9 \\
\hline IAC-9 x Santa Rosa & 137,5 & 139,2 & 162,6 & 153,9 & 165,9 & 156,3 \\
\hline IAC-9 x SS-1 & 141,5 & 141,8 & 154,6 & 144,9 & 161,8 & 155,8 \\
\hline IAC-11 x Santa Rosa & 134,0 & 133,8 & 156,8 & 148,5 & 162,5 & 153,4 \\
\hline IAC-11 x SS-1 & 134,0 & 134,4 & 154,3 & 143,9 & 163,3 & 148,0 \\
\hline Santa Rosa x SS-1 & 135,3 & 138,8 & 157,8 & 147,4 & 163,1 & 155,9 \\
\hline Parentais & 135,9 & 136,3 & 159,2 & 148,6 & 161,0 & 150,1 \\
\hline Linhagens & 138,2 & 138,7 & 159,9 & 149,4 & 163,8 & 153,4 \\
\hline$\overline{\mathrm{DMS}}_{0.05}$ & 6,1 & 3,6 & 3,9 & 6,4 & 5,3 & 12,7 \\
\hline
\end{tabular}


Tabela 14. APM: altura da planta na maturidade (cm), médias dos parentais e das linhagens $F_{7: 6}$ e $F_{8: 6}$ dos 45 cruzamentos dialélicos, em Anhembi e Areão. Soja semi-tardia/tardia. Parcela de uma fileira de $2 \mathrm{~m} \times$ 0,5 m com semeadura em 17-12-1992 nos dois locais para $\mathrm{F}_{7: 6}$. Parcela de uma fileira de $4 \mathrm{~m}$ x 0,5 m com semeadura em 08 e 18-11-1993 em Anhembi e Areão, respectivamente para $\mathrm{F}_{8: 6}$ (QLEs e QLPs). Piracicaba-SP.

\begin{tabular}{|c|c|c|c|c|c|c|}
\hline \multirow[b]{2}{*}{ Tratamentos } & \multicolumn{2}{|c|}{$\mathrm{F}_{7: 6}$} & \multicolumn{2}{|c|}{$F_{8: 6}(\mathrm{QLEs})$} & \multicolumn{2}{|c|}{$\mathrm{F}_{8: 6}$ (QLPs) } \\
\hline & Anhembi & Areão & Anhembi & Areão & Anhembi & Arežo \\
\hline 1-FT-Cristalina & 79,2 & 87,4 & 123,8 & 110,5 & 122,5 & 110,0 \\
\hline 2 - EMGOPA-301 & 91,6 & 95,7 & 139,4 & 140,3 & 143,1 & 127,5 \\
\hline $3-I A C-4$ & 65,7 & 79,4 & 90,0 & 101,6 & 90,6 & 101,3 \\
\hline $4-$ IAC-5 & 78,6 & 91,8 & 129,4 & 126,0 & 128,1 & 121,3 \\
\hline 5 - IAC-6 & 87,7 & 103,1 & 121,9 & 137,5 & 130,6 & 118,8 \\
\hline $6-$ IAC-8 & 88,9 & 97,8 & 99,4 & 115,4 & 109,5 & 106,3 \\
\hline 7-IAC-9 & 75,2 & 91,6 & 107,9 & 111,9 & 111,9 & 110,0 \\
\hline 8 - IAC-11 & 81,5 & 93,3 & 112,5 & 121,4 & 108,1 & 111,9 \\
\hline 9-Santa Rosa & 76,6 & 84,2 & 98,8 & 104,3 & 87,5 & 97,5 \\
\hline 10 - SS-1 & 77,0 & 89,2 & 103,1 & 107,4 & 114,4 & 106,3 \\
\hline FT-Cristalina $x$ EMGOPA-301 & 91,5 & 98,8 & 128,8 & 121,4 & 138,8 & $\overline{130,6}$ \\
\hline FT-Cristalina x IAC-4 & 71,6 & 87,3 & 118,8 & 114,0 & 120,0 & 115,6 \\
\hline FT-Cristalina $\times$ IAC-5 & 81,3 & 90,1 & 116,9 & 102,4 & 129,4 & 107,5 \\
\hline FT-Cristalina x IAC-6 & 77,9 & 88,6 & 119,4 & 116,6 & 125,6 & 121,9 \\
\hline FT-Cristalina $\times$ IAC-8 & 86,1 & 101,8 & 96,3 & 106,9 & 125,0 & 107,5 \\
\hline FT-Cristalina x IAC-9 & 79,5 & 94,8 & 119,4 & 112,0 & 130,6 & 116,3 \\
\hline FT-Cristalina x IAC-11 & 79,8 & 91,1 & 115,6 & 125,8 & 122,5 & 109,4 \\
\hline FT-Cristalina x Santa Rosa & 82,4 & 96,8 & 116,9 & 122,9 & 125,6 & 122,5 \\
\hline FT-Cristalina x SS-1 & 78,1 & 93,4 & 105,0 & 95,4 & 110,0 & 104,4 \\
\hline EMGOPA-301 x IAC-4 & 82,6 & 86,2 & 125,0 & 114,6 & 130,6 & 118,1 \\
\hline EMGOPA-301 x IAC-5 & 51,1 & 63,5 & 101,9 & 96,5 & 111,9 & 106,3 \\
\hline EMGOPA-301 x IAC-6 & 92,0 & 100,1 & 129,4 & 125,0 & 146,9 & 136,3 \\
\hline EMGOPA-301 x IAC-8 & 88,1 & 103,0 & 126,9 & 129,4 & 128,1 & 123,1 \\
\hline EMGOPA-301 x IAC-9 & 83,9 & 97,2 & 127,5 & 124,1 & 131,3 & 118,1 \\
\hline EMGOPA-301 x IAC-11 & 81,1 & 94,7 & 129,4 & 120,9 & 131,9 & 122,6 \\
\hline EMGOPA-301 x Santa Rosa & 86,3 & 96,5 & 138,1 & 131,3 & 140,0 & 130,6 \\
\hline EMGOPA-301 x SS-1 & 88,1 & 95,9 & 105,0 & 110,0 & 138,8 & 126,3 \\
\hline IAC-4 x IAC-5 & 77,1 & 85,8 & 123,1 & 124,1 & 121,9 & 119,4 \\
\hline IAC- $4 \times$ IAC- 6 & 75,8 & 87,6 & 106,9 & 113,5 & 121,3 & 116,9 \\
\hline IAC- $4 \times$ IAC- 8 & 77,9 & 84,2 & 101,9 & 98,8 & 108,1 & 98,8 \\
\hline IAC-4 x IAC-9 & 75,1 & 86,7 & 110,6 & 110,1 & 115,0 & 103,1 \\
\hline IAC-4 x IAC-11 & 77,1 & 85,2 & 114,3 & 108,0 & 112,5 & 112,5 \\
\hline IAC-4 x Santa Rosa & 73,8 & 83,1 & 87,5 & 101,9 & 116,9 & 108,1 \\
\hline IAC- 4 x SS-1 & 73,8 & 89,3 & 113,8 & 122,0 & 118,8 & 119,4 \\
\hline IAC-5 x IAC-6 & 96,0 & 104,8 & 131,3 & 124,8 & 156,9 & 130,0 \\
\hline IAC-5 x IAC- 8 & 89,1 & 100,3 & 109,4 & 106,6 & 129,4 & 107,5 \\
\hline IAC-5 x IAC-9 & 91,5 & 97,7 & 117,5 & 108,0 & 151,3 & 127,5 \\
\hline IAC-5 x IAC-11 & 90,3 & 100,2 & 116,4 & 121,1 & 137,5 & 126,3 \\
\hline IAC-5 x Santa Rosa & 80,8 & 91,0 & 120,6 & 130,5 & 127,5 & 121,9 \\
\hline IAC-5 x SS-1 & 92,3 & 105,1 & 126,3 & 126,8 & 134,4 & 117,5 \\
\hline IAC-6 $\times$ IAC-8 & 87,1 & 103,0 & 119,4 & 125,5 & 126,9 & 120,6 \\
\hline IAC-6 x IAC-9 & 89,2 & 102,7 & 121,9 & 128,1 & 138,8 & 115,6 \\
\hline IAC-6 x IAC-11 & 83,5 & 94,9 & 121,9 & 120,0 & 128,8 & 121,3 \\
\hline IAC-6 x Santa Rosa & 89,1 & 103,9 & 128,1 & 127,6 & 136,9 & 123,1 \\
\hline IAC-6 x SS-1 & 90,9 & 95,8 & 125,0 & 125,8 & 134,4 & 128,1 \\
\hline IAC-8 x IAC-9 & 81,9 & 98,3 & 114,4 & 114,4 & 122,5 & 109,4 \\
\hline IAC-8 x IAC-11 & 81,2 & 92,4 & 85,0 & 93,0 & 124,4 & 123,8 \\
\hline IAC- 8 x Santa Rosa & 77,3 & 86,3 & 84,4 & 77,8 & 123,8 & 109,4 \\
\hline IAC-8 x SS-1 & 86,7 & $\mathbf{9 8 , 0}$ & 102,5 & 108,5 & 110,0 & 110,6 \\
\hline IAC-9 x IAC-11 & $.80,5$ & 92,6 & 115,6 & 120,9 & 113,8 & 110,0 \\
\hline IAC-9 x Santa Rosa & 75,9 & 89,0 & 128,1 & 122,3 & 126,9 & 120,6 \\
\hline IAC-9 x SS-1 & 83,3 & 95,3 & 99,3 & 106,5 & 111,9 & 110,6 \\
\hline IAC-11 x Sant a Rosa & 81,2 & 90,8 & 115,0 & 116,3 & 132,5 & 118,8 \\
\hline IAC-11 x SS-1 & 74,4 & 86,7 & 93,1 & 107,5 & 115,6 & 103,8 \\
\hline Santa Rosa x SS-1 & 83,4 & 95,8 & 117,5 & 111,5 & 124,4 & 126,9 \\
\hline Parentais & 80,1 & 91,3 & 112,7 & 117,6 & 114,6 & 111,1 \\
\hline Linhagens & 82,2 & 93,5 & 115,0 & 114,9 & 126,9 & 117,3 \\
\hline $\mathrm{DMS}_{0 . \overline{ }} \overline{(1)}$ & 9,0 & 10,1 & 19,3 & 21,5 & 21,1 & 21,2 \\
\hline
\end{tabular}


Tabela 15. VA: valor agronômico (nota: $1=$ péssimo a $\mathbf{5}=$ excelente), médias dos parentais e das linhagens $F_{7: 6}$ e $F_{8: 6}$ dos 45 cruzamentos dialélicos, em Anhembi e Areão. Soja semitardia/tardia. Parcela de uma fileira de $2 \mathrm{~m} \mathrm{x} \mathrm{0,5} \mathrm{m} \mathrm{com} \mathrm{semeadura} \mathrm{em} \mathrm{17-12-1992} \mathrm{nos}$ dois locais para $F_{7: 6}$. Parcela de uma fileira de $4 \mathrm{~m} \times 0,5 \mathrm{~m}$ com semeadura em 8 e 18-111993 em Anhembi e Areão, respectivamente para $F_{8: 6}$ (QLEs e QLPs). Piracicaba-SP.

\begin{tabular}{|c|c|c|c|c|c|c|}
\hline \multirow[b]{2}{*}{ Tratamentos } & \multicolumn{2}{|c|}{$\mathrm{F}_{7: 6}$} & \multicolumn{2}{|c|}{$F_{8: 6}$ (QLEs) } & \multicolumn{2}{|c|}{$F_{8: 6}(Q L P s)$} \\
\hline & Anhembi & Areão & Anhembi & Areāo & Anhembi & Areāo \\
\hline 1 - FT-Cristalina & 3,64 & 3,82 & 3,69 & 3,25 & 3,31 & 3,19 \\
\hline 2 - EMGOPA-301 & 4,21 & 3,93 & 3,75 & 3,19 & 3,50 & 3,06 \\
\hline $3-\mathrm{IAC}-4$ & 2,96 & 3,52 & 2,94 & 3,25 & 3,75 & 3,50 \\
\hline 4 - IAC-5 & 3,34 & 3,76 & 2,81 & 3,13 & 3,81 & 2,88 \\
\hline 5 - IAC-6 & 3,96 & 4,02 & 3,06 & 3,06 & 3,25 & 2,88 \\
\hline 6 - IAC-8 & 4,02 & 4,19 & 3,06 & 3,31 & 3,00 & 2,75 \\
\hline 7 - IAC-9 & 3,31 & 3,67 & 3,14 & 3,06 & 3,06 & 2,94 \\
\hline 8 - IAC-11 & 3,52 & 4,11 & 3,13 & 3,38 & 2,88 & 3,00 \\
\hline 9 - Santa Rosa & 3,37 & 3,81 & 3,00 & 3,38 & 2,81 & 3,31 \\
\hline 10 - SS-1 & 3,01 & 3,77 & 2,75 & 3,00 & 3,00 & 3,00 \\
\hline FT-Cristalina x EMGOPA-301 & 3,68 & 3,89 & 3,81 & 3,25 & 3,56 & 2,88 \\
\hline FT-Cristalina x IAC-4 & 3,36 & 3,78 & 3,19 & 3,06 & 3,06 & 3,00 \\
\hline FT-Cristalina x IAC-5 & 3,56 & 3,72 & 3,25 & 2,88 & 3,25 & 3,00 \\
\hline FT-Cristalina x IAC-6 & 3,58 & 3,66 & 3,25 & 3,06 & 3,00 & 2,88 \\
\hline FT-Cristalina x IAC-8 & 3,73 & 4,08 & 2,88 & 3,06 & 3,31 & 3,13 \\
\hline FT-Cristalina x IAC-9 & 3,56 & 3,74 & 3,63 & 3,25 & 3,25 & 3,00 \\
\hline FT-Cristalina x IAC-1 1 & 3,61 & 3,87 & 3,25 & 3,19 & 3,25 & 3,06 \\
\hline FT-Cristalina x Santa Rosa & 3,61 & 3,87 & 3,00 & 3,13 & 2,88 & 2,69 \\
\hline FT-Cristalina x SS-1 & 3,28 & 3,85 & 2,64 & 2,94 & 3,13 & 2,75 \\
\hline EMGOPA-301 x IAC-4 & 3,64 & 3,81 & 3,31 & 3,31 & 3,38 & 3,25 \\
\hline EMGOPA-301 x IAC-5 & 2,39 & 2,78 & 2,38 & 2,56 & 2,94 & 2,88 \\
\hline EMGOPA-301 x IAC-6 & 3,98 & 3,89 & 3,38 & 3,06 & 3,63 & 2,81 \\
\hline EMGOPA-301 x IAC-8 & 3,99 & 4,06 & 3,31 & 3,13 & 3,19 & 2,94 \\
\hline EMGOPA-301 x IAC-9 & 3,81 & 3,89 & 3,00 & 3,06 & 3,25 & 3,00 \\
\hline EMGOPA-301 x IAC-11 & 3,76 & 3,91 & 3,31 & 2,94 & 3,19 & 2,81 \\
\hline EMGOPA-301 x Santa Rosa & 3,76 & 3,87 & 3,44 & 3,06 & 3,50 & 2,75 \\
\hline EMGOPA-301 x SS-1 & 3,79 & 3,91 & 2,94 & 3,00 & 3,31 & 3,13 \\
\hline IAC-4 x IAC-5 & 3,42 & 3,68 & 3,00 & 3,19 & 3,00 & 2,88 \\
\hline IAC- 4 x IAC- 6 & 3,37 & 3,76 & 3,06 & 3,19 & 2,88 & 2,94 \\
\hline IAC-4 x IAC-8 & 3,46 & 3,58 & 2,81 & 3,00 & 3,00 & 3,00 \\
\hline IAC-4 x IAC-9 & 3,34 & 3,64 & 3,00 & 3,13 & 2,94 & 3,25 \\
\hline IAC-4 x IAC-11 & 3,59 & 3,81 & 3,00 & 3,19 & 3,00 & 3,06 \\
\hline IAC-4 x Santa Rosa & 3,21 & 3,66 & 2,81 & 3,13 & 2,75 & 3,00 \\
\hline LAC- $-4 \times$ SS-1 & 3,29 & 3,74 & 2,94 & 2,94 & 3,00 & 3,19 \\
\hline IAC-5 x IAC-6 & 3,94 & 3,97 & 2,75 & 2,88 & 3,13 & 2,94 \\
\hline IAC-5 x IAC-8 & 3,87 & 3,91 & 2,63 & 2,75 & 3,00 & 3,06 \\
\hline IAC-5 x IAC-9 & 3,68 & 3,64 & 3,13 & 3,06 & 2,81 & 2,75 \\
\hline IAC-5 x IAC-11 & 3,84 & 4,02 & 2,86 & 2,88 & 3,13 & 2,94 \\
\hline IAC-5 x Santa Rosa & 3,41 & 3,66 & 2,75 & 2,94 & 2,44 & 2,81 \\
\hline IAC-5 x SS-1 & 3,83 & 4,04 & 3,19 & 3,06 & 2,94 & 2,81 \\
\hline IAC-6 x IAC-8 & 3,86 & 3,97 & 2,81 & 3,06 & 3,13 & 2,69 \\
\hline IAC-6 x IAC-9 & 3,84 & 3,72 & 3,00 & 3,00 & 3,00 & 2,69 \\
\hline IAC-6 x IAC-11 & 3,69 & 3,89 & 2,94 & 3,06 & 2,94 & 2,88 \\
\hline IAC-6 x Santa Rosa & 3,81 & 3,95 & 2,88 & 2,94 & 3,31 & 2,88 \\
\hline IAC-6 x SS-1 & 4,04 & 3,93 & 3,06 & 3,06 & 3,13 & 2,94 \\
\hline IAC-8 x IAC-9 & 3,54 & 3,93 & 3,31 & 3,06 & 2,94 & 3,06 \\
\hline IAC-8 x IAC-11 & 3,54 & 3,91 & 2,69 & 3,00 & 3,06 & 3,31 \\
\hline IAC-8 x Santa Rosa & 3,64 & 3,85 & 2,75 & 2,81 & 3,06 & 3,06 \\
\hline IAC-8 x SS-1 & 3,65 & 3,87 & 2,81 & 3,13 & 3,38 & 3,00 \\
\hline LAC-9 x IAC-11 & 3,51 & 3,74 & 3,00 & 3,06 & 3,13 & 2,94 \\
\hline IAC-9 x Santa Rosa & 3,42 & 3,36 & 3,06 & 3,06 & 3,13 & 3,19 \\
\hline IAC-9 x SS-1 & 3,37 & 3,76 & 2,43 & 2,81 & 2,88 & 2,75 \\
\hline IAC-11 x Santa Rosa & 3,53 & 3,78 & 2,94 & 3,00 & 3,13 & 3,00 \\
\hline IAC-11 x SS-1 & 3,13 & 3,72 & 2,75 & 3,31 & 2,81 & 3,00 \\
\hline Santa Rosa x SS-1 & 3,40 & 3,93 & 3,25 & 3,00 & 3,19 & 3,06 \\
\hline Parentais & 3,53 & 3,86 & 3,13 & 3,20 & 3,04 & 3,05 \\
\hline Linhagens & 3,58 & 3,87 & 3,02 & 3,04 & 3,09 & 2,96 \\
\hline $\mathrm{DMS}_{0.05}$ & 0,33 & 0,29 & 0,19 & 0,15 & 0,16 & 0,20 \\
\hline
\end{tabular}


Tabela 16. PG: produtividade de grãos $\left(\mathrm{g} / \mathrm{m}^{2}\right)$, médias dos parentais e das linhagens $\mathrm{F}_{7.6}$ e $\mathrm{F}_{8: 6}$ dos 45 cruzamentos dialélicos, cm Anhembi e Areão. Soja semi-tardia/tardia. Parcela de uma fileira de $2 \mathrm{~m} \mathrm{x} \mathrm{0,5} \mathrm{m} \mathrm{com} \mathrm{semeadura} \mathrm{em} \mathrm{17-12-1992} \mathrm{nos} \mathrm{dois} \mathrm{locais} \mathrm{para} F_{7: 6}$. Parcela de uma fileira de $4 \mathrm{~m} \times$ 0,5 m com semeadura em 08 e 18-11-1993 em Anhembi e Areão, respectivamente para $F_{8: 6}$ (QLEs e QLPs). Piracicaba-SP.

\begin{tabular}{|c|c|c|c|c|c|c|}
\hline \multirow[b]{2}{*}{ Tratamentos } & \multicolumn{2}{|c|}{$F_{7: 6}$} & \multicolumn{2}{|c|}{$\mathrm{F}_{8: 6}$ (QLEs) } & \multicolumn{2}{|c|}{$\mathrm{F}_{8: 6}(\mathrm{QLPs})$} \\
\hline & Anhembi & Areão & Anhembi & Areão & Anhernbi & Areāo \\
\hline 1-FT-Cristalina & 320 & 200 & 636 & 361 & 521 & 370 \\
\hline 2 - EMGOPA-301 & 360 & 181 & 685 & 308 & 613 & 306 \\
\hline 3 - IAC-4 & 191 & 124 & 342 & 312 & 267 & 341 \\
\hline 4 - IAC-5 & 150 & 93 & 413 & 245 & 249 & 235 \\
\hline 5 - IAC-6 & 292 & 179 & 455 & 301 & 448 & 281 \\
\hline 6 - IAC-8 & 224 & 146 & 519 & 321 & 337 & 245 \\
\hline 7 - IAC-9 & 257 & 171 & 518 & 302 & 378 & 295 \\
\hline 8 - IAC-11 & 226 & 163 & 469 & 279 & 238 & 285 \\
\hline 9- Santa Rosa & 239 & 144 & 500 & 360 & 302 & 351 \\
\hline $10-$ SS-1 & 146 & 139 & 349 & 240 & 316 & 209 \\
\hline FT-Cristalina $x$ EMGOPA-301 & 332 & 143 & 644 & 350 & 519 & 216 \\
\hline FT-Cristalina x IAC-4 & 232 & 174 & 458 & 283 & 309 & 230 \\
\hline FT-Cristalina x IAC-5 & 239 & 165 & 449 & 270 & 512 & 258 \\
\hline FT-Cristalina x IAC-6 & 273 & 166 & 479 & 313 & 335 & 232 \\
\hline FT-Cristalina x IAC-8 & 266 & 193 & 444 & 230 & 486 & 256 \\
\hline FT-Cristalina x IAC-9 & 327 & 191 & 621 & 286 & 480 & 328 \\
\hline FT-Cristalina x IAC-11 & 275 & 196 & 497 & 261 & 486 & 352 \\
\hline FT-Cristalina x Santa Rosa & 288 & 180 & 510 & 311 & 384 & 236 \\
\hline FT-Cristalina x SS-1 & 210 & 150 & 303 & 147 & 434 & 224 \\
\hline EMGOPA-301 x IAC-4 & 236 & 150 & 566 & 265 & 448 & 254 \\
\hline EMGOPA-301 x IAC-5 & 76 & 88 & 220 & 194 & 355 & 216 \\
\hline EMGOPA-301 x IAC-6 & 278 & 173 & 574 & 268 & 607 & 179 \\
\hline EMGOPA-301 x IAC-8 & 319 & 172 & 578 & 253 & 492 & 248 \\
\hline EMGOPA-301 x IAC-9 & 306 & 158 & 435 & 233 & 391 & 252 \\
\hline EMGOPA-301 x IAC-11 & 247 & 161 & 482 & 225 & 439 & 223 \\
\hline EMGOPA-301 x Santa Rosa & 312 & 171 & 512 & 309 & 505 & 234 \\
\hline EMGOPA-301 x SS-1 & 268 & 158 & 411 & 210 & 460 & 258 \\
\hline IAC-4 x IAC-5 & 202 & 134 & 351 & 290 & 290 & 196 \\
\hline IAC-4 x IAC-6 & 199 & 155 & 412 & 308 & 297 & 245 \\
\hline IAC-4 x IAC-8 & 204 & 128 & 385 & 266 & 369 & 180 \\
\hline IAC-4 x IAC-9 & 232 & 178 & 324 & 247 & 305 & 279 \\
\hline IAC-4 x IAC-11 & 262 & 166 & 366 & 221 & 351 & 285 \\
\hline IAC-4 x Santa Rosa & 212 & 148 & 306 & 254 & 275 & 210 \\
\hline IAC-4 x SS-1 & 208 & 151 & 382 & 175 & 414 & 263 \\
\hline IAC-5 x IAC-6 & 272 & 156 & 302 & 205 & 547 & 256 \\
\hline IAC-5 x IAC-8 & 219 & 115 & 297 & 199 & 434 & 266 \\
\hline IAC-5 x IAC-9 & 234 & 130 & 373 & 213 & 300 & 205 \\
\hline IAC-5 x IAC-11 & 232 & 135 & 334 & 186 & 347 & 155 \\
\hline IAC-5 x Santa Rosa & 181 & 103 & 317 & 243 & 251 & 201 \\
\hline IAC-5 x SS-1 & 199 & 129 & 373 & 208 & 389 & 224 \\
\hline IAC-6 x IAC-8 & 233 & 157 & 446 & 249 & 375 & 225 \\
\hline IAC-6 x IAC-9 & 282 & 161 & 514 & 275 & 443 & 245 \\
\hline IAC-6 x IAC-11 & 245 & 165 & 297 & 216 & 308 & 206 \\
\hline IAC-6 x Santa Rosa & 259 & 167 & 367 & 290 & 473 & 224 \\
\hline IAC-6 x SS-1 & 303 & 173 & 469 & 229 & 460 & 275 \\
\hline IAC-8 x IAC-9 & 246 & 158 & 451 & 252 & 382 & 255 \\
\hline IAC-8 x IAC-11 & 215 & 146 & 374 & 233 & 437 & 264 \\
\hline IAC-8 x Santa Rosa & 190 & 135 & 285 & 201 & 381 & 248 \\
\hline IAC-8 x SS-1 & 194 & 158 & 377 & 284 & 501 & 271 \\
\hline IAC-9 x IAC-11 & 242 & 170 & 379 & 318 & 333 & 262 \\
\hline IAC-9 x Santa Rosa & 215 & 149 & 425 & 284 & 381 & 287 \\
\hline IAC-9 x SS-1 & 202 & 139 & 273 & 168 & 353 & 223 \\
\hline IAC-11 x Santa Rosa & 203 & 172 & 414 & 245 & 451 & 264 \\
\hline IAC-11 x SS-1 & 152 & 130 & 371 & 217 & 270 & 204 \\
\hline Santa Rosa x SS-1 & 195 & 126 & 498 & 206 & 382 & 230 \\
\hline Parentais & 240 & 154 & 488 & 304 & 367 & 292 \\
\hline Linhagens & 238 & 154 & 416 & 247 & 403 & 241 \\
\hline $\mathrm{DMS}_{0.05}$ & 85 & 47 & 224 & 135 & 217 & 129 \\
\hline
\end{tabular}


Tabela 17. Valores mínimo (mín.), máximo (máx.) e amplitude (amp.) para NDM - número de dias para a maturidade (dias) e APM - altura da planta na maturidade $(\mathrm{cm})$ dos parentais e dos 45 cruzamentos dialélicos, em Anhembi e Areão. Soja semi-tardia/tardia, linhagens $F_{7: 6}$, semeadura em 17-12-1992, parcela 1 linha de $2 \mathrm{~m}$ x 0,5 m. Piracicaba-SP.

\begin{tabular}{|c|c|c|c|c|c|c|c|c|c|c|c|c|}
\hline \multirow[b]{3}{*}{ Tratamentos } & \multicolumn{6}{|c|}{ NDM } & \multicolumn{6}{|c|}{ APM } \\
\hline & \multicolumn{3}{|c|}{ Anhembi } & \multicolumn{3}{|c|}{ Areão } & \multicolumn{3}{|c|}{ Anhembi } & \multicolumn{3}{|c|}{ Areão } \\
\hline & min. & máx. & amp. & $\min$. & máx. & amp. & mín. & máx. & amp. & $\min$. & máx. & amp. \\
\hline 1-FT-Cristalina & 133,0 & 160,0 & 27,0 & 141,0 & 157,0 & 16,0 & 70,0 & 95,0 & 25,0 & 65,0 & 105,0 & 40,0 \\
\hline 2 - EMGOPA-301 & 133,0 & 162,0 & 29,0 & 133,0 & 145,0 & 12,0 & 75,0 & 105,0 & 30,0 & 53,0 & 112,0 & 59,0 \\
\hline $3-\mathrm{LAC}-4$ & 130,0 & 138,0 & 8,0 & 130,0 & 136,0 & 6,0 & 45,0 & 85,0 & 40,0 & 50,0 & 95,0 & 45,0 \\
\hline 4 - IAC-5 & 130,0 & 136,0 & 6,0 & 130,0 & 138,0 & 8,0 & 65,0 & 90,0 & 25,0 & 75,0 & 105,0 & 30,0 \\
\hline $5-I A C-6$ & 133,0 & 142,0 & 9,0 & 133,0 & 157,0 & 24,0 & 65,0 & 103,0 & 38,0 & 85,0 & 120,0 & 35,0 \\
\hline 6 - IAC-8 & 133,0 & 155,0 & 22,0 & 133,0 & 144,0 & 11,0 & 79,0 & 100,0 & 21,0 & 75,0 & 115,0 & 40,0 \\
\hline 7 - IAC-9 & 133,0 & 159,0 & 26,0 & 135,0 & 144,0 & 9,0 & 55,0 & 100,0 & 45,0 & 65,0 & 110,0 & 45,0 \\
\hline 8 - IAC-11 & 130,0 & 136,0 & 6,0 & 130,0 & 141,0 & 11,0 & 70,0 & 95,0 & 25,0 & 62,0 & 115,0 & 53,0 \\
\hline 9 - Santa Rosa & 133,0 & 142,0 & 9,0 & 130,0 & 142,0 & 12,0 & 60,0 & 95,0 & 35,0 & 45,0 & 105,0 & 60,0 \\
\hline 10 - SS-1 & 130,0 & 133,0 & 3,0 & 130,0 & 137,0 & 7,0 & 70,0 & 90,0 & 20,0 & 60,0 & 120,0 & 60,0 \\
\hline $\begin{array}{l}\text { Cruz } 1 \times 2 \\
\text { Cruz } 1 \times 3\end{array}$ & $\begin{array}{l}135,4 \\
126,7\end{array}$ & $\begin{array}{l}161,7 \\
160,8\end{array}$ & $\begin{array}{l}26,3 \\
34,1\end{array}$ & $\begin{array}{l}135,9 \\
128,8\end{array}$ & $\begin{array}{l}165,7 \\
166,7\end{array}$ & $\begin{array}{l}29,8 \\
37,9\end{array}$ & $\begin{array}{l}63,7 \\
35,0\end{array}$ & $\begin{array}{r}117,0 \\
85,5\end{array}$ & $\begin{array}{l}53,3 \\
50,5\end{array}$ & $\begin{array}{l}85,8 \\
59,4\end{array}$ & $\begin{array}{l}121,4 \\
106,3\end{array}$ & $\begin{array}{l}35,6 \\
46,9\end{array}$ \\
\hline Cruz 1 x 4 & 129,7 & 160,9 & 31,2 & 128,5 & 166,3 & 37,8 & 61,3 & 101,8 & 40,5 & 72,8 & 107,8 & 35,0 \\
\hline Cruz $1 \times 5$ & 127,7 & 156,3 & 28,6 & 129,4 & 157,2 & 27,8 & 60,7 & 98,9 & 38,2 & 67,2 & 121,3 & 54,1 \\
\hline Cruz 1 x 6 & 129,7 & 160,7 & 31,0 & 133,4 & 158,3 & 24,9 & 71,5 & 105,0 & 33,5 & 88,1 & 119,5 & 31,4 \\
\hline Cruz 1 x 7 & 131,3 & 159,8 & 28,5 & 137,8 & 157,2 & 19,4 & 68,5 & 101,0 & 32,5 & 75,1 & 118,1 & 43,0 \\
\hline Cruz. 1 x 8 & 126,7 & 150,5 & 23,8 & 129,9 & 142,6 & 12,7 & 61,8 & 95,0 & 33,2 & 73,5 & 107,0 & 33,5 \\
\hline Cruz 1 x 9 & 129,7 & 161,8 & 32,1 & 129,9 & 164,3 & 34,4 & 67,9 & 103,5 & 35,6 & 85,8 & 120,1 & 34,3 \\
\hline Cruz 1 x 10 & 123,7 & 161,2 & 37,5 & 128,8 & 168,2 & 39,4 & 55,5 & 98,4 & 42,9 & 71,3 & 119,5 & 48,2 \\
\hline Cruz 2 x 3 & 123,7 & 160,2 & 36,5 & 129,8 & 145,3 & 15,5 & 60,0 & 100,0 & 40,0 & 48,5 & 112,8 & 64,3 \\
\hline Cruz. 2 x 4 & 123,7 & 138,4 & 14,7 & 126,8 & 133,2 & 6,4 & 40,7 & 76,3 & 35,6 & 29,5 & 101,3 & 71,8 \\
\hline Cruz 2 × 5 & 131,7 & 161,5 & 29,8 & 131,9 & 162,8 & 30,9 & 75,5 & 116,1 & 40,6 & 80,8 & 119,2 & 38,4 \\
\hline Cruz 2 x 6 & 129,5 & 159,3 & 29,8 & 129,8 & 165,9 & 36,1 & 66,7 & 108,4 & 41,7 & 75,2 & 121,3 & 46,1 \\
\hline Cruz 2 x 7 & 134,5 & 159,9 & 25,4 & 131,2 & 162,3 & 31,1 & 65,9 & 115,0 & 49,1 & 81,3 & 110,6 & 29,3 \\
\hline Cruz 2 × 8 & 131,5 & 158,9 & 27,4 & 128,5 & 158,6 & 30,1 & 38,5 & 97,0 & 58,5 & 67,6 & 119,3 & 51,7 \\
\hline Cruz 2 x 9 & 126,7 & 161,5 & 34,8 & 130,9 & 160,9 & 30,0 & 58,6 & 110,0 & 51,4 & 66,3 & 117,8 & 51,5 \\
\hline Cruz 2 x 10 & 129,7 & 157,8 & 28,1 & 129,8 & 165,2 & 35,4 & 72,0 & 107,7 & 35,7 & 81,3 & 124,8 & 43,5 \\
\hline Cruz 3 x 4 & 123,5 & 150,0 & 26,5 & 126,2 & 145,3 & 19,1 & 53,6 & 98,3 & 44,7 & 57,8 & 111,3 & 53,5 \\
\hline Cruz 3 x 5 & 127,0 & 157,8 & 30,8 & 129,4 & 162,8 & 33,4 & 63,1 & 107,5 & 44,4 & 71,4 & 122,8 & 51,4 \\
\hline Cruz. 3 x 6 & 125,7 & 151,5 & 25,8 & 128,5 & 143,5 & 15,0 & 57,5 & 101,4 & 43,9 & 61,2 & 106,3 & 45,1 \\
\hline Cruz $3 \times 7$ & 130,8 & 158,6 & 27,8 & 134,4 & 160,8 & 26,4 & 60,7 & 86,4 & 25,7 & 53,5 & 102,1 & 48,6 \\
\hline Cruz 3 × 8 & 126,7 & 142,9 & 16,2 & 128,8 & 153,8 & 25,0 & 60,7 & 103,1 & 42,4 & 59,8 & 109,5 & 49,7 \\
\hline Cruz 3 × 9 & 126,7 & 142,4 & 15,7 & 128,2 & 157,9 & 29,7 & 57,7 & 108,1 & 50,4 & 57,8 & 109,3 & 51,5 \\
\hline Cruz 3 x 10 & 123,7 & 156,8 & 33,1 & 126,8 & 157,8 & 31,0 & 45,4 & 97,7 & 52,3 & 52,3 & 115,1 & 62,8 \\
\hline Cruz 4 × 5 & 127,5 & 158,3 & 30,8 & 128,2 & 157,9 & 29,7 & 71,5 & 127,7 & 56,2 & 58,5 & 135,3 & 76,8 \\
\hline Cruz 4 × 6 & 123,7 & 150,5 & 26,8 & 128,5 & 155,2 & 26,7 & 72,7 & 111,0 & 38,3 & 71,3 & 132,3 & 61,0 \\
\hline Cruz 4 x 7 & 129,7 & 156,3 & 26,6 & 131,5 & 144,5 & 13,0 & 65,9 & 112,7 & 46,8 & 70,6 & 121,2 & 50,6 \\
\hline Cruz 4 × 8 & 126,7 & 151,7 & 25,0 & 128,8 & 142,2 & 13,4 & 67,7 & 115,5 & 47,8 & 70,1 & 124,2 & 54,1 \\
\hline Cruz 4 × 9 & 123,7 & 136,2 & 12,5 & 128,2 & 135,9 & 7,7 & 69,0 & 98,1 & 29,1 & 73,1 & 106,2 & 33,1 \\
\hline Cruz 4 x 10 & 124,0 & 144,7 & 20,7 & 129,4 & 144,9 & 15,5 & 61,3 & 115,9 & 54,6 & 76,3 & 125,1 & 48,8 \\
\hline Cruz 5 x 6 & 126,7 & 159,3 & 32,6 & 130,4 & 163,7 & 33,3 & 71,4 & 105,9 & 34,5 & 80,6 & 119,5 & 38,9 \\
\hline Cruz. 5 x 7 & 130,3 & 159,5 & 29,2 & 135,5 & 157,7 & 22,2 & 68,4 & 106,9 & 38,5 & 66,6 & 125,1 & 58,5 \\
\hline Cruz $5 \times 8$ & 129,5 & 141,6 & 12,1 & 130,8 & 144,3 & 13,5 & 71,8 & 98,0 & 26,2 & 75,6 & 116,4 & 40,8 \\
\hline Cruz 5 x 9 & 130,0 & 160,7 & 30,7 & 128,5 & 162,9 & 34,4 & 67,0 & 105,0 & 38,0 & 75,6 & 127,0 & 51,4 \\
\hline Cruz $5 \times 10$ & 129,5 & 140,1 & 10,6 & 132,9 & 153,8 & 20,9 & 78,7 & 105,5 & 26,8 & 75,8 & 108,5 & 32,7 \\
\hline Cruz $6 \times 7$ & 129,7 & 156,8 & 27,1 & 130,4 & 145,3 & 14,9 & 61,8 & 101,0 & 39,2 & 77,8 & 121,3 & 43,5 \\
\hline Cruz 6 × 8 & 128,8 & 160,6 & 31,8 & 129,4 & 143,6 & 14,2 & 60,9 & 108,4 & 47,5 & 61,2 & 112,8 & 51,6 \\
\hline Cruz $6 \times 9$ & 126,7 & 142,4 & 15,7 & 128,5 & 142,5 & 14,0 & 66,3 & 91,7 & 25,4 & 62,6 & 105,1 & 42,5 \\
\hline Cruz 6 x 10 & 126,5 & 143,5 & 17,0 & 132,8 & 144,8 & 12,0 & 69,8 & 102,7 & 32,9 & 71,3 & 115,1 & 43,8 \\
\hline Cruz 7 × 8 & 129,7 & 158,8 & 29,1 & 130,4 & 153,8 & 23,4 & 63,4 & 117,0 & 53,6 & 81,8 & 113,1 & 31,3 \\
\hline Cruz 7 × 9 & 126,7 & 157,8 & 31,1 & 129,4 & 161,7 & 32,3 & 50,7 & 107,7 & 57,0 & 65,5 & 117,8 & 52,3 \\
\hline Cruz 7 x 10 & 129,7 & 162,7 & 33,0 & 131,5 & 160,2 & 28,7 & 61,3 & 105,9 & 44,6 & 74,8 & 127,0 & 52,2 \\
\hline Cruz 8 x 9 & 126,7 & 140,7 & 14,0 & 128,8 & 141,8 & 13,0 & 61,8 & 110,9 & 49,1 & 71,3 & 107,0 & 35,7 \\
\hline Cruz $8 \times 10$ & 123,5 & 158,7 & 35,2 & 128,2 & 160,2 & 32,0 & 54,0 & 106,1 & 52,1 & 66,2 & 111,6 & 45,4 \\
\hline Cruz $9 \times 10$ & 123,7 & 158,9 & 35,2 & 128,2 & 163,8 & 35,6 & 48,9 & 125,7 & 76,8 & 63,2 & 120,8 & 57,6 \\
\hline $\begin{array}{l}\text { Parentais } \\
\text { Linhagens. }\end{array}$ & $\begin{array}{l}130,0 \\
123,5\end{array}$ & $\begin{array}{l}162.0 \\
162,7\end{array}$ & $\begin{array}{l}32,0 \\
39,2\end{array}$ & $\begin{array}{l}130.0 \\
128,5\end{array}$ & $\begin{array}{l}157,0 \\
168,2\end{array}$ & $\begin{array}{l}27,0 \\
39,7\end{array}$ & $\begin{array}{l}45,0 \\
35,0\end{array}$ & $\begin{array}{l}105.0 \\
127,7\end{array}$ & $\begin{array}{l}60,0 \\
92,7\end{array}$ & $\begin{array}{l}45,0 \\
29,5\end{array}$ & $\begin{array}{l}120,0 \\
135,3\end{array}$ & $\begin{array}{r}75,0 \\
105,8\end{array}$ \\
\hline
\end{tabular}


Tabela 18. Valores mínimo (mín.), máximo (máx.) e amplitude (amp.) para VA - valor agronômico (nota: 1 = péssimo a $5=$ excelente) PG - produtividade de grãos $\left(\mathrm{g} / \mathrm{m}^{2}\right)$ dos parentais e dos 45 cruzamentos dialélicos, em Anhembi e Areão. Soja semi-tardia/tardia, linhagens $F_{7: 6}$, semeadura em 17-12-1992, parcela 1 linha de $2 \mathrm{~m}$ x 0,5 m. Piracicaba-SP.

\begin{tabular}{|c|c|c|c|c|c|c|c|c|c|c|c|c|}
\hline \multirow[b]{3}{*}{ Tratamentos } & \multicolumn{6}{|c|}{ VA } & \multicolumn{6}{|c|}{ PG } \\
\hline & \multicolumn{3}{|c|}{ Anhembi } & \multicolumn{3}{|c|}{ Areão } & \multicolumn{3}{|c|}{ Anhembi } & \multicolumn{3}{|c|}{ Areão } \\
\hline & min. & máx. & amp. & min. & máx. & amp. & $\min$. & máx. & amp. & mín. & máx. & amp. \\
\hline 1 - FT-Cristalina & 3,0 & 4,0 & 1,0 & 3,5 & 4,5 & 1,0 & 142,0 & 511,0 & 369,0 & 112,0 & 284,0 & $\overline{172,0}$ \\
\hline 2 - EMGOPA-301 & 3,0 & 5,0 & 2,0 & 4,0 & 4,5 & 0,5 & 125,0 & 527,0 & 402,0 & 59,0 & 268,0 & 209,0 \\
\hline $3-\mathrm{IAC}-4$ & 2,0 & 3,5 & 1,5 & 2,5 & 4,0 & 1,5 & 85,0 & 320,0 & 235,0 & 59,0 & 173,0 & 114,0 \\
\hline 4-IAC-5 & 2,5 & 4,0 & 1,5 & 3,0 & 4,5 & 1,5 & 67,0 & 253,0 & 186,0 & 37,0 & 162,0 & 125,0 \\
\hline $5-I A C-6$ & 3,0 & 5,0 & 2,0 & 3,5 & 4,5 & 1,0 & 102,0 & 530,0 & 428,0 & 86,0 & 288,0 & 202,0 \\
\hline $6-\mathrm{IAC}-8$ & 3,5 & 4,5 & 1,0 & 3,5 & 4,5 & 1,0 & 117,0 & 356,0 & 239,0 & 92,0 & 205,0 & 113,0 \\
\hline 7 - IAC-9 & 2,5 & 4,0 & 1,5 & 3,0 & 4,0 & 1,0 & 59,0 & 397,0 & 338,0 & 102,0 & 274,0 & 172,0 \\
\hline 8 - IAC-11 & 2,5 & 4,0 & 1,5 & 3,0 & 5,0 & 2,0 & 106,0 & 333,0 & 227,0 & 67,0 & 257,0 & 190,0 \\
\hline 9 - Santa Rosa & 3,0 & 4,0 & 1,0 & 2,5 & 4,5 & 2,0 & 111,0 & 342,0 & 231,0 & 89,0 & 252,0 & 163,0 \\
\hline 10 - SS-1 & 2,5 & 3,5 & 1,0 & 3,0 & 4,5 & 1,5 & 53,0 & 366,0 & 313,0 & 76,0 & 267,0 & 191,0 \\
\hline Cruz $1 \times 2$ & 2,9 & 4,8 & 1,9 & 3,3 & 4,4 & 1,2 & 112,3 & 561,2 & 448,9 & 59,7 & 263,6 & 203,9 \\
\hline Cruz. 1 x 3 & 2,1 & 4,2 & 2,1 & 3,0 & 4,4 & 1,4 & 107,4 & 417,6 & 310,2 & 118,5 & 232,5 & 114,0 \\
\hline Cruz $1 \times 4$ & 2,8 & 4,4 & 1,7 & 2,5 & 4,3 & 1,8 & 81,0 & 342,6 & 261,6 & 80,7 & 259,8 & 179,1 \\
\hline Cruz $1 \times 5$ & 2,9 & 4,9 & 2,1 & 2,4 & 4,4 & 2,0 & 131,6 & 542,4 & 410,8 & $-4,5$ & 268,7 & 273,2 \\
\hline Cruz. 1 x 6 & 2,6 & 4,9 & 2,4 & 3,8 & 4,5 & 0,7 & 122,0 & 396,4 & 274,4 & 118,2 & 282,0 & 163,8 \\
\hline Cruz. $1 \times 7$ & 2,8 & 4,3 & 1,5 & 3,1 & 4,6 & 1,5 & 136,1 & 546,2 & 410,1 & 108,9 & 349,4 & 240,5 \\
\hline Cruz 1 × 8 & 2,8 & 4,4 & 1,6 & 3,1 & 4,8 & 1,6 & 166,4 & 478,0 & 311,6 & 98,7 & 313,4 & 214,7 \\
\hline Cruz $1 \times 9$ & 2,8 & 4,5 & 1,7 & 3,4 & 4,9 & 1,5 & 151,1 & 458,2 & 307,1 & 89,5 & 306,8 & 217,3 \\
\hline Cruz. 1 x 10 & 2,3 & 3,9 & 1,7 & 3,1 & 4,5 & 1,4 & 114,2 & 432,3 & 318,1 & 13,5 & 305,0 & 291,5 \\
\hline Cruz. 2 × 3 & 3,1 & 4,4 & 1,3 & 3,2 & 4,4 & 1,2 & 112,2 & 455,7 & 343,5 & 61,4 & 265,0 & 203,6 \\
\hline Cruz. $2 \times 4$ & 1,9 & 3,1 & 1,2 & 1,5 & 4,0 & 2,5 & $-1,0$ & 226,1 & 227,1 & 9,8 & 214,5 & 204,7 \\
\hline Cruz. 2 × 5 & 3,2 & 4,9 & 1,7 & 3,4 & 4,3 & 0,9 & 106,3 & 438,8 & 332,5 & 69,9 & 278,7 & 208,8 \\
\hline Cruz 2 x 6 & 3,3 & 4,9 & 1,5 & 3,5 & 4,7 & 1,2 & 153,3 & 450,7 & 297,4 & 47,9 & 258,7 & 210,8 \\
\hline Cruz. $2 \times 7$ & 2,8 & 4,9 & 2,1 & 3,3 & 4,8 & 1,5 & 101,3 & 539,7 & 438,4 & 52,7 & 238,1 & 185,4 \\
\hline Cruz 2 × 8 & 2,9 & 4,3 & 1,4 & 3,1 & 4,7 & 1,5 & 84,4 & 479,2 & 394,8 & 84,7 & 268,2 & 183,5 \\
\hline Cruz. 2 × 9 & 2,9 & 4,8 & 1,8 & 2,9 & 4,8 & 1,9 & 156,0 & 505,1 & 349,1 & 60,7 & 327,0 & 266,3 \\
\hline Cruz 2 x 10 & 3,2 & 4,3 & 1,1 & 3,4 & 4,4 & 1,1 & 107,4 & 457,2 & 349,8 & 47,0 & 251,0 & 204,0 \\
\hline Cruz. 3 x 4 & 2,7 & 4,3 & 1,6 & 3,1 & 4,3 & 1,2 & 37,7 & 364,9 & 327,2 & 69,0 & 273,8 & 204,8 \\
\hline Cruz. 3 × 5 & 2,9 & 3,8 . & 1,0 & 3,0 & 4,8 & 1,8 & 65,0 & 415,3 & 350,3 & 79,8 & 234,7 & 154,9 \\
\hline Cruz. 3 x 6 & 2,4 & 4,3 & 1,9 & 3,0 & 4,1 & 1,1 & 123,7 & 398,0 & 274,3 & 45,5 & 243,7 & 198,2 \\
\hline Cruz $3 \times 7$ & 2,6 & 3,9 & 1,3 & 2,4 & 4,3 & 1,9 & 86,0 & 390,9 & 304,9 & 85,2 & 253,2 & 168,0 \\
\hline Cruz. $3 \times 8$ & 3,0 & 4,4 & 1,4 & 3,2 & 4,3 & 1,2 & 128,0 & 447,3 & 319,3 & 95,4 & 295,7 & 200,3 \\
\hline Cruz. $3 \times 9$ & 2,3 & 4,4 & 2,1 & 2,5 & 4,4 & 1,9 & 108,7 & 398,5 & 289,8 & 66,9 & 299,0 & 232,1 \\
\hline Cruz. $3 \times 10$ & 2,2 & 4,3 & 2,1 & 2,7 & 4,4 & 1,8 & 60,3 & 383,2 & 322,9 & 81,9 & 245,0 & 163,1 \\
\hline Cruz 4 × 5 & 3,0 & 4,6 & 1,7 & 3,4 & 4,6 & 1,2 & $-10,7$ & 507,7 & 518,4 & 73,5 & 255,0 & 181,5 \\
\hline Cruz $4 \times 6$ & 3,1 & 4,4 & 1,3 & 3,4 & 4,9 & 1,5 & 50,0 & 346,9 & 296,9 & 69,2 & 205,0 & 135,8 \\
\hline Cruz $4 \times 7$ & 2,8 & 4,5 & 1,7 & 2,4 & 4,1 & 1,7 & 72,7 & 354,1 & 281,4 & 76,4 & 191,5 & 115,1 \\
\hline Cruz 4 × 8 & 2,9 & 4,9 & 2,0 & 2,8 & 4,8 & 1,9 & 126,2 & 408,8 & 282,6 & 62,7 & 263,4 & 200,7 \\
\hline Cruz $4 \times 9$ & 2,7 & 3,9 & 1,2 & 2,8 & 4,0 & 1,2 & 81,3 & 249,4 & 168,1 & 12,5 & 169,1 & 156,6 \\
\hline Cruz. $4 \times 10$ & 2,9 & 5,1 & 2,3 & 3,4 & 4,9 & 1,5 & 101,3 & 296,2 & 194,9 & 46,7 & 201,2 & 154,5 \\
\hline Cruz. 5 x 6 & 3,2 & 4,4 & 1,2 & 3,4 & 4,4 & 1,0 & 93,0 & 455,0 & 362,0 & 86,0 & 238,8 & 152,8 \\
\hline Cruz. $5 \times 7$ & 2,9 & 5,2 & 2,4 & 2,4 & 4,4 & 2,0 & 180,4 & 429,3 & 248,9 & 84,5 & 236,8 & 152,3 \\
\hline Cruz. $5 \times 8$ & 3,0 & 4,3 & 1,4 & 3,2 & 4,5 & 1,3 & 154,7 & 458,2 & 303,5 & 78,4 & 303,8 & 225,4 \\
\hline Cruz. $5 \times 9$ & 2,8 & 5,1 & 2,3 & 3,3 & 4,9 & 1,6 & 105,7 & 417,7 & 312,0 & 76,5 & 290,4 & 213,9 \\
\hline Cruz. $5 \times 10$ & 3,4 & 4,4 & 1,0 & 3,4 & 4,4 & 1,1 & 98,0 & 435,5 & 337,5 & 92,8 & 252,7 & 159,9 \\
\hline Cruz. 6 x 7 & 2,8 & 4,4 & 1,6 & 3,2 & 4,6 & 1,4 & 97,0 & 384,4 & 287,4 & 42,5 & 245,8 & 203,3 \\
\hline Cruz $6 \times 8$ & 2,9 & 4,6 & 1,8 & 3,0 & 4,7 & 1,6 & 71,3 & 393,2 & 321,9 & 51,7 & 196,7 & 145,0 \\
\hline Cruz. 6 ×9 & 2,8 & 4,3 & 1,5 & 3,1 & 4,4 & 1,3 & 109,5 & 361,7 & 252,2 & 50,2 & 251,7 & 201,5 \\
\hline Cruz 6 x 10 & 2,3 & 4,5 & 2,2 & 3,0 & 4,4 & 1,3 & 27,3 & 411,3 & 384,0 & 55,5 & 246,5 & 191,0 \\
\hline Cruz 7 × 8 & 2,9 & 4,8 & 1,9 & 3,4 & 4,4 & 1,1 & 94,0 & 445,7 & 351,7 & 89,9 & 275,8 & 185,9 \\
\hline Cruz. 7 × 9 & 2,2 & 4,3 & 2,1 & 3,1 & 4,1 & 0,9 & 64,4 & 347,7 & 283,3 & 7,7 & 251,8 & 244,1 \\
\hline Cruz. 7 x 10 & 2,2 & 4,5 & 2,3 & 3,2 & 4,8 & 1,6 & 65,0 & 321,2 & 256,2 & 71,7 & 209,5 & 137,8 \\
\hline Cruz 8 × 9 & 2,2 & 4,7 & 2,5 & 2,8 & 4,4 & 1,6 & 13,7 & 403,4 & 389,7 & 82,9 & 246,5 & 163,6 \\
\hline Cruz. $8 \times 10$ & 2,3 & 4,1 & 1,8 & 3,2 & 4,7 & 1,5 & 18,7 & 430,3 & 411,6 & 89,6 & 215,8 & 126,2 \\
\hline Cruz 9 x 10 & 2,2 & 4,5 & 2,2 & 3,1 & 4,7 & 1,5 & 99,3 & 355,4 & 256,1 & 36,5 & 220,2 & 183,7 \\
\hline $\begin{array}{l}\text { Parentais } \\
\text { Linhagens. }\end{array}$ & $\begin{array}{l}2,0 \\
1,9\end{array}$ & $\begin{array}{l}5,0 \\
5,2\end{array}$ & $\begin{array}{l}3,0 \\
3,4\end{array}$ & $\begin{array}{l}2.5 \\
1,5\end{array}$ & $\begin{array}{l}5.0 \\
4,9\end{array}$ & $\begin{array}{l}2,5 \\
3,4\end{array}$ & $\begin{array}{r}53.0 \\
-10,7\end{array}$ & $\begin{array}{l}530,0 \\
561,2\end{array}$ & $\begin{array}{l}477,0 \\
571,9\end{array}$ & $\begin{array}{r}20,0 \\
-4,5\end{array}$ & $\begin{array}{l}288,0 \\
353,2\end{array}$ & $\begin{array}{l}268,0 \\
357,7\end{array}$ \\
\hline
\end{tabular}




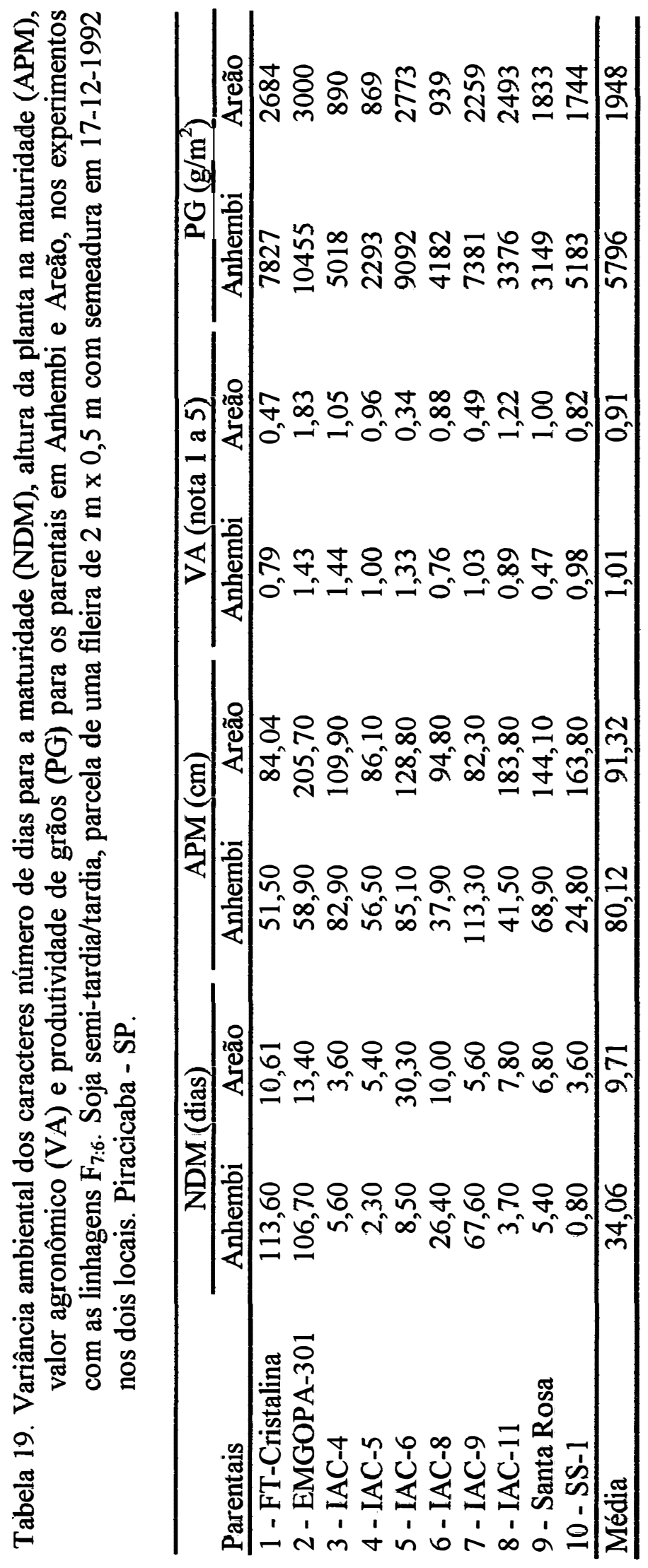


Tabela 20. Herdabilidade ao nível de cruzamento, com base em 20 linhagens $F_{7: 6}$ de cada um dos 45 cruzamentos dialélicos, e coeficiente de determinação genotípica dos parentais envolvidos para os caracteres número de dias para a maturidade (NDM), altura da planta na maturidade (APM), valor agronômico (VA) e produtividade de grãos (PG). em Anhembi e Areão. Soja semi-tardia/tardia, parcela de uma fileira de $2 \mathrm{~m}$ x 0,5 m, semeadura em 17-12-1992. Piracicaba - SP.

\begin{tabular}{|c|c|c|c|c|c|c|c|c|}
\hline \multirow[b]{2}{*}{ Tratamentos } & \multicolumn{2}{|c|}{ NDM } & \multicolumn{2}{|c|}{ APM } & \multicolumn{2}{|l|}{ VA } & \multicolumn{2}{|l|}{ PG } \\
\hline & Anhembi & Areão & Anhembi & Areāo & Anhembi & Areão & Anhembi & Areão \\
\hline $\begin{array}{l}\text { FT-Cristalina } \times \text { EMGOPA-301 } \\
\text { FT-Cristalina } \times \text { IAC-4 }\end{array}$ & $\begin{array}{l}0,62 \\
0,72\end{array}$ & $\begin{array}{l}0,88 \\
0,89\end{array}$ & $\begin{array}{l}0,52 \\
0,47\end{array}$ & $\begin{array}{l}0,30 \\
0,35\end{array}$ & $\begin{array}{l}0,54 \\
0,40\end{array}$ & $\begin{array}{r}-0,09 \\
0,15\end{array}$ & $\begin{array}{l}0,62 \\
0,24\end{array}$ & $\begin{array}{r}0,62 \\
-1,04\end{array}$ \\
\hline FT-Cristalina x IAC-5 & 0,70 & 0,85 & 0,55 & 0,17 & 0,26 & 0,26 & -050 & 0,43 \\
\hline FT-Cristalina $\times$ IAC-6 & 0,24 & 0,72 & 0,54 & 0,62 & 0,56 & 0,53 & 0,29 & 0,51 \\
\hline FT-Cristalina x IAC-8 & 0,58 & 0,76 & $-0,10$ & 0,01 & 0,51 & $-1,68$ & $-0,14$ & 0,12 \\
\hline FT-Cristalina x IAC-9 & 0,51 & 0,65 & 0,05 & 0,53 & 0,13 & 0,07 & 0,16 & 0,50 \\
\hline FT-Cristalina x IAC-1 1 & 0,22 & 0,34 & 0,25 & 0,14 & 0,35 & 0,28 & 0,07 & 0,39 \\
\hline FT-Cristalina x Santa Rosa & 0,73 & 0,82 & 0,16 & $-0,25$ & $-0,04$ & $-0,09$ & 0,04 & 0,27 \\
\hline FT-Cristalina x SS-1 & 0,77 & 0,91 & 0,52 & 0,55 & 0,46 & 0,28 & $-0,16$ & 0,59 \\
\hline EMGOPA-301 $\times$ IAC-4 & 0,66 & 0,67 & 0,35 & 0,61 & 0,10 & $-0,62$ & 0,44 & 0,38 \\
\hline EMGOPA-301 x IAC-5 & $-0,51$ & $-3,03$ & 0,29 & 0,73 & 0,16 & 0,81 & $-0,59$ & 0,19 \\
\hline EMGOPA-301 x IAC-6 & 0,73 & 0,88 & 0,57 & 0,26 & 0,33 & $-1,03$ & 0,34 & 0,36 \\
\hline EMGOPA-301 x IAC-8 & 0,62 & 0,89 & 0,30 & 0,43 & $-0,02$ & $-0,07$ & 0,34 & 0,36 \\
\hline EMGOPA-301 x IAC-9 & 0,64 & 0,89 & 0,61 & $-0,07$ & 0,31 & 0,08 & 0,51 & 0,32 \\
\hline EMGOPA-301 x IAC-11 & 0,68 & 0,84 & 0,65 & 0,53 & 0,28 & 0,27 & 0,51 & 0,21 \\
\hline EMGOPA-301 x Santa Rosa & 0,72 & 0,82 & 0,59 & 0,29 & 0,37 & 0,30 & 0,48 & 0,59 \\
\hline EMGOPA-301 x SS-1 & 0,44 & 0,86 & 0,41 & 0,35 & $-0,42$ & $-0,56$ & 0,48 & 0,37 \\
\hline IAC-4 x IAC-5 & $-0,12$ & 0,63 & 0,63 & 0,53 & 0,30 & 0,00 & 0,16 & 0,33 \\
\hline IAC-4 $\times$ IAC-6 & 0,40 & 0,82 & 0,49 & 0,61 & $-0,26$ & 0,26 & 0,22 & 0,01 \\
\hline IAC-4 x IAC-8 & 0,21 & 0,45 & 0,55 & 0,62 & 0,57 & 0,19 & $-0,11$ & $-0,09$ \\
\hline IAC-4 x IAC-9 & 0,58 & 0,79 & 0,08 & 0,53 & $-0,20$ & 0,43 & 0,11 & 0,63 \\
\hline IAC-4 x IAC-11 & $-0,93$ & 0,64 & 0,28 & 0,36 & 0,13 & $-0,71$ & 0,37 & 0,35 \\
\hline IAC-4 x Santa Rosa & $-2,16$ & 0,77 & 0,64 & 0,60 & 0,48 & 0,49 & 0,05 & 0,40 \\
\hline IAC-4 x SS-1 & 0,40 & 0,78 & 0,69 & 0,75 & 0,70 & 0,48 & 0,38 & 0,21 \\
\hline IAC-5 x IAC-6 & 0,50 & 0,77 & 0,75 & 0,74 & 0,09 & 0,08 & 0,54 & 0,23 \\
\hline IAC-5 x IAC-8 & $-0,14$ & 0,73 & 0,58 & 0,68 & $-0,05$ & 0,30 & $-0,03$ & $-0,31$ \\
\hline LAC-5 x IAC-9 & 0,43 & 0,40 & 0,65 & 0,53 & 0,28 & 0,30 & 0,16 & $-0,59$ \\
\hline IAC-5 x IAC-11 & $-0,14$ & 0,33 & 0,60 & 0,55 & 0,28 & 0,38 & 0,28 & 0,29 \\
\hline IAC-5 x Santa Rosa & $-1,34$ & $-0,89$ & $-0,38$ & $-0,01$ & $-0,38$ & $-0,21$ & $-1,99$ & $-0,34$ \\
\hline LAC-5 x SS-1 & $-0,51$ & 0,33 & 0,70 & 0,51 & 0,58 & 0,08 & $-0,65$ & 0,26 \\
\hline IAC-6 x IAC-8 & 0,59 & 0,85 & 0,38 & 0,39 & $-0,01$ & $-0,62$ & 0,36 & $-0,01$ \\
\hline IAC-6 x IAC-9 & 0,65 & 0,68 & 0,20 & 0,39 & 0,38 & 0,52 & $-0,10$ & $-0,10$ \\
\hline IAC-6 x IAC-11 & $-2,07$ & 0,35 & $-0,01$ & 0,36 & $-0,21$ & 0,01 & $-0,27$ & 0,55 \\
\hline IAC-6 x Santa Rosa & 0,70 & 0,91 & 0,36 & 0,61 & 0,38 & 0,09 & 0,35 & 0,49 \\
\hline IAC-6 x SS-1 & $-3,30$ & 0,63 & $-0,03$ & 0,24 & $-0,90$ & $-0,45$ & 0,30 & $-0,19$ \\
\hline IAC-8 x IAC-9 & 0,43 & 0,47 & 0,34 & 0,33 & 0,19 & $-0,28$ & 0,04 & 0,21 \\
\hline LAC-8 x IAC-11 & 0,63 & 0,43 & 0,41 & 0,74 & $-0,01$ & 0,38 & 0,05 & $-0,61$ \\
\hline LAC-8 x Santa Rosa & $-0,60$ & 0,20 & $-0,15$ & 0,44 & 0,01 & 0,02 & $-0,26$ & 0,04 \\
\hline IAC-8 x SS-1 & $-0,70$ & $-0,16$ & 0,31 & 0,28 & 0,57 & 0,22 & 0,39 & 0,37 \\
\hline LAC-9 x IAC-11 & 0,46 & 0,58 & 0,58 & $-0,16$ & 0,27 & $-0,56$ & 0,18 & 0,09 \\
\hline IAC-9 x Santa Rosa & 0,43 & 0,85 & 0,77 & 0,62 & 0,56 & $-1,07$ & $-0,01$ & 0,47 \\
\hline IAC-9 x SS-1 & 0,78 & 0,84 & 0,61 & 0,39 & 0,53 & 0,23 & 0,08 & $-0,10$ \\
\hline LAC-11 x Santa Rosa & $-1,67$ & 0,41 & 0,36 & 0,22 & 0,56 & 0,39 & 0,39 & 0,04 \\
\hline IAC-1 1 x SS-1 & 0,48 & 0,80 & 0,48 & 0,50 & 0,45 & 0,09 & 0,11 & $-0,64$ \\
\hline Santa Rosa x SS-1 & 0,68 & 0,92 & 0,67 & 0,72 & 0,55 & 0,11 & $-0,18$ & 0,06 \\
\hline $\begin{array}{l}\text { Parentais } \\
\text { Linhagens }\end{array}$ & $\begin{array}{l}0,93 \\
0,58\end{array}$ & $\begin{array}{l}0,97 \\
084\end{array}$ & 0,95 & 0,92 & 0,96 & 0,82 & 0,94 & 0,91 \\
\hline & 0,58 & 0,84 & 0,64 & 0,62 & 0,50 & 0,36 & 0,38 & 0,38 \\
\hline
\end{tabular}


Tabela 21. Coeficientes de determinação genotípica e de herdabilidade respectivamente, dos parentais e das linhagens $\mathrm{F}_{7: 6}$ e $\mathrm{F}_{8: 6}$ dos 45 cruzamentos em dialélico dos caracteres número de dias para a maturidade (NDM), altura da planta na maturidade (APM), valor agronômico (VA) e produtividade de grãos (PG). em Anhembi e Areão. Soja semi-tardia/tardia. Parcela de uma fileira de $2 \mathrm{~m} \mathrm{x}$ 0,5 m com semeadura em 17-12-1992 nos dois locais para $F_{7: 6}$. Parcela de uma fileira de $4 \mathrm{~m} \times 0,5 \mathrm{~m}$ com semeadura em 08 e 18-11-1993 em Anhembi e Areão, respectivamente para $F_{8: 6}$ (QLEs e QLPs). Piracicaba-SP.

\begin{tabular}{|c|c|c|c|c|c|c|}
\hline \multirow[b]{2}{*}{ Tratamentos } & \multicolumn{2}{|c|}{$F_{7: 6}$} & \multicolumn{2}{|c|}{$\mathrm{F}_{8: 6}$ (QLEs) } & \multicolumn{2}{|c|}{$\mathrm{F}_{8: 6}$ (QLPs) } \\
\hline & Anhembi & Areão & Anhembi & Areão & Anhembim & Areão \\
\hline \multirow{3}{*}{$\begin{array}{l}\text { Parentais } \\
\text { Linhagens }\end{array}$} & \multicolumn{6}{|c|}{ NDM } \\
\hline & 0,93 & 0,97 & 0,96 & 0,95 & 0,89 & 0,74 \\
\hline & 0,58 & 0,84 & 0,98 & 0,81 & 0,80 & 0,60 \\
\hline \multirow{3}{*}{$\begin{array}{l}\text { Parentais } \\
\text { Linhagens }\end{array}$} & \multicolumn{6}{|c|}{ APM } \\
\hline & 0,95 & 0,92 & 0,94 & 0,90 & 0,94 & 0,79 \\
\hline & 0,64 & 0,62 & 0,84 & 0,75 & 0,80 & 0,68 \\
\hline \multirow{4}{*}{$\begin{array}{l}\text { Parentais } \\
\text { Linhagens }\end{array}$} & \multicolumn{6}{|c|}{ VA } \\
\hline & 0,96 & 0,82 & 0,80 & 0,22 & 0,76 & 0,54 \\
\hline & 0,50 & 0,36 & 0,61 & 0,32 & 0,51 & 0,28 \\
\hline & \multicolumn{6}{|c|}{ PG } \\
\hline \multirow{2}{*}{$\begin{array}{l}\text { Parentais } \\
\text { Linhagens }\end{array}$} & 0,94 & 0,91 & 0,84 & 0,95 & 0,88 & 0,75 \\
\hline & 0,38 & 0,38 & 0,63 & 0,60 & 0,59 & 0,56 \\
\hline
\end{tabular}




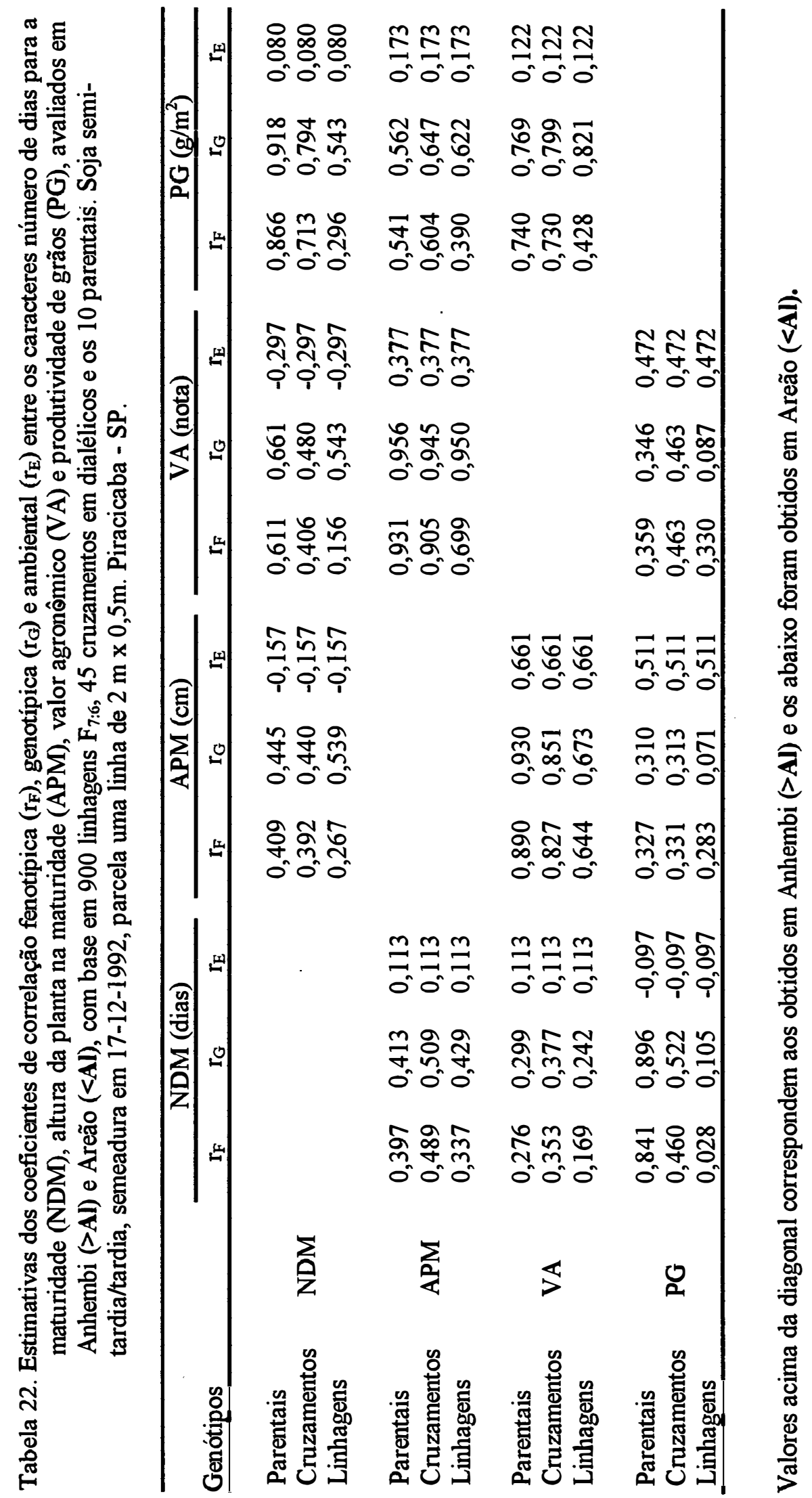


Tabela 23. Capacidade média de combinação $\left(\mathrm{cmc}_{\mathrm{i}}\right)$ dos parentais para os caracteres número de dias para a maturidade (NDM), altura da planta na maturidade (APM), valor agronômico (VA) e produtividade de grãos $(\mathrm{PG})$ com base no desempenho de suas linhagens $F_{7: 6}$ e $F_{8: 6}$ dos 45 cruzamentos dialélicos, em Anhembi e Areão. Soja semi-tardia/tardia, parcela de uma fileira de $2 \mathrm{~m} \times 0,5 \mathrm{~m}$ com semeadura em 17-12-1992 nos dois locais para linhagens $F_{7: 6} \mathrm{e}$ parcela de uma fileira de $4 \mathrm{~m}$ x 0,5 m com semeadura em 08-11-1993 em Anhembi e 1811-1993 em Areão para linhagens F $_{8: 6}$ (QLEs e QLPs). Piracicaba - SP.

\begin{tabular}{|c|c|c|c|c|c|c|c|}
\hline \multirow[b]{2}{*}{ Parentais } & \multirow[t]{2}{*}{$\mathrm{F}^{\mathrm{a}}$} & \multicolumn{2}{|c|}{$\mathrm{F}_{7.6}$} & \multicolumn{2}{|c|}{$\mathrm{F}_{8.6}$ (OLEs) } & \multicolumn{2}{|c|}{$\mathrm{F}_{8: 6}$ (QLPs) } \\
\hline & & Anhembi & Areão & Anhembi & Areão & Anhembi & Areão \\
\hline & \multicolumn{7}{|c|}{ NDM (dias) } \\
\hline 1 - FT-Cristalina & 5,60 & 2,44 & 2,95 & 2,72 & 2,99 & 2,43 & 3,84 \\
\hline 2 - EMGOPA-301 & 2,63 & 3,32 & 2,55 & 2,07 & 3,13 & 2,42 & 1,91 \\
\hline $3-\mathrm{IAC}-4$ & $-7,24$ & $-1,36$ & $-1,35$ & 1,15 & $-0,33$ & 0,57 & $-2,04$ \\
\hline $4-\mathrm{IAC}-5$ & 3,20 & $-2,70$ & $-3,33$ & $-1,00$ & $-2,94$ & $-1,42$ & $-3,09$ \\
\hline 5 - IAC-6 & 3,47 & 0,97 & 1,41 & 0,35 & 2,20 & 0,37 & 2,11 \\
\hline 6 - IAC-8 & 1,83 & $-0,43$ & $-0,79$ & $-2,50$ & $-2,85$ & $-2,15$ & $-2,00$ \\
\hline 7 - IAC-9 & 3,34 & 2,19 & 2,61 & 1,14 & 1,88 & 0,06 & 1,84 \\
\hline 8 - IAC-11 & 0,04 & $-1,89$ & $-2,08$ & $-1,59$ & $-1,24$ & $-1,35$ & $-1,23$ \\
\hline 9 - Santa Rosa & $-6,57$ & $-0,73$ & $-1,09$ & 0,19 & $-0,18$ & 0,58 & 0,59 \\
\hline 10 - SS-1 & 0,10 & $-1,78$ & $-0,83$ & $-2,69$ & $-2,64$ & $-1,51$ & $-1,91$ \\
\hline \multirow{2}{*}{ Média do caráter } & 122,63 & 138,24 & 138,70 & 159.88 & 149.41 & 163.78 & 153,43 \\
\hline & \multicolumn{7}{|c|}{$\mathrm{APM}(\mathrm{cm})$} \\
\hline 1 - FT-Cristalina & 0,88 & $-1,26$ & 0,16 & 0,24 & $-1,87$ & $-1,60$ & $-2,22$ \\
\hline 2 - EMGOPA-301 & 4,18 & 0,57 & $-0,59$ & 8,57 & 4,34 & 6,25 & 6,27 \\
\hline $3-$ IAC-4 & $-9,59$ & $-6,09$ & $-7,32$ & $-3,66$ & $-3,01$ & $-8,54$ & $-4,86$ \\
\hline $4-$ IAC-5 & 9,64 & 1,12 & $-0,31$ & 3,18 & 0,74 & 6,46 & 0,91 \\
\hline 5 - IAC-6 & 1,42 & 4,67 & 4,44 & 7,60 & 8,09 & 8,26 & 6,46 \\
\hline 6 - IAC-8 & 2,65 & 1,77 & 2,89 & $-10,52$ & $-8,15$ & $-4,86$ & $-5,00$ \\
\hline 7 - IAC-9 & $-1,99$ & 0,14 & 1,44 & 2,18 & 1,37 & 0,00 & $-2,70$ \\
\hline 8 - IAC-11 & 0,03 & $-1,16$ & $-1,41$ & $-3,15$ & $-0,08$ & $-2,50$ & $-0,82$ \\
\hline 9 - Santa Rosa & $-8,01$ & $-1,04$ & $-0,88$ & 0,17 & 0,87 & 1,39 & 2,92 \\
\hline 10 - SS-1 & 0,77 & 1,27 & 1,54 & $-5,26$ & $-2,25$ & $-4,86$ & $-0,90$ \\
\hline \multirow[t]{2}{*}{ Média do caráter } & 54.94 & 82,15 & 93.45 & 114,97 & 114,90 & 126,88 & 117,29 \\
\hline & \multicolumn{7}{|c|}{ VA (nota 1 a 5$)$} \\
\hline 1 - FT-Cristalina & 0,052 & $-0,04$ & 0,02 & 0,19 & 0,05 & 0,10 & $-0,03$ \\
\hline 2 - EMGOPA-301 & 0,050 & 0,04 & $-0,02$ & 0,19 & 0,00 & 0,24 & $-0,02$ \\
\hline 3 - IAC-4 & $-0,148$ & $-0,16$ & $-0,10$ & $-0,01$ & 0,09 & $-0,09$ & 0,10 \\
\hline $4-$ IAC-5 & 0,041 & $-0,04$ & $-0,10$ & $-0,14$ & $-0,13$ & $-0,13$ & $-0,06$ \\
\hline 5 - IAC-6 & 0,043 & 0,20 & 0,07 & $-0,01$ & $-0,01$ & 0,04 & $-0,11$ \\
\hline 6 - IAC-8 & 0,042 & 0,12 & 0,11 & $-0,13$ & $-0,04$ & 0,03 & 0,07 \\
\hline 7 - IAC-9 & 0,014 & 0,00 & $-0,06$ & 0,04 & 0,01 & $-0,05$ & 0,00 \\
\hline 8 - IAC-11 & 0,006 & 0,00 & 0,07 & $-0,05$ & 0,03 & $-0,02$ & 0,04 \\
\hline 9 - Santa Rosa & $-0,114$ & $-0,04$ & $-0,02$ & $-0,03$ & $-0,03$ & $-0,05$ & $-0,02$ \\
\hline 10 - SS-1 & 0,013 & $-0,04$ & 0,07 & $-0,13$ & $-0,01$ & 0,00 & 0,00 \\
\hline \multirow[t]{2}{*}{ Média do caráter } & 3.050 & 3,58 & 3.80 & 3,02 & 3.04 & 3.09 & 2,96 \\
\hline & \multicolumn{7}{|c|}{ PG $\left(g / P\right.$ lanta e $\left.g / \mathrm{m}^{2}\right)$} \\
\hline 1-FT-Cristalina & 14,09 & 33,0 & 19,0 & 74,0 & 25,7 & 35,0 & 18,0 \\
\hline 2 - EMGOPA-301 & 2,20 & 25,4 & $-1,3$ & 75,7 & 9,7 & 65,0 & $-10,2$ \\
\hline $3-\mathrm{IAC}-4$ & $-16,24$ & $-17,6$ & $-0,1$ & $-21,3$ & 9,9 & $-63,6$ & $-3,3$ \\
\hline 4 - IAC-5 & 0,48 & $-32,3$ & $-25,5$ & $-80,6$ & $-23,5$ & $-22,8$ & $-21,6$ \\
\hline 5 - IAC-6 & $-1,14$ & 22,0 & 9,6 & 13,1 & 14,8 & 23,8 & $-9,4$ \\
\hline 6 - IAC-8 & 1,97 & $-6,5$ & $-2,5$ & $-11,5$ & $-6,0$ & 25,3 & 4,7 \\
\hline 7 - IAC-9 & 3,05 & 15,6 & 5,4 & 6,0 & 6,3 & $-29,0$ & 18,2 \\
\hline 8 - IAC-11 & 7,35 & $-6,8$ & 6,7 & $-25,3$ & $-10,9$ & $-23,1$ & 4,7 \\
\hline 9 - Santa Rosa & $-19,43$ & $-8,9$ & $-3,7$ & $-12,0$ & 13,6 & $-16,3$ & $-4,1$ \\
\hline 10 - SS-1 & 7,66 & $-23,8$ & $-7,1$ & $-31,5$ & $-41,9$ & 3,6 & 0,0 \\
\hline Média do caráter & 78,60 & 238,3 & 153.9 & 415,5 & 246,6 & 403,3 & 2412 \\
\hline
\end{tabular}

${ }^{a}$ Fonte: Nass (1989). Parcela com nove plantas, em covas individuais espaçadas de 0,60 m entre covas e 1,20 m entre parcelas. Semeadura em 21-01-1988. 
Tabela 24. Estimativas das correlações de Spearman $\left(r_{s}\right)$ entre Capacidade Geral de Combinação. $\left(g_{j}\right)$ e capacidade média de combinação $\left(\mathrm{cmc}_{\mathrm{i}}\right)$ dos parentais para os caracteres: número de dias para a maturidade (NDM), altura da planta na maturidade (APM), valor agronômico (VA) e produtividade de grãos (PG) com base no desempenho de suas linhagens $F_{2}^{a}, F_{7: 6}$ e $F_{8: 6}$ dos 45 cruzamentos dialélicos, em Anhembi e Areão. Soja semi-tardia/tardia, parcela de uma fileira de $2 \mathrm{~m}$ x 0,5 m com semeadura em 17-12-1992 nos dois locais para linhagens $F_{7: 6}$ e parcela de uma fileira de $4 \mathrm{~m} \mathrm{x}$ 0,5 m com semeadura em 08-11-1993 em Anhembi e 18-11-1993 em Areão para linhagens $\mathrm{F}_{8: 6}$ (QLEs e QLPs). Piracicaba - SP.

\begin{tabular}{|c|c|c|c|c|c|c|}
\hline \multirow[b]{2}{*}{ Parentais } & \multicolumn{2}{|c|}{$F_{7: 6}$} & \multicolumn{2}{|c|}{$\mathrm{F}_{8: 6}$ (QLEs) } & \multicolumn{2}{|c|}{$\mathrm{F}_{8: 6}(\mathrm{QLPs})$} \\
\hline & Anhembi ${ }^{2}$ & Areão $^{3}$ & Anhembi $^{4}$ & Areão ${ }^{5}$ & Anhembi $^{6}$ & Areão ${ }^{7}$ \\
\hline & \multicolumn{6}{|c|}{ NDM (dias) } \\
\hline $\mathbf{F}_{2}{ }^{1}$ & 0,53 & $0,66^{*}$ & 0,37 & 0,41 & 0,17 & 0,60 \\
\hline$F_{7: 6}$ Anhembi $^{2}$ & & $0,93 * *$ & $0,70 *$ & $0,85^{* *}$ & 0,61 & $0,79 * *$ \\
\hline $\mathrm{F}_{7: 6}$ Areão $^{3}$ & & & 0,55 & $0,74^{* *}$ & 0,44 & $0,81 * *$ \\
\hline $\mathrm{F}_{8: 6}$ QLEs/Anhembi ${ }^{4}$ & & & & $0,82 * *$ & $0,89 * *$ & 0,57 \\
\hline $\mathrm{F}_{8: 6}$ QLEs/Areão ${ }^{5}$ & & & & & $0,85 * *$ & $0,89 * *$ \\
\hline $\mathrm{F}_{8: 6} \mathrm{QLPs} / \mathrm{Anhembi}^{6}$ & & & & & & $0,66 * *$ \\
\hline
\end{tabular}

\begin{tabular}{|c|c|c|c|c|c|c|}
\hline & \multicolumn{6}{|c|}{ APM (cm) } \\
\hline $\mathrm{F}_{2}^{1}$ & 0,62 & 0,45 & 0,42 & 0,19 & 0,50 & 0,32 \\
\hline$F_{7: 6}$ Anhembi $^{2}$ & & $0,82 * *$ & 0,13 & 0,24 & 0,39 & 0,30 \\
\hline $\mathrm{F}_{7: 6}$ Areão $^{3}$ & & & 0,04 & 0,11 & 0,23 & 0,01 \\
\hline $\mathrm{F}_{8: 6}$ QLEs/Anhembi ${ }^{4}$ & & & & $0,89 * *$ & $0,89 * *$ & $0,72 *$ \\
\hline $\mathrm{F}_{8: 6}$ QLEs/Areão ${ }^{5}$ & & & & & $0,88^{* *}$ & $0,81 * *$ \\
\hline $\mathrm{F}_{8: 6} \mathrm{QLPs} / \mathrm{Anhembi}^{6}$ & & & & & & $0,82 * *$ \\
\hline
\end{tabular}

\begin{tabular}{|c|c|c|c|c|c|c|}
\hline & \multicolumn{6}{|c|}{ VA (notas 1 a 5) } \\
\hline $\mathrm{F}_{2}^{1}$ & 0,53 & 0,28 & 0,39 & $-0,11$ & $0,75^{* *}$ & $-0,58$ \\
\hline$F_{7: 6}$ Anhembi $^{2}$ & & 0,59 & 0,11 & $-0,29$ & 0,58 & $-0,19$ \\
\hline $\mathrm{F}_{7: 6}$ Areão $^{3}$ & & & $-0,20$ & $-0,18$ & 0,61 & 0,09 \\
\hline $\mathrm{F}_{8: 6}$ QLEs/Anhembi ${ }^{4}$ & & & & $0,67^{*}$ & 0,51 & $-0,15$ \\
\hline $\mathrm{F}_{8: 6}$ QLEs/Areão 5 & & & & & 0,14 & 0,34 \\
\hline $\mathrm{F}_{8: 6} \mathrm{QLPs} /$ Anhembi $^{6}$ & & & & & & $-0,24$ \\
\hline
\end{tabular}

\begin{tabular}{|c|c|c|c|c|c|c|}
\hline \multirow{7}{*}{$\begin{array}{l}F_{2}^{1} \\
F_{7: 6} \text { Anhembi }^{2} \\
F_{7: 6} \text { Areão }^{3} \\
F_{8: 6} \text { QLEs/Anhembi }{ }^{4} \\
F_{8: 6} \text { QLEs/Areão } \\
F_{8: 6} \text { QLPs/Anhembi }\end{array}$} & \multicolumn{6}{|c|}{ PG (g/planta e g/m $\left./ \mathrm{m}^{2}\right)$} \\
\hline & 0,32 & 0,30 & 0,11 & $-0,26$ & 0,28 & 0,58 \\
\hline & & $0,76 * *$ & $0,95 * *$ & $0,66 *$ & 0,60 & 0,32 \\
\hline & & & 0,61 & 0,65 & 0,09 & 0,48 \\
\hline & & & & $0,72 *$ & 0,61 & 0,16 \\
\hline & & & & & 0,27 & 0,05 \\
\hline & & & & & & $-0,16$ \\
\hline
\end{tabular}

${ }^{a}$ Nass, 1989. Parcela com nove plantas, em covas individuais espaçadas de $0,60 \mathrm{~m}$ entre covas $\mathrm{e}$ 1,20 m entre parcelas. Semeadura em 21-01-1988.

*, **: Significativo a $5 \%$ e $1 \%$ de probabilidade, respectivamente, pelo teste $\mathrm{F}$. 
Tabela 25. Ganho em porcentagem para produtividade de grãos (PG) para os cruzamentos e parentais com base nas linhagens $\mathrm{F}_{8: 6}$ (QLEs e QLPs) dos 45 cruzamentos dialélicos em Anhembi e Areão. Soja semi-tardia/tardia. Parcela de uma fileira de $4 \mathrm{~m} \times 0,5 \mathrm{~m}$ com semeadura em 08-11-1993 em Anhembi e 18-11-1993 em Areão. Piracicaba - SP.

\begin{tabular}{|c|c|c|c|c|c|c|}
\hline \multirow[b]{2}{*}{ Tratamentos } & \multicolumn{3}{|c|}{$\mathrm{F}_{8: 6}$ (QLEs) } & \multicolumn{3}{|c|}{$F_{8: 6}$ (QLPs) } \\
\hline & Anhembi & Areão & Média & Anhembi & Areão & Média \\
\hline FT-Cristalina $x$ EMGOPA-301 & 60,25 & 102,68 & 81,47 & 22,57 & 8,74 & 15,65 \\
\hline FT-Cristalina x IAC-4 & 49,83 & 28,07 & 38,95 & $-14,56$ & $-2,61$ & $-8,58$ \\
\hline FT-Cristalina $\times$ IAC-5 & 41,21 & 26,69 & 33,95 & 67,72 & 19,56 & 43,64 \\
\hline FT-Cristalina x IAC-6 & 34,86 & 51,72 & 43,29 & $-18,02$ & 2,91 & $-7,56$ \\
\hline FT-Cristalina x IAC-8 & 25,13 & $-12,81$ & 6,16 & 40,92 & 0,74 & 20,83 \\
\hline FT-Cristalina x IAC-9 & 55,81 & 18,23 & 37,02 & 12,77 & 40,20 & 26,48 \\
\hline FT-Cristalina $\times$ LAC-11 & 40,52 & 2,16 & 21,34 & 36,61 & 48,97 & 42,79 \\
\hline FT-Cristalina x Santa Rosa & 38,50 & 39,07 & 38,78 & $-5,14$ & $-2,82$ & $-3,98$ \\
\hline FT-Cristalina x SS-1 & $-8,44$ & $-43,07$ & $-25,75$ & 53,63 & 8,68 & 31,16 \\
\hline EMGOPA-301 x IAC-4 & 92,91 & 35,95 & 64,43 & 43,12 & 28,42 & 35,77 \\
\hline EMGOPA-301 x IAC-5 & 44,36 & 49,95 & 47,15 & 221,47 & 75,33 & 148,40 \\
\hline EMGOPA-301 x LAC-6 & 66,43 & 19,59 & 43,01 & 78,22 & $-31,96$ & 23,13 \\
\hline EMGOPA-301 x IAC-8 & 46,34 & 11,66 & 29,00 & 19,59 & 8,72 & 14,15 \\
\hline EMGOPA-301 x IAC-9 & 5,85 & 8,67 & 7,26 & $-8,69$ & 20,81 & 6,06 \\
\hline EMGOPA-301 x IAC-11 & 49,89 & 1,81 & 25,85 & 32,70 & 0,39 & 16,54 \\
\hline EMGOPA-301 x Santa Rosa & 28,34 & 44,93 & 36,64 & 25,97 & 1,01 & 13,49 \\
\hline EMGOPA-301 x SS-1 & 12,05 & $-5,85$ & 3,10 & 30,51 & 25,01 & 27,76 \\
\hline IAC-4 x IAC-5 & 18,35 & 71,13 & 44,74 & $-11,74$ & 0,62 & $-5,56$ \\
\hline IAC-4 $\times$ IAC-6 & 51,08 & 59,26 & 55,17 & $-6,59$ & 18,72 & 6,07 \\
\hline IAC-4 x IAC-8 & 33,76 & 59,62 & 46,69 & 26,00 & $-7,12$ & $\mathbf{9 , 4 4}$ \\
\hline IAC- $-4 \times$ IAC- 9 & $-8,16$ & 4,57 & $-1,80$ & $-16,31$ & 22,43 & 3,06 \\
\hline IAC-4 x IAC-11 & $-2,96$ & $-3,95$ & $-3,46$ & $-8,73$ & 34,50 & 12,89 \\
\hline IAC-4 x Santa Rosa & $-8,19$ & 30,33 & 11,07 & $-22,75$ & 0,83 & $-10,96$ \\
\hline IAC-4 x SS-1 & 30,34 & $-25,08$ & 2,63 & 45,69 & 33,04 & 39,37 \\
\hline IAC-5 x IAC-6 & $-29,84$ & $-7,72$ & $-18,78$ & 60,33 & 24,87 & 42,60 \\
\hline IAC-5 x IAC-8 & $-15,27$ & 19,94 & 2,33 & 47,59 & 77,94 & 62,77 \\
\hline IAC-5 x IAC-9 & 12,01 & 16,48 & 14,24 & $-18,97$ & 10,30 & $-4,33$ \\
\hline IAC-5 x IAC-11 & $-4,15$ & $-7,03$ & $-5,59$ & 1,55 & $-30,27$ & $-14,36$ \\
\hline IAC-5 x Santa Rosa & 13,54 & 76,74 & 45,14 & $-22,78$ & 35,83 & 6,52 \\
\hline IAC-5 x SS-1 & 31,30 & 13,87 & 22,58 & 39,34 & 26,01 & 32,67 \\
\hline IAC-6 x IAC-8 & 43,85 & 19,72 & 31,79 & 13,49 & 4,55 & 9,02 \\
\hline IAC-6 x IAC-9 & 42,45 & 33,12 & 37,79 & 17,54 & 14,29 & 15,91 \\
\hline IAC-6 x IAC-11 & $-24,19$ & $-6,12$ & $-15,16$ & $-19,69$ & $-11,90$ & $-15,80$ \\
\hline IAC- 6 x Santa Rosa & $-1,17$ & 37,29 & 18,06 & 39,85 & $-2,26$ & 18,79 \\
\hline IAC-6 x SS-1 & 18,12 & $-2,84$ & 7,64 & 15,32 & 23,41 & 19,36 \\
\hline IAC-8 x IAC-9 & 38,31 & 21,07 & 29,69 & 10,20 & 22,71 & 16,46 \\
\hline IAC-8 x IAC-11 & 22,00 & 17,71 & 19,86 & 51,20 & 39,11 & 45,15 \\
\hline IAC-8 x Santa Rosa & $-8,57$ & $\mathbf{3 , 2 7}$ & $-2,65$ & 42,27 & 38,26 & 40,27 \\
\hline IAC-8 x SS-1 & 36,82 & 40,67 & 38,75 & 100,28 & 32,69 & 66,49 \\
\hline IAC-9 x IAC-11 & 10,67 & 51,52 & 31,09 & $-8,25$ & 18,14 & 4,94 \\
\hline IAC-9 x Santa Rosa & 45,81 & 49,17 & 47,49 & 25,58 & 51,44 & 38,51 \\
\hline IAC-9 x SS-1 & $-19,93$ & $-23,65$ & $-21,79$ & 19,84 & 15,84 & 17,84 \\
\hline IAC-11 x Santa Rosa & 49,19 & 6,84 & 28,02 & 67,82 & 17,59 & 42,70 \\
\hline IAC-11 x SS-1 & 70,81 & 19,82 & 45,32 & 4,37 & 9,52 & 6,94 \\
\hline Santa Rosa x SS-1 & 97,84 & 14,22 & 56,03 & 38,60 & 33,79 & 36,19 \\
\hline Média & 27,73 & 20,54 & 24,14 & 22,60 & 17,03 & 19,81 \\
\hline 1 - FT-Cristalina & 37,52 & 23,64 & 30,58 & 21,83 & 13,82 & 17,83 \\
\hline 2 - EMGOPA-301 & 45,16 & 29,93 & 37,55 & 51,72 & 15,16 & 33,44 \\
\hline $3-\mathrm{IAC}-4$ & 28,55 & 28,88 & 28,71 & 3,79 & 14,31 & 9,06 \\
\hline 4 - IAC-5 & 12,39 & 28,89 & 20,64 & 42,72 & 26,69 & 34,71 \\
\hline $5-$ IAC- 6 & 22,40 & 22,67 & 22,53 & 20,05 & 4,74 & 12,39 \\
\hline $6-\mathrm{IAC}-8$ & 24,71 & 20,09 & 22,40 & 39,06 & 24,18 & 31,62 \\
\hline 7 - IAC-9 & 20,31 & 19,91 & 20,11 & 3,75 & 24,02 & 13,88 \\
\hline $8-I A C-11$ & 23,53 & 9,20 & 16,36 & 17,51 & 14,01 & 15,75 \\
\hline 9 - Santa Rosa & 28,37 & 33,54 & 30,95 & 21,05 & 19,30 & 20,17 \\
\hline 10 -SS-1 & 29,88 & $-1,32$ & 14,28 & 38,62 & 23,11 & 30,86 \\
\hline
\end{tabular}




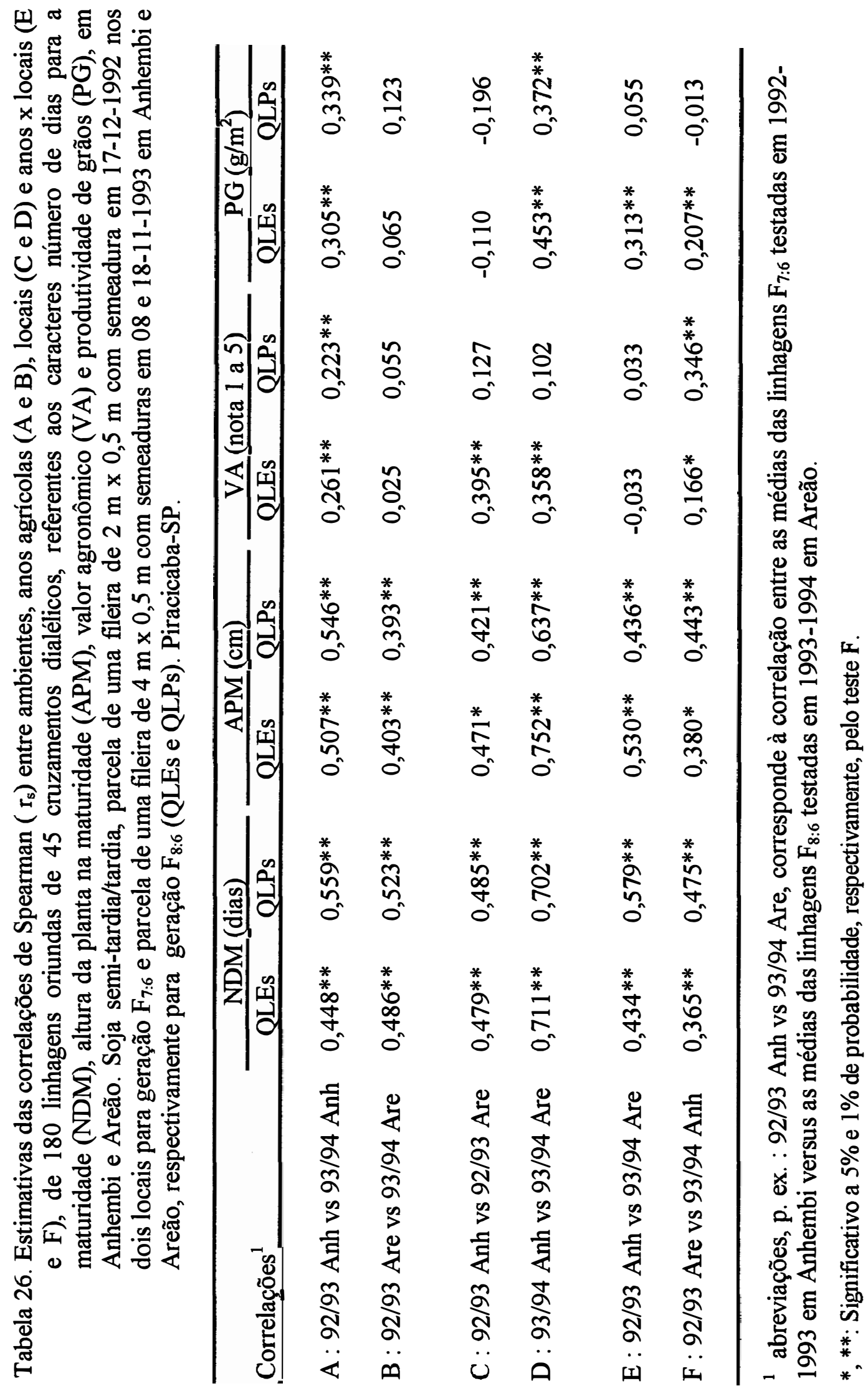




\section{APÊNDICES}




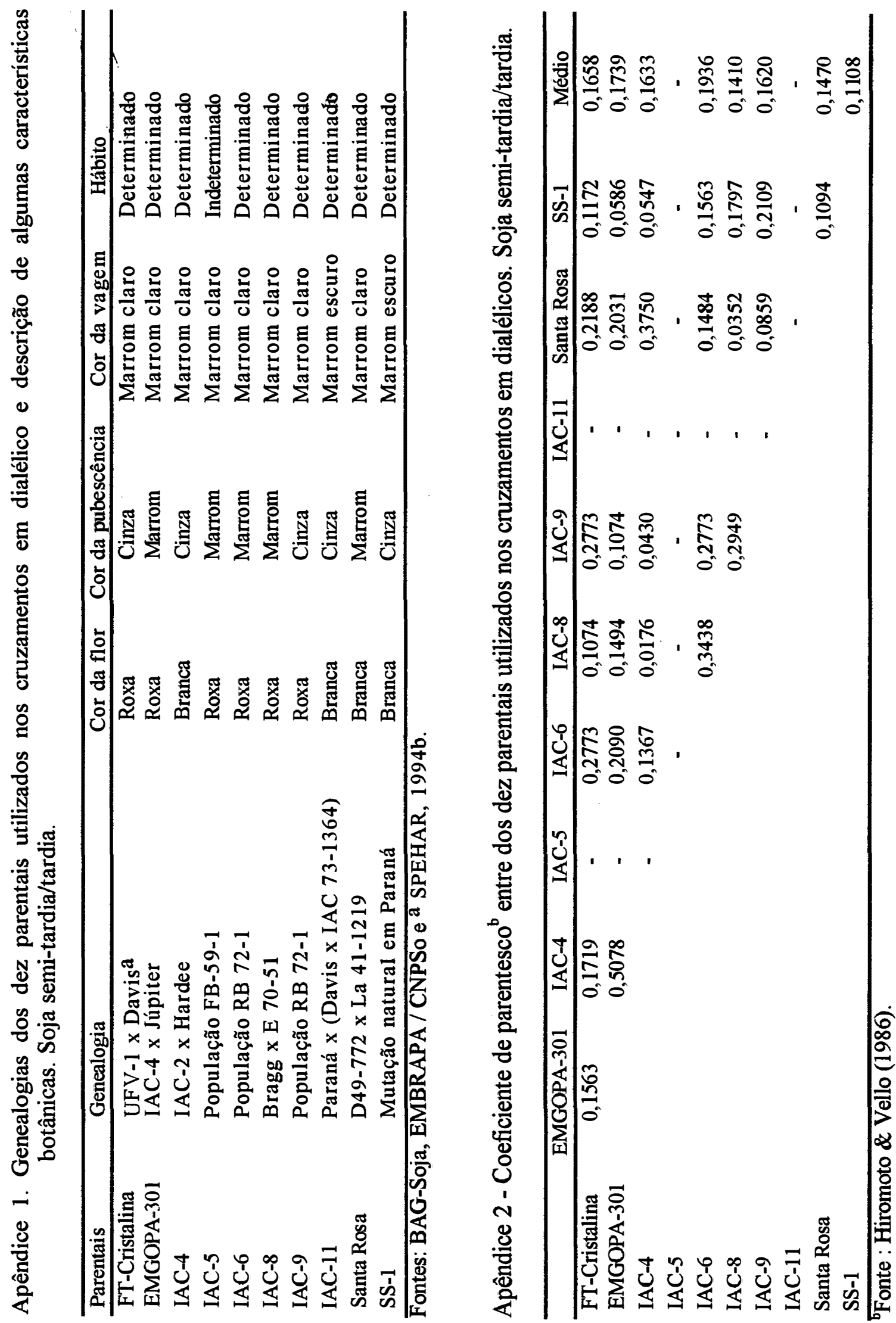


Apêndice 3 - Composição química e fisica média dos solos nas camadas de 0-20 cm e 20$40 \mathrm{~cm}$ em Anhembi e Areão, Piracicaba-SP.

\begin{tabular}{|c|c|c|c|c|c|c|c|c|}
\hline \multirow{3}{*}{$\begin{array}{l}\text { Características } \\
\text { químicas e fisicas }\end{array}$} & \multicolumn{4}{|c|}{ Geração $F_{7: 6}$} & \multicolumn{4}{|c|}{ Geração $F_{8: 6}$} \\
\hline & \multicolumn{2}{|c|}{ Anhembi } & \multicolumn{2}{|c|}{ Areão } & \multicolumn{2}{|c|}{ Anhembi } & \multicolumn{2}{|c|}{ Areão } \\
\hline & $0-20$ & $20-40$ & $0-20$ & $20-40$ & $0-20$ & $20-40$ & $0-20$ & $20-40$ \\
\hline $\mathrm{pH}(\mathrm{CaCl})$ & 4,1 & 4,2 & 4,7 & 4,7 & 5,2 & 4,1 & 4,8 & 5,1 \\
\hline$P$ res. $\left(\mathrm{mg} / \mathrm{dm}^{3}\right)$ & 30,5 & 4,2 & 5,6 & 0,2 & 48,2 & 5,8 & 12,8 & 3,1 \\
\hline $\mathrm{K}\left(\mathrm{mmol}_{\mathrm{d}} / \mathrm{dm}^{3}\right)$ & 2,5 & 1,4 & 2,2 & 1,8 & 2,6 & 1,4 & 2,3 & 1,7 \\
\hline $\mathrm{Ca}\left(\mathrm{mmol}_{\mathrm{c}} / \mathrm{dm}^{3}\right)$ & 7,1 & 5,9 & 28,0 & 27,0 & 28,0 & 10,7 & 34,9 & 55,1 \\
\hline $\mathrm{Mg}\left(\mathrm{mmol}_{\mathrm{d}} / \mathrm{dm}^{3}\right)$ & 3,8 & 3,1 & 14,1 & 12,0 & 15,5 & 6,1 & 10,1 & 14,2 \\
\hline $\mathrm{Al}\left(\mathrm{mmol} / \mathrm{dm}^{3}\right)$ & 24,5 & 26,0 & 5,5 & 7,0 & 0,5 & 16,5 & 1,0 & 1,0 \\
\hline $\mathrm{H}+\mathrm{Al}\left(\mathrm{mmol}_{\mathcal{C}} / \mathrm{dm}^{3}\right)$ & 67,9 & 64,4 & 50,5 & 42,3 & 21,3 & 44,6 & 30,8 & 25,0 \\
\hline $\mathrm{S}\left(\mathrm{mmol}_{\mathrm{d}} / \mathrm{dm}^{3}\right)$ & 13,4 & 10,4 & 44,3 & 40,8 & 46,1 & 18,2 & 47,3 & 71,0 \\
\hline $\mathrm{T}\left(\mathrm{mmol}_{\mathrm{d}} / \mathrm{dm}^{3}\right)$ & 81,0 & 75,0 & 95,0 & 83,0 & 67,0 & 63,0 & 78,0 & 96,0 \\
\hline $\mathrm{m}(\%)$ & 64,6 & 71,4 & 11,0 & 14,6 & 10,7 & 47,5 & 2,1 & 1,4 \\
\hline V (\%) & 16,5 & 13,9 & 46,6 & 49,2 & 68,8 & 28,9 & 60,6 & 74,0 \\
\hline $\mathrm{MO}\left(\mathrm{g} / \mathrm{dm}^{3}\right)$ & 15,4 & 9,1 & 16,6 & 12,0 & 25,0 & 16,8 & 25,0 & 14,9 \\
\hline $\operatorname{Mn}\left(\mathrm{mg} / \mathrm{dm}^{3}\right)$ & 4,2 & 1,6 & 22,7 & 5,9 & 3,2 & 1,2 & 57,6 & 26,7 \\
\hline $\mathrm{Cu}\left(\mathrm{mg} / \mathrm{dm}^{3}\right)$ & 0,2 & 0,2 & 2,9 & 2,3 & 0,8 & 0,8 & 3,3 & 2.3 \\
\hline $\mathrm{Fe}\left(\mathrm{mg} / \mathrm{dm}^{3}\right)$ & 86,9 & 39,6 & 42,9 & 19,8 & 32,4 & 27,0 & 26,2 & 12,2 \\
\hline $\mathrm{Zn}\left(\mathrm{mg} / \mathrm{dm}^{3}\right)$ & 1,0 & 0,4 & 1,6 & 0,3 & 2,9 & 1,7 & 3,6 & 1,0 \\
\hline Areia grossa (\%) & 9,0 & 7,0 & 11,0 & 9,0 & - & - & - & - \\
\hline Areia fina (\%) & 61,0 & 57,0 & 31,0 & 21,0 & - & - & - & - \\
\hline Silte (\%) & 8,0 & 10,0 & 21,0 & 16,0 & - & - & - & - \\
\hline Argila (\%) & 22,0 & 26,0 & 37,0 & 54,0 & - & - & - & - \\
\hline
\end{tabular}

As análises químicas e fisicas foram realizadas, respectivamente nos laboratórios de Nutrição Mineral de Plantas e Física do Solo da ESALQ/USP. 

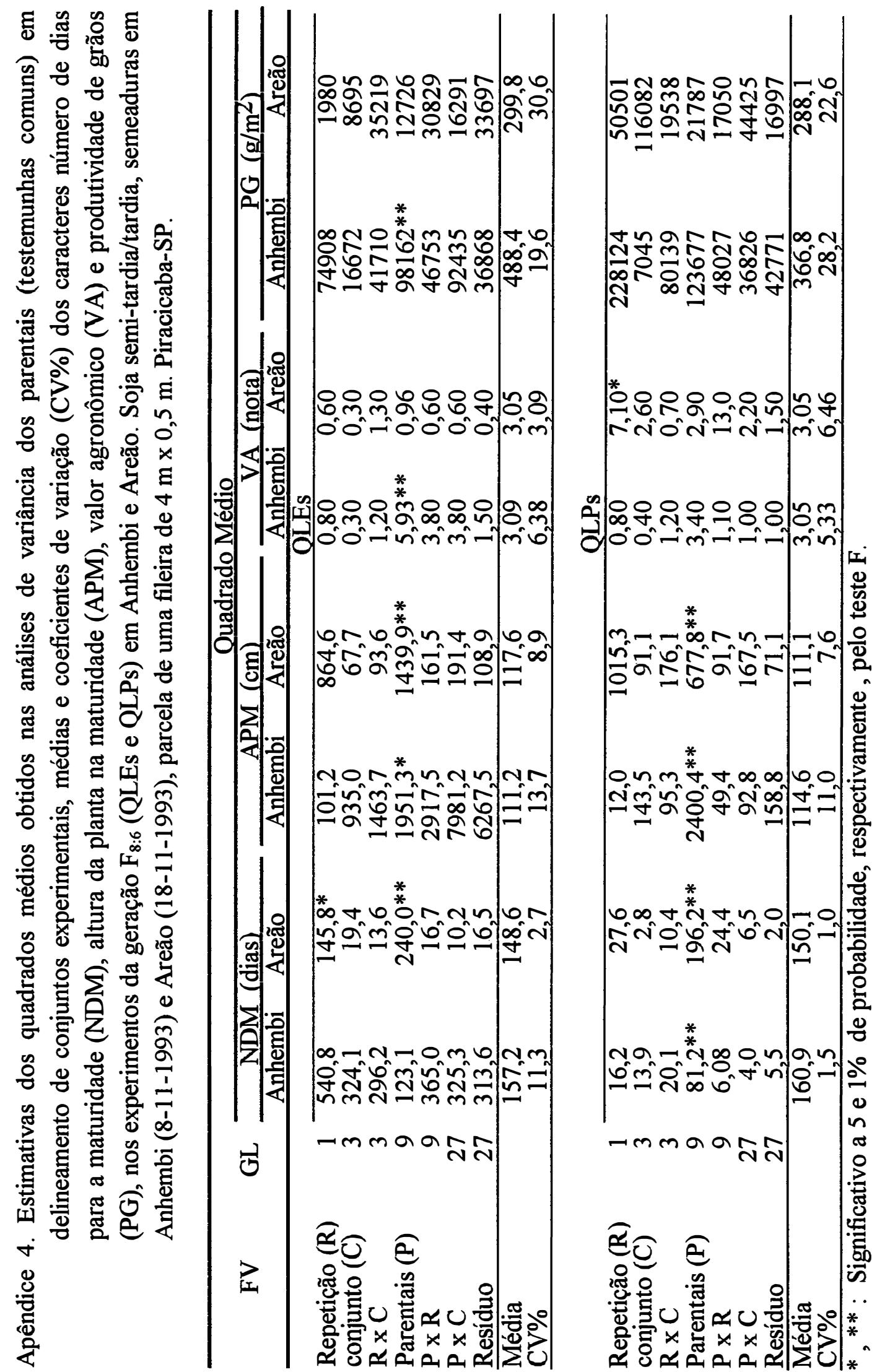
Apêndice 5 - Dados meteorológicos: fotoperíodo, temperatura média, umidade relativa do ar e precipitação pluviométrica mensal, nos períodos de dezembro1992 a maio-1993 e novembro-1993 a maio-1994, respectivamente, gerações $\mathrm{F}_{7: 6}$ e $\mathrm{F}_{8: 6}$. Piracicaba-SP.

\begin{tabular}{lccccccr}
\hline & $\begin{array}{c}\text { Fotoperíodo } \\
\text { (horas) }\end{array}$ & \multicolumn{2}{c}{$\begin{array}{c}\text { Temperatura média } \\
\left({ }^{\circ} \mathrm{C}\right)\end{array}$} & \multicolumn{2}{c}{$\begin{array}{c}\text { Umidade relativa } \\
(\%)\end{array}$} & \multicolumn{2}{c}{$\begin{array}{c}\text { Precipitação mensal } \\
(\mathrm{mm})\end{array}$} \\
\cline { 2 - 8 } Mês & & $\mathrm{F}_{7: 6}$ & $\mathrm{~F}_{8: 6}$ & $\mathrm{~F}_{7: 6}$ & $\mathrm{~F}_{8: 6}$ & $\mathrm{~F}_{7: 6}$ & \multicolumn{1}{c}{$\mathrm{F}_{8: 6}$} \\
\cline { 2 - 8 } Novembro & 13,06 & 23,03 & 25,25 & 77,53 & 73,87 & 232,30 & 91,60 \\
Dezembro & 13,37 & 23,50 & 24,84 & 73,94 & 82,61 & 142,20 & 146,40 \\
Janeiro & 13,24 & 25,34 & 24,78 & 81,55 & 83,71 & 179,90 & 134,80 \\
Fevereiro & 12,73 & 23,81 & 26,58 & 85,18 & 82,71 & 232,10 & 154,40 \\
Março & 12,20 & 24,73 & 24,08 & 79,61 & 84,39 & 155,90 & 222,70 \\
Abril & 11,46 & 23,26 & 22,80 & 80,57 & 81,10 & 57,70 & 114,90 \\
Maio & 10,92 & 19,68 & 20,91 & 79,65 & 81,81 & 119,70 & 56,20 \\
\hline
\end{tabular}

Fonte: Departamento de Física e Meteorologia da Escola Superior de Agricultura "Luiz de Queiroz"/USP.

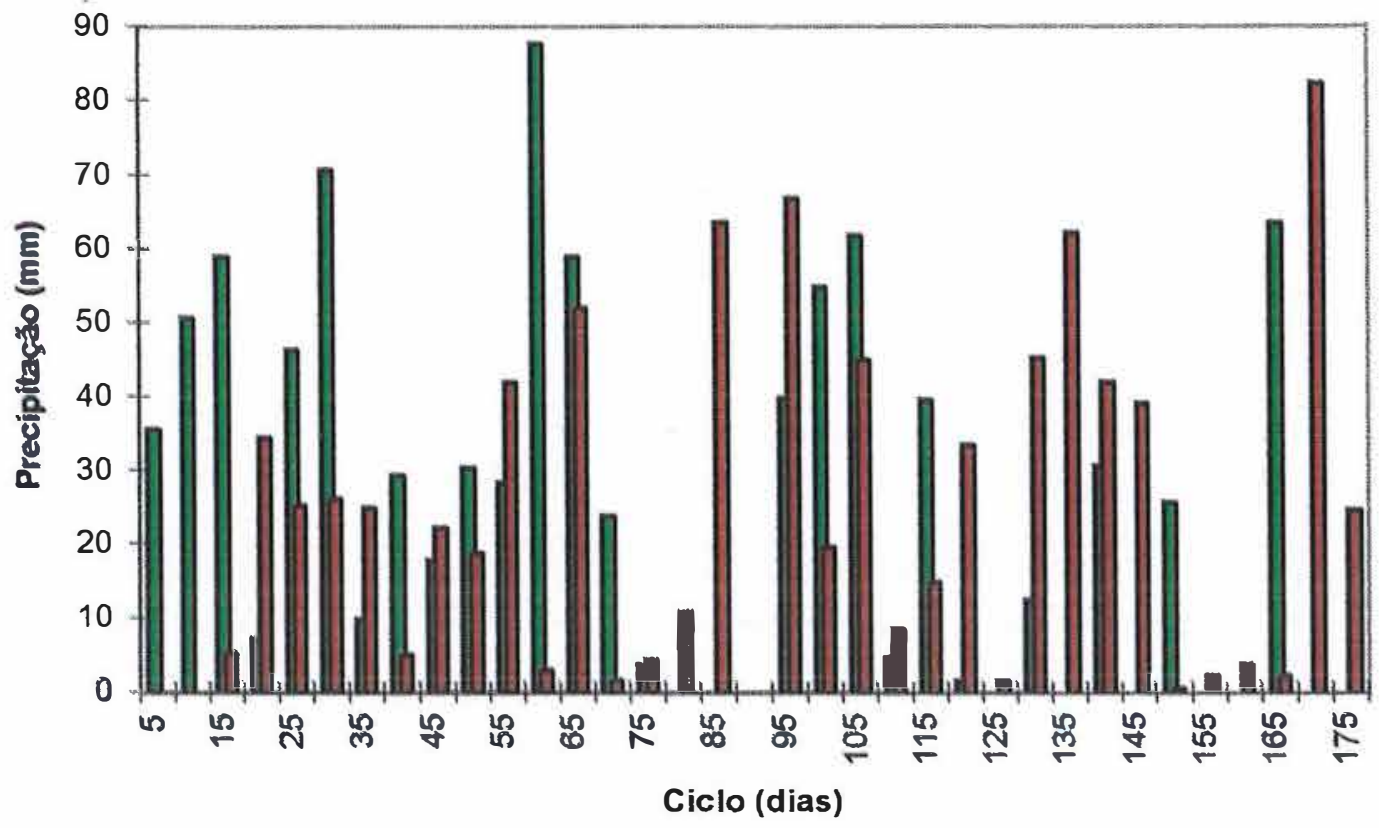

$1992-1993 \square 1993-1994$

Figura - Precipitação pluviométrica, grafado de cinco em cinco dias, durante os ciclos da cultura da soja nas safras 1992-1993 $\left(\mathrm{F}_{7: 6}\right)$ e 1993-1994 $\left(\mathrm{F}_{8: 6}\right)$, Piracicaba-SP. 
Apêndice 6 - Identificação dos 45 cruzamentos dialélicos, soja semi-tardia/tardia. Piracicaba - SP.

\begin{tabular}{|c|c|c|c|c|}
\hline Cruz. & Designação do genótipo & Cruz. & Designação do genótipo & \\
\hline $1 \times 2$ & FT-Cristalina $x$ EMGOPA-301 & $3 \times 10$ & IAC $-4 \times$ SS-1 & \\
\hline $1 \times 3$ & FT-Cristalina $x$ IAC-4 & $4 \times 5$ & IAC-5 $\times$ IAC-6 & \\
\hline $1 \times 4$ & FT-Cristalina $x$ IAC-5 & $4 \times 6$ & IAC-5 $\times$ IAC-8 & \\
\hline $1 \times 5$ & FT-Cristalina $x$ IAC-6 & $4 \times 7$ & IAC-5 x IAC-9 & \\
\hline $1 \times 6$ & FT-Cristalina $x$ IAC-8 & $4 \times 8$ & IAC-5 x IAC-11 & \\
\hline $1 \times 7$ & FT-Cristalina x IAC-9 & $4 \times 9$ & IAC-5 x Santa Rosa & \\
\hline $1 \times 8$ & FT-Cristalina x IAC-11 & $4 \times 10$ & IAC-5 x SS-1 & \\
\hline $1 \times 9$ & FT-Cristalina x Santa Rosa & $5 \times 6$ & IAC-6 $\times$ IAC-8 & \\
\hline $1 \times 10$ & FT-Cristalina $\times$ SS-1 & $5 \times 7$ & IAC-6 x IAC-9 & \\
\hline $2 \times 3$ & EMGOPA-301 x IAC-4 & $5 \times 8$ & IAC-6 x IAC-11 & \\
\hline $2 \times 4$ & EMGOPA-301 x IAC-5 & $5 \times 9$ & IAC-6 x Santa Rosa & \\
\hline $2 \times 5$ & EMGOPA-301 x IAC-6 & $5 \times 10$ & IAC-6 x SS-1 & \\
\hline $2 \times 6$ & EMGOPA-301 x IAC-8 & $6 \times 7$ & IAC-8 $\times$ IAC-9 & \\
\hline $2 \times 7$ & EMGOPA-301 x IAC-9 & $6 \times 8$ & IAC-8 x IAC-11 & \\
\hline $2 \times 8$ & EMGOPA-301 x IAC-11 & $6 \times 9$ & IAC-8 x Santa Rosa & \\
\hline $2 \times 9$ & EMGOPA-301 x Santa Rosa & $6 \times 10$ & IAC-8 $\times$ SS-1 & \\
\hline $2 \times 10$ & EMGOPA-301 x SS-1 & $7 \times 8$ & IAC-9 x IAC-11 & \\
\hline $3 \times 4$ & IAC-4 x IAC-5 & $7 \times 9$ & IAC-9 x Santa Rosa & \\
\hline $3 \times 5$ & IAC $-4 \times$ IAC- 6 & $7 \times 10$ & IAC-9 x SS-1 & \\
\hline $3 \times 6$ & IAC-4 $\times$ IAC-8 & $8 \times 9$ & IAC-11 x Santa Rosa & \\
\hline $3 \times 7$ & IAC-4 x IAC-9 & $8 \times 10$ & IAC-11 x SS-1 & \\
\hline $3 \times 8$ & IAC-4 x IAC-11 & $9 \times 10$ & Santa Rosa x SS-1 & \\
\hline $3 \times 9$ & IAC-4 x Santa Rosa & & & \\
\hline
\end{tabular}

